\title{
PROFESSIONAL LEARNING AND DEVELOPMENT (PLD) IN HIGHER EDUCATION: THE EXPERIENCES OF TEACHER EDUCATORS IN VIETNAM
}

\author{
Hue Thi Thanh Tran
}

A thesis

submitted to Victoria University of Wellington in fulfilment of the requirements for the degree of Doctor of Philosophy in Education 


\begin{abstract}
A key challenge for educators in Vietnamese higher education (HE) lies in the implementation of top-down national educational reforms. Professional learning and development (PLD) is viewed by the government as a primary means to enhance lecturers' capacity to implement national educational initiatives. However, the nature of PLD for lecturers and its roles in supporting HE reforms in developing countries like Vietnam remain under-investigated. This study explores the practices of PLD for English as a foreign language (EFL) lecturers who are teacher educators within higher education, and the social, cultural, and political contexts within which these occur. The study employs a mixed-methods research methodology with a focus on qualitative approach and the use of Cultural Historical Activity Theory (CHAT) as the framework of analysis. A case study across three tertiary institutions provides the basis for an analysis of the phenomenon of PLD for EFL lecturers in Vietnam involving academic leaders and EFL lecturers. Complementary data collection methods were used: a questionnaire, individual semi-structured interviews, observations of PLD sessions, and relevant document review. Data were analysed both deductively and inductively to explore the roles of PLD in the educators' personal and professional growth, and their capacity to enact mandated initiatives in the selected institutions. The findings indicate that PLD is a complex, political and culturally situated phenomenon that plays a key role in supporting the professional aspirations of lecturers. The study foregrounds the lecturers' PLD experiences, the implications of PLD, and the influence of government and institutional policies and initiatives on the lecturers' PLD. This study proposes a model of PLD that raises critical questions about how HE institutions and policy makers might provide a supportive PLD environment to better foster lecturers' capacity to bring about changes at both personal and institutional levels. This model shows that PLD needs to be viewed across diverse forms including formal, collaborative and informal PLD. For PLD to be effective, consideration should be given to ensuring lecturers experience it as: (1) needs-based, relevant and meaningful for their learning and applicable to their teaching contexts, (2) encouraging them to be active and self-regulated learners, (3) promoting reflective and experiential learning, and (4) based on negotiated understandings of the purpose and function of PLD among all involved stakeholders. The study contributes to an understanding of PLD requirements for EFL teacher educators in an Asian context, and may be relevant to PLD for tertiary lecturers in a wider international context.
\end{abstract}




\section{ACKNOWLEGEMENTS}

My sincere gratitude goes to Associate Professor Dr. Roseanna Bourke, and Dr. Margaret Gleeson, my supervisors, who have accompanied me and provided me with wise guidance, encouragement and great care for both my personal and academic life. Your trust in my ability empowered me to complete the thesis and be confidence in the value of my research. It has been my privilege to work with you over a four-year learning process, and you play a crucial role in my PLD experience and professional growth during my $\mathrm{PhD}$ journey.

I am grateful to the participants in this research, the EFL lecturers and academic leaders, who were willing to share with me their professional experience and insightful reflections on their PLD engagement. It's a privilege to have them in my professional network, and their professional experiences inspired me to strive for a successful accomplishment of the research which invites a better understanding of lecturers' learning and how to support their learning in a Vietnamese tertiary environment.

I'd like to express my heartfelt gratitude to Victoria University of Wellington (VUW) student advisors, particularly Dr. Deborah Laurs, who has given me on-going support and encouragement. I'd like to thank Dr. Carolyn Tait for her support and helpful professional conversations within our research cohort. I'm also grateful to the three examiners whose constructive feedback have challenged my thinking and helped to further improve the thesis. Special thanks also go to my office-mates and friends whose friendship and encouragement have made my PhD journey more joyful.

I'm very grateful for the scholarships and support from Vietnamese government and VUW. My sincere thanks also go to my institution, An Giang University, and An Giang Provincial People Committee for giving me a work leave and supporting my learning.

Finally, I'd like to thank my family for their love and encouragement. I'm whole-heartedly grateful for my mother, who always gives me the most inspiring support and endless love. Thank you very much for your company at the final stage of my thesis writing, taking care of my family and giving us great spiritual support so that my husband and I can complete our $\mathrm{PhD}$ theses. $\mathrm{My}$ special thanks also go to my husband - Tien Huynh, and our beloved son - An Huynh, whose company and love throughout the journey is precious. I value the meaningful and enjoyable time we have spent together in New Zealand and grown as a happy family. 
To my grandfather, $\mathcal{N}$ guyen Sy Dong, and my mother, $\mathcal{N g u y e n}$ Thi Hoat, for your endless love, aspirations, and trust in my personal and academic growth 


\section{TABLE OF CONTENT}

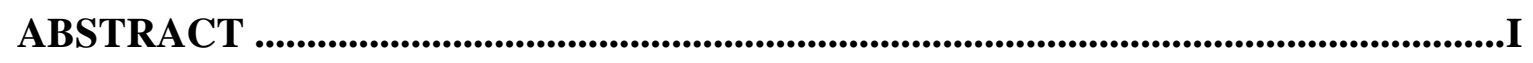

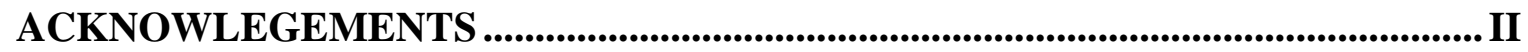

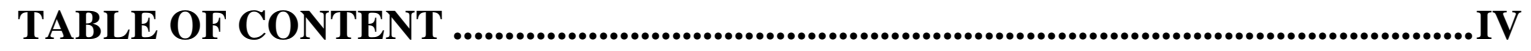

LIST OF FIGURES .......................................................................................................................VIII

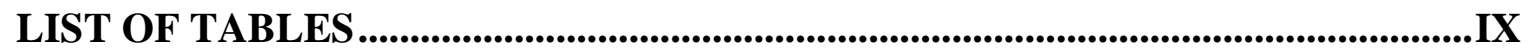

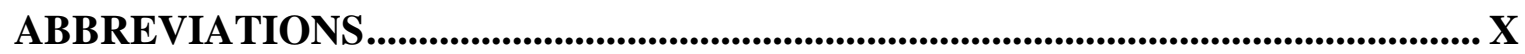

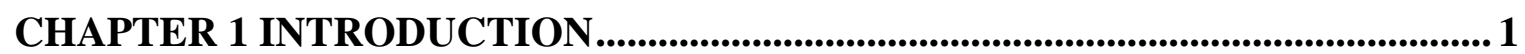

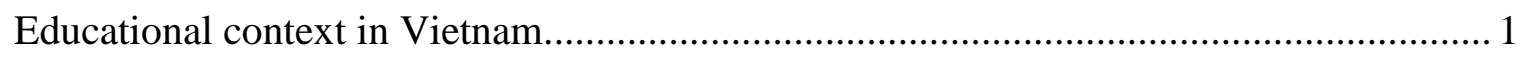

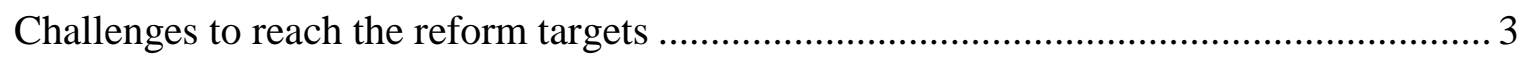

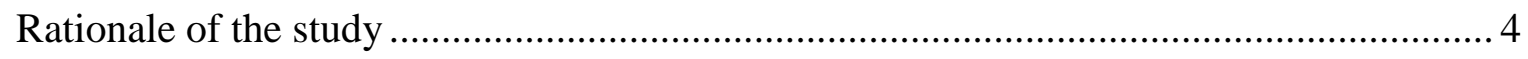

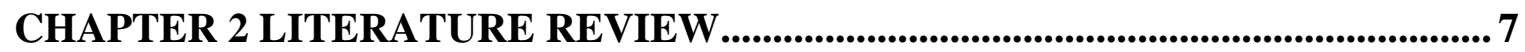

Professional learning and development in education ........................................................ 7

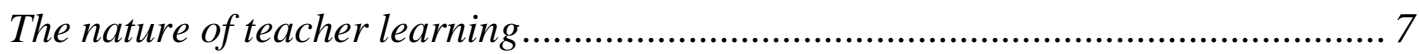

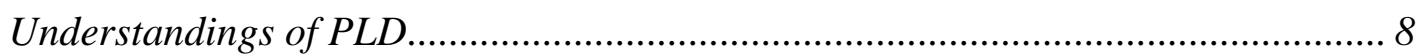

Changes in perspectives and implementations of PLD ......................................... 11

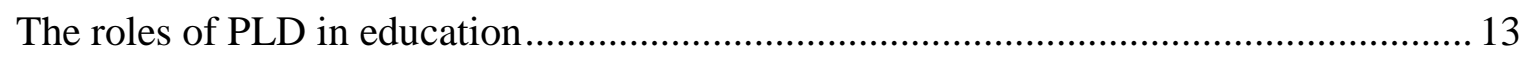

Impact of PLD on teachers' changes .................................................................. 13

Teacher impact on institutional changes and educational reforms ........................ 15

Impact of teachers' PLD on students ................................................................... 17

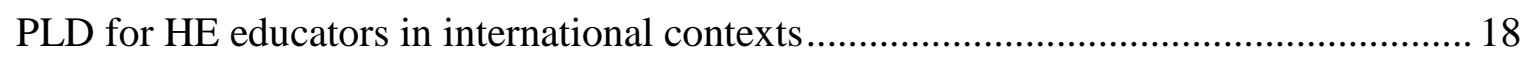

Teacher educators' professional practices and professional learning................................ 20

English Language Teaching (ELT) and PLD for EFL teachers ..................................... 22

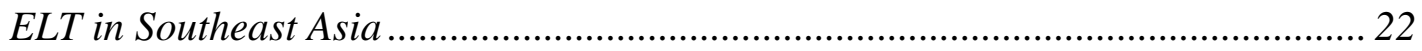

English teaching and PLD for EFL teachers in Vietnam...................................... 25

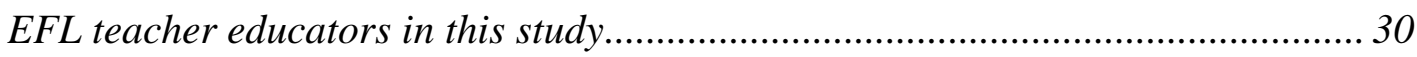

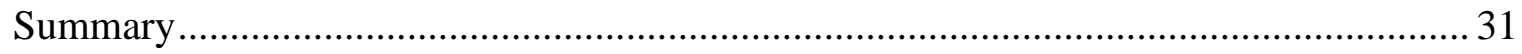




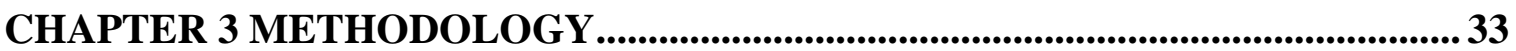

Theoretical framework: Cultural Historical Activity Theory (CHAT) ............................. 33

Employing CHAT as a theoretical framework for analysis .................................. 38

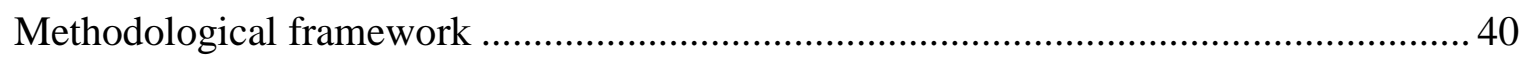

Ontological and epistemological assumptions.................................................. 40

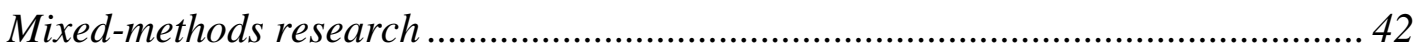

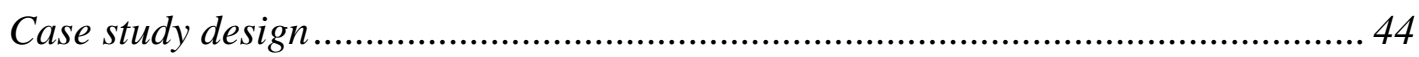

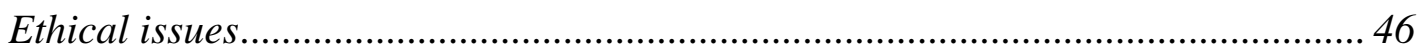

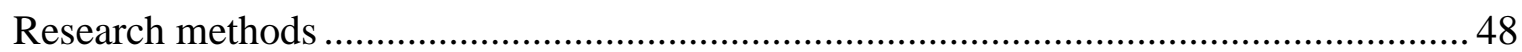

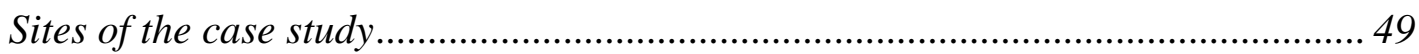

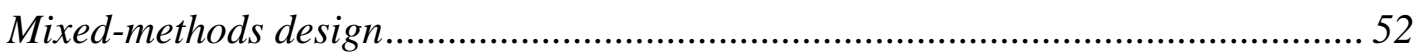

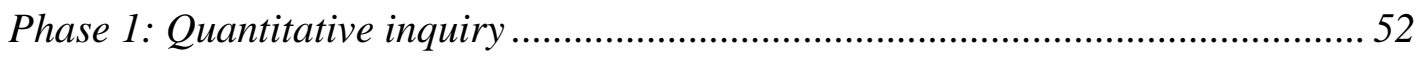

Phase 2: Qualitative inquiry ........................................................................... 57

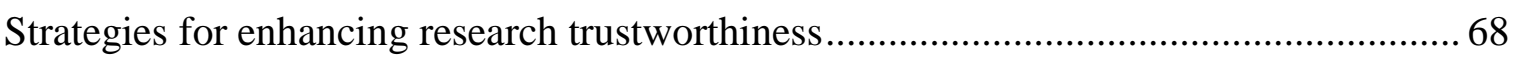

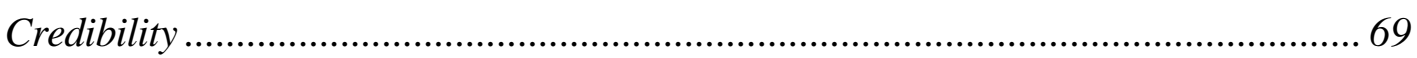

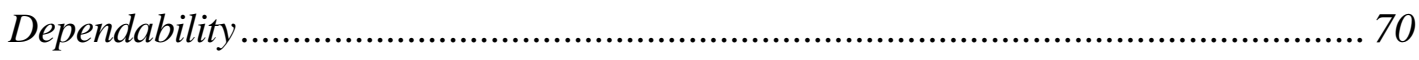

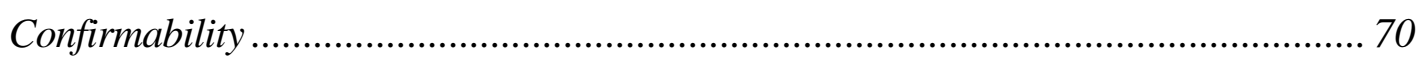

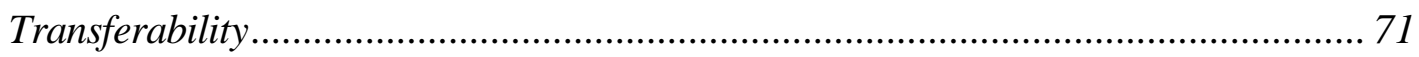

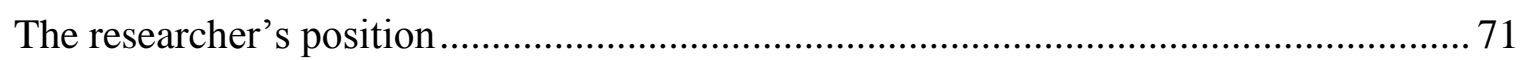

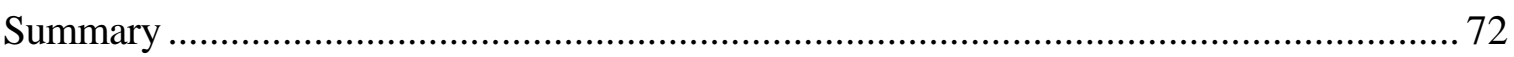

CHAPTER 4 RESULTS: UNDERSTANDING PLD ..................................................... 75

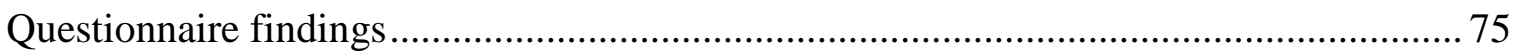

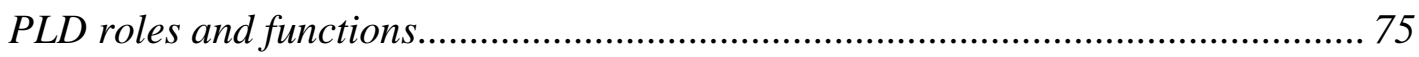

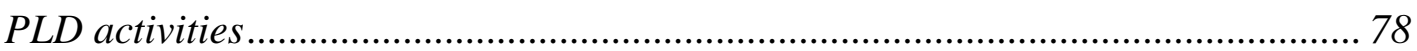

The participants' report on their PLD experience ................................................. 80

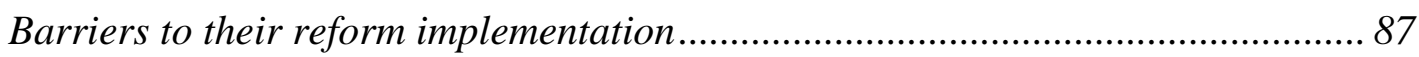

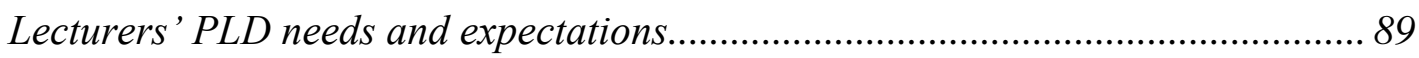

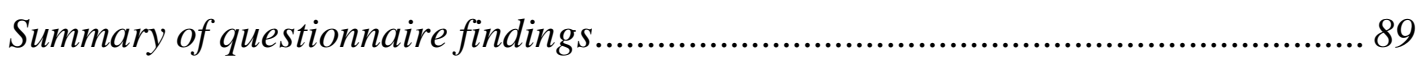

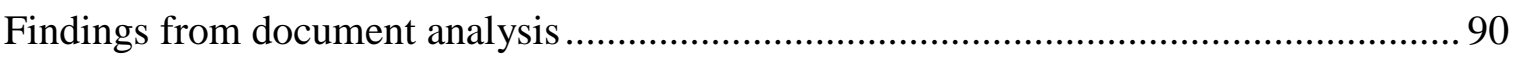

General espoused professional policies for lecturers ........................................... 91

Reform initiatives and PLD supporting reform implementation............................. 94

Cultural perspectives on lecturers ' professional roles and status .......................... 97 
Case study findings 99

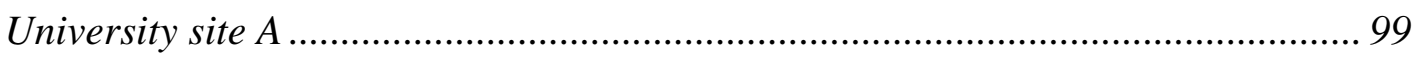

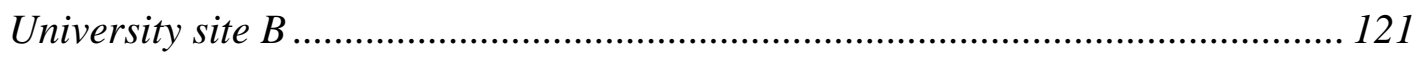

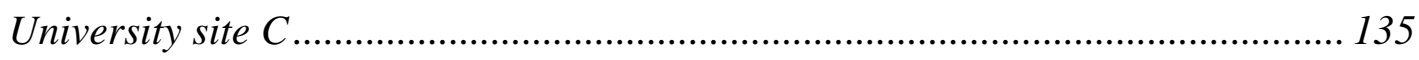

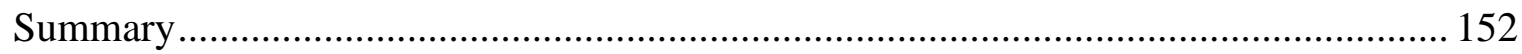

CHAPTER 5 RESULTS: THE PLD CASE ............................................................... 153

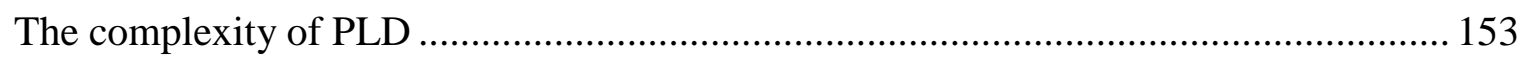

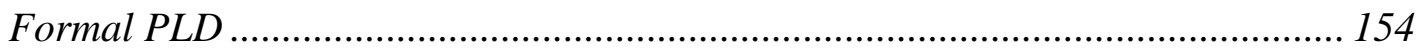

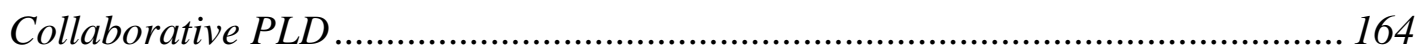

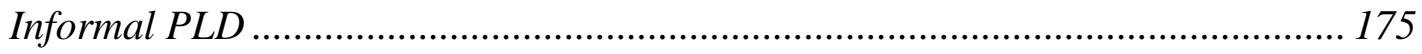

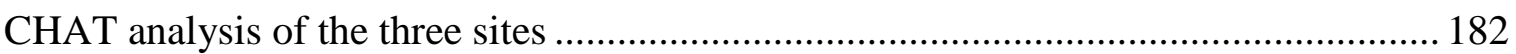

Exploring dimensions of PLD through a CHAT analysis of each site .................. 182

Commonalities across the three university sites .................................................. 193

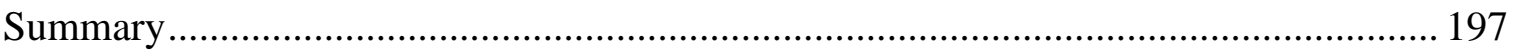

CHAPTER 6 DISCUSSION ................................................................................. 199

The sociocultural context of tertiary education in Vietnam ......................................... 200

Context of Vietnamese higher education.................................................................. 204

Impact of institutional features on PLD .............................................................. 207

Lecturers' responses to mandatory reforms: Transferring the fire ....................... 208

Teacher educators' professional identity: A role-model of 'tài' and 'đúc' ...................... 210

PLD: Maintaining the pride and managing the burden ...................................... 210

Striving to be a role-model......................................................................................... 211

Transformative professional identity ................................................................. 216

The nature of tertiary lecturers' learning: Introducing a PLD model ............................. 218

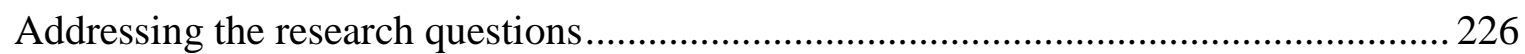

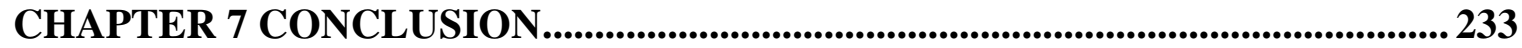

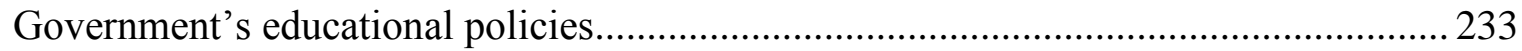

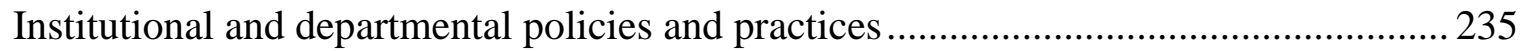

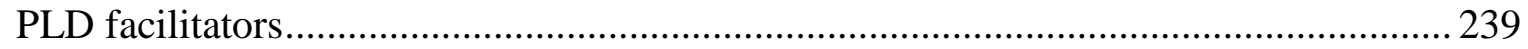

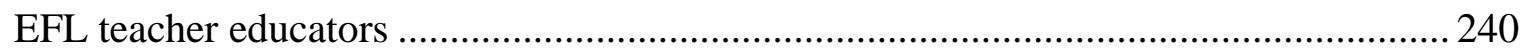

Limitations and recommendations for further research............................................ 242

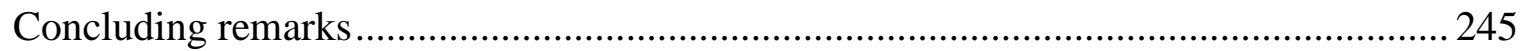




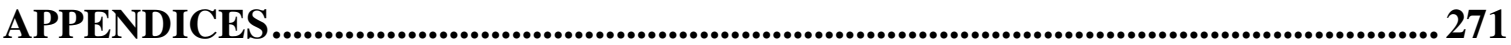

Appendix A. Questionnaire for EFL lecturers ................................................... 271

Appendix B. Information sheet for questionnaire participants ................................ 278

Appendix C. Letter to the Rectors of selected tertiary institutions ........................... 281

Appendix D. Consent form for Rectors.................................................................. 283

Appendix E. Interview protocol for EFL lecturers ................................................ 284

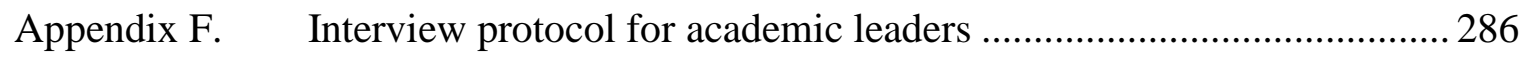

Appendix G. Information sheet for interviewed lecturers....................................... 288

Appendix H. Information sheet for interviewed leaders …....................................... 291

Appendix I. Consent form for interview participants ............................................. 293

Appendix J. Information sheet for PLD providers ................................................. 294

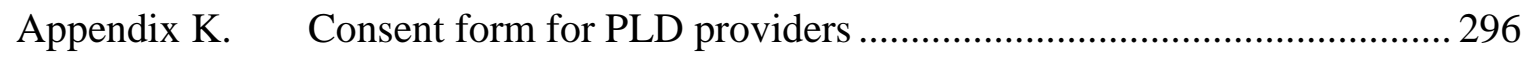

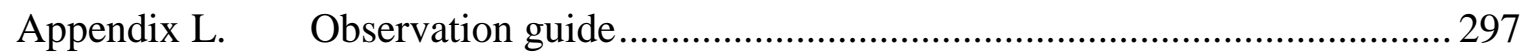

Appendix M. Summary of a PLD observation ....................................................... 298

Appendix N. National policy documents for review .............................................. 300

Appendix O. A translated interview transcript......................................................... 301

Appendix P. Summary of PLD observations ............................................................ 312 


\section{LIST OF FIGURES}

Figure 2.1 Vygotsky's model of mediated action (Engeström, 2001)............................... 34

Figure 2.2 The structure of a human activity system (Engeström, 2001)........................ 35

Figure 2.3 A model for the third generation of activity theory (Engeström, 2001) .......... 37

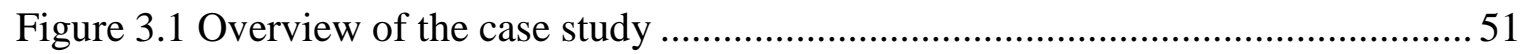

Figure 4.1 Lecturers' perceptions of PLD role in enhancing leadership ......................... 78

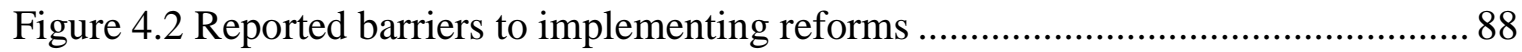

Figure 5.1 PLD for improving English proficiency .................................................. 178

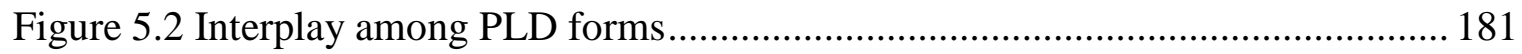

Figure 5.3 The influences of PLD within this system (Site A) .................................... 184

Figure 5.4 The influence of institutional regulations on PLD (site B) .......................... 187

Figure 5.5 The interactions among components of the PLD activity system (Site C) .... 190

Figure 5.6 Different perspectives on PLD role and function (PLD as artefact) .............. 195

Figure 6.1 PLD model for EFL tertiary teacher educators in Vietnam ........................... 223 


\section{LIST OF TABLES}

Table 2.1 Basic requirements of EFL teachers' professional competencies .................... 26

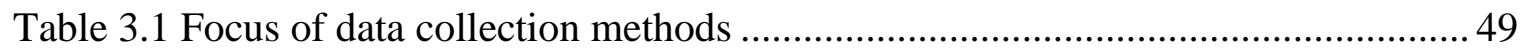

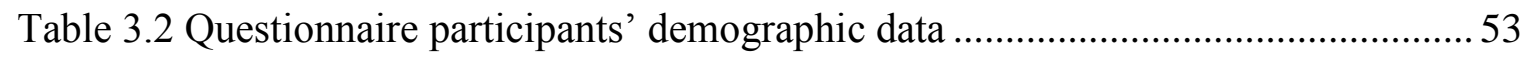

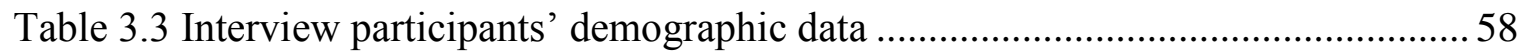

Table 3.4 Guidelines for analysing the PLD activity systems in individual sites ............ 67

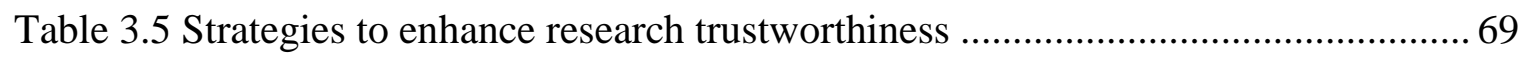

Table 4.1 Participants' perception of the importance of PLD roles and functions............ 76

Table 4.2 PLD for enhancing leadership viewed by academic leaders and lecturers........ 77

Table 4.3 Participants' perceptions of the importance of PLD activities ......................... 79

Table 4.4 Lecturers' report on their participation in PLD activities................................. 81

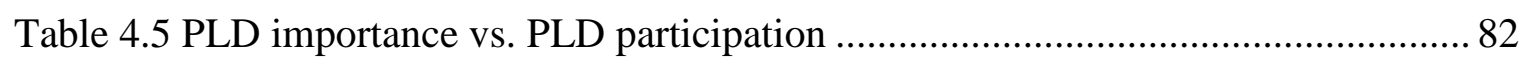

Table 4.6 Lecturers' report on their participation in informal and collaborative PLD...... 83

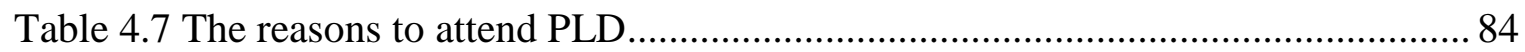

Table 4.8 Reasons to attend PLD reported by different age groups ................................ 86

Table 4.9 Identified qualification targets for HE staff................................................... 96

Table 4.10 Institutional targets for lecturers' qualifications (2007-2020) ..................... 109

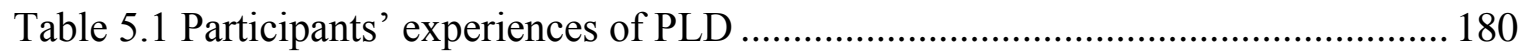




\section{ABBREVIATIONS}

\begin{tabular}{ll} 
ASEAN & Association of Southeast Asian Nations \\
CEFR & Common European Framework of References \\
CFG & Critical Friend Groups \\
CHAT & Cultural Historical Activity Theory / Activity Theory \\
CLT & Communicative Language Teaching \\
CPD & Continuous Professional Development \\
EFL & English as a Foreign Language \\
ELT & English Language Teaching \\
EMI & English as the Medium of Instruction \\
ESP & English for Specific Purposes \\
ESC & English Speaking Club \\
EILTS & International English Language Testing System \\
HE & Higher Education \\
HEIs & Higher Education Institutions \\
HERA & Higher Education Reform Agenda \\
ILP & Inquiry Learning Partnership \\
MOET & Ministry of Education and Training \\
PL & Professional Learning \\
PLD & Professional Learning and Development \\
PD & Professional Development \\
TE & Teacher Education \\
TOEFL & Test of English as a Foreign Language \\
TOEIC & Test of English for Intercultural Communication \\
TESOL & Teach English to Speakers of Other Languages \\
\hline
\end{tabular}




\section{CHAPTER 1 \\ INTRODUCTION}

Over the last decade government initiatives in Vietnam have resulted in major education reforms in higher education (HE) to establish a quality assurance system, link teaching and research, and upgrade foreign language education. A key challenge for Vietnamese institutions lies in implementing the ambitious targets of these top-down initiatives set by the government and the Ministry of Education and Training (MOET) (Hayden \& Lam, 2007a). Although the policies have been in operation for several years, educators and administrators question the feasibility of reaching many of the assigned targets (K. D. Nguyen ${ }^{1}$, Oliver, \& Priddy, 2009). The Vietnamese reform agenda emphasises professional learning and development (PLD) for lecturers so that they can respond to mandated initiatives in HE; however, the national directives have not provided these educators with clear guidelines for the provision of PLD. There is a need for effective PLD to enable lecturers to better understand these initiatives, fulfil their roles and implement the government policies successfully (K. D. Nguyen et al., 2009).

The nature of PLD for educators and its roles in supporting HE reforms in developing countries like Vietnam are not fully understood, and an in-depth investigation is necessary to identify the effects and influences of PLD on staff in the tertiary context. The aim of this study is to analyse these issues in depth to better understand the phenomenon of PLD in bringing about change in educators' practice at tertiary level. This chapter outlines the educational context in Vietnam and challenges to meeting the government's educational targets, and presents the rationale for this study.

\section{Educational context in Vietnam}

Education in Vietnam is regarded as a driving force for national development. Together with science and technology, education is prioritised in national policy (Vietnamese

\footnotetext{
${ }^{1}$ Initials are provided to distinguish Vietnamese authors with the same surnames.
} 
Assembly, 2005). The government of Vietnam and MOET have launched strategic plans for educational development and national directives for Higher Education Reform Agenda (HERA) for the period 2006-2020, which aim to boost educational quality and provide high quality intellectual human resources for globalisation (Vietnamese government, 2005).

The HERA emphasises that higher education institutions (HEIs) must promote both teaching and research in order to raise the competitive position of Vietnamese education in the Southeast Asian region and in the world. Major universities in Vietnam are to develop into national scientific research centres and provide advanced undergraduate education programmes with English as an instructional medium. The government has signalled that world-class universities are to be built and operational by 2020 in major cities of the country. The HERA has also set specific targets: 20,000 more lecturers with doctoral qualifications at HEIs by $2020,60 \%$ of academics with an MA degree and $35 \%$ with a $\mathrm{PhD}$ degree, and reduction of the student/teacher ratio to 20/1 (Vietnamese government, 2005).

There are several initiatives to develop quality assessment and quality assurance across all sectors of the educational system (MOET, 2007). Educational programmes for all disciplines are expected to be updated, focusing more on raising graduates' outcomes and their work-related and lifelong learning skills. These practices aim at standardising educational quality, and informing society of the resources, objectives and student outcomes from a particular institution (MOET, 2007).

English language and EFL teaching and learning plays a crucial role in the broader context of national goals and strategies to advance Vietnam and its educational system within Southeast Asian region and in the world. EFL teaching and learning policies are influenced by the Vietnamese socio-cultural and political context and the government's goals and visions for national advancement. Enhancing English competence of Vietnamese work-force will support the national goals and development in the context of globalisation and economical integrations. There has been a significant reform in teaching and learning foreign languages, particularly English as a Foreign Language (EFL), targeted in a national project named "Teaching and learning foreign languages in the national education system from 2008 to 2020" (Vietnamese Prime Minister, 2008). This project aims to improve the 
quality of foreign language education and implement new foreign language programmes across all sectors. The projected outcome is that by 2020, most Vietnamese graduates will be able to use foreign languages confidently and successfully in communication, when studying, and when working in a multi-cultural and integrated environment. English is considered the key foreign language, and EFL has become a compulsory subject in the tenyear school curriculum, from grades three to twelve. Foreign languages are intended as a tool to strengthen the Vietnamese people's contribution to national industrialisation and modernisation.

The language education project involves three stages varying in focus. The first stage, from 2008 to 2010, focused on developing curricula and teaching materials, assessment methods for all sectors, preparing qualified teachers, and piloting the ten-year EFL curriculum. The next stage, 2011-2015, was spent popularising the ten-year EFL curriculum, and developing intensive language programs in HE. The last stage, 2016-2020, will focus on implementing the new curriculum, and intensive language programs in vocational, tertiary education throughout the country. This national reform, particularly in ELT, has raised the important role of both EFL tertiary teacher educators and EFL school teachers in implementing the government policies. Their changing roles require them to undertake PLD to improve their professional competencies and be able to enact top-down initiatives in education.

\section{Challenges to reach the reform targets}

Educators have raised concerns that there are insufficient human resources to enact government's initiatives in education (Hayden \& Lam, 2007a; K. D. Nguyen et al., 2009). Teaching and research are considered to be the two most important tasks for university academics (MOET, 2008). However, barriers such as a full teaching load, limited time, resources, knowledge and skills, and limited institutional support prevent Vietnamese educators from effective professional learning and research engagement $(\mathrm{H}$. H. Pham, 2006). Additionally, there are challenges related to the numbers of EFL teachers who have the resources to enact the reform in EFL education. The majority of EFL teachers in primary schools struggle to meet the English standard to teach the new curriculum (VietNamNet 
Bridge, 2012; Parks, 2011). Similarly, in HE the quality of curricula, teaching, assessment, and student outcomes in EFL education is considered problematic ( $\mathrm{Vu}, 2010)$.

The current educational context suggests that those working in HE need support to understand, implement, and creatively work through the government's priorities. However, current practices of PLD seem anecdotally to be unsatisfactory. Common forms of PLD such as workshops, seminars and short training courses for educators in Vietnam are perceived by educators to be of little benefit, a waste of time and money, and often fail to meet the participants' needs (Ngo, 2011; Thanh Binh, 2010).

\section{Rationale of the study}

I am an EFL teacher educator in a small university in Vietnam where there are few opportunities for teacher learning and professional support. I recognise the need for PLD to improve my own teaching as an EFL lecturer, but also acknowledge how PLD might help me to maintain the necessary skills and capacity to function as a teacher educator and a facilitator who can work alongside EFL university graduates when they enter the teaching profession in schools.

Studies on PLD for educators have largely taken place in Western rather than in Asian countries, and PLD for teacher educators, or teachers of teachers, has not been widely investigated (Ben-Peretz, Kleeman, Reichenberg, \& Shimoni, 2010; McGee, 2011; Swennen \& Bates, 2010). Specifically, PLD for EFL lecturers may vary greatly from PLD for educators in other disciplines because it involves language learning theory and language teaching pedagogy, and thus is worth investigating. Moreover, although the relationship between PLD provision and contextual factors is well acknowledged (Hamano, 2008; Liu, 2009), the impact of sociocultural factors on EFL lecturers' PLD in a developing country has not been fully investigated. Asian cultural features such as a hierarchical system, the dominant role of MOET, and top-down policies (Hallinger, 2010; Hayden \& Lam, 2007b) might influence Vietnamese EFL lecturers' learning and teaching, especially given their changing roles in a time of educational reforms. 
This study aims to investigate the role and function of PLD in supporting EFL teacher educators' personal and professional growth and their capability to implement government initiatives in Vietnamese context. Just as teachers' impact on their students' learning, teacher educators' learning and their teaching capabilities have a crucial influence in the quality of teacher education (Boei et al., 2015; Smith, 2003). Additionally, it is clearly stated in Vietnamese educational policy documents that for national educational reforms to be effective, teachers, and teacher educators alike, are key change agents (MOET, 2011; Vietnamese Prime Minister, 2008, 2012). Taking the above issues into consideration, in order to find out how to enhance Vietnamese teacher educators' professional competencies through PLD engagement, it is important to understand these educators' perceptions of PLD, how their PLD actually occurs, and what meanings and expectations they have for their PLD. An in-depth study of these aspects of PLD for educators will inform evidencebased policies to foster these educators' learning, which will empower their ability to act on required changes, and ultimately benefit their students' learning. Broadly, this study is responsive to an international-wide call for in-depth understanding of teacher educators' PLD in their teaching contexts (Ben-Peretz, Kleeman, Reichenberg, \& Shimoni, 2010; Smith, 2003). This study on PLD for Vietnamese teacher educators of EFL is especially timely as PLD is a key strategy for improving their teaching quality and implementation of educational initiatives. 



\section{CHAPTER 2 \\ LITERATURE REVIEW}

While there has been a wealth of literature on PLD for school teachers, PLD for teacher educators has not been widely investigated. However, teacher educators are also teachers, which means that PLD for teacher educators shares common features with PLD experienced by school teachers (Davey \& Ham, 2010; Knight et al., 2014). Indeed, PLD for both groups has a focus on teacher learning, and aims to support these teachers' teaching and their student learning. The theoretical foundation of this study, therefore, is built on recent literature on teacher learning, PLD for teachers in general, and PLD for teacher educators in particular.

This chapter explores the concept of PLD and the role it plays in education. It then reviews PLD for HE educators, and PLD specifically for teacher educators in international contexts. An overview of English language teaching in Southeast Asia is provided, followed by a review of English teaching and PLD for EFL teachers in Vietnam. The final section describes EFL teacher educators in this study. Literature in these areas reveals the complexity of PLD in different contexts.

\section{Professional learning and development in education}

This section describes the following aspects of PLD in education: (1) the nature of teacher learning, (2) understandings of PLD, and (3) changes in perspectives and implementations of PLD.

\section{The nature of teacher learning}

Lawler and King (2000) emphasise that tertiary educators' learning is consistent with adult learning, and suggest utilising principles of adult learning for planning educators' learning and development. They describe six major principles for promoting adult learning, including respect for learners' prior knowledge and experience, active participation, experience-based learning, collaborative inquiry, learning for action, and participants' 
empowerment. However, unlike novice adult learners, in-service teachers possess professional experience, knowledge, and skills which affect their learning goals. Building on this assertion, King and Newmann (2001) highlight four principles of teachers' learning, stating that effective learning occurs:

1. When teachers focus on instructions and students' outcomes in their own teaching

2. When teachers have continuous opportunities for learning new things, trying them in their practice, and getting feedback on their work

3. When teachers collaborate with their peers and have access to support and expertise from both inside and outside experts

4. When teachers can impact on their own process of professional development.

Given that teacher learning is similar to, and consistent with, teacher educators' learning, literature on PLD for teachers can be used to provide a theoretical foundation for studying PLD for teacher educators in this study.

\section{Understandings of PLD}

Professional learning and development could simply be understood as the process by which lecturers learn to update and improve their knowledge and teaching skills. The function of this form of PLD is typically to enable educators to perform their job and meet the required qualifications for teaching. Traditionally within Vietnam, PLD is viewed as professional development (PD) and consists of attending training courses, workshops, and conferences, and undertaking independent learning (lecturers learning on their own, in their own ways). In Vietnamese, lecturers and educational leaders use the terms bồi duỡng chuyên môn (improving one's expertise), or phát triển chuyên môn (developing one's expertise), or tụ bồi duõng chuyên môn (self-improving one's expertise) to refer to two kinds of PD practice: attending PD provided by experts, and undertaking independent learning such as reading books, practising English skills, and learning from teaching experience. Sometimes, the

\footnotetext{
${ }^{2}$ English equivalences for bồi dữ̃ng can be: foster, nurture, or improve.

In this study, Vietnamese words are italicised and their English translations are provided to clarify the meanings if needed.
} 
term hoc tạp (learning) is used together with the above terms, but not as frequently, particularly in policy documents. However, this thesis incorporates the concept of 'learning' into the conceptualisation and function of PLD in HE.

Professional learning and development has been described in the literature in diverse ways including teacher development, professional development (Day, 1999; Guskey, 2000), in-service education for teachers or INSET, continuous professional development (CPD) (Kelchtermans, 2004), continuing education and lifelong learning. These terms have overlapping meanings and are defined differently by different researchers (Bolam \& McMahon, 2004). The same terms used by the authors of the reviewed literature will be used in this section.

Many of the various definitions of PD focus on improving students' learning. For example, Diaz-Maggioli (2004) states that PD is a career-long process during which educators change and improve their pedagogical practices to meet students' learning needs. Similarly, Guskey (2000, p. 16) defines PD as "an intentional, ongoing, and systemic process" that enhances educators' professional knowledge, skills, and attitudes so that they might improve the students' learning.

Other researchers focus more on a broader concept of PLD, especially on teachers' changes and their teaching capacities. For example, CPD is defined as "all activities in which teachers engage during the course of a career which are designed to enhance their work" (Day \& Sachs, 2004, p. 2). In terms of its impact, teachers' professional learning is considered to address the development of personal, social and occupational aspects (Bell $\&$ Gilbert, 1996). Further, taking into account the complexity of teaching which involves not only teachers' cognitive but also affective competencies, Hargreaves (2003) emphasises the moral purpose of teaching, and the role of PD in supporting teachers' emotional intelligence and emotional understandings which are vital in helping them to improve their work performance, personal relationships and the development of the organisation.

While Hargreaves (2003) separates the two concepts professional learning and professional development, other authors integrate them when referring to $\mathrm{PD}$ as learning experiences or learning processes (Day, 1999; Kelchtermans, 2004). Acknowledging the complexity of the teacher learning and the range of daily learning opportunities teachers 
have, Day (1999) includes the notion of critical reflection within the definition that involves "the process by which, alone and with others, teachers review, renew and extend their commitment as change agents to develop critically the knowledge, skills and emotional intelligence essential to good professional thinking, planning and practice" (p. 5).

In these definitions, teachers' development is understood to be located both in their personal and professional lives, and in the context and policies of the school within which they work (Day, 1999). Kelchtermans (2004) develops this further by considering CPD as a learning process resulting from meaningful interaction with the context leading to changes in teachers' practice and in their thinking about that practice. Similarly, teachers' learning is viewed as a complicated process of a "multicausal and multidimensional nature" with three types of inter-related influences mediating teachers' learning: the teachers' individual learning orientation, the school-level learning orientation, and the learning activities themselves (Pedder, Opfer, McCormick, \& Storey, 2010, p. 390). When exploring PD for tertiary teacher educators Smith (2003) explains that PD is for professionals to improve the quality of their work and try to "become the best professional one can possibly be" (p. 203).

Contemporary definitions of 'PD' have started to move towards 'PLD' in order to reconceptualise these concepts (O’Brien \& Jones, 2014; Opfer \& Pedder, 2011; WebsterWright, 2009). Webster-Wright (2009) argues that the current conceptualisation of PD draws on a deficient approach implying that professionals are inadequate and need to be developed or filled with new knowledge. There has been a tendency for PD research and practices to separate PL from professionals' working contexts and under-investigate informal professional learning. Webster-Wright (2009) addresses these limitations and proposes an alternative term "continuous professional learning" (CPL) referring to lived learning experiences of practicing professionals in context.

This study addresses the call in literature for research focusing on teacher learning in their natural working contexts (Opfer \& Pedder, 2011; Webster-Wright, 2009) and adopts the term PLD to foreground both the learning and developing components in lecturers' experiences. The understanding of PLD used in my study includes Day's (1999) definition of PD and is grounded in characteristics of teachers' learning (Bell \& Gilbert, 1996; Hargreaves, 2003; King \& Newmann, 2001; Knight, Tait, \& Yorke, 2007) that provide 
empirical evidence of features of effective professional development and professional learning practices. This study takes a sociocultural perspective that emphasises authentic teacher professional learning situated in a particular social and cultural context (Kelchtermans, 2004; Opfer \& Pedder, 2011; Rogoff, 2003; Vygotsky, 1978; WebsterWright, 2009). In this study PLD is also contextualised within Vietnamese HE, and includes understanding of PLD as specified in Vietnamese educational policy documents.

In this study, PLD is considered as an on-going learning process that contributes to a rounded development of an individual both personally and professionally during her or his career. As stated in the regulations for lecturers' professional development (MOET, 2013), PLD plays a role in enhancing both lecturers' phẩm chất (moral qualities) and năng lục (competencies). Specifically, the document specifies four purposes of professional development for lecturers. These purposes are adopted to elaborate on the definition of PLD in this study, including:

1. Update new content knowledge for teaching and improving educational quality;

2. Meet the requirements of professional standards as required for different titles of lecturers;

3. Improve competencies in teaching, research, and organising and managing institutional activities;

4. Improve moral qualities, political premise, and professional conscience required for lecturers.

Hereafter, I will use PLD as an alternative term for PD or CPD used by other researchers in previous studies. In this study PLD specifically refers to any activities undertaken by lecturers to enable them to fulfil their professional roles effectively and to meet the required qualifications and competencies in the profession.

\section{Changes in perspectives and implementations of PLD}

The traditional view of PLD for teachers as an activity to fix their 'deficiencies' or 'inadequacies' in knowledge and teaching skills now seems to be inappropriate (Fiszer, 2004; Guskey, 2000). Research has analysed problems inherent in previous PLD practices designed and implemented based on traditional approaches (Fiszer, 2004; VillegasReimers, 2003). Models of PLD are limiting when they represent one-size-fits-all 
workshops and seminars (Mundry, 2005, p. 9), or dialogue-free sessions when teachers passively listen to outside experts talking about something that may not be relevant to their own teaching contexts (Fiszer, 2004, p. 1). It has been argued that these models of PLD are not likely to promote teachers' learning and practice (Steyn, 2010).

Traditional PLD has been described as ineffective, unsatisfactory or failed for various reasons (Chaudary, 2011; Fiszer, 2004; Guskey, 2000; Mundry, 2005; Villegas-Reimers, 2003). First, it may not consider participants' needs or their teaching problems because the PLD planning may be carried out in a top-down manner (Fiszer, 2004). Time limits mean there are usually limited opportunities for discussion or collaborative activities (Fiszer, 2004). Participants tend to be viewed as passive learners during these PLD programmes. There is often a lack of follow-up activities to help teachers apply new knowledge and skills (Ebert-May et al., 2011). Finally, evaluating a PLD programme can be problematic when using "a one-page evaluation form" asking about the participants' satisfaction with the presentations rather than evaluating PLD effects on teachers' practice (Fiszer, 2004, p. 2).

The learning and working of teachers, and lecturers alike, are influenced by a variety of cultural and organisational factors, including organisational norms and cultures, bureaucratic regulations, workload, student characteristics, and collegial relationships (Bartell, 2005; Hwang, 2014). A school context with little collegial interaction and collaboration, insufficient administrative support, and a tight curriculum schedule may hinder teachers' learning and capacity for implementing instructional changes (Liu, 2009).

Other factors affecting PLD may include teachers' stress and tension derived from the workplace context and the pressure to implement educational reforms (Gao, 2008; Kwakman, 2002; Pattie, 2009; Yamagata-Lynch, 2003). Bartell (2005) also states that teachers' growth is influenced by personal factors related to family, personal goals and interests, and life stage. These studies point out the interrelation between teachers' daily work and life, and their working contexts, and highlight the necessity of constructing a supportive working environment to enhance teachers' PLD and well-being. 


\section{The roles of PLD in education}

This section reviews the effects of PLD at individual and institutional levels. The role of PLD as a means to support teachers' professional growth, facilitate policy implementation, and improve student learning is explored.

\section{Impact of PLD on teachers' changes}

PLD helps to address teachers' learning needs and enhance their teaching motivation. Shumack and Forde (2011) investigated PLD activities, and the interests and perceptions of 109 secondary business teachers over 12 months. Results from this online survey indicated that teachers perceived that PLD had a positive impact on their classroom practice and led to an improvement in their content knowledge, confidence, co-operation with colleagues, and motivation for trying new teaching practices. However, data from this online survey did not provide an in-depth understanding of these teachers' experiences of PLD and their motivation for engaging in PLD. Additionally, the study did not investigate how variations in these teachers' characteristics and school types affected their PLD experiences.

Green (2010) investigated secondary English teachers' perceptions of further education as a form of PLD and the reasons why they undertook it. Data were collected by means of questionnaires delivered to 119 English teachers with various degree backgrounds, and from different secondary schools in London. The most common reasons for teachers' participation in postgraduate programmes related to their desire for academic development, career development and promotion, and personal interests. However, other kinds of teacher learning within their local teaching contexts were not included in this study, which prevented a holistic understanding of the variety of learning activities school teachers undertook and how they evaluated their experiences. Also, the study did not analyse how teachers' PLD needs and motivation varied according to individual differences.

The issue of teachers' changing needs for and concerns about PLD over their career has attracted other researchers. A study involving 520 teachers (360 at primary schools and 160 at junior high schools and high schools) in Israel found that teachers expressed different 
attitudes toward pedagogical changes during various stages of their career (Maskit, 2011). Data were collected by using two questionnaires completed by these teachers, followed by an open interview with 15 randomly selected teachers. The study found that teachers identified different preferences for the forms of PLD according to their career-stage and experience. Richer, Kunter, Klusmann, Ludtke, and Baumert (2011) reported similar findings. They examined how secondary maths and science teachers engaged in formal and informal learning activities. They defined formal learning as structured learning following a specified curriculum (e.g., training, conferences, and workshops). Informal learning was defined as voluntary learning, involving teachers' initiatives, and including both individual (e.g., reading books and observing their peers' classrooms) and collaborative learning activities (e.g., mentoring, conversations with colleagues, and teachers' network). Data from questionnaires delivered to 1939 teachers at 198 German secondary schools showed that formal learning activities and self-directed learning were used most frequently by midcareer teachers. In contrast, informal learning forms, especially collaboration and observations, were used more frequently by less-experienced teachers. However, the two studies above, despite acknowledging individual perspectives in PLD, neglected the relationship between teachers' learning and their own work context which might significantly affect their motivation, career goals and learning interests. Moreover, they do not acknowledge that teachers' learning often occurs in a social context rather than in isolation (Bourke \& St. George, 2008).

Mentoring and coaching is identified as an important form of PLD for teacher learning within a collaborative learning environment. Marlow (2009) studied the impact of a leadership project that connected beginning school science teachers (1-2 year teachers) with experienced science teachers and university mentors in planning workshops and presenting in a national science conference in California. The project provided participants with both informal and formal learning opportunities for working collaboratively to finish a task (e.g., attending workshops, working in teams to prepare for a presentation, reflecting on their learning experiences through teachers' journals and digital stories). For assessing the impact of this project on the teachers' sense of self, the study employed Likert-type questionnaires and interviews that focused on teachers' attitudes towards professionalism. Results showed that mentoring as a form of PLD had a positive impact on strengthening the professional identity of both mentors (experienced teachers) and mentees (beginning 
teachers). The study addressed problems of disconnection and feelings of reduced motivation facing mid-career teachers, and found that their practice of leading and mentoring new teachers helped to solve these problems. This also increased the mid-career teachers' sense of professional identity, connection to the profession, and "a renewal of commitment to teaching" (p. 1). The mentored group in the study also experienced growth in their professional identity. This study is consistent with the work of Lawler and King (2000) who suggested that the direction of faculty development needed to move away from keeping educators up-to-date in their field, focusing on their disciplinary expertise or teaching skills, and understanding the complexity of teaching and learning process. Instead, PLD would be more effective if it were channelled towards improving educators' vitality and renewal.

Teaching, especially in tertiary contexts, can at times be a stressful profession (Klassen, Usher, \& Bong, 2010; Lai, Du, \& Li, 2014). Therefore, PLD addressing teachers' beliefs, attitudes, and perceptions, all of which greatly influence their practices, can lead to fundamental changes in their motivation and quality of teaching. Research shows that PLD can help develop teachers' well-being, confidence and professional satisfaction. Supporting teachers to deal with changes, stress, and obstacles may also encourage them to stay on the job (Forde, McMahon, McPhee, \& Patrick, 2006; Shawer, 2010).

\section{Teacher impact on institutional changes and educational reforms}

Teachers have been identified as key agents for change and school improvement (Day, 1999). They can contribute to the professional growth of colleagues, build a professional community, change school cultures and structures, and enhance school capacity (King \& Newmann, 2001; Little, 1992). When teachers within a school work collaboratively towards a shared goal and mission, this collective power strengthens the organisational capacity to change (Jones, Stanley, McNamara, \& Murray, 2011; Sales, Traver, \& Garcia, 2011; Youngs \& King, 2002).

There is evidence that PLD functions as a mechanism to support major education changes. A study by Starkey et al., (2009) on PLD for implementing assessment reforms in senior secondary schools in New Zealand is an example of a successful model of PLD for system change. The study focused on the embedding stage of the reform. Results from 
teacher surveys and case-studies of selected schools highlighted crucial features for effective practice. These features included teachers' networks and shared learning, PLD personalised to meet the needs of individual teachers, and facilitators' expertise. The study emphasised the necessity of tailoring PLD to the purpose of the reform and teachers' needs at each stage of the reform.

Similarly, Borko, Elliott, and Uchiyma (2002) studied the role of PLD in an education reform in Kentucky. The policies to support PLD in Kentucky included (1) viewing PLD as the "lynch pin" of the reform (p. 985), (2) offering substantial resources, (3) providing extensive, multifaceted PLD addressing all reform strands, and (4) ensuring that PLD support reached all schools. The study emphasised outstanding features of the four exemplary schools: having PLD plans that met teachers' needs, allocating PLD funds flexibly based on the school context, and using Kentucky resources for on-going PLD that targeted all aspects of school capacity. The research concluded that Kentucky provided a successful PLD model for a large-scale standards-based educational reform, and that the exemplary schools showed evidence of the link between PLD and improved school capacity.

There are cases where educational innovations have failed due to insufficient preparation of resources or acknowledgement of contextual factors (Hu \& McGrath, 2011; Lai, 2011). A study in a HE context found that although the success of educational reform mainly depended on the quality of teachers who were given responsibilities to implement the reforms in their own practice, it was uncommon for teachers to be involved in initiating reform or given adequate preparation and support to fulfil their tasks (Hu \& McGrath, 2011). These oversights undermined the success of top-down reforms.

In addition to limited resources and a tendency to overlook the needs of teaching staff, distinctive cultural features may also act as barriers to reform enactment. Hallinger (2010) analysed educational reforms in five rapidly developing countries in Southeast Asia and found that these societies experienced similar responses to innovations imported from Western cultures. The countries shared 'distinctively Asian' obstacles to reform progress, namely (1) top-down initiations, (2) reform overload, (3) the cultural distance created by power structures leading to passive receptiveness or passive resistance to policy 
implementation, (4) lack of stability in the change process, (5) insufficient staff preparation, and (6) the mismatch between reform initiatives and the local context (pp. 408-412). Hallinger's study, however, investigated educational initiatives in general, rather than focusing on reforms in tertiary contexts.

Although Vietnam was not included in the above study, the process and strategies for education reforms in Vietnam may have followed a similar pattern to those outlined in Hallinger's (2010) study. Therefore, further research is needed to understand sociocultural influences on the practice of PLD for Vietnamese educators and on reform efforts, particularly in tertiary education.

\section{Impact of teachers' PLD on students}

Positive changes in teachers' knowledge, skills and classroom instructions from effective PLD may lead to better student outcomes (Guskey, 2000). For example, Buczynski and Hansen (2010) studied the effect of an Inquiry Learning Partnership (ILP) for year 4-6 teachers in elementary science education. The ILP programme was carried out through the collaboration of a university, a science centre and two urban school districts. This programme aimed at improving teachers' science content knowledge and pedagogy, the quality of math and science teaching, and students' achievement in maths and science. Buczynski and Hansen (2010) reported that data were collected from multiple sources such as pre/post content exams, surveys, focus group interviews, and assessment data in order to analyse the effect of the ILP programme on teachers' pedagogical practices and students' outcomes. The study found that the programme increased teachers' science content knowledge and skills, and their implementation of inquiry instructions in the classroom. There were also modest gains in the students' grade in the standardised science achievement exams after one year of the PLD programme. The researchers described several barriers to this PLD practice in the studied school, including limited resources, time constraints, and teachers' difficulty in mastering the required curriculum pacing and classroom management techniques.

To find out the impact of teachers' instructional practices on their student outcomes, this study compared the science standard test scores of students from 2005 to 2006 . The results revealed a slight improvement among students taught by ILP teachers, and these 
students' improvement was slightly higher than that of non-ILP teachers, yet this trend was not consistent across different districts. Additional results of the locally developed assessments based on inquiry learning showed that students taught by ILP teachers performed better than students in the classes of non-ILP teachers. Teachers who engaged in ILP programme also perceived that their inquiry strategies contributed to their students' improvement achievement in the successive year. However, the connection between teachers' practices and student outcomes was not significantly proved in this study.

It is commonly accepted by scholars of PLD that it is difficult to establish a causal relationship between student achievements and teachers' PLD (Yoon, Duncan, Lee, Scarloss, \& Shapley, 2007). This relationship is not addressed in the current study, and I will instead focus more on understanding the nature of PLD for educators and their organisations.

\section{PLD for HE educators in international contexts}

Tertiary lecturers' roles are becoming increasingly diverse and challenging. Besides teaching, these educators play other roles such as researcher, scholar, adviser, manager (D’Andrea \& Gosling, 2005; Davey \& Ham, 2010; Smith, 2003). It is widely agreed that tertiary lecturers feel under increasing pressure from managers and students alike that they should excel in all these responsibilities (Blackmore \& Blackwell, 2006; Teräs, 2014). These roles compete for time, priority, and effort and require educators' engagement in continuous learning. Professional learning can help lecturers meet new demands and perform multiple roles in their rapidly changing work environment.

Despite the important role of PLD in supporting lecturers' teaching and their students' learning, studies suggest that in some contexts lecturers perceive PLD aimed at supporting their teaching as inadequate (Chaudary, 2011; Liu, 2012). For example, in a viewpoint article, Chaudary (2011) comments that PLD provision for tertiary lecturers in Pakistan is problematic because "in most cases, it does not exist; and if it does, it is very brief, sporadic and traditional, and is conveyed off-site through top-down teacher training strategies" (p. 633). Data from a qualitative case study of "six information-rich cases" and semi-structured interviews found that Pakistan tertiary lecturers valued their experience of 
self-directed, reflective and experiential learning (p. 634). They also wished to have PLD organised locally within their workplace. This shows that from these lecturers' perspectives, PLD needed to allow for autonomy in their learning and relate to their teaching context and professional practice. This article, however, did not clarify details of the lecturer participants, their backgrounds, professional roles and practices, and their tertiary work contexts. Insufficient information about these issues limited readers' specific understanding of how PLD for Pakistan lecturers actually occurred, what motivated their PLD engagement, and what factors influenced their PLD experience. Further details about these issues would enable a better understanding of the reason why "tertiary teachers are 'at-risk' practitioners in Pakistan" who have a pressing need for changes in their PLD access (p. 637).

Other studies identified diverse expectations and experiences of PLD in both formal and informal PLD settings (Knight, Tait, \& Yorke, 2007; Teräs, 2014; Wichadee, 2012). There is an increasing interest in the impact of professional learning communities on tertiary lecturers' learning. For example, Teräs (2014) studied tertiary lecturers' engagement in online professional development. The study involved seven Finnish tertiary lecturers from different backgrounds participating in an authentic learning-based, online postgraduate certificate programme on tertiary teaching and learning. Findings from a narrative analysis indicated that the participants perceived significant improvement in their teaching practices and their professional attitudes. This learning model, however, did not fully address variations in the participants' learning needs, expectations and interests. The study aimed to use online PLD programmes to enhance lecturers' self-regulation skills and authentic learning rather than striving to accommodate their differences. Also, a crucial factor for this model to be effective was the support for and facilitation of lecturers' collaborative learning. The study sheds light on online collaborative learning communities as a promising form of PLD for tertiary lecturers in the $21^{\text {st }}$ century where lecturers must adapt to rapid change. This study, however, employed the participants' self-stories as the sole source of data and involved only seven lecturers who were highly motivated to participate in the programme. The findings, therefore, are unlikely to reflect the perceptions of and engagement in this kind of PLD by a wider population of university lecturers. While lecturers' individual characteristics (e.g., age, backgrounds, disciplines, experience) and 
their working contexts may have an impact on their PLD engagement, as found in the literature (Wichadee, 2012), these factors were not fully discussed in this study.

\section{Teacher educators' professional practices and professional learning}

Literature on teacher learning and teacher education can provide an appropriate knowledge base for the practices and PLD of teacher educators (Davey \& Ham, 2010; Knight et al., 2014). However, teachers and teacher educators differ in their working contexts, degree of professional autonomy, responsibilities, and expectations of competencies attached to their respective roles (Loughran, 2014). Specifically, teacher educators are considered as "a professional group that for all intents and purposes has much more autonomy and control over their work than teachers per se" (p. 271). Tertiary teaching is perceived increasingly demanding as teacher educators are required to implement policy changes as well as to manage both teaching and scholarship development. Therefore, research on teacher educators, their roles, professional practices and PLD is gaining more attention (Loughran, 2014; McGee, 2011). Recent studies aim to gain better understandings and interpretations of teacher educators' professional practices and learning, and to offer "a well-developed knowledge base" to explain the complexity of teacher educators' learning (Knight et al., 2014, p. 268). This section presents an international perspective on teacher educators' professional practices and professional learning. A review of previous studies on PLD for teacher educators in different contexts helps to establish a theoretical ground for the current research.

There is a consensus that teacher educators have an important influence on the quality of teacher education and of education in general. Indeed, they play a key role in determining the quality of teachers, who in turn have great influence on the quality of their students' learning in the school sectors (Boei et al., 2015; Smith, 2003). Research on teacher educators who work in tertiary contexts highlights challenges teachers educators face in fulfilling two key roles: being teachers of teachers and being lecturer-researchers (Hill \& Haigh, 2012; Robinson \& McMillan, 2006). The important roles teacher educators play in education, and challenges they face in order to undertake both teaching and research require them to possess certain competencies and undertake continuous learning to be the most effective teacher educators possible (Boei et al., 2015). 
In the field of teacher education, there seems to be an agreement about the advantages of teachers' and/or teacher educators' learning in a professional community. McNicholl (2013) conducted a case study of a collaborative inquiry project involving a group of five biology teachers working together with a university teacher educator. The collaborative project aimed to foster these teachers' ability to conduct inquiries into their own practices. The study employed multiple data collection methods, including initial questionnaires, workshop notes and follow-up questionnaires, and final interviews with the teachers. The study showed that this PLD model encouraged teachers' self-regulated learning, ownership of their learning and the skills to work towards authentic goals that supported their teaching improvement. The teacher participants perceived this collaborative PLD as effective because it promoted changes in the teachers' recognition of their students' perspectives, and subsequently changes in their teaching practices. This form of PLD also improved the teachers' confidence, and their ability to impact each other. The study identified factors that contributed to positive outcomes to the project, including (1) the teachers' engagement in self-directed learning related to their needs, (2) the inquiry activities which were rooted in teachers' experiences and classroom practice, and (3) a supportive collaborative working environment which enabled critical reflection and sharing of expertise and experiences among the participants. The study highlighted the teacher educator's dual roles of being both a co-researcher and a facilitator who worked resourcefully to support the teachers' inquiries and their capacity to work with others toward the desired outcomes. However, it did not offer insightful understanding about the professional practice and professional learning of the teacher educators as they engaged in this collaborative project. It did not consider how this experience was perceived from the teacher educators' perspective.

Other studies investigated PLD programmes which focused on the collaborative learning of teacher educators from the point of view of the participants (Lamont, 2011; McGee, 2011; McGee \& Lawrence, 2009). The teacher educators in these studies reported positive perceptions and learning outcomes from engaging in collaborative inquiry. Integral features of collaborative learning included: establishing learning communities based on mutual trust, respect and support; teacher educators reflecting critically on their practices; and enhanced leadership capacity to support this form of PLD. These studies also identified 
such factors as time and competing institutional PLD priorities as challenges to sustaining effective collaborative learning within an organisation.

Overall, studies reviewed in this section focused more on the implementation and effects of particular PLD initiatives or PLD programmes designed for teacher educators. Contemporary research tends to address the issue of teacher educators' research engagement and their PLD through participating in collaborative inquiry or self-study research. There is still a lack of a holistic understanding of potential PLD inherent in teacher educators' daily practices and working contexts, reasons why educators chose to engage in PLD, and how their learning actually happens. Although offering in-depth understandings of collaborative inquiry as a promising PLD model for teacher educators, most of these studies took place in Western countries (e.g., New Zealand, Australia, United Kingdom) where teacher educators normally had teaching experience in the school sectors before entering tertiary institutions. These teacher educators' multiple roles in teaching and research varied across university-based and school-based settings. In contrast, Vietnamese teacher educators' roles, professional practices, and work conditions may be culturally and contextually different from those of their Western colleagues. This suggests that a study on PLD for teacher educators in Vietnam and how they engage in different forms of PLD will contribute to current understanding of PLD for teacher educators in different cultures.

\section{English Language Teaching (ELT) and PLD for EFL teachers}

This section first provides an overview of ELT in the Southeast Asian region in order to capture the wider context in which this study is situated. It then reviews English teaching and PLD for EFL teachers in Vietnam. Finally, a general description of EFL teacher educators in this study is provided.

\section{ELT in Southeast Asia}

In the context of globalisation, English plays an important role in the communication and economic integration in the world, as well as among countries in the Association of Southeast Asian Nations (ASEAN), which includes ten countries, namely Burma, Brunei, Cambodia, Indonesia, Laos, Malaysia, the Philippines, Singapore, Thailand, and Vietnam 
(Kirkpatrick, 2011). Indeed, the political decision to adopt English as the official language of ASEAN, increases the value of and demand for English in the Southeast Asian region. Within the international context and in the ASEAN community, English is the dominant language of communication in many fields such as education, science, employment, technology and trade.

English has assumed a growing importance as an international global language and lingua franca, or "transnational contact language" (Canagarajah, 2006, p. 198) within ASEAN. This major role in regional communication has had a trickle-down influence on English teaching and learning policies in Southeast Asian countries. Key trends in English language policies in the region include: (1) teaching and learning of English in primary education, (2) focus on English as a medium of instruction, (3) pedagogical initiatives in ELT, including adopting the communicative language teaching (CLT) approach and using technology in teaching, and (4) governmental initiatives to enhance the quality of English teacher education, including both pre-service and in-service teacher education.

First, there is a trend for English to be taught at an earlier age, from primary school in Southeast Asian countries (Hamid \& Nguyen, 2016; Nunan, 2003). English is a compulsory or a core subject in the primary school curricula of most countries in the region. Although Indonesia is the only country which does not have English as a compulsory subject in primary school, English is also taught in many primary schools there due to social and parental demand for English (Kirkpatrick, 2011). The introduction of English earlier in educational curricula is based on a common belief that the earlier children learn a language, the better language users they can become.

There is also an increasing use of English as the medium of instruction (EMI) across educational sectors in the region (Hamid, Nguyen, \& Baldauf, 2013). For example, many countries such as Brunei and Singapore use EMI in primary schools, particularly for teaching maths and science (Kirkpatrick, 2011). In HE, there is also a greater focus on delivering advanced university programmes in English in countries such as Malaysia, Vietnam, and China (Hall, 2015; Hamid \& Nguyen, 2016; Vu \& Burns, 2014). The purpose of this policy is to enhance graduates' English competencies, and to raise the international ranking of HEIs amongst educational competition (Hall, 2015). However, the 
implementation of EMI both in pre-tertiary and tertiary levels faces great challenges, including teachers'/lecturers' limited English competence, pedagogical skills, and professional confidence in delivering subject knowledge in English; a shortage of teaching resources; and students' limited language proficiency and learning styles (Hamid et al., 2013; Vu \& Burns, 2014).

In terms of ELT methodology, CLT has been widely implemented in most Asian countries. However, previous studies show that there have been great challenges to implementing CLT effectively in Asia in the face of cultural and contextual factors (Nunan, 2003; Stroupe, 2012). Limited teaching and learning resources, especially in rural areas, and unfavourable classroom conditions (e.g., large class sizes, developing English proficiency of students, limited student motivation) hindered successful application of pedagogical innovations in ELT. Additionally, due to teachers' and students' limited exposure to English outside the classroom, the application of communicative methodologies appears to be more difficult in EFL contexts such as in Indonesia, Thailand, Cambodia, Laos, and Vietnam (Hamid \& Nguyen, 2016; Kam, 2002).

Changes in English language policies highlight the important role of English teachers in enhancing students' English proficiency and implementing national language policies. However, the rapid increase in the demand for English and the implementation of nationwide policies in English language teaching and learning have brought to light a number of unforeseen challenges. The most common problem is a shortage of suitable English teachers. There are also few teachers holding appropriate qualifications at all levels of the educational system to implement national policies in ASEAN countries (Kam, 2002; Schneider, 2014; Stroupe, 2012). Previous studies highlight the problem of in-service EFL teachers with limited English proficiency and pedagogical skills, as found in Thailand, Indonesia (Yuwono \& Harbon, 2010), and Vietnam (Dudzik \& Nguyen, 2015; T. N. Pham, 2014).

To enhance English language teaching and learning quality, several countries have invested in upskilling English teachers and improving the quality of English teacher education. Countries such as Malaysia (Hall, 2015), Thailand, and Vietnam (Dudzik \& Nguyen, 2015) have undertaken nation-wide assessments of in-service teachers' English 
language proficiency in order to ensure that they meet the required national standards of language proficiency. These assessments are followed up with PLD programmes to enhance teachers' English proficiency so that they can improve their teaching and thus student learning outcomes, as found in Indonesia (Widiati \& Hayati, 2015). However, there is insufficient PLD provision to meet the high local demand for qualified English teachers in the region (Hamid \& Nguyen, 2016; Nunan, 2003).

Another problem across ASEAN is the workload pressure faced by English teachers to comply with mandated top-down reforms in ELT. Teachers find that implementing innovations in ELT and achieving the objectives of language education reforms is unfeasible and problematic in practice in their local contexts. This implies that tensions may occur when policy-makers fail to consult practitioners at the grass-roots level (Hall, 2015; Hayes, 2016). Hamid and Nguyen (2016) refer to this situation as "policy dumping" in which local schools and English teachers are required to enact top-down policies without receiving on-going PLD and professional support (p. 26).

Overall, countries in Southeast Asia have followed a similar trend in implementing major educational reforms and changes over the past few decades (Hallinger, 2010). The importance of English in ASEAN is evident in the language education policies enacted in the region. In the field of ELT and English education, Vietnam shares common trends with other Southeast Asian countries (Nunan, 2003; T. N. Pham, 2014). Thus, this study on PLD for EFL teacher educators in Vietnam offers new understanding about the role and function of PLD in an EFL context in Vietnam, and may have broader implications for the field of PLD for EFL teacher educators within the Southeast Asian region, particularly within the ASEAN community.

\section{English teaching and PLD for EFL teachers in Vietnam}

English language teaching and learning policies in Vietnam have been influenced by the increasing role of English as a priority foreign language and the government's strategic plan for enhancing educational quality as a prerequisite for social and economic development and globalisation. As English is recognised as the lingua franca in ASEAN, there is an urgent need for Vietnamese people to be able to communicate in English to 
support their learning and working in inter-cultural environments. English is, therefore, considered as a necessary tool for both individual and national advancement.

As described in Chapter 1, Vietnam is implementing foreign language education reform across all sectors. This national reform in foreign language education aims to raise students' competence in English across all educational sectors, and strives to ensure that university graduates meet the standards of English proficiency for employment, communication, and further studies. The reform specifies English outcomes for students across all educational sectors, and English proficiency standards for teachers of different disciplines. In a recent policy document (MOET, 2014), MOET has specified five basic requirements of professional competencies of English teachers. As presented in Table 2.1, these include: (1) knowledge about the subject and curriculum, (2) knowledge about ELT, (3) knowledge about students, (4) professional values and attitudes, and (5) networking and reflection on ELT.

Table 2.1 Basic requirements of EFL teachers' professional competencies

\begin{tabular}{|c|c|}
\hline $\begin{array}{c}\text { Aspect of } \\
\text { competencies }\end{array}$ & Demonstrations of competence \\
\hline $\begin{array}{l}\text { 1. Knowledge } \\
\text { about the } \\
\text { subject and } \\
\text { curriculum }\end{array}$ & $\begin{array}{l}\text { - English competence or proficiency standards for EFL teachers (e.g., } \\
\text { level } 4 / 6 \text { for teachers at primary and secondary schools, and level 5/6 } \\
\text { for teachers at high schools, according to CEFR }{ }^{3} \text { levels) } \\
\text { - Knowledge about CEFR and ability to apply it in ELT in Vietnam } \\
\text { - Content knowledge, or knowledge of English language (e.g., } \\
\text { pronunciation, vocabulary, grammar) } \\
\text { - Knowledge about English learning and applying this in teaching and } \\
\text { independent learning } \\
\text { - Knowledge about the cultures of English-speaking countries, and ability } \\
\text { to integrate intercultural knowledge in teaching } \\
\text { - Ability in using materials in English appropriately in teaching } \\
\text { - Knowledge about English curricula at school and ability to use the } \\
\text { textbooks and materials appropriately to achieve educational objectives. }\end{array}$ \\
\hline
\end{tabular}

${ }^{3}$ CEFR: Common European Framework of References 
Aspect of

Demonstrations of competence competencies

2. Knowledge about ELT

- Ability in teaching and employing different methods in teaching the four language skills (listening, speaking, reading, and writing)

- Ability in lesson planning relevant to curriculum objectives and developing the four language skills for students

- Ability in organising a variety of learning activities effectively

- Ability in assessing student learning

- Ability in selecting, adapting, and exploring teaching resources

- Using technology in teaching English

3. Knowledge about students
- Understanding students' cognitive, physical and psychological development factors

- Understanding characteristics in students' language development

- Developing students' cultural values and experiences

- Developing students' creativity and critical thinking
4. Professional values and attitudes

- Demonstration of professionalism in ELT

- Demonstration of collaboration in ELT

- Ability for professional development and life-long learning

- Contribution to English teaching and learning through engaging in professional training programmes, sharing experiences with colleagues

5. Networking and reflection on ELT
- Understanding the importance of networking, sharing their learning and teaching experiences with colleagues

- Engaging in on-going self-reflection, teaching evaluation, and independent learning to improve the quality of teaching and learning

It can be seen that the requirements focus greatly on content knowledge, pedagogical skills, and standards of English proficiency. These reflect EFL teachers' professional competencies. This MOET document identifies EFL teachers' professional competencies and standards necessary for qualified EFL teachers to implement the reform in foreign language education. MOET also recommends that these professional competencies be used in designing and revising EFL teacher education programmes in HEIs. 
The implementation of the EFL teaching and learning policy has faced several problems, mainly related to the teaching staff. Currently, EFL teachers in primary schools are neither sufficient in number nor have sufficient EFL proficiency and pedagogical skills to meet the standards (VietNamNet Bridge, 2012). Although the reform policies have been in effect for several years, MOET and local schools are still at the stage of upskilling and preparing qualified teachers.

A case study by H. T. M. Nguyen (2011) on EFL teaching at primary schools illustrates how teacher capacity presents challenges to the reform. Results showed that the schools (one private and one public primary school) did not have enough teachers, teaching materials, resources, or PLD provision. The participating teachers reported struggling because they had been trained to teach at secondary schools rather than primary schools. Additionally, PLD activities offered by MOET and by the schools were insufficient, and PLD sessions were perceived as having little benefit (H. T. M. Nguyen, 2011). Despite reporting the same problems as the public school, the private school had more resources and better PLD opportunities. The study revealed local challenges in enacting government policies, and highlighted the need to improve PLD quality for teachers and HEIs' responsibility for preparing qualified EFL teachers.

There have also been problems related to the quality of EFL teaching and learning at tertiary level. The biggest issue appears to be lecturers' limited understanding of the teaching and learning process, leading to a lack of consistency in setting learning objectives and students' outcomes for different educational levels ( $\mathrm{Vu}, 2010)$. Large mixed-ability classrooms also challenge EFL lecturers and hinder effective application of pedagogical innovations.

Universities in Vietnam tend to use international English tests to assess students' English language skills. Many HEIs prefer the Test of English for Intercultural Communication (TOEIC) as it claims to measure candidates' ability to use English for communication in work-oriented contexts, and graduates with high TOEIC scores can find jobs more easily. However, $\mathrm{Vu}$ (2010) argues that TOEIC may not be appropriate because in reality many lecturers just train students in test-taking strategies and neglect proficiency practice. Ironically, because TOEIC tests limited skills (it does not examine speaking and 
writing), many students with high TOEIC scores are actually unable to communicate in English. Vu (2010) concludes that PLD for university EFL lecturers is critical in improving lecturers' ability to design programmes and teaching materials for inclusive education, and employ effective kinds of assessment to evaluate and promote learning.

There are only a few studies on PLD for EFL tertiary lecturers in Vietnam. H. H. Pham (2006) addressed the problem of lecturers' research engagement. Although research is a requirement as well as teaching, most EFL lecturers in Pham's study were not motivated to conduct research. They reported discouraging institutional policies related to research funding, regulations in research, evaluation processes, and challenges in disseminating research products. Other obstacles included lecturers' limited research knowledge and skills, few resources and their high teaching workload.

Research was not the only challenge to teacher educators. H. T. M. Nguyen (2008) showed that most EFL young lecturers in her study were dissatisfied with their mentoring experience. The mentors were too busy to provide them with careful feedback and professional support. Although the mentors were experienced lecturers, they apparently did not have sufficient skills in mentoring. From these findings, H. T. M. Nguyen (2008) suggests that PLD programmes should be carefully designed to equip mentors with necessary knowledge and skills for mentoring young EFL lecturers.

Another aspect of lecturers' collaborative learning was studied by Vo and Nguyen (2010). They investigated the value of Critical Friend Groups (CFG), a type of PLD involving lecturers' collaboration in problem-solving and mutual learning. The four beginning EFL university lecturers involved in their study had a positive perception of $\mathrm{CFG}$, and reported that it promoted their motivation, instructional practices, and collaboration in solving teaching problems through peer observations and giving feedback. Vo and Nguyen (2010) suggested CFG as a possible PLD model for Vietnamese EFL lecturers and recommended further research on a wider application of a collaborative approach to PLD.

Overall, PLD for EFL teacher educators within the reform context of Vietnamese HE has not been widely investigated. Therefore, it is both timely and warranted to study how the current social, cultural, and political context affects Vietnamese EFL teacher educators' 
PLD, and how they manage to enact mandated initiatives in tertiary context as well as to support EFL school teachers in implementing the new EFL curriculum.

\section{EFL teacher educators in this study}

In the context of my research, EFL teacher educators are defined as lecturers who work in a tertiary institution and teach prospective EFL teachers enrolled in a pre-service teacher education programme. These educators also support in-service EFL local teachers through providing university-based PLD programmes on content knowledge and pedagogical skills to the teachers.

Higher education in Vietnam shares recent trends and demands with HE contexts internationally in terms of a desire to improve teaching and learning quality, research outputs, and competitive capacity for globalisation and integration (Bai \& Hudson, 2010; Boei et al., 2015; Hayden \& Lam, 2007; Hwang, 2014). In this respect, teacher educators in Vietnam share similar responsibilities and challenges to those of their international colleagues. However, the process of becoming a teacher educator Vietnam greatly differs from the experience of teacher educators in other contexts. Unlike Western contexts where most teacher educators have teaching experience in schools before becoming teacher educators (Davey \& Ham, 2010; Lamont, 2011; McGee, 2011; Murray, 2010), Vietnamese teacher educators do not necessarily have teaching experience as school teachers, as previously mentioned. Rather, they can be graduates from pre-service teacher education programmes who were trained to become teachers in school sectors. These graduates, if satisfying required qualifications for university lecturers, are recruited to become teacher educators at universities. As a result, it may be challenging for these educators, especially novice teacher educators in Vietnamese HEIs to fulfil multiple roles of being teacher educators and university researchers, and striving to develop as academics.

An increasing body of literature on PLD for teacher educators has been established mainly in Western contexts (Davey \& Ham, 2010; Gallagher, Griffin, Parker, Kitchen, \& Figg, 2011; Lamont, 2011; McGee, 2011; McGee \& Lawrence, 2009; Murray, 2010) while PLD for Asian teacher educators, including Vietnamese ones, has not been widely investigated. Sociocultural factors, HE context, and the backgrounds of teacher educators in Vietnam may shape the phenomenon of PLD for these educators uniquely. It is, 
therefore, important to study Vietnamese teacher educators' experiences of PLD to widen an understanding of PLD for professionals across different cultures. This study also helps to inform PLD policies to support teacher educators' learning and professional practice in Vietnam.

\section{Summary}

The literature review shows that PLD can be a means of enhancing educators' personal and professional growth, implementing educational initiatives, and possibly improving student learning. Previous studies indicate that PLD can be effective when it is ongoing, jobembedded, relevant to educators' needs, collaborative, reflective, and enhances meaningful learning. As PLD is socially situated, it is important to consider factors related to policies, cultures, leadership, and learning communities as these all have the potential to influence educators' PLD practices and their professional growth.

There is a trend towards taking into account key principles of teacher learning and characteristics of teachers as adult learners, as professionals, and as reflective practitioners. There is a call for shifting the focus of PLD research and practices from merely delivering content towards an in-depth understanding of how professionals learn in their contexts and how their continuing learning can be fostered (Webster-Wright, 2009). In addition, some vital issues of PLD have not been sufficiently investigated, including educators' motivation to engage in PLD, and how PLD might transfer into their daily work context. While PLD for teachers is widely studied, there is limited international literature on tertiary educators' PLD, especially empirical studies on PLD for EFL teacher educators in the context of educational reforms. This study responds to these gaps in PLD research. It considers redefining the concept of PLD and focuses on the authentic and transformative learning experiences of EFL teacher educators in Vietnamese tertiary education. This study contributes to the knowledge base of PLD for teacher educators in an Asian context as well as providing insights for policy-making and improving the quality of PLD for teacher educators in general. 
The study sets out to explore the following research questions:

1. What role and function does professional learning and development (PLD) play in EFL teacher educators' learning in tertiary education settings?

2. Why do EFL teacher educators in Vietnam access particular models of PLD? And what PLD do they value?

3. How do the educational reforms in Vietnam influence the forms of PLD promoted and accessed by EFL lecturers?

4. How does PLD support educators' capacity to implement these educational reforms?

The following chapter outlines how this will be achieved, and the methodological approaches most relevant for this endeavour. 


\section{CHAPTER 3 \\ METHODOLOGY}

Teachers' learning is seen as a complicated and multidimensional process (Pedder, Opfer, McCormick, \& Storey, 2010) which is influenced by their work contexts. Tertiary institutions are dynamic with different stakeholders (e.g., lecturers, academic leaders, students, policy makers) serving various roles. This complexity requires methodological approaches that can offer an in-depth account of both 'what' and 'how' PLD can influence and support lecturers. It is also important to utilise a research approach that best fits the research objectives (Johnson \& Christensen, 2012), and that can ensure ethical integrity. This chapter outlines and justifies the appropriateness of methodological approaches, including: the theoretical framework of the study, methodological framework, research methods, and strategies for enhancing the research trustworthiness.

\section{Theoretical framework: Cultural Historical Activity Theory (CHAT)}

It is important to employ a framework that can encapsulate the context of PLD and reveal how PLD is conceptualised and operationalised within and across tertiary settings, and within the government reform agenda. Given that PLD for Vietnamese lecturers cannot be fully understood without understanding its context, this study employs cultural historical activity theory (CHAT) as a theoretical framework of analysis. Activity theory takes account of the social, political and cultural context of activity within a system, and allows for a sophisticated understanding of lecturers' engagement in PLD activities. This framework also enables an understanding of both internal and external factors, tensions, and contradictions within the lecturers' PLD activity systems, as shown in previous studies on PLD in education (Bourke \& McGee, 2012; Bourke, Mentis, \& O’Neill, 2013; Yamagata-Lynch \& Smaldino, 2007).

This research was predicated on sociocultural understanding of learning where learning is achieved through participants' use of mediating artefacts (PLD) as proposed by Vygotsky (1978). Activity Theory originates in the earlier work of Vygotsky which 
emphasised the social origins of thoughts and learning. Vygotsky viewed learning and development as interactive and dependent upon the context, theorising that learning and development are concurrently social, cultural, historical and individual processes. Vygotsky identified that artefacts (tools and social others) played an important role in mediating individual learning and development. He argued that all human social activities and learning are mediated by tools, artefacts and signs which have been created by members of a society. Through their interactions in cultural, historical, and institutional settings, individuals make meanings of the world while modifying and creating new activities that transform artefacts, tools and people in their environment (Rogoff, 2003; Yamagata-Lynch, 2010). Vygotsky's (1978, p. 40) concept of mediated action was normally transcended by a triangular model of "a complex, mediated act" (Figure 2.1).

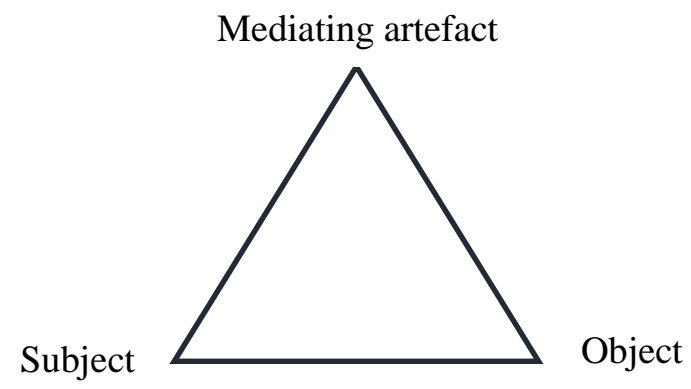

Figure 2.1 Vygotsky's model of mediated action (Engeström, 2001)

This model of object-oriented action mediated by cultural tools and signs (Vygotsky, 1978) is referred to as the first generation CHAT (Engeström, 2001; Yamagata-Lynch, 2010). However, in this model, the unit of analysis was the individual (Engeström, 2009), and mediation by other human beings and social relations was not fully depicted (Engeström \& Miettinen, 1999). The second generation of CHAT was built on Leont'ev's work that further developed Vygotsky's theory and emphasised the collective rather than individual nature of human activity (Yamagata-Lynch, 2010). The concept of mediated action is expanded to object-oriented activity:

Object-oriented activity refers to mediation processes in which individuals and groups of individuals participate driven by their goals and motives, which may lead them to create or gain new artefacts or cultural tools intended to make the activity robust. (Yamagata-Lynch, 2010, p. 17). 
The concept of activity focuses on a complex interrelation between the individual subject and his or her community (Engeström, 2001). In his example of the "primeval collective hunt" Leont'ev (1981, pp. 210-213) distinguished between individual goaloriented action and collective object-oriented activity, and elaborated the division of labour among individuals engaging in this collective cultural activity (Engeström \& Miettinen, 1999). Although driven by a shared motive to achieve the general object of the collective activity, individuals, depending on the role they play within the activity, undertake different individual actions directed at specific and temporary goals. Their actions contribute to the overall achievement of the object of the entire activity. The relationship between action and activity is hierarchical and interrelated, because "actions constitute activities, but activities motivate particular action sequences" (Roth \& Lee, 2007, p. 201).

Leont've's theorising of human activity was further developed by Engeström (2001) through the model of a collective activity system illustrating its complex structure and internal relations (Figure 2.2).

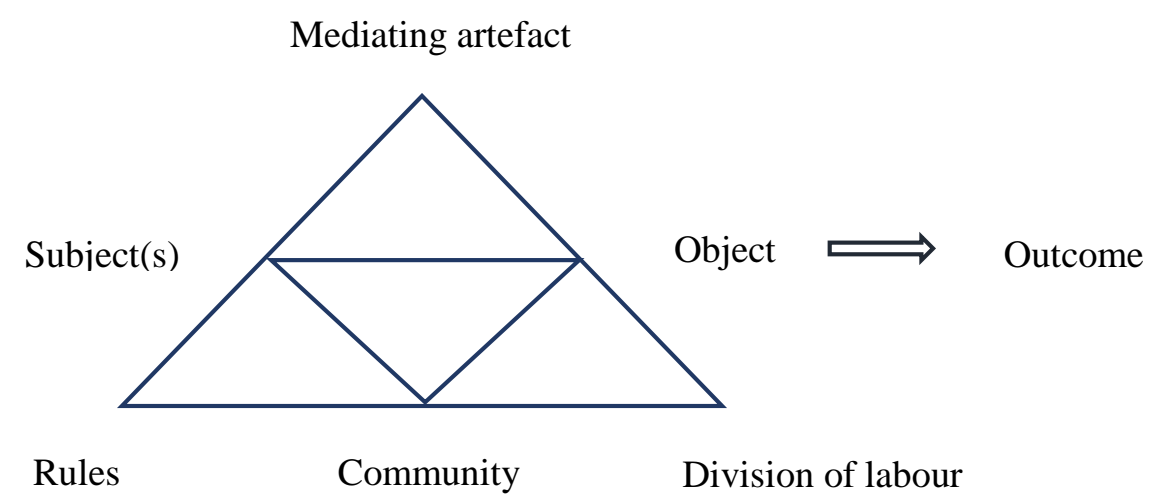

Figure 2.2 The structure of a human activity system (Engeström, 2001)

Key elements of the activity system include: subject/subjects, object, artefacts, rule, community, and division of labour (Engeström, 2001). Artefacts refer to instruments, tools, or other people that act as resources mediating the subjects to engage in the activity. Artefacts are culturally and socially created and transferred from one generation to another in the society. However, when people take part in activities, they not only use existing artefacts, but also change these and create new ones to facilitate their actions and help to achieve their object of the activity. The subject(s) can be an individual or groups of 
individuals involved in the activity. They are motivated by an object and act toward the object. Object refers to the goal or the motive of the activity, something that draws all elements of the activity system together. The rules, community and division of labour components highlight the socio-historical aspects of the activity. These elements influence the way people participate in the activity, how they may or may not achieve the object, and how they perceive the meaning of the experiences. The rules are formal or informal regulations that influence the subject's ability to achieve the object. Every organisation has its own sets of rules which can be implicit or explicit, and serve to guide organisational members' perceptions and behaviours. Cultural practices and expectations of people's behaviours are also part of the rules mediating people's engagement in activities. The community is the social group which the subject belongs to. The division of labour refers to how the tasks are shared among members of the community. Because a community usually involves members of different backgrounds, expertise, characteristics, and experiences, issues related to power relations and diversity of individual roles, perspectives and interests may influence the interactions and behaviours of the community members when taking part in a collaborative activity.

The second generation of CHAT identifies a single, complex, and changeable activity system as the core unit of analysis (Bourke et al., 2013). In reality, "all activity systems are part of a network of activity systems that in its totality constitutes human society" (Roth \& Lee, 2007, p. 200). Also, within its process of development a new activity system may historically evolve from the current central activity system, which forms a network of interacting activity systems. As each activity system is constantly changing and inherent inner contradictions arise (Engeström, 1999, 2000), a joint activity system will certainly encompass multiple voices, perspectives, interactions, and contradictions among its elements (Engeström, 2001; Roth \& Lee, 2007). There is a need to provide "conceptual tools to understand dialogue, multiple perspectives, and networks of interacting activity systems" (Engeström, 2001, p. 135). As a result, the third generation of CHAT was developed by Engeström to involve an analysis of networks of activity systems. The basic model of CHAT is expanded to include minimally two interacting activity systems (Figure 2.3). 


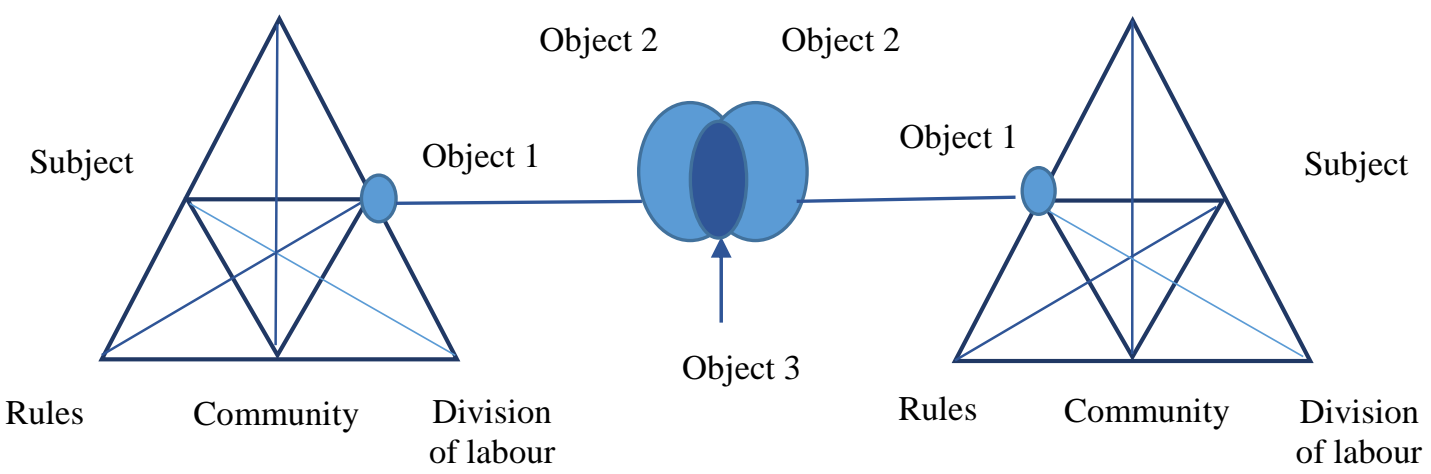

Figure 2.3 A model for the third generation of activity theory (Engeström, 2001)

In this analytical model, "the object of activity is a moving target, not reducible to conscious short-term goals" (Engeström, 2001, p. 136). For Engeström, it is crucial to distinguish between short-lived goal-directed actions and durable, object-oriented activity systems in activity theory (Engeström, 2000, p. 960). In his view, activity systems, which are in constant movement, realise and reproduce themselves by generating actions and operations (Engeström, 2000). This means that the overall object of a collective activity system is constantly changing and reconstructed after individual or group actions are accomplished. The transformation of objects, as seen in Figure 2.3, proposes that the interactions within activity systems in a network will create contradictions (resulted from a lack of alignment among different objects of the individual systems, and by multiple perspectives within and across these systems). This creates the need to redesign the object of each constitutive system. For example, Object 1 refers to the initial ('raw material') object determined for each single activity system. When two individual activity systems cooperate and become a joint activity system, their initial objects are modified to create a collectively meaningful object (Object 2). When the joint activity system unfolds in practice, due to the complexity of interrelatedness and interactions among different elements in its structures, the modified objects in the two interacting activity systems may be different, but potentially there is a shared or jointly constructed object (Object 3).

This third generation of CHAT research enables the exploration of multiple voicedness as well as structural tensions and contradictions both within and between 
activity systems (Roth \& Lee, 2007). An examination and analysis of multiple perspectives in interacting activity systems of an individual or a group of individuals who share the same object, or strive for different objects, will help to raise people's awareness of structural contradictions and stimulate changes to resolve them. To do this, there are generally five principles of Activity Theory to adhere to (Engeström, 2001), all of which serve to inform the discussion around PLD as the object. These will be briefly elaborated on.

The first principle takes into account the notion that all action and activity takes place in multiple contexts in which "a collective, artefact-mediated and object-oriented activity system, seen in its network relations to other activity systems, is taken as the prime unit of analysis" (Engeström, 2001, p. 136). Individuals normally belong to different activity systems at the same time and are mediated by interrelated elements between these systems (Roth \& Lee, 2007). Therefore, human activities and learning can only be understood when taking into account the multiple perspectives as well as the social mediational settings in their entire activity system. The second principle is the multi-voicedness of activity systems which reveals multiple points of views, traditions and interests among different members involved within the activity systems. The third principle is historicity which refers to transformation of activity systems over periods of time. Historical issues, therefore, need to be taken into consideration in order to fully understand problems and potentials of the activity systems. The fourth principle highlights the central role of contradictions and tensions as sources of change and development. Contradictions within the activity systems may generate either conflicts and tensions or opportunities for changing the activity. Finally, the fifth principle refers to the possibility of expansive transformation in activity systems. For Engeström, it is essential for an organisation to have the ability to change and a CHAT analysis allows for an analysis of this change. As he notes, "An expansive transformation is accomplished when the object and motive of the activity are reconceptualised to embrace a radically wider horizon of possibilities than in the previous mode of the activity" (Engeström, 2001, p. 137).

\section{Employing CHAT as a theoretical framework for analysis}

Several studies have employed CHAT to explore PLD in a range of contexts (Ahn, 2009; Bourke \& McGee, 2012; Bourke et al., 2013; Cho, 2014). Because this study focuses on 
the phenomenon of PLD involving university lecturers, and as noted above, within a dynamic cultural and political setting in Vietnam, CHAT is a useful framework to employ.

Lecturers' learning is a socially constructed activity which takes place both within their individual and classroom contexts, as well as their institutional environment with its own rules, resources, and cultures. Their professional practice and PLD are also situated in the wider context of rules and requirements from the government, MOET, and society. Any changes in the context (e.g., the introduction of an initiative as a new rule) have the potential to influence the work of the whole system (e.g., teacher educators' motives, their use of tools and artefacts, their interactions with others within the system, and new kinds of division of labour). Therefore, CHAT is a suitable approach for analysing lecturers' PLD experiences in within such a dynamic work environment.

The use of CHAT as the theoretical framework was influenced by the research objective which is to gain a deep understanding of PLD from the Vietnamese lecturers' perspectives and experiences. As a relevant analytical tool, CHAT also enable an analysis of data in a manageable and meaningful way (Yamagata-Lynch, 2010). A CHAT analysis allows an analysis of possible tensions and contradictions inherent in the PLD activity systems (e.g., lecturers' PLD activity system, and its interacting systems), as highlighted in earlier research on PLD in educational settings (Ahn, 2009; Bourke \& McGee, 2012; Bourke et al., 2013; Lim \& Hang, 2003).

In this study both the 2nd and the 3rd generations of CHAT are used in order to fully understand the phenomenon of PLD across three university sites, at both individual and system levels. The 2nd generation of CHAT enables a specific analysis of the inter-relations and interactions between different components in the PLD activity system within each university site. In a broader sense the 3rd generation of CHAT allows for a holistic understanding of PLD for lecturers at a system level, highlighting multiple voices of different stakeholders involved in the PLD activity systems, and providing insights into contradictions and tensions inherent within and between the network of the lecturers' PLD activity system and its interacting systems. Overall, the findings from a CHAT analysis will enable a better understanding of different perspectives on the nature of PLD for the lecturers in the study. The CHAT analysis also reveals tensions and contradictions within the tertiary 
contexts and possible ways to resolve them in order to better support the lecturers' PLD and professional work.

\section{Methodological framework}

This section outlines and justifies the appropriateness of methodological approaches underpinning the study. Specifically, the following aspects will be presented: (1) ontological and epistemological assumptions, (2) the use of mix-methods research, (3) case study design, and (4) ethical issues.

\section{Ontological and epistemological assumptions}

A worldview, or paradigm is defined as "a basic set of beliefs that guide action" (Guba, 1990, p. 17). A research paradigm comprises four concepts: ontology, epistemology, methodology, and ethics (Denzin \& Lincoln, 2000). This section addresses my ontological and epistemological views as a researcher and how these influence the research process.

Ontology refers to nature of reality and truth (Johnson \& Christensen, 2014), or "how we see the world and our place within it" (Burton \& Bartlette, 2009, p. 17). Epistemology refers to the theory of knowledge (Johnson \& Christensen, 2014). It is about how knowledge is created (Burton \& Bartlette, 2009), and the relationship between the inquirer and the would-be known (Denzin \& Lincoln, 2000). There are different views on reality and knowledge creation. Two distinctive research paradigms, corresponding to quantitative and qualitative research respectively, are positivism and interpretivism (Burton \& Bartlette, 2009, Denscome, 2002). While positivism views social reality as existing externally to people, intepretivism stresses the way that people shape society and their experiences. Researchers following interpretivism, which is also referred to as constructivism (Denscome, 2002), tend to focus their attention on the way people make sense of the world and how they create their social world through their actions and interpretation of the world.

My study aims at seeking a deep understanding of the phenomenon of PLD in the participants' natural settings, how they experienced PLD, and how they evaluated their experiences. The methodology of the study was determined by the research purpose, and 
reflects my worldview, ontological and epistemological assumptions as a researcher (Johnson \& Christensen, 2012).

The interpretivist or constructivist approach fits my existing professional and personal beliefs. I consider learning as co-constructed when individuals participate in social activities. People learn and make sense of the world based on their prior knowledge and experiences which shape and are shaped by sociocultural and political contexts they belong to. Therefore, in this study the understanding of PLD is co-constructed between the participants and myself as a researcher. Additionally, such understanding would be obtained through different complementary tools which serve the research purpose.

This study is predominantly qualitative in nature. As a researcher, I am the main research instrument (Eisner, 1998), and therefore my own knowledge, experiences, professional identity, and assumptions possibly influenced the research design, data analysis, and interpretations of findings. My beliefs about PLD and the teaching profession were shaped by my prior education in the field of TESOL, and over 12 years of experience as an EFL lecturer/ teacher educator at a university in Vietnam. My PLD experiences and perceptions have been formed through my pre-service teacher education programme, my current teaching of both pre- and in-service teachers, and my participation in postgraduate programmes. This PLD experience has been embedded both in my attendance at PLD sessions as a learner, and in my practices of providing PLD for school teachers.

I believe that there are "multiple constructions of reality and knowledge" (Lee, 2012, p. 411). That means individuals may have different perspectives and interpretations of a single phenomenon. As a result, this research aims to explore the different perspectives individual lecturers may have when experiencing a particular professional practice (e.g., a PLD activity) and the meanings they associate with their experiences. My knowledge and understanding about Vietnamese sociocultural and political context, educational policies, and tertiary teaching and learning experience are of an insider (e.g., a lecturer within the same education context as the participants), and this facilitates my understanding and interpretations of the participants' responses. This understanding not only offers insights into the participants' experiences, but also helps me respect their expertise and attempt to 
present their experiences and perceptions accurately and fairly (Eisner, 1998; Israel \& Hay, 2006).

As well as deciding how well the research adheres to a particular research paradigm such as positivist or interpretivist, a guiding principle for research is to select the methods and analysis that work best to address the research questions and its purposes (Denscome, 2002; Green, 2007). For the purpose of the study, the research philosophy of pragmatism, a worldview which is placed between the positivism and interpretivism or constructivism spectrum (Denscombe, 2002), is employed. Pragmatism is defined as "a worldview, or philosophy [that] arises out of actions, situations, and consequences rather than antecedent conditions" (Creswell, 2014, p. 245). Pragmatism is the advocated paradigm for mixedmethods research (Johnson \& Onwuegbuzie, 2004). A pragmatic paradigm views truth, meaning, and knowledge as tentative and changing over time, and takes an explicitly valueoriented approach to research that is derived from cultural contexts (Johnson \& Onwuegbuzie, 2004). This paradigm values flexibility in research, and suggests that inquirers choose the combination of methods and procedures that works best for answering the research questions (Green, 2007). The pragmatic philosophical stance acknowledges the importance of contexts (Johnson \& Onwuegbuzie, 2004). This fits well with the utility of CHAT to explore the influence of a complex and dynamic Vietnamese tertiary context on EFL lecturers' PLD. A reflection on the CHAT analysis of lecturers' PLD will explore multiple perspectives of those involved in tertiary PLD, and offer insights into necessary changes in order to improve PLD quality and resolve potential contradictions and tensions within and between the lecturers' PLD activity systems. This approach relates well to the emphasis of pragmatism on problem-solving.

\section{Mixed-methods research}

Mixed-methods research design integrates both quantitative and qualitative data and analyses and enables a multidimensional approach to inquiry (Creswell, 2014; Miles, Huberman, \& Saldana, 2014). Green (2007) emphasises the value of mixed-methods inquiry in allowing "better understanding of social phenomena, which are inherently complex and contextual" (p. 14, italics in the original). 
In this study a mixed-methods research design was employed for various purposes, including complementarity, triangulation, and development (Creswell, 2014; Green, 2007). Different research methods that capture different facets or dimensions of the same complex phenomenon enable "broader, deeper, and more comprehensive social understandings" of the researched issue (Green, 2007, p. 101). Results from the different methods serve to elaborate, enhance, deepen, and broaden the overall interpretations and inferences from the study. Multiple sources of data provide a more comprehensive and complete account of the investigation of the lecturers' PLD perceptions and experiences.

Another strong rationale for employing a mixed-methods approach is for the purpose of triangulation, which refers to seeking convergence, corroboration, or correspondence of results from multiple methods (Creswell, 2014; Green, 2007; Silverman, 2011; Yin, 2014). As Silverman (2011) identifies, triangulation of findings from various data sources helps to produce a more accurate, comprehensive and objective representation of the studied issue. This enhances the validity and credibility of the findings (Creswell, 2014; Green, 2007; Yin, 2014) because drawing conclusions based on different data sources helps to reduce the likelihood of misinterpretations of the data (Stake, 2008). When the findings obtained from different methods correspond and draw the same or similar conclusions, the validity of those findings and conclusions has been enhanced (Silverman, 2011). In this study, the corroboration of quantitative and qualitative data sources accommodates multiple viewpoints of PLD, and increases the researcher's confidence that the combined data sets address the research questions. The use of different methods also enables additional interpretations and meanings in addition to confirming particular conclusions (Flick, 2006).

Finally, a mixed-methods research design is used for the purpose of development (i.e., using the results of the first method to inform the design of the follow-up method). A sequential explanatory mixed-methods design (Creswell \& Plano Clark, 2011; Johnson \& Christensen, 2012) was employed in this study. Explanatory sequential mixed-methods is a strategy that involves a two-phase project in which the researcher collects quantitative data in the first phase, analyses the results, and then uses the results to plan the qualitative phase (Creswell, 2014, p. 243). The overall aim is for better understanding of the researched issue as well as making full use of each method (Green, 2007). 
This study, however, foregrounds the qualitative approach in order to seek an indepth understanding of the research problem (Johnson \& Christensen, 2012; Merriam, 2001). Although both quantitative and qualitative methods are incorporated, my own qualitative thinking about the issues tertiary educators face in relation to PLD opportunities was a starting point (Mason, 2006). Thus, my research questions were mainly based on a qualitative worldview and aimed to provide deep understanding of people's lived experiences in their social contexts. My study employed "a qualitatively driven approach of mixing methods", and that was appropriate for researching questions about multidimensional social experiences because "our understandings are impoverished and may be inadequate if we view these phenomena only along a single dimension" (Mason, 2006, p. 9).

\section{Case study design}

Case studies are employed when it is important to understand a phenomenon in detail and in circumstances when 'how' and 'why' questions are posed, the investigator has little control over events, and the focus is on a contemporary phenomenon within a real-life context (Yin, 2009). Case study research is used to figure out complex phenomena (Johnson \& Christensen, 2012), and is "the method of choice when the phenomenon under study is not really distinguishable from its context" (Yin, 2003, p. 4). In case study design, the researcher is interested in a holistic description of the case and how different parts of the system (the case) operate together (Johnson \& Christensen, 2012). As "case studies are characterised by their multilevel, multidimensional characteristics" (Sharp et al., 2012, p. 48), a case study approach is suitable for exploring the nature of PLD in its dynamic natural contexts.

A qualitative case study is normally intensive and studied in-depth (Stake, 1995). The strength of a case study is in its richness, completeness, depth, and closeness to real-life situations which allow an exploration of the phenomena as they unfold in practice (Flyvbjerg, 2011). The qualitative case study approach is, therefore, relevant for studying PLD for EFL lecturers in complex settings such as Vietnamese tertiary institutions with multiple interrelated levels of interactions among various stakeholders involved in PLD. 
In case study research, the case is a specific, bounded system, and it is necessary for the case boundaries to be clearly defined (Stake, 1995, 2008). Stake describes three kinds of case study: intrinsic, instrumental, and collective case study. Briefly explained, intrinsic case study is used when the researcher is interested in understanding a specific case itself. In instrumental case study, the primary interest is in understanding something more general than the particular case. That means using the case as an instrument in order to better understand an important issue, or phenomenon. In a collective case study, or multiple case study (Yin, 2014), multiple cases are studied concurrently for the purpose of gaining a greater understanding, or better insight into a researched issue. In a collective case study, the cases are usually studied instrumentally rather than intrinsically.

This study was designed as a single instrumental case study (Stake, 1995). The purpose of investigating the phenomenon of PLD is consistent with the definition of an instrumental case study which is used when "we have a research question, a puzzlement, a need for general understanding, and feel that we may get insight into the question by studying a particular case" (Stake, 1995, p. 3). In an instrumental case study, the researcher studies the case to learn about something more general (Johnson \& Christensen, 2008). As with the current research, the focus is on explanation as a key goal, and on understanding how and why an important phenomenon such as PLD within a tertiary context operates as it does.

In this study, the case is defined as the phenomenon of PLD for EFL lecturers. The case is bounded by time, location, and sociocultural factors in relation to PLD. Specifically, the study aimed at investigating the lecturers' experiences of PLD over two academic years (2011-2013) across the three university settings. However, in order to obtain a holistic analysis (Stake, 1995) of PLD as a situated and culturally grounded phenomenon, there is a need to account for social, cultural, and political factors that shape the interpretation and enactment of educational policies, as well as influence the way PLD is conceptualised and experienced in its natural setting. The three selected universities involved in this research function as instrumental sites to enable an in-depth understanding of the PLD phenomenon. This study aims to provide a detailed account and analysis of the tertiary lecturers' PLD perceptions and experiences of the phenomenon and how these are influenced by sociocultural and contextual factors, rather than to evaluate the selected universities 
themselves. Overall, studying the phenomenon of PLD across three university sites allows an in-depth understanding of the complexity of the case: PLD for the lecturers in Vietnamese tertiary education. The case study design involving different sites also fits well with the sociocultural and socio-historical methodological approach employed in this study.

\section{Ethical issues}

Ethical principles underpin educational research and ethical practice throughout the process is needed in order to enhance the trustworthiness and reliability of the research findings (Basit, 2013; Walker, 2007). Ethics refers to "the system of moral principles by which individuals can judge their actions as right or wrong, good or bad" (Denscombe, 2002, p. 175). In practice, there is a set of principles that assists researchers in conducting research ethically and sensitively throughout the research process (Johnson \& Christensen, 2012). Educational researchers must be aware of the importance of establishing trust with participants and aim to respect the rights and interests of those participating in their study. Therefore, ethical consideration is more than regulatory compliance. Instead, ethical conduct reflects the researchers' commitment to enhance the quality standards and professional integrity of their research (Denscombe, 2002; Israel \& Hay, 2006). This research followed ethical guidelines, especially in ensuring ethical principles were used when working with the research participants. The study received ethical approval from the Ethics Committee of Victoria University of Wellington (No. SEPP/2012/75 RM19494).

Informed consent is a benchmark, or a central concept in ethical research practice (Denscombe, 2002; Johnson \& Christensen, 2014; Wiles, 2013). Informed consent refers to the potential participants' voluntary agreement to participate in a study after being informed of its aim, procedures, risks, benefits, and limits of confidentiality (Israel \& Hay, 2006; Johnson \& Christensen, 2014). Informed consent is necessary to ensure that their participation is voluntary and that they feel comfortable to take part in the study. Voluntary participation is important because it shows the participants' autonomy in their decision and intentional commitment to the research. This also follows the principle of respect for those who trust the researcher and contribute to the research (Israel \& Hay, 2006).

In this study potential participants received detailed and comprehensive information about the research such as its purposes, methods, demands, inconveniences, possible 
outcomes, and how results might be published (Israel \& Hay, 2006). The information was presented in Vietnamese to ensure the participants' understanding. The participants were also consulted about the schedules for data collection, the locations of the interviews, and observations of events to ensure convenience for the participants. The participants received a clear message that they had a right to refuse to participate or to withdraw from the research. Before the interview, participants were provided with the research information and encouraged to express their concerns, questions or interests related to the research, their roles and rights (Israel \& Hay, 2006). Written informed consent was gained from the institutions' leaders and all participants who agreed to take part in the interview.

Confidentiality is another key principle for an ethically conducted study. Confidentiality means that the participants' identities are not revealed to anyone other than the researcher and the supervision team (Israel \& Hay, 2006; Johnson \& Christensen, 2014). In this study, participants and their institutions were assured that their identities would not be revealed at any stage and in any reports of the research findings. Identifiers such as names of the participants and their institutions were removed and replaced by codes. Geographical clues and demographic data of the institutions and of participants (e.g., age group, qualifications, gender) were presented selectively or removed when necessary in the writing up stage to ensure the participants' identities were not revealed (Israel \& Hay, 2006).

However, it is at times difficult to hide the identities of some participants from themselves, their peers, or members of their communities (Denscombe, 2002). In this case, participants who shared sensitive details (e.g., disapproval of policies) were clustered to avoid attributing ideas to particular individuals. Additionally, the researcher made an effort to remove sensitive and identifying information when preparing research publications. Ensuring the confidentiality of data and of the participants' identities will minimise any possible adverse effect on the participants (Denscombe, 2002).

Other ethical matters arose in this study. The hierarchical structure and culture within a Vietnamese tertiary organisation might make it socially inappropriate for individuals to express disapproval of their leaders' practices or question top-down policies. Therefore, the participants might have wished to protect the prestige of their university by just revealing 
positive aspects. By ensuring the confidentiality of the participants' identities and the name of their institution, the participants might have felt free to express their true thoughts and reflections on their own and the institutional practices. By assuring trust and behaving honestly and honourably, I encouraged the participants to contribute openly and fully to the study (Israel \& Hay, 2006).

Additionally, there was a concern that if the lecturers expressed disapproval of their institutional and national policies, this may negatively affect their work and position. To work through this problem, care was taken in the wording of the questions in the questionnaire and interviews. For example, instead of asking "Are you satisfied with PLD opportunities for EFL lecturers?" the question was framed as "To what extent do PLD opportunities meet your needs?" With the latter questions, the participants did not need to make negative judgements, but could reflect on the key issue. Additionally, the participants were informed that they had the right to refuse to answer any questions, and they could remove or change any of their comments in the interview transcripts written in Vietnamese (the language used during the interviews). One participant reworded some details in order to clarify her ideas. The others either accepted the content recorded in the transcript or gave no responses. In the findings report and discussion, the participants' perspectives were reported in a respectful way. For instance, if the participants used negative or critical language, I translated and paraphrased this using non-inflammatory phrases such as 'challenging the policies', or 'concern about the relevance of the policies'. Careful word use helped to report the participants' responses and views accurately without unnecessarily or inaccurately positioning them as adversarial.

\section{Research methods}

The study employed complementary data collection methods including a questionnaire, individual interviews, observations, and document analysis. Method triangulation enhances data credibility and trustworthiness in a study (Eisner, 1998; Johnson \& Christensen, 2012; Yin, 2009). Using multiple sources for data collection also enhances the richness and depth of the case. A summary of the focus of each data collection method is presented in Table 3.1 , and details of these methods are presented in later sections of this chapter, according to the research phase in which each method was used. 
Table 3.1 Focus of data collection methods

\begin{tabular}{|c|c|}
\hline Methods & Focus \\
\hline \multirow{2}{*}{ Questionnaire } & $\begin{array}{l}\text { Overall understanding of the participants' perceptions and experiences } \\
\text { of PLD }\end{array}$ \\
\hline & $\begin{array}{l}\text { Preliminary trends and patterns of PLD that could be explored further in } \\
\text { the interviews and observations. }\end{array}$ \\
\hline \multirow{3}{*}{ Interviews } & $\begin{array}{l}\text { In-depth exploration of the participants' PLD perceptions and } \\
\text { experiences }\end{array}$ \\
\hline & Sociocultural factors that influenced the participants' PLD \\
\hline & Further explanations of questionnaire choices \\
\hline \multirow{4}{*}{ Observations } & Understanding of PLD in practice \\
\hline & PLD types and processes \\
\hline & Contextual factors \\
\hline & Triangulating data from the other sources \\
\hline \multirow{2}{*}{ Document analysis } & $\begin{array}{l}\text { Understanding of context and policies in } \mathrm{HE} \text { and in the selected } \\
\text { institutions }\end{array}$ \\
\hline & Triangulating data from the other sources \\
\hline
\end{tabular}

\section{Sites of the case study}

The case study focused on the Mekong Delta in Vietnam because this vast region has been found to have the lowest quality of education compared to other regions in the country. The total population of the region is over 17 million, among which the proportion of college and university students only accounts for 2.6\% (VietNamNet Bridge, 2011). Common problems in the region include the shortage of teaching staff, low average grades achieved by students in secondary national examinations, limited funding and resources, and low enrolment of tertiary students. The central government, local authority and HEIs have made a concerted effort to upgrade educational quality in this area. Therefore, investigating HEIs to provide a better understanding of EFL lecturers' learning experiences will provide insights into how to support their PLD in the future, which will help to improve the quality of education in the region. 
The study involved three public universities in the Mekong Delta. The selected institutions were accessible to me given my role as a tertiary educator. Public universities were selected because they have full-time lecturers, who are expected to strictly follow MOET directives, especially in implementing reforms. Therefore, this kind of university would provide information-rich cases for my research (Patton, 2002). The HEIs were purposively selected to vary according to their location, organisational structure, and experience in teacher education. The three HEIs were located in different provinces in the region. One university served a whole region, and was recognised by the MOET as a key university in Vietnam. The other two universities were at provincial levels, and recruited students from fewer provinces in the region. The three universities, therefore, varied in size, training capacity, resources and funding. The selection of HEIs of various types was intended to reveal whether different contexts affected EFL lecturers' PLD and their professional practice differently. There had not been any official guidelines for PLD in support of the current HE reforms in Vietnam, so there may have been differences in the way management and staff within HEIs interpreted the reforms and related policies to enact these reforms. Although these HEIs shared common educational and geographical features, variations in their own institutional structures, capacity and resources may have affected their choices of PLD and reform efforts. Studying three sites, as a result, enabled a full understanding of the contexts in which PLD was conceptualised and operational, and the influence of contextual factors on the case, as shown in Figure 3.1. 


\section{Case study}

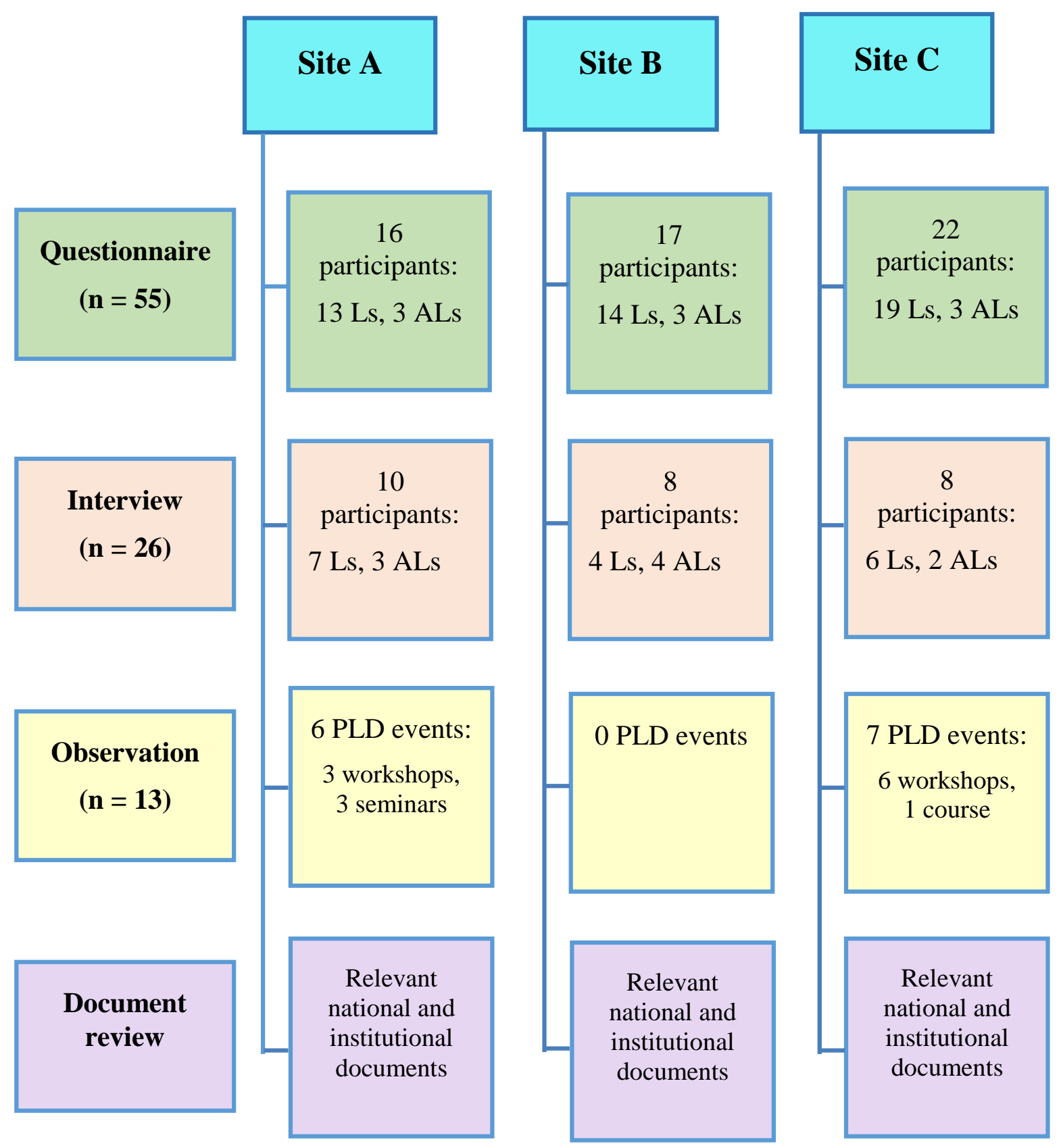

Notes: AL: Academic leader; L: Lecturer

Figure 3.1 Overview of the case study 


\section{Mixed-methods design}

The purpose of this mixed-methods sequential explanatory study was to identify the tertiary lecturers' perceptions and experiences of PLD in a Vietnamese tertiary context. The quantitative phase involved a questionnaire survey which aimed to elicit a broad understanding of lecturers' experiences of PLD, and to identify "wide patterns and changes", as well as "trends, commonalities and averages" from their responses (Mason, 2006, p. 16). The questionnaire was also used as a means to invite the participants to participate in the next stage of the study. The qualitative phase of the research was conducted with semi-structured interviews, observations of PLD sessions, and policy document analysis to provide multiple insights into the tertiary educators' experiences in their academic environment, and to uncover the meanings they attached to their experiences (Creswell, 2009; Patton, 2002).

In this study, the integration of the two phases occurred at the intermediate stage when preliminary findings of the survey were used to inform the interview protocol and aspects of PLD observations in the qualitative phase. Results from both quantitative and qualitative phases were integrated during the interpretation of the study findings, which resulted in higher quality of inferences (Creswell, 2009).

\section{Phase 1: Quantitative inquiry}

\section{Participants}

The quantitative phase of the study employed the questionnaire (Appendix A) in order to obtain an overall understanding of PLD experienced by the EFL lecturers from the three selected universities. Purposive sampling was used to select the best possible sites (as described previously) and participants that would best help the researcher understand the research problem and provide in-depth insights into this specific phenomenon (Creswell, 2014; Yin, 2014).

Specific criteria for participation were described in the Information Sheet (Appendix B) to optimise the opportunities to invite questionnaire participants who were eligible and had rich experience of the PLD phenomenon. These criteria included: (1) being a full-time EFL lecturer who trained school teachers of EFL or other disciplines, and (2) with at least 
two years of working experience in tertiary education. This was to ensure that they had experience of PLD and reform implementation in their institutions. Although there were around 20-30 EFL lecturers eligible for the questionnaire survey in each university, many of them were engaged in full-time post-graduate programmes, and were not available for the study. Among the 62 questionnaires delivered to the lecturers (20, 20, and 22 in sites A, B, and C, respectively), 57 were completed and returned. This represented a high response rate of $91.9 \%$. However, two of the returned questionnaires were not valid (one participant had not engaged in teacher education within their institution, and thus did not meet the selection criteria; the other did not provide any demographic data in the first part of the questionnaire). As a result, 55 completed questionnaires were analysed (16, 17, and 22 participants from sites $\mathrm{A}, \mathrm{B}$, and $\mathrm{C}$, respectively). A detailed description of the participants' demographic data is presented in Table 3.2.

Table 3.2 Questionnaire participants' demographic data

\begin{tabular}{ccccccccccccc}
\hline & \multicolumn{3}{c}{ Gender } & \multicolumn{3}{c}{ Position } & \multicolumn{3}{c}{ Age group } & \multicolumn{5}{c}{ Years of teaching experience } \\
\cline { 2 - 11 } Sites & Male & Female & Ls & ALs & $20-30$ & $31-40$ & $41-50+$ & $2-5$ & $6-10$ & $11-15$ & $16-20+$ \\
\hline $\begin{array}{l}\text { Site A } \\
\mathrm{n}=16\end{array}$ & 5 & 11 & 13 & 3 & 3 & 10 & 3 & 3 & 4 & 5 & 4 \\
\hline $\begin{array}{l}\text { Site B } \\
\mathrm{n}=17\end{array}$ & 7 & 10 & 14 & 3 & 5 & 6 & 6 & 6 & 4 & 3 & 4 \\
\hline $\begin{array}{l}\text { Site C } \\
\mathrm{n}=22\end{array}$ & 7 & 15 & 19 & 3 & 4 & 15 & 3 & 4 & 14 & 4 & 0 \\
\hline $\begin{array}{l}\text { Total } \\
\mathbf{n}=\mathbf{5 5}\end{array}$ & $\mathbf{1 9}$ & $\mathbf{3 6}$ & $\mathbf{4 6}$ & $\mathbf{9}$ & $\mathbf{1 2}$ & $\mathbf{3 1}$ & $\mathbf{1 2}$ & $\mathbf{1 3}$ & $\mathbf{2 2}$ & $\mathbf{1 2}$ & $\mathbf{8}$ \\
\hline
\end{tabular}

Note: $\mathrm{Ls}=$ lecturers, ALs $=$ academic leaders

In total, 19 male and 36 female participants participated. Of the 55 participants, two had a $\mathrm{PhD}$ degree, 50 had a master's degree, and three had a bachelor's degree. The participants represented different age groups, ranging from 20-30 to over 50 years old, and with different teaching experience, from two to over 20 years. The highest number of participants (31) was in the age group of 31-40, and had 6-10 years of experience (22). 
All participants had teaching roles in EFL teaching within the Faculty ${ }^{4}$ of Education or the Faculty/Department of Foreign Languages. Nine participants (four males and five females) were lecturers with leadership roles in addition to their teaching roles, and 46 were lecturers without leadership roles. Hereafter these nine participants will be referred to as academic leaders (AL) when there is a need to distinguish them from the lecturers. When findings or statements apply for both groups, they all will be referred generally as the lecturers, the teacher educators, or the participants.

\section{Questionnaire}

A 55-item questionnaire was distributed to EFL educators. The purpose of the questionnaire was to gain an overall understanding of the phenomenon of PLD before investigating specific issues in-depth. From the preliminary analysis of the participants' responses, important issues, initial trends, themes and patterns about their perceptions and experiences of PLD and of reform implementation were identified (Johnson \& Christensen, 2012). These issues were explored in greater details in the interviews. Further, the questionnaire data helped to identify which participants were likely to contribute rich insights during the interview phase.

The questionnaire was developed based on the research questions, an initial review of national educational policy documents in Vietnamese tertiary context, features of effective PLD drawn from empirical studies on PLD and teachers' learning (Borko et al., 2002; Starkey et al., 2009), and questionnaires used in previous PLD research (Pedder et al., 2010; Starkey et al., 2009). The questionnaire included both closed and open-ended questions and was written in Vietnamese, the local language, to ensure clarity of meaning for the participants.

The questionnaire was developed by the researcher because there was no other instrument available within the Vietnamese context. Given the need to focus on PLD for EFL teacher educators in this specific context of change, an original instrument for the purpose of this research was created. Since this study gives priority to the qualitative strand,

\footnotetext{
${ }^{4}$ In this study, a faculty (khoa) is an institutional unit that comprises several department (bọ môn) in a university structure.
} 
it does not aim to quantify the research issues as required within a purely quantitative approach. Therefore, standardisation of the research instrument (e.g., questionnaire survey) and generalisation were not major concerns in this study (Stake, 2008).

To test the validity of this instrument, the initial questionnaire was piloted with five non-participant EFL Vietnamese lecturers who had similar characteristics to the intended participants. The pilot participants were asked to complete the first draft of the questionnaire in Vietnamese. After that, they provided either oral or written feedback about the following issues: (1) the clarity of the questions; (2) how they felt about answering the questions; (3) the time they spent on the questionnaire; (4) and other comments or suggestions regarding the questions and the format of the questionnaire. The questionnaire was then modified on the basic of their feedback to ensure its clarity and relevance to the research focus. Suggested changes included rewording two questions to clarify the meaning, and modifying the format of the questionnaire to make it more user-friendly.

\section{Procedure of data collection}

Three public universities in the Mekong Delta of Vietnam were chosen purposively to reflect different training experiences, capacity and resources. Permission to conduct the research in each university was gained from the rector - the senior university leader who is responsible for managing all aspects of the university (Appendix C).

After receiving written consent from the rector of each university (Appendix D), at initial visits to the selected universities, I worked with a key person (e.g., a leader of the EFL department) to explain the research and ask for their support. From these meetings, I gained general information about the EFL lecturers as well as a schedule of coming PLD activities within the department. In two of the three universities, the key person also provided me with relevant institutional documents related to PLD for EFL lecturers.

For the questionnaire, potential participants were provided an information sheet explaining the study, but not a consent form. The participants' completion of the questionnaire indicated their consent. To distribute the questionnaire, in one university, I contacted eligible participants in person to invite them to participate in the survey. I also provided them with an information sheet and the questionnaire in an envelope. Those who 
agreed to participate in the research completed the questionnaire, and put it inside a sealed envelope without stating their names. The participants were asked to put their completed questionnaire in my research folder in the EFL lecturers' staffroom. I collected the completed questionnaires on a scheduled date.

At the other two sites, because the EFL lecturers had no staff meetings scheduled at the beginning stage of my data collection, a colleague who was an EFL lecturer sent the information sheet and the questionnaire to eligible lecturers on my behalf, and was able to ensure that the lecturers' participation was voluntary. Those who agreed to take part in the study completed the questionnaire and returned it within two weeks. The lecturers were also asked to put the completed questionnaire in the envelope provided, seal it (without writing their names) as mentioned above, and leave it in my research folder in the staffroom. My colleague at each of these universities collected the questionnaires and returned them to me at an agreed time.

The questionnaire also functioned as a recruiting tool for the individual interviews. At the end of the questionnaire, there was an invitation for the participants to participate in the follow-up individual interview. Those who were willing to take part in the interview were asked to write down their contact details so that I could contact them later.

\section{Quantitative data analysis}

Appropriate data analysis strategies enable the researcher to make sense of the data in order to answer the research questions. The software SPSS 19 was used to analyse quantitative data from the questionnaire. Descriptive statistical analyses were used to describe, summarise and make sense of the data (Johnson \& Christensen, 2012). Specifically, measures of central tendency (e.g., percentage and mean) were produced to describe and summarise overall trends and patterns in the participants' reports of their PLD perceptions and practices.

Because the questionnaire aimed to capture an overall picture of PLD in the selected HEIs, an analysis of the participants' responses across the three sites was conducted as a whole. However, further analysis and cross-tabulations were conducted when necessary to explore the differences across the kinds of participants (academic leaders vs. lecturers, 
novice vs. experienced lecturers). The participants' responses to the two open-ended questions in the questionnaire were analysed manually in order to identify key trends and categories in these responses, including a list of educational reforms they have been implementing, and the kinds of PLD the participants wanted to have in the future.

\section{Phase 2: Qualitative inquiry}

\section{Participants of the semi-structured interview}

For the individual in-depth interviews, purposive sampling was also employed to select the participants from a wide range of personal and academic circumstances, and including both lecturers and academic leaders. This selection was based on an assumption that lecturers at different career stages, and with different academic responsibilities would vary in terms of teaching perceptions, PLD engagement, PLD preferences, and learning needs.

The questionnaire was used as a recruiting tool to invite the participants to participate in the follow-up interview, as previously mentioned. This strategy of using an anonymous questionnaire to recruit interview participants who belonged to the larger survey group enabled an investigation and elaboration upon findings from the preceding quantitative phase (Creswell, 2014; Green, 2007).

The study involved 26 interviewed participants in total $(10,8$, and 8 from site A, B, and $\mathrm{C}$, respectively). Among these participants, 24 completed the questionnaire and volunteered to take part in the individual interview in the next stage. The other two participants did not complete the questionnaire, but were invited to participate in the interview. These two participants were leaders (one in site A, and one in site C) who were reported by the lecturer participants to be responsible for organising and supporting PLD activities for lecturers within the universities. Therefore, these leaders were approached and invited to the interview for the purpose of obtaining different perspectives regarding PLD for lecturers. Generally, all participants who volunteered to take part in the interview met the selection criteria. As a group, they provided variations in their age, gender, teaching experience (from two to 20+ years), academic qualifications (from BA to $\mathrm{PhD}$ degrees), and academic roles (with and without academic leadership). Their questionnaire responses 
provided a range of PLD perceptions and experiences. Table 3.3 describes the interview participants.

Table 3.3 Interview participants' demographic data

\begin{tabular}{|c|c|c|c|c|c|c|c|c|c|c|c|}
\hline \multirow[b]{2}{*}{ Sites } & \multicolumn{2}{|c|}{ Gender } & \multicolumn{2}{|c|}{ Position } & \multicolumn{3}{|c|}{ Age group } & \multicolumn{4}{|c|}{ Years of teaching experience } \\
\hline & Male & Female & Lecturers & $\begin{array}{l}\text { Academic } \\
\text { leaders }\end{array}$ & $20-30$ & $31-40$ & $41-50+$ & $2-5$ & $6-10$ & $11-15$ & 16-20+ \\
\hline $\begin{array}{l}\text { Site A } \\
\mathrm{n}=10\end{array}$ & 3 & 7 & 6 & 4 & 3 & 4 & 3 & 3 & 3 & 1 & 3 \\
\hline $\begin{array}{l}\text { Site B } \\
\mathrm{n}=8\end{array}$ & 4 & 4 & 3 & 5 & 0 & 2 & 6 & 2 & 5 & 1 & 0 \\
\hline $\begin{array}{l}\text { Site C } \\
\mathrm{n}=8\end{array}$ & 4 & 4 & 6 & 2 & 0 & 7 & 1 & 1 & 6 & 1 & 0 \\
\hline $\begin{array}{l}\text { Total } \\
\mathrm{n}=\mathbf{2 6}\end{array}$ & 11 & 15 & 15 & 11 & 3 & 13 & 10 & 6 & 14 & 3 & 3 \\
\hline
\end{tabular}

In total, among the 26 participants, nine were academic leaders and 17 were lecturers. The academic leaders included the leaders of the Education Faculty and the Foreign Language Department or Foreign Language Faculty in each university. These people had at least an MA degree in Education or in English teaching, and also had a teaching role. They played important roles in informing the educators about institutional goals and reform requirements as well as arranging and supporting PLD for lecturers. The lecturers were mainly responsible for teaching EFL to students who would become teachers in schools. The lecturers were also supposed to undertake research and other professional duties. A few of them had been assigned additional duties such as organising extra-curricular activities for students, working as student advisors, or helping the leaders to facilitate PLD activities within the universities. Among 26 interviewees, 3 had a $\mathrm{PhD}$ degree; 21 had an MA degree, and 2 had a BA degree.

A code was assigned to each participant in order to protect their individual identity. Each code included a letter indicating the site (University A, B, or C), the group the participant belonged to (L means lecturers; AL means academic leaders), and a number. For example, A.L1 refers to lecturer participant 1 from University A; A.AL1 refers to academic leader 1 from University A. 


\section{Data collection}

\section{Interview data - 26 individual interviews}

In-depth individual interviews provided the major source of data in this study. Individual interviews with participants enabled the researcher to find out things that could not be observed, enter into the participants' perspectives, and discover the meaning they attached to their own experiences (Patton, 2002). Similarly, a "well-conducted interview is a powerful tool for eliciting rich data on people's views, attitudes, and the meanings that underpin their lives and behaviours" (Gray, 2009, p. 370). Therefore, in-depth interviews were an effective tool to explore EFL educators' and other stakeholders' experiences of PLD, and probe the value and meanings of these experiences to them.

Each interview was semi-structured, with pre-determined key questions about the research focus to guide the interview (Johnson \& Christensen, 2012). The order of the questions changed according to the flow of the conversation, and follow-up questions were used for clarification or to elicit more details and examples (Merriam, 2009). Therefore, semi-structured interviews provided flexibility, and allowed the researcher to respond to the emerging worldview of the respondent, and to pursue new ideas on the topic (Merriam, 2009).

The individual interviews were piloted with two non-participants (one lecturer and one academic leader) who used to work as EFL teacher educators in Vietnamese tertiary institutions. They both had experience in PLD for EFL lecturers. The interviews were audio-recorded and conducted in Vietnamese. After the interviews, the interviewees provided oral feedback about the clarity of the questions, the relevance of the questions, the interviewer's manner and asking techniques, their feeling and comfort during the interviews, and other comments they had. The interview transcripts were translated into English to enable the analysis to be discussed with my supervisors, including how to improve the question clarity and the interview techniques. The interview questions were then modified accordingly. The trial interviews helped to increase the research method validity (Johnson \& Christensen, 2012), as well as to enhance my interviewing strategies to establish a positive interaction with the respondents (Merriam, 2009). 
The interviews with the EFL lecturers prompted them to share their perceptions and experiences of PLD, evaluations of PLD policies and PLD impact, barriers in reform implementation, contextual factors and collegial relationship, and PLD needs (Appendix E). The interviews with the academic leaders focused on institutional needs, goals, and resources, PLD policies, their roles in PLD provision, their evaluation of reform implementation, and strategic plans for PLD (Appendix F). The interviews were conducted in Vietnamese at the participants' request. Each interview took between 45 to 60 minutes, depending on the participants' willingness to provide further responses. The interviews were audio-recorded to ensure that all information was preserved for analysis (Merriam, 2009).

The participants who volunteered to take part in the interview were contacted via email and telephone to provide further information about the interview and arrange an interview schedule (Appendix G, Appendix H). Prior to the interview, the ethical implications of their participation were explained, and then interviewees were given a consent form to sign (Appendix I).

There were potential problems inherent in conducting interviews. For example, the participants might have responded according to social expectations (Johnson \& Christensen, 2012; Patton, 2002), especially within a Vietnamese culture that values face, authority and organisational reputation. This cultural practice might have prevented the interviewees from showing disapproval or expressing negative aspects of their institutional policies or collegial relationships. To avoid these problems, I explained clearly the research aims, and assured the participants of the confidentiality of their responses (Johnson \& Christensen, 2012). Before the actual interviews, a list of key topics included in the interview was sent to the participants. This allowed the participants to have time to think about their responses and recall their experiences of the studied issues, which would make them feel more comfortable and prepared in the interviews. During the interview, I showed my willingness to listen to the participants' experiences, and my respect for their voices, perspectives, and expertise in their own contexts (Merriam, 2009). By listening carefully and probing for concrete examples and feelings, I felt that I gained genuinely meaningful information from the participants (Eisner, 1998). 


\section{Observations - 13 PLD sessions}

The study included observations of PLD sessions happening at two of the three university sites. "Observations take place in the setting where the phenomenon of interest naturally occurs" and "observational data represent the first-hand encounter" with the research issues (Merriam, 2009, p. 117). Therefore, observations were used to understand how PLD actually occurred in practice and participants' engagements in particular forms of PLD within their natural contexts. Observational data also helped to triangulate emerging findings from the questionnaire survey and the interviews, and to identify points for subsequent interviews (Merriam, 2009).

The process of conducting observations of PLD sessions was as follows. When there was a relevant PLD session, I contacted the chairperson or PLD provider of this session and asked for permission to observe and collect the PLD materials. An information sheet and consent form were given to these facilitators prior to the event (Appendix J, Appendix K). I tried to observe things in an unobtrusive way (Johnson \& Christensen, 2012) to ensure that my presence did not affect people's behaviours in the studied sites. Instead of videorecording events, which might have inhibited people's reactions, I used an observation guide (Appendix L), and took careful field notes of PLD forms and functions, the structures, the content and purposes of PLD, roles of facilitator(s), and their use of resources. The notes were transcribed immediately after each site-visit and observation to ensure all necessary data were recorded accurately (Appendix M). To protect the attendees' identity, the observation notes did not record data generated by or about individual attendees or attribute any information to any individual. The materials used in each PLD session were collected whenever possible to support the analysis of the observation notes later.

The opportunities for observations varied from one university to another. Also, the observations were completed concurrently across the three sites depending on the availability of PLD sessions at each institution. Altogether, I observed 13 PLD sessions for EFL lecturers including workshops, seminars, and training courses (six at site A and seven in site $\mathrm{C}$ ). At site $\mathrm{B}$, no observations took place because of limited access to information about the staff events as well as the limited number of PLD sessions held at this university during the period of data collection. 


\section{Document collection}

The study involved an analysis of related policy documents at both national and institutional levels. Relevant documents were identified based on the research objectives, educational reforms in HE in Vietnam over the past ten years, and the documents or policies mentioned by the interviewees. Selected national policy documents (Appendix N), including the Education Law, the University Charter, HERA, and the foreign language education reform project were reviewed. Institutional documents, including HEIs' functions and missions, strategic plans, and policies for staff management and reform implementation were collected. In addition, professional meeting minutes, PLD plans, and records of PLD activities were collected from the Department of EFL, whenever possible. These documents revealed the historical and cultural context of each HEI, their interpretation and implementation of national directives, and their strategies and policies for lecturers' PLD.

The material within policy and official documents provided a rich data source as they highlight the areas foregrounded by government or institutional priorities and areas for focus. Such data can contribute to understanding the context within which the research takes place. Document analysis can "furnish descriptive information, verify emerging hypotheses, advance new categories and hypotheses, offer historical understanding, track change and development" (Merriam, 2009, p. 155). Unlike other sources, documents are unobtrusive and can be accessed easily (Merriam, 2009; Yin, 2009). Documentary data supplemented data from the other sources to capture a multifaceted picture of how PLD was conducted across the three sites.

\section{Qualitative data analysis}

In this study, data analysis was an iterative process (Patton, 2002) taking place during data collection (Merriam, 1988; Miles et al., 2014; Stake, 1995). The analysis was "interactive, involving a back-and-forth process between data collection and data analysis" (Teddlie \& Tashakkori, 2009, p. 251). For example, the researcher's reflections on the initial interviews at each site informed the adaptation of the following interviews. After the two or three first interviews at each site, important aspects of PLD began to surface. These initial reflections and insights prompted certain issues to be explored further in the following interviews, or 
additional participants to be invited to offer different perspectives on the studied problem. During data collection, the researcher's observations of the sites and their contextual factors, and memos of insights into the data contributed to decisions on what issues to further investigate, who else to include, and how to analyse different data sources. The data analysis started in the field during data collection and continued while research findings were written up (Teddlie \& Tashakkori, 2009) when the analyst needed to come back to the original data to double check the validity of a finding, or to obtain more insightful inferences.

Overall, the analysis was conducted through several steps, from general to more specific, deductive to inductive, and analysing and synthesising segments of data. A CHAT analysis was employed to analyse qualitative data for the overall purpose of obtaining an in-depth understanding about the participants' perceptions and experiences of PLD in their real-life contexts.

Data from all sources were coded directly from Vietnamese language to ensure their original meanings. Relevant data were translated by the researcher from Vietnamese to English for discussion in the thesis. To ensure the trustworthiness of the translation, backtranslation was used (Brislin, 1970). Specifically, a colleague who is an EFL lecturer in Vietnam and is fluent in both languages translated the English version back into Vietnamese to compare the language, tone, and voice of the two versions to make sure that they matched each other.

Before analysing qualitative data, a database for each site was established which consisted of all data accumulated about each site from the interviews, observations, and document review (Patton, 2002). All qualitative data were managed using the NVivo 10 software programme.

\section{Analysing national policy documents}

The government policy documents were analysed separately in order to provide an overall picture of Vietnamese HE context as cultural and contextual factors were embedded within official regulations and these related to the researched issues. Content analysis was employed which refers to "any qualitative data reduction and sense-making effort that takes 
a volume of qualitative material and attempts to identify core consistencies and meanings" (Patton, 2002, p. 453). After collection the policy documents were read through and relevant parts for analysis were identified. Then all selected parts of the documents were coded according to a pre-established set of categories (Silverman, 2011) which were based on the key trends found from the questionnaire survey and preliminary analysis of interview data. Key categories included: the PLD models mentioned in the documents, the official role and function of PLD, key initiatives and imperatives in tertiary educations, lecturers' roles and responsibilities. During the process of analysing the documents, new categories (e.g., professional identity, social status of the teaching profession) emerging from the materials were added to the coding scheme. The key categories from the document analysis helped to capture a picture of the cultural, social and political context to which the documents belonged. Findings from the national policy document analysis were presented separately from findings of the quantitative phase and of the qualitative site findings in order to foreground the context and official policies related to tertiary education and PLD in Vietnam.

\section{Analysing interview data}

All interviews were transcribed in Vietnamese. The interview data were analysed both deductively and inductively. Interview data analysis from one university site was conducted and completed before moving to the next site.

First, each interview transcript was read at least three times to gain familiarity with the data and an overall understanding of the data. Next, a list of questions was used to deductively guide the initial analysis of each interview, and identified key issues that arose in each participant's responses to the interview prompts. Although most of the guiding questions were similar across the interviews and based on key interview prompts, a few questions varied from one interview to another due to the differences in the participants' responses about their PLD experiences. Sample questions included: How did the participant define PLD? What kinds of PLD did the participants engage in, and why? What were examples of PLD that related to a government or university initiative? What supported his/her PLD? What hindered his/her PLD? What key phrases or concepts might I follow up 
with? What really surprised me? This stage of the analysis was conducted manually using different colours for key ideas and making notes on the margins of the transcripts.

After that, a more focused analysis was conducted for each interview. An initial list of categories of description was established by drawing upon empirical research on PLD practices in literature (Miles \& Huberman, 1994), the research questions, main ideas in the interview prompts, and key trends from the findings of the questionnaire survey. This strategy was crucial because "establishing basic descriptive categories early on for coding [allowed] easy access to information in the analysis and interpretation stage" (Merriam, 2009 , p. 152). During the coding process, however, the list of categories was modified and new categories were added in order to capture key trends and insights emerging from the participants' responses (Miles \& Huberman, 1994).

At the end of this stage, a summary of the key categories and important ideas for each interview was undertaken. To enhance the validity of this analytical process and assure the relevance of the key categories identified in an interview, I translated two interview transcripts from Vietnamese to English (Appendix O), and discussed the categories emerging in these interviews with my primary supervisor. This strategy also helped to gain a greater inter-rater reliability (Thomas, 2006). After that, I coded and analysed the other interviews directly in Vietnamese, as previously mentioned, in order to retain the original meanings in the participants' responses.

After finishing the initial analysis of all interviews in site A, all interview summaries were collated and key trends identified. All sites were analysed in this way. The key categories and their relations identified from the three sites were pulled together in order to highlight similarities, consistencies, as well as tensions and contradictions within and across the sites. These categories and their relationships were also used to provide a context and inform the CHAT analysis. The synthesis of findings from various sites and data sources would offer a holistic understanding of the complexity of the case - PLD for tertiary lecturers. Key findings from the study were later synthesised to identify fundamental concepts underpinning lecturers' PLD engagement in the Discussion Chapter. 


\section{Analysing observation notes and institutional policy documents}

In this study observations provided useful data which helped to explore what and how PLD actually occurred in authentic settings. This captured PLD in practices and the diversity and complexity of the context it occurred. However, ethical issues were considered when deciding how much detailed observational data related to institutional factors, policies and observed PLD events should be revealed and discussed so that the identities of the universities and their members were still protected. For example, identifying details of observed PLD events (titles/ topics, dates, locations, activities) were either removed or generalised. Furthermore, as I only obtained informed consent from the Chairs and/or the presenters at the PLD sessions rather than consent from all attendants of these events (which is usually impossible regarding the PLD processes and organisations in Vietnamese context), I decided to minimise detailed descriptions about attendants' engagement, behaviours, and ideas during the observed PLD sessions. Therefore, despite their richness, observation data were used only when relevant to support, justify, or elaborate the participants' interview responses on their PLD experiences and what meaning they associated with these particular PLD experiences.

Similarly, data from relevant institutional documents were used to justify findings from interviews and other data sources rather than being analysed separately to generate their own themes or findings. Ethical issues were also considered when presenting institutional documents, and identifying information such as document titles, institutional names and websites, and demographic data were not reported in order to protect the institutions' identities.

In this study, the analysis of institutional documents and observation notes was conducted after the interview data analysis in order to justify, explain or elaborate further the findings of the interviews. The observation notes and documents were coded and analysed according to the categories identified from the interview analysis for the purpose of triangulation of the study findings. Data from observations of PLD events and relevant institutional policy documents also offered insights into participants' perceptions and experiences of PLD, and the meanings attached to their experiences as well. 


\section{Conducting a CHAT analysis of the three sites}

Further analysis of the findings from the three sites was conducted using CHAT as a theoretical framework. Key components of the PLD activity systems (subjects, object, artefact, community, rules, and division of labour) were identified within the activity systems in each site. A set of guidelines was used to prompt the analysis of the activity systems (Table 3.4).

Table 3.4 Guidelines for analysing the PLD activity systems in individual sites

\begin{tabular}{|c|c|}
\hline Components & Descriptions \\
\hline $\begin{array}{l}\text { Artefacts or } \\
\text { tools }\end{array}$ & $\begin{array}{l}\text { - Various PLD types (formal, collaborative, informal); } \\
\text { - Resources (teaching and learning facilities, reference books and other materials); } \\
\text { - Social others (PLD providers, colleagues, managers) mediating PLD for lecturers. }\end{array}$ \\
\hline Subjects & $\begin{array}{l}\text { - Individual lecturers, or a group of lecturers engaging in PLD, and acting to achieve } \\
\text { the objects. }\end{array}$ \\
\hline Object & $\begin{array}{l}\text { - Improve teaching effectiveness; improve self-image and professional identity; } \\
\text { - Improve students' learning/ outcomes; } \\
\text { - Improve lecturers' qualifications (e.g., degrees, English proficiency); } \\
\text { - Develop research ability, knowledge and skills, other professional skills; } \\
\text { - Enact educational reforms / initiatives from the university and MOET/ government. }\end{array}$ \\
\hline Rules & $\begin{array}{l}\text { - Formal central and institutional regulations (e.g., educational law, university chatter, } \\
\text { regulations on lecturers' work and responsibilities, policies related to PLD provision, } \\
\text { lecturers' assessments, professional management); } \\
\text { - Informal rules: unspoken norms and cultural practices (e.g., peer-respect, maintaining } \\
\text { group harmony, and obedience for authority). These were considered part of informal } \\
\text { rules because they influenced the participants' views of PLD, their behaviours and } \\
\text { their PLD practices. These informal rules affected how PLD took place. }\end{array}$ \\
\hline
\end{tabular}

Community - Within the institution: students (of various types, needs and expectations), colleagues, ALs, university administrators, PLD providers;

- Within lecturers' personal lives: family members who may (not) provide support, or have expectations on the lecturers' roles and responsibilities in the family);

- Within a larger society: other universities, society, government, MOET. 


\begin{tabular}{ll}
\hline Components & \multicolumn{1}{c}{ Descriptions } \\
\hline Division of & - Individual lecturers' roles and responsibilities: teaching, researching, supporting \\
labour & students' learning (inside and outside the classroom), their own PLD \\
& - Colleagues' roles and responsibilities: providing mutual support, engage in \\
& professional discussion, observing and giving feedback on peers' teaching. \\
- & Leaders' roles and responsibilities: support, encourage, give demands, assess and \\
& manage, solve problems, communicate with the lecturers about goals/ policies \\
- & Students' roles and responsibilities: make effort and agency in learning, give feedback \\
& on teaching / learning issues \\
- & The policy makers' roles and responsibilities: provide support, strategic plans, \\
& communicate goals/ visions, understand the lecturers' needs \\
- & PLD providers' roles and responsibilities: provide effective PLD, assess PLD effects, \\
& provide on-going support and follow-up activities.
\end{tabular}

The CHAT analysis aimed to reveal the inter-connection and interactions between different components of the PLD activity systems. This helped to highlight tensions and contradictions inherent within the PLD activity systems as well as across a network of interacting systems (e.g., lecturers' activity system, policy makers' activity system, and institutional leaders' activity system). The CHAT analysis of the three university sites, therefore, provided a better understanding of how and why PLD for lecturers took place and of the multiple voices and roles of different agents engaging in the activity systems of PLD for lecturers in the selected sites.

\section{Strategies for enhancing research trustworthiness}

Because the researcher is also the instrument of data collection and interpreter of the data in qualitative research, the researcher's perspectives of the research phenomenon were likely to affect the ways of collecting, analysing and interpreting the data (Johnson \& Christensen, 2012). Therefore, it was important to enhance the trustworthiness of the research findings - the term often used to refer to the validity (Johnson \& Christensen, 2012) or authenticity (Creswell \& Miller, 2000) of qualitative research. The study employed various strategies to enhance four components of trustworthiness: credibility, 
dependability, confirmability, and transferability (Lincoln \& Guba, 1985). Table 3.5 summarises strategies used to enhance research trustworthiness.

Table 3.5 Strategies to enhance research trustworthiness

\begin{tabular}{ll}
\hline \multicolumn{1}{c}{ Components } & \multicolumn{1}{c}{ Strategies } \\
\hline Credibility & - Triangulation of data and methods \\
& - Piloted data collection instruments \\
& - Analysis of negative cases \\
\hline Dependability & Participants' feedback \\
\hline Confirmability & Peer-debriefing in coding and identifying categories \\
& - Researcher reflexivity \\
& - Peer-review \\
\hline Transferability & - Thick description \\
& Possibility for the readers to relate the findings to similar \\
& educational contexts \\
\hline
\end{tabular}

\section{Credibility}

Credibility refers to the validity or authenticity (Creswell \& Miller, 2000), or the "true value" of the research (Lincoln \& Guba, 1985, p. 296). These qualities were enhanced by using triangulation of data and triangulation of methods. In fact, the data from different methods and sources supplemented each other and enhanced credibility of the findings (Yin, 2003). Furthermore, the credibility of data collection tools (e.g., the questionnaire and interview protocol) was assured by piloting them with non-participant Vietnamese EFL lecturers, and the content and procedure of these instruments were modified if necessary to ensure that they are understandable and relevant to the research purposes. My engagement over a 6-month data collection period also strengthened the credibility of the findings (Yin, 1994). The study took account of 'negative cases' or instances that did not fit the patterns and trends identified from the data analysis (Johnson \& Christensen, 2012; Patton, 2002). For example, further attention was paid to explore the reasons why a particular participant, unlike the others, expressed little interest and engagement in PLD activities. An analysis of alternative explanations added credibility by "showing the analyst's authentic search for what made most sense rather than marshalling all the data toward a single conclusion" (Patton, 2002, pp. 554-555). Being open- 
minded to new understandings and aware that my existing beliefs and knowledge could be challenged by the research findings helped to reduce the problem of researcher's bias in analysing and interpreting data (Johnson \& Christensen, 2012).

\section{Dependability}

Dependability is an assessment of the quality of the integrated processes of data collection, data analysis, and theory generation (Lincoln \& Guba, 1985). Dependability is enhanced if threats to inaccuracies of data collection and interpretation are reduced. To enhance descriptive and interpretive accuracy, I used low-interference descriptors such as field-notes, and audiorecordings of interviews to capture all necessary information (LeCompte \& Goetz, 1982). Also, the interview transcripts were shared with the actual participants for member checking (Johnson \& Christensen, 2012). For data analysis, I used peer-debriefing, discussing the coding process and initial trends with my supervisors, to enhance the credibility of the process of coding, identifying emerging categories, and interpreting data. I discussed the research findings and conclusions with my supervisors, my colleagues who were also Vietnamese EFL lecturers attending $\mathrm{PhD}$ programmes at VUW, and other experts in education. From these discussions, problems such as misinterpretation, unconvincing explanations, and researcher bias were identified. Resolving such problems enabled more credible and defensible findings.

\section{Confirmability}

Confirmability is defined as "the degree to which findings are determined by the respondents and conditions of the inquiry and not by the biases, motivations, interests or perspectives of the inquirer" (Lincoln \& Guba, 1985, p. 290). In this study, I clearly acknowledge that my perspectives, experiences, and motivations as an insider - an EFL lecturer in Vietnam - might have influenced the way I interpreted the data and the studied problem. Further, by actively engaging in critical self-reflection, I became more aware of my own potential influence on the research and the participants and attempted to address this problem (Johnson \& Christensen, 2012). For example, a reflective journal was used to keep a detailed record of my own thoughts, reasons for each decision, and interpretations during the process of data collection and analysis. On-going reflections helped me to acknowledge and explore how my assumptions, personal and professional experiences, thinking, beliefs, and emotions might influence the research. 


\section{Transferability}

Transferability refers to the degree to which the findings may be transferred to other contexts outside the study (Lincoln \& Guba, 1985). The quantitative part of this study involved a small number of participants and the study was mainly qualitative in nature. Therefore, this study does not aim to make generalisations from the research findings to other populations or other contexts (Stake, 1995; Stake, 2008). Instead, the study focused on understanding "the particular in-depth", PLD for educators at the selected HEIs in their real settings (Merriam, 1988, p. 177). The thesis provides a thick description of the research problem (Johnson \& Christensen, 2012), and a detailed and precise description of the research process and methodology to help readers make sense of the findings, consider their own contexts, and to evaluate the study. This enables the readers to relate the insights of the study to similar educational contexts.

\section{The researcher's position}

Being a university lecturer in Vietnam, I am aware that PLD plays a crucial role in HE, especially in supporting lecturers' professional practices and capacities to enact educational initiatives. I also have a passion for teaching and learning. However, as a researcher, I understand that my beliefs and professional values may influence the way I collect data, analyse the data, and interpret the findings. Therefore, as previously presented, I have used several strategies in this study to minimise this potential influence. This section further elaborates my position in this study.

In the Vietnamese context, researchers are respected as having expertise in their research areas and thus the communication between researchers and participants may be influenced by the power culturally associated to the role of researchers. In this study, I positioned myself as a researcher who was also a colleague of the participants. This helped me to build rapport with the participants and reduce the power gap between our roles. Showing that the researcher is also an 'insider' within the research context is a useful strategy to enhance the participants' trust and willingness to express their ideas with the researcher (Nguyen, 2015). During the interviews, I neither relied on my own understanding about PLD and the HE context nor assumed that I understood everything the participants were talking about. Instead, I used follow-up questions to elicit further 
explanations or examples in order to fully explore what the participants actually meant and how they perceived the meaning of their PLD experiences. Through questioning I was able to avoid making judgements about the participants' opinions, their personalities, or professional values based on their interview responses. Similarly, when conducting observations of PLD, I played the role of a participant observer who also took part in the PLD sessions as a member of the participants' community. This role allowed me to collect trustworthy data as explained previously.

When analysing the data, I allowed new understandings and insights from the data to evolve rather than trying to look for predetermined findings from the data. For example, I was alert to the negative case (Johnson \& Christensen, 2012) emerging from interview data, and made an effort to explore further information to explain it. Similarly, I avoided making conclusions about observed PLD activities based on my own perceptions of effective factors of PLD sessions. Instead, I linked observation data to the participants' interview responses in order to analyse how the observed PLD sessions were perceived from the participants' perspectives. The conclusions in this study were based on findings from different data sources, which strengthened the trustworthiness of the findings.

In this study, my background, professional beliefs and values, and cultural understandings definitely influenced the research process and interpretations of the findings. However, regarding the qualitative dominance of this study, I consider my expertise in EFL teaching and learning in HE and understanding of the socio-cultural and political context in Vietnam as a strength contributing to the appropriateness in interpreting and communicating the research findings.

\section{Summary}

For the purpose of investigating the complexity of PLD for tertiary lecturers in Vietnamese contexts, this study employed CHAT as a theoretical framework, and took a sequential explanatory mixed-methods approach that gave priority to the qualitative inquiry. The study was designed as a single case study across three sites in order to fully investigate the complexity of PLD for teacher educators in Vietnamese tertiary sector. Using the questionnaire survey, the study aimed to obtain an overall understanding of the multidimensional phenomenon of PLD reflected in the participants lived experiences. The qualitative stage that followed involved 
individual interviews, observations of PLD sessions, and policy document analysis to enable an in-depth understanding of the participants' perceptions of PLD, the meanings they held about their experiences, and the influence of contexts on their PLD. Using both quantitative and qualitative methods, therefore, contributed to the completeness of the research findings about the case - the phenomenon of PLD for Vietnamese teacher educators. The study employed several strategies to improve the research trustworthiness and ethical standards. The next two chapters present the results of the study. 



\section{CHAPTER 4 \\ RESULTS: UNDERSTANDING PLD}

This chapter presents the findings from both the quantitative and qualitative phases of the study. In the first section, questionnaire results are described, providing an overview of the participants' PLD perceptions and experiences. Next, findings from the national policy document analysis are presented to foreground the context and official policies related to tertiary education and PLD in Vietnam. Finally, results from the case study are described, focusing on the participants' perceptions and experiences of PLD within each university site. Findings from the case study create a deeper and more insightful understanding of the participants' perceptions of PLD and the meanings attached to their experiences.

\section{Questionnaire findings}

The total number of participants from the three universities completing the questionnaire was 55 (16, 17, and 22 participants from site A, B, and C, respectively), as outlined in the previous chapter. Findings from the questionnaire analysis are presented in five sections. The first two sections describe the participants' perceptions of PLD roles and functions, and of PLD activities. The following sections present their PLD experiences, reported barriers to the implementation of educational reforms, and their perceived PLD needs. The frequency of the participants' responses is presented in the form of percentages which are based on the number of valid respondents who answered each item in the questionnaire. For almost all of the items, the number of respondents was 55. Only a few items were answered by either 54 or 53 respondents. Such a small variation in data did not affect the general results of the questionnaire, thus these are not specified.

\section{PLD roles and functions}

Overall, the participants showed a positive perception of all the roles and functions of PLD mentioned in the questionnaire. All participants believed PLD was either 'very important' $(60 \%)$ or 'important' $(40 \%)$ in supporting their professional needs and goals. For most 
participants (around 80\%) PLD was considered 'very important' in improving their teaching effectiveness or updating their content knowledge and skills (Table 4.1).

Table 4.1 Participants' perception of the importance of PLD roles and functions

\begin{tabular}{|c|c|c|c|c|}
\hline How important are the following roles and & $\begin{array}{c}\text { Not } \\
\text { important }\end{array}$ & $\begin{array}{l}\text { Of little } \\
\text { importance }\end{array}$ & Important & $\begin{array}{c}\text { Very } \\
\text { important }\end{array}$ \\
\hline teaching? & $\%$ & $\%$ & $\%$ & $\%$ \\
\hline Update my content knowledge and teaching skills & 0 & 0 & 18 & 82 \\
\hline Improve my teaching effectiveness & 0 & 0 & 20 & 80 \\
\hline Improve my student learning outcomes & 0 & 2 & 25 & 73 \\
\hline Support my professional needs and goals & 0 & 0 & 40 & 60 \\
\hline $\begin{array}{l}\text { Improve my ability to facilitate EFL school } \\
\text { teachers' teaching and learning }\end{array}$ & 0 & 5 & 30 & 65 \\
\hline Improve my teaching confidence and motivation & 0 & 0 & 44 & 56 \\
\hline Improve my research ability & 0 & 3 & 44 & 53 \\
\hline Address national educational reforms & 0 & 2 & 51 & 47 \\
\hline $\begin{array}{l}\text { Meet professional standards stated by the } \\
\text { institution and by MOET }\end{array}$ & 2 & 3 & 42 & 53 \\
\hline Address institutional needs and goals & 0 & 7 & 49 & 44 \\
\hline Build a learning community in my institution & 0 & 9 & 51 & 40 \\
\hline Enhance collaboration and collegial support & 0 & 5 & 62 & 33 \\
\hline Change my beliefs and attitudes & 2 & 9 & 60 & 29 \\
\hline Enhance my leadership & 7 & 40 & 34 & 19 \\
\hline
\end{tabular}

The PLD associated with updating content knowledge and teaching skills, improving teaching effectiveness, and improving student learning outcomes was strongly identified by participants as important. Given these roles directly relate to lecturers' teaching, this is consistent with their professional aspirations.

The participants also highly valued PLD that supported their ability to facilitate learning for school teachers, improved their own motivation and confidence, and developed 
research skills. The roles of PLD in helping the participants to meet professional standards, and those addressing national educational reforms were also given high values.

As shown in Table 4.1, compared with PLD roles and functions which directly related to the participants' individual needs and teaching duties, PLD roles in addressing institutional needs and goals, building a learning community, and improving collaborative support were less important to the lecturers. While some felt that PLD was 'very important' in contributing to changing their beliefs $(29 \%)$, the majority saw this role as 'important' $(60 \%)$.

The least important role PLD played for these participants was enhancing their leadership which was considered of little or no importance by $47 \%$ of the participants. However, further analysis showed that lecturers with leadership roles, or academic leaders, put much higher value on the role of PLD in enhancing leadership, compared with lecturers without leadership (Table 4.2). For example, $56 \%$ and $22 \%$ of academic leaders perceived this role as important or very important, compared to only $28 \%$ and $17 \%$ of lecturers selecting these responses.

Table 4.2 PLD for enhancing leadership viewed by academic leaders and lecturers

\begin{tabular}{lcccccccc}
\hline $\begin{array}{c}\text { How important is the role } \\
\text { and function of PLD in } \\
\text { enhancing leadership? }\end{array}$ & Not important & $\begin{array}{c}\text { Of little } \\
\text { importance }\end{array}$ & Important & $\begin{array}{c}\text { Very } \\
\text { important }\end{array}$ \\
\cline { 2 - 8 } & $\mathrm{N}$ & $\%$ & $\mathrm{~N}$ & $\%$ & $\mathrm{~N}$ & $\%$ & $\mathrm{~N}$ & $\%$ \\
\hline Lecturers & 4 & 9 & 19 & 41 & 13 & 28 & 8 & 17 \\
Academic leaders & 0 & 0 & 2 & 22 & 5 & 56 & 2 & 22 \\
\hline
\end{tabular}

The differences in the responses on leadership enhancement from the academic leaders and from the lecturers without leadership is illustrated in Figure 4.1. 


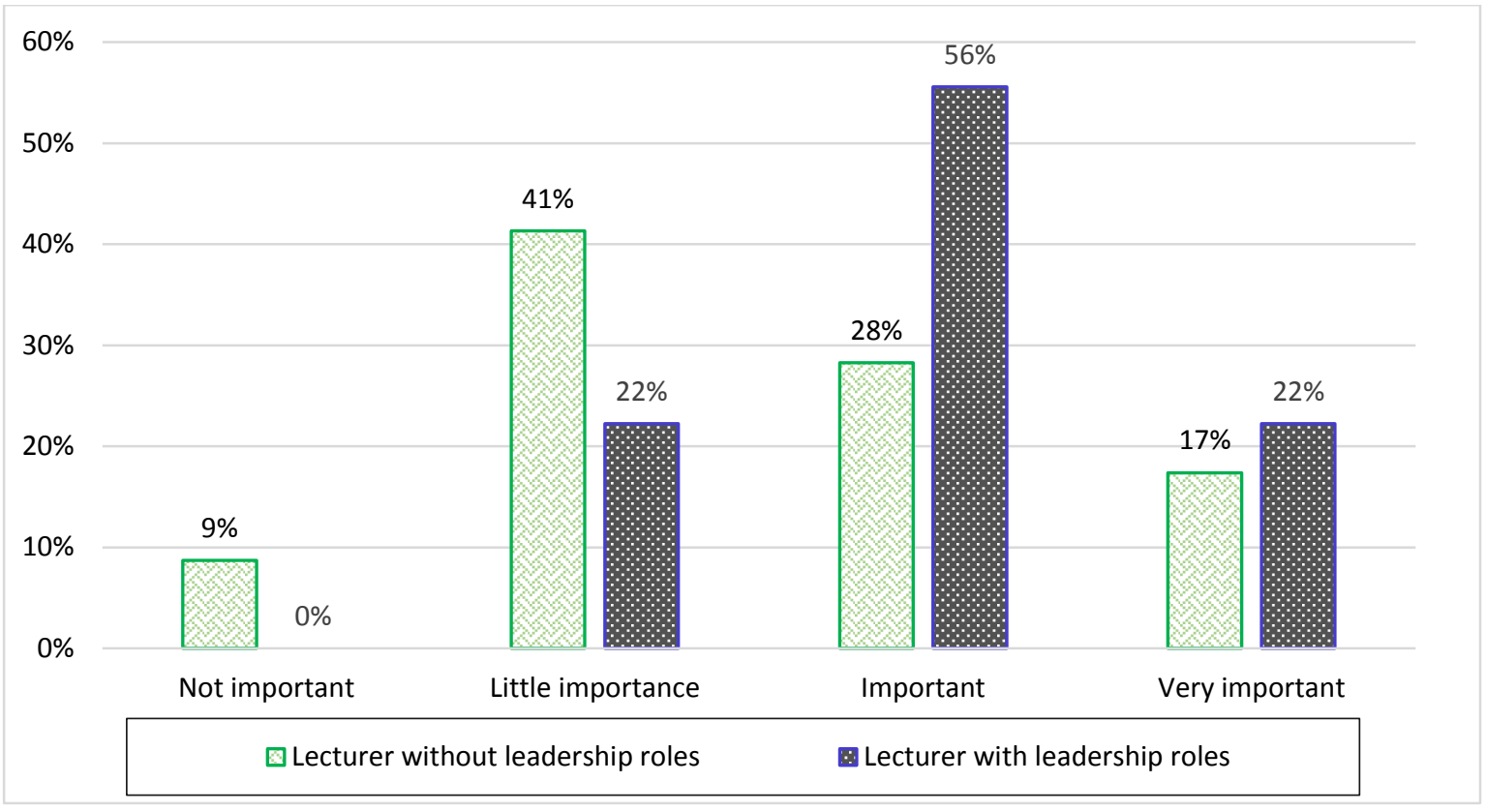

Figure 4.1 Lecturers' perceptions of PLD role in enhancing leadership

A number of participants did not place a high value on the roles of PLD in in enhancing their leadership (47\%), or changing their beliefs and attitudes (10\%). This may suggest that these participants either had limited awareness of the role played by PLD in these areas, or that they prioritised teaching and disregarded these aspects. This may also indicate that these participants did not see themselves as leaders in their profession. Their responses may have reflected their understanding of leadership and towards their professional development. It was necessary to investigate further whether these perceptions were related to lecturers' motivation in seeking for PLD opportunities and their decisions to take part in PLD available to them.

\section{PLD activities}

The participants were asked to select the level of importance they attributed to different PLD activities. There were 14 listed activities ranging from more formal to less formal, as often described in the literature (Callanan, Cervantes, \& Loomis, 2011; Richer et al., 2011). More formal forms (hereafter referred to as formal PLD) included workshops, seminars, postgraduate courses, training courses, and organising/delivering PLD for teachers. More informal forms of PLD (hereafter referred to as informal PLD) included research, supervising student teachers' research or teaching practice, and independent study. More 
informal activities which involved participants' collaborative working or learning with their colleagues or with student teachers were referred hereafter as collaborative PLD. These included engaging in peer observations and feedback, mentoring/coaching, coresearch, team work to complete assigned tasks, and participating in a teaching club or professional association.

Results show that the participants generally held positive perceptions of various PLD activities (Table 4.3).

Table 4.3 Participants' perceptions of the importance of PLD activities

\begin{tabular}{|c|c|c|c|c|}
\hline \multirow{2}{*}{$\begin{array}{c}\text { How important are the following PLD activities for } \\
\text { your learning and teaching? }\end{array}$} & $\begin{array}{c}\text { Not } \\
\text { important }\end{array}$ & $\begin{array}{l}\text { Of little } \\
\text { importance }\end{array}$ & Important & $\begin{array}{c}\text { Very } \\
\text { important }\end{array}$ \\
\hline & $\%$ & $\%$ & $\%$ & $\%$ \\
\hline $\begin{array}{l}\text { Independent learning by reading books, research reports, } \\
\text { journals }\end{array}$ & 0 & 0 & 20 & 80 \\
\hline Inside or outside training courses & 0 & 2 & 47 & 51 \\
\hline $\begin{array}{l}\text { Committee or task force (e.g., curriculum development, } \\
\text { course-book design, programme assessment) }\end{array}$ & 0 & 2 & 49 & 49 \\
\hline Individual research & 0 & 6 & 44 & 50 \\
\hline $\begin{array}{l}\text { Formal post-graduate courses leading to a degree or } \\
\text { diploma }\end{array}$ & 0 & 7 & 46 & 47 \\
\hline $\begin{array}{l}\text { Supervising EFL teacher trainees' research or teaching } \\
\text { practicum }\end{array}$ & 0 & 2 & 64 & 34 \\
\hline Inside workshops, seminars, conferences & 0 & 7 & 58 & 35 \\
\hline Outside workshops, seminars, conferences & 0 & 5 & 64 & 31 \\
\hline Organising PLD programmes for EFL school teachers & 0 & 4 & 67 & 29 \\
\hline Co-research with other lecturers & 0 & 5 & 66 & 29 \\
\hline $\begin{array}{l}\text { Observing other lecturers' classroom practice in your } \\
\text { institution }\end{array}$ & 2 & 13 & 65 & 20 \\
\hline Observing lessons by EFL school teachers & 4 & 16 & 60 & 20 \\
\hline Mentoring or coaching other lecturers in your institution & 4 & 16 & 62 & 18 \\
\hline Participating in a teaching club or a lecturers' association & 7 & 35 & 49 & 9 \\
\hline
\end{tabular}


Independent learning through reading books, research reports and journals was seen as either very important (80\%) or important (20\%) by the participants. Other activities such as attending inside or outside ${ }^{5}$ training courses and post-graduate study, and serving on a committee or task force were also perceived as either very important or important by over $90 \%$ of the participants. Research was also given high values although individual research was perceived as more important than collaborative research.

Participants felt that PLD activities involving collaborative learning such as coresearch, peer-observing, and coaching or mentoring were less important, although these activities were still positively valued. While over half of the participants (58\%) considered it important to participate in a teaching club or association, about one-third (35\%) thought that this was of little importance. The overall trend was that individual learning activities were more highly valued than collegial or collaborative activities. Formal PLD activities were also rated higher than informal ones.

\section{The participants' report on their PLD experience}

Overall, the participants reported a low level of engagement in listed PLD activities. The participants were asked to select the relevant level of frequency for each of the listed PLD activities ( $1=$ never, 2 = sometimes, $3=$ often, 4 = always $)$. This question asked about the same 14 activities as those in the previous question.

As seen in Table 4.4, the most frequent activity was independent study, followed by serving on a committee or task force which participants reported undertaking either often or always (84\% and 53\% respectively). Among formal PLD activities, attending inside workshops, seminars and conferences, and inside or outside training courses were experienced more frequently than outside formal events and post-graduate courses.

\footnotetext{
${ }^{5}$ Inside, or internal, PLD refers PLD activities organised within the participants' institutions. External, or outside PLD refers to PLD activities organised outside the participants' institutions.
} 
Table 4.4 Lecturers' report on their participation in PLD activities

\begin{tabular}{|c|c|c|c|c|}
\hline \multirow{2}{*}{$\begin{array}{l}\text { How often have you participated in these activities in the } \\
\text { past two years? }\end{array}$} & Never & $\begin{array}{l}\text { Some- } \\
\text { times }\end{array}$ & Often & Always \\
\hline & $\%$ & $\%$ & $\%$ & $\%$ \\
\hline Independent study by reading books, research reports & 0 & 16 & 51 & 33 \\
\hline $\begin{array}{l}\text { Committee or task force (e.g., curriculum development, } \\
\text { course-book design, programme assessment) }\end{array}$ & 5 & 42 & 31 & 22 \\
\hline Inside workshops, seminars, conferences & 2 & 65 & 29 & 4 \\
\hline Inside or outside training courses & 4 & 68 & 26 & 2 \\
\hline Individual research & 24 & 37 & 30 & 9 \\
\hline Organising PLD programmes for EFL school teachers & 29 & 25 & 46 & 0 \\
\hline Supervising EFL teacher trainees' research or teaching & 29 & 33 & 33 & 5 \\
\hline Outside workshops, seminars, conferences & 15 & 60 & 25 & 0 \\
\hline Post-graduate courses leading to a degree or diploma & 24 & 54 & 18 & 4 \\
\hline Observing other lecturers' classroom practice in your institution & 20 & 64 & 16 & 0 \\
\hline Co-research with other lecturers & 33 & 46 & 19 & 2 \\
\hline Mentoring or coaching other lecturers in your institution & 38 & 51 & 11 & 0 \\
\hline Observing lessons by EFL school teachers & 60 & 31 & 9 & 0 \\
\hline Participating in a teaching club or a lecturers' association & 69 & 31 & 0 & 0 \\
\hline
\end{tabular}

PLD activities which directly related to lecturers' professional duties such as individual research, organising PLD for EFL school teachers, and supervising EFL student teachers' research and teaching practice were also more frequently undertaken than the rest of the activities. Collaborative activities with colleagues such as peer observations, coresearch, mentoring and coaching were reported as occurring at low rates of frequency. The least frequent PLD activities were participating in a teaching club or association, and observing EFL school teachers' lessons which around $60 \%$ of the participants had never undertaken. In general, the participants reported a low engagement in most PLD activities except for independent study. Participation in formal PLD activities and individual PLD were reported as occurring more frequently than collective ones. 
A comparison between participants' responses in Table 4.3 and Table 4.4 showed that although the participants valued many aspects of PLD in theory, this was not reflected in their participation in PLD in practice. Table 4.5 displays a cross-tabulation of participants' responses to the questions in Tables 4.3 and 4.4. Their responses were presented as means (referred as importance mean and participation mean, respectively) and put together in order to explore further how often the participants actually engaged in the PLD activities they perceived as important.

Table 4.5 PLD importance vs. PLD participation

\begin{tabular}{llcc}
\hline \multicolumn{1}{c}{ PLD activities } & $\begin{array}{c}\text { Importance } \\
\text { Mean }\end{array}$ & $\begin{array}{c}\text { Participation } \\
\text { Mean }\end{array}$ & $\begin{array}{c}\text { Mean } \\
\text { differences }\end{array}$ \\
\hline Workshops, seminars, conferences & 3.3 & 2.4 & 0.9 \\
Outside workshops, seminars, conferences & 3.3 & 2.1 & 1.1 \\
Inside or outside course training courses & 3.5 & 2.3 & 1.2 \\
Participating in a teaching club or a lecturers' association & 2.6 & 1.3 & 1.3 \\
Mentoring or coaching other lecturers in your institution & 3.0 & 1.7 & 1.2 \\
$\begin{array}{l}\text { Observing other lecturers' classroom practice in your } \\
\text { institution }\end{array}$ & 3.0 & 2.0 & 1.1 \\
Co-research with other lecturers & 3.2 & 1.9 & 1.4 \\
Organising PLD programmes for EFL school teachers & 3.3 & 2.2 & 1.1 \\
Observing lessons by EFL school teachers & 3.0 & 1.5 & 1.5 \\
$\begin{array}{l}\text { Supervising EFL teacher trainees' research or teaching } \\
\text { practicum }\end{array}$ & 3.3 & 2.2 & 1.2 \\
$\begin{array}{l}\text { Formal post-graduate courses leading to a degree or } \\
\text { diploma }\end{array}$ & 3.4 & 2.0 & 1.4 \\
$\begin{array}{l}\text { Independent study by reading books, research reports, } \\
\text { journals }\end{array}$ & 3.8 & 3.2 & 0.6 \\
$\begin{array}{l}\text { Individual research } \\
\text { Committee or task force }\end{array}$ & 3.4 & 2.2 & 1.2 \\
\hline
\end{tabular}

Notes: Rating of importance: $1=$ not important, $2=$ of little importance, $3=$ important, $4=$ very important; Rating of participation: 1 = never, 2 = sometimes, 3 = often, 4 = always

As seen in Table 4.5, there were significant differences between the participants' perceptions of the importance of PLD activities and their actual experience in these 
activities. This means that while lecturers highly appreciated the roles and functions of PLD, they reported a low level of participation in these activities. The importanceparticipation mean gaps ranged between 0.6 and 1.5. The activity with the biggest mean gap between lecturers' perceptions and their participations was observing EFL school teachers' lessons, whereas the activity with the smallest value-participation gap was individual study. Research participation, either individually or collaboratively, was also reported at low rates (with the means of 2.2 and 1.9, respectively) while it was rated at a high level of importance (with the means ranging from 3.4 and 3.2). This suggests that there might be factors that influenced participants' engagement in research activities, and this needed further investigation.

The results also showed patterns in the participants' perceptions of the importance of PLD activities that were consistent with their participation in these activities. That means activities with higher values (e.g., individual and formal learning) were experienced more often than those with lower values (e.g., collaborative activities). Further investigation was necessary to explain why these participants reported lower frequencies in participating in all listed PLD activities while they gave very high values to these activities.

The participants were also asked about their experiences of particular informal and collaborative PLD activities (See Table 4.6).

Table 4.6 Lecturers' report on their participation in informal and collaborative PLD

\begin{tabular}{lcccc}
\hline How often did these practices happen in your PLD over & Never & Sometimes & Often & Always \\
\cline { 2 - 5 } & $\%$ & $\%$ & $\%$ & $\%$ \\
\hline Modify teaching based on self-evaluation & 2 & 4 & 58 & 36 \\
Modify teaching based on students' feedback & 0 & 13 & 62 & 25 \\
$\begin{array}{l}\text { Discuss teaching problems and practices with colleagues in } \\
\text { informal conversations }\end{array}$ & 0 & 34 & 53 & 13 \\
$\begin{array}{l}\text { Read research reports as one source of ideas for improving } \\
\text { practices }\end{array}$ & 0 & 36 & 51 & 11 \\
$\begin{array}{l}\text { Modify teaching based on feedback from academic leaders } \\
\text { and colleagues }\end{array}$ & 2 & 47 & 40 \\
Engage in collaborative learning with colleagues & 13 & 47 & 35 \\
Plan PLD activities with other colleagues & 9 & 55 & 30 & 6 \\
\hline
\end{tabular}


As seen in Table 4.6, participants were most likely to modify their teaching based on self-evaluation and on students' feedback. Over $90 \%$ of the participants reported either often or always engaging in these activities. Other activities such as informal conversations to discuss teaching problems with colleagues, and seeking research-oriented ideas for better practices were also undertaken quite often, but at a lower frequency. Similar to the results from the previous parts of the questionnaire, activities involving collaborative work such as planning PLD activities and engaging in collaborative learning with other colleagues were reported with the lowest frequency.

The participants were also asked about the importance of various reasons for their decisions to engage in PLD activities. Ten reasons were listed in the questionnaire and the participants were asked to rate the importance of each reason from 1 to 4 ( $1=$ not important, $2=$ of little importance, 3 = important, 4 = very important). Table 4.7 presents the participants' responses to this part of the questionnaire.

Table 4.7 The reasons to attend PLD

\begin{tabular}{|c|c|c|c|c|}
\hline I participated in PLD activities in order to / & $\begin{array}{c}\text { Not } \\
\text { important }\end{array}$ & $\begin{array}{c}\text { Of little } \\
\text { importance }\end{array}$ & Important & $\begin{array}{c}\text { Very } \\
\text { important }\end{array}$ \\
\hline & $\%$ & $\%$ & $\%$ & $\%$ \\
\hline Get new knowledge and skills related to my major & 0 & 0 & 22 & 78 \\
\hline Find solutions to improve my teaching effectiveness & 0 & 0 & 25 & 75 \\
\hline Improve students' learning outcomes & 0 & 4 & 34 & 62 \\
\hline These activities were relevant to my PLD needs & 0 & 2 & 54 & 44 \\
\hline Improve my teaching motivation & 0 & 7 & 47 & 46 \\
\hline Improve understanding of educational reforms & 0 & 11 & 54 & 35 \\
\hline Follow up previous professional learning activities & 2 & 17 & 63 & 18 \\
\hline Have opportunities to meet other colleagues & 2 & 27 & 60 & 11 \\
\hline The institution/ department required me to participate & 9 & 29 & 46 & 16 \\
\hline Gain certificates and formal qualifications & 16 & 25 & 53 & 6 \\
\hline
\end{tabular}


The results show that the most important reasons were directly related to their teaching practice, and the qualifications they needed to improve teaching and students' learning outcomes. All of the participants considered it very important or important to attend PLD that directly supported their teaching by promoting knowledge and skills and offering solutions to teaching problems. Improving students' learning outcomes was also seen as very important (62\%) or important $(34 \%)$ by the participants.

Other important reasons were seeking PLD relevant to their needs and motivation, developing understanding about educational reforms, and having follow-up PLD. These reasons were perceived as either important or very important by around $90 \%$ of the participants. The participants also considered it was important to seek PLD opportunities that followed up their previous learning $(81 \%)$, or supported their collegial network $(71 \%)$. Almost half of the participants $(41 \%)$ did not feel that engaging in PLD to gain formal qualifications/certificates was important. Similarly, $38 \%$ of the participants did not think that being required to attend PLD was a very important driver for their PLD.

Further analysis shows that there are some differences in the responses given by the participants of different age groups. Table 4.8 illustrates the means of the importance rates of the reasons given by different age groups. Generally, the youngest group, aged 20-30, showed a tendency of giving the highest values to most of the reasons, compared with the other three groups. Particularly, they gave very high rates of importance to reasons related to seeking for solutions to teaching problems, getting new knowledge and skills, improving motivation, and having PLD relevant to their needs, with the means ranging between over 3.9 and 3.6. These reasons were also considered very important to the other groups, but with lightly lower rates.

Although all groups considered gaining formal qualifications and attending PLD due to the requirements from the administrators not very important, these reasons were rated with the lowest means (1.9 and 2.1, respectively) by the participants aged 41-50. Similarly, the participants in the over 50 group gave very low values to these two reasons (with the mean of 2.5), as well as to other reasons related to having the opportunities to meet other colleagues, and to having follow-up PLD (with means of 2.0 and 2.5, respectively). 
Table 4.8 shows that younger participants had different reasons to attend PLD. They rated PLD that enhanced lecturers' formal qualifications and collegial network higher than the older participants did. It was necessary to explore further whether age and experience factors influenced their PLD perceptions and engagement.

Table 4.8 Reasons to attend PLD reported by different age groups

\begin{tabular}{|c|c|c|c|c|c|c|c|c|c|c|}
\hline \multirow{3}{*}{ Reasons to attend PLD } & \multicolumn{8}{|c|}{ Age groups } & & \\
\hline & \multicolumn{2}{|c|}{$20-30$} & \multicolumn{2}{|c|}{$31-40$} & \multicolumn{2}{|c|}{$41-50$} & \multicolumn{2}{|c|}{$>50$} & \multicolumn{2}{|c|}{ Total } \\
\hline & Mean & $\mathrm{N}$ & Mean & $\mathrm{N}$ & Mean & $\mathrm{N}$ & Mean & $\mathrm{N}$ & Mean & $\mathrm{N}$ \\
\hline $\begin{array}{l}\text { Gain certificates and } \\
\text { formal qualifications }\end{array}$ & 2.58 & 12 & 2.61 & 31 & 1.90 & 10 & 2.50 & 2 & 2.47 & 55 \\
\hline $\begin{array}{l}\text { Improve my teaching } \\
\text { motivation }\end{array}$ & 3.67 & 12 & 3.29 & 31 & 3.30 & 10 & 3.50 & 2 & 3.38 & 55 \\
\hline $\begin{array}{l}\text { Get new knowledge and } \\
\text { skills related to my major }\end{array}$ & 3.83 & 12 & 3.77 & 31 & 3.80 & 10 & 3.50 & 2 & 3.78 & 55 \\
\hline $\begin{array}{l}\text { Find solutions to improve } \\
\text { my teaching effectiveness }\end{array}$ & 3.92 & 12 & 3.71 & 31 & 3.70 & 10 & 3.50 & 2 & 3.75 & 55 \\
\hline $\begin{array}{l}\text { Have opportunities to meet } \\
\text { other colleagues }\end{array}$ & 2.67 & 12 & 2.94 & 31 & 2.70 & 10 & 2.00 & 2 & 2.80 & 55 \\
\hline $\begin{array}{l}\text { Follow up previous } \\
\text { professional learning } \\
\text { activities }\end{array}$ & 3.17 & 12 & 2.93 & 30 & 3.00 & 10 & 2.50 & 2 & 2.98 & 54 \\
\hline $\begin{array}{l}\text { Improve understanding of } \\
\text { educational reforms }\end{array}$ & 3.42 & 12 & 3.19 & 31 & 3.20 & 10 & 3.00 & 2 & 3.24 & 55 \\
\hline $\begin{array}{l}\text { Improve students' learning } \\
\text { outcomes }\end{array}$ & 3.58 & 12 & 3.52 & 31 & 3.90 & 10 & 3.00 & 2 & 3.58 & 55 \\
\hline $\begin{array}{l}\text { These activities were } \\
\text { relevant to my PLD needs }\end{array}$ & 3.67 & 12 & 3.32 & 31 & 3.50 & 10 & 3.00 & 2 & 3.42 & 55 \\
\hline $\begin{array}{l}\text { The institution/faculty/ } \\
\text { department required me to } \\
\text { participate }\end{array}$ & 2.33 & 12 & 3.03 & 31 & 2.10 & 10 & 2.50 & 2 & 2.69 & 55 \\
\hline
\end{tabular}

Other cross-tabulations were conducted in order to see if other personal factors such as the participants' genders, qualifications, and years of experiences influenced their perceptions and experiences of PLD. However, these analyses did not reveal significant differences in the responses given by the participants of different groups. Due to the small sample of questionnaire participants $(\mathrm{N}=55)$ and the dominant qualitative nature of the 
study, the influences of these demographic factors on individuals' perceptions and experiences of PLD were not focused. However, this is an area for further exploration in the qualitative stage.

\section{Barriers to their reform implementation}

The first part of this section describes the participants' reports of their experience of educational reforms over the previous two years (2011-2012). This was an open-ended question in the questionnaire and the participants were asked to list the reforms they had implemented.

The most commonly reported reforms were the ones related to pedagogical aspects (e.g., applying a new teaching method and changes in learning assessment) and those aimed at improving students' independent learning skills and activeness in their own learning. Only a few lecturers mentioned reforms at institutional or national levels such as teaching according to the credit training system, or enacting the language education reform project directed by MOET (2008-2020).

The following were recurring responses from the participants when listing educational reforms they had implemented:

- Applying new teaching methods: student-centredness, task-based learning, project-based learning

- Changing assessment methods: combining formative assessment and summative assessment

- $\quad$ Using IT and teaching facilities: applying blended learning methods, using open learning software in teaching

- Varying classroom activities, using pair/group work, music and games to improve students' motivation and participation

- $\quad$ Updating teaching materials and syllabi

- $\quad$ Promoting students' ability to self-regulate and develop autonomy

It was interesting to find that lecturers mainly mentioned reforms related to their teaching methods and classroom-based practices even though the government had 
emphasised several reforms at the general and systemic level (e.g., quality assurance and accreditation, upgrading human resources in HE, the foreign language education reform project). It is not clear why there was such a different interpretation of the notion of 'reforms' from these two perspectives, and how this variation may have affected lecturers' PLD as well as their implementation of top-down initiatives in their institutions.

The participants reported barriers to their implementation of educational reforms over the past two years. The percentages of participants who answered 'yes' to the given barriers are presented in Figure 4.2.

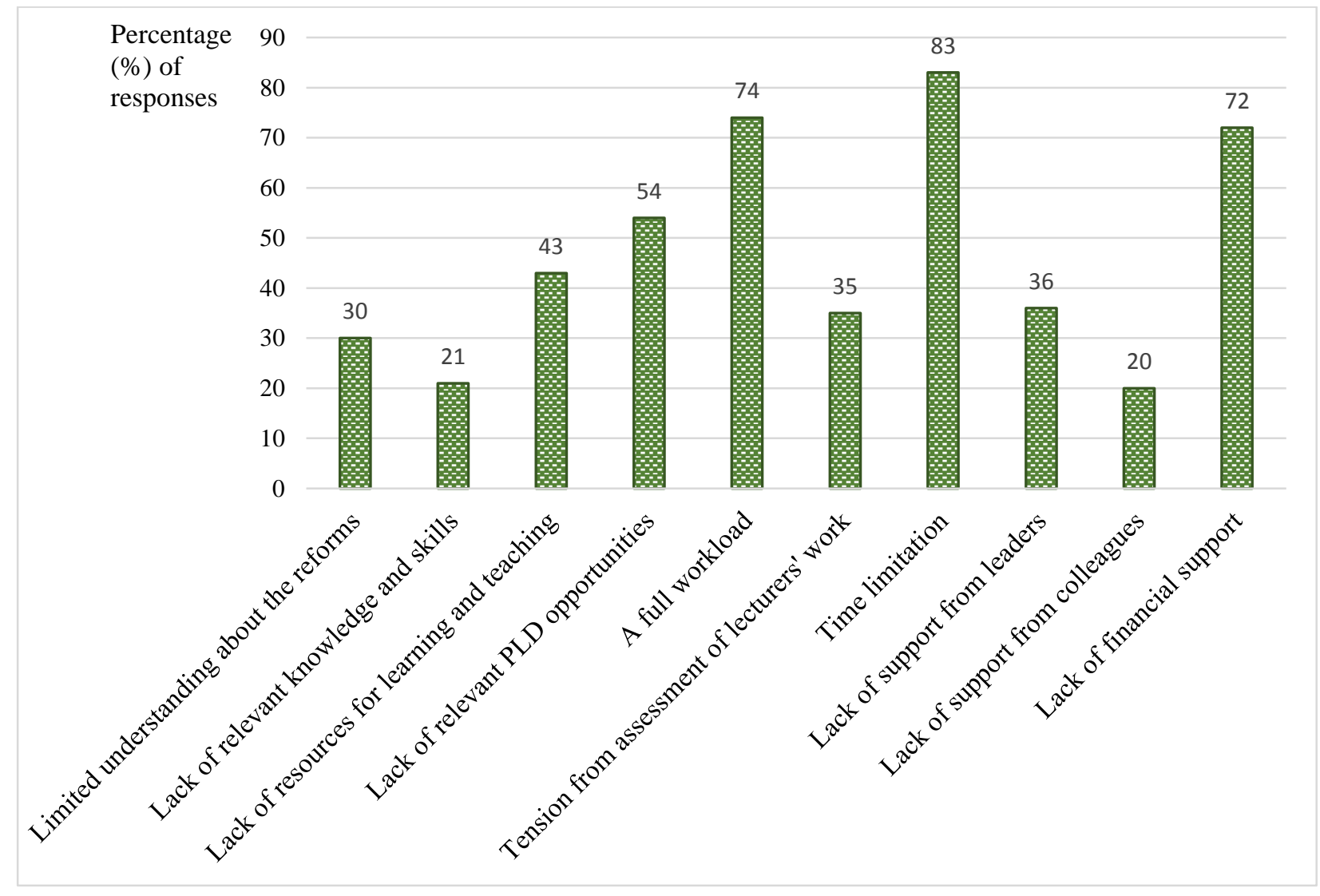

Figure 4.2 Reported barriers to implementing reforms

The findings show that the biggest reported barriers included time limitation, a full workload, and lack of financial support. These barriers were experienced by $83 \%, 74 \%$, and $72 \%$ of the participants, respectively. Over half of the participants (54\%) reported having limited opportunities for relevant PLD, and 43\% cited a shortage of learning and teaching resources as obstacles to their reform implementation. About one-third reported 
facing tensions from the assessment of lecturers' work and from lack of leaders' support. Barriers from lack of collegial support, limited knowledge and skills, and poor understanding of reforms were reported by the smallest numbers of lecturers (ranging between $20 \%$ and $30 \%$ ).

The lecturers experienced more obstacles from external conditions than from subjective or internal factors. These results might be explained by the challenges from the participants' working contexts which required them to balance fulfilling their working responsibilities and PLD engagement. Contextual factors might have affected their participation in PLD and the types of PLD that were offered or accessed over the previous two years.

\section{Lecturers' PLD needs and expectations}

The final question in the questionnaire was open-ended and asked the participants to express their PLD needs and preferences. The participants' responses show that the most desired forms of PLD, for both lecturers and academic leaders, were seminars, workshops, and short courses or training programmes, with a focus on teaching methods. There was a particularly strong desire to have opportunities to attend PLD events such as workshops, short courses, and learning trips in English-speaking countries. Over half of the participants suggested having seminars within the department and having more opportunities to share experience and teaching materials among lecturers of the same courses. Only ten lecturers referred to PLD programmes that promoted collaboration between university lecturers and school teachers.

\section{Summary of questionnaire findings}

The findings from the analysis of the questionnaire data indicate that the participants held positive perceptions of the roles and functions of PLD. They gave the highest values to the roles directly related to improving their teaching and qualifications, especially updating knowledge and skills, and improving students' outcomes. In terms of the perceptions of PLD activities, individual learning activities such as independent study and individual research were given higher values than collaborative activities. Formal PLD activities also received higher ratings than informal ones. 
There were significant differences between how important the participants' perceived PLD activities to be and whether they took part in these activities. While the participants rated the importance of PLD roles and functions highly, they reported a much lower level of participation in these activities, except for independent study. It appears that formal PLD activities and individual PLD were accessed more frequently than collective forms of PLD. In terms of informal PLD, the participants reported that they were most likely to modify their teaching in response to self-evaluation and on students' feedback.

There was a link between the perceived importance of a PLD role and the reasons why the participants decided to undertake PLD. Their priority was improving their teaching practice, and gaining qualifications to improve their own teaching and students' learning outcomes. The participants reported that they had mainly implemented reforms related to pedagogical changes focusing on improving students' learning and autonomy. The most commonly reported barriers to the participants' implementation of reforms included time limitation, a full workload, and lack of financial support. Most participants wished to be provided with more formal PLD such as seminars, workshops, and short courses or training programmes, especially those with a focus on teaching methods. Most of them expressed a strong desire to attend PLD overseas, especially in English-speaking countries.

There are slight differences in the responses given by participants holding different positions in their institutions (Figure 4.1), or participants of different age groups (Table 4.8) regarding some PLD issues. However, the questionnaire findings did not clearly reveal the influences of other individual factors such as gender, qualifications, and experiences on the participants' PLD perceptions and engagement as well as their ability to implement educational reforms. These variations would be explored in the qualitative stage. The analysis of the questionnaire data raised some issues that were further investigated in individual interviews with selected participants and during PLD observations.

\section{Findings from document analysis}

Key criteria were identified for selecting documents to be reviewed. First, they were documents issued by the government or the universities over the past ten years, and still current. National documents were issued by Vietnamese government or by MOET in the 
form of reports, decisions, regulations, directives, or legal documents. Institutional documents were issued within the research universities, at the institutional, faculty, or departmental levels.

The first group of documents centres around general government policies related to lecturers' professional standards, professional responsibilities, and professional duties. The second group of documents represents national educational reforms and the government's directions and strategies for lecturers' PLD to support reform implementation. These documents were selected for the review because they revealed the current contexts of tertiary education and lecturers' professional activities as well as variations around PLD for lecturers. Other documents reviewed included those identified by the participants in their interview responses (e.g., educational reforms, university mission and vision, strategic plans, regulations about lecturers' assessment, and research policies) where available. This supported the clarification, verification, and triangulation of information provided by the interview participants.

The document analysis informs understanding of whether required standards and responsibilities assigned for lecturers and the government's initiatives in tertiary education had an impact on institutional plans and policies for lecturers' PLD. The document review also supports the analysis in Chapter 5 of the effect of government policies relating to language education and HE reforms on the ways lecturers plan and practise their own PLD.

This section focuses on key issues highlighted from the analysis of national policy documents, and specific institutional documents are presented for each of the studied sites. The analysis outlined three areas: (1) general espoused policies related to lecturers' standards, professional responsibilities, and professional rights, (2) reform initiatives and PLD supporting reform implementation, and (3) cultural perspectives on lecturers' professional roles and status.

\section{General espoused professional policies for lecturers}

General criteria for recruitment and standards for lecturers were clearly stated in the Education Law (Vietnamese Assembly, 2005), and elaborated later in the University Charter (Vietnamese Prime Minister, 2010), and the Higher Education Law (Vietnamese 
Assembly, 2012). As stated in the University Charter, the required criteria to become a lecturer at university include: (1) having good character, morality, and ideology; (2) meeting the required formal qualifications of possessing at least a BA degree and a certificate of educational pedagogical skills, possessing at least an MA degree to teach theoretical courses of university programmes, and possessing a PhD degree to teach the courses as well as to supervise research and theses in Master and Doctoral programmes; (3) having sufficient IT and foreign language skills for work requirements; (4) being in good health; and (5) having a clean background ${ }^{6}$. The document states that from the year 20142015 universities must ensure that their lecturers meet the above minimum standards. The Higher Education Law stipulates that the standard qualification (trìn độ chuẩn) for lecturers teaching university programmes should be a Master degree or higher.

Lecturers' professional responsibilities are also identified in the above policy documents, and particularly specified in MOET's regulations of lecturers' work (MOET, 2008). This document aims at providing guidelines for institutional policies and regulations on PLD and on lecturers' required working hours and qualifications. The document also directs academic leaders to plan PLD for lecturers and assess lecturers' academic performance. Being informed about these policies assists lecturers' in fulfilling their duties and planning their own PLD.

The analysis of the documents (e.g., Education Law; the University Charter, and MOET's regulations of lecturers' work) highlighted an expectation that lecturers actively engage in research alongside teaching responsibilities. The documents suggest that the focus of lecturers' research should support curriculum design, material design and teaching resources, innovations in teaching methods, testing and assessment at departmental and institutional levels. Lecturers are required to complete their assigned research hours, publish research findings in scientific journals in Vietnam and overseas, or present their research in national or international conferences and workshops. Annually, each lecturer is required to publish their research results, at least in the form of an article reviewed and published in a scientific journal, or an approved research project at the institutional level. Other research activities may include organising and participating in workshops and

\footnotetext{
${ }^{6} \mathrm{~A} \mathrm{CV}$ indicating no criminal convictions and no behaviours / thoughts against the government policies
} 
seminars within the faculty and department, and supervising students' research. Lecturers' responsibilities for engaging in managing training and research activities in their institutions are also presented in the documents.

Participating in PLD is another duty stipulated for lecturers. Common terms used in the documents to refer to the concept of PLD include: học tập và bồi duỡng để nâng cao trình độ (learning and developing to upgrade qualifications), đào tạo và bồi duỡng giảng viên (training and developing lecturers), and phát triển giảng viên (developing lecturers).

All three documents (Education Law, University Charter, and MOET's regulations of lecturers' work) identify in some way that the purposes of professional learning are to upgrade the standard of qualifications required for lecturers, and to upgrade lecturers' professional skills. The documents also require lecturers to undertake continuous learning to upgrade their general and professional knowledge, political reasoning, foreign language proficiency, and IT skills.

Learning and development are also duties of academic leaders. The documents state that educational leaders also have to study continuously and develop expertise, leadership ability, good character and responsibility. However, the documents do not differentiate among the forms of continuous learning lecturers and academic leaders need to undertake.

In addition to professional duties, lecturers' rights are described in the reviewed documents. The University Charter describes lecturers' rights in terms of teaching, research, PLD and other academic activities. Lecturers are allowed to teach and participate in research activities which are relevant to their trained specialisations. They are ensured access to facilities, technology and other services at the university to support their teaching, research, learning and professional development. Lecturers have a right to select resources, methods and facilities in order to enhance personal capacity and ensure the quality of their training, research and technological activities.

In terms of variations of PLD, it is explicitly stated that lecturers are entitled to attend relevant PLD such as training, workshops, and conferences for upgrading their knowledge, skills and qualifications. For example, the Education Law (Vietnamese Assembly, 2005) states that lecturers have the right to "be trained to upgrade their qualification" (đươc đào 
tạo để nâng cao trình độ), and to "be developed" (được bồi duỡng) in the areas of specialisation and pedagogy (p. 24). The document states that the government has policies to support lecturers and help them attain the required standards. Lecturers who are approved to study for a higher degree, or to develop in a specialisation or pedagogical skills, will still receive salaries and financial support according to relevant government policies. These descriptions reveal a strong focus on providing formal PLD for lecturers, and a view of PLD as gaining credentials.

Similarly, the University Charter states that lecturers can expect to "be trained and developed to upgrade expertise" (Vietnamese Prime Minister, 2010, p. 9). The document also supports lecturers to travel overseas for collaborative teaching, collaborative research, and academic exchange programmes as well as to attend workshops, and conferences in Vietnam and overseas. Other PLD forms which are less formal (e.g., collaborative teaching and learning activities within the faculty and the department, self-regulated learning) are not mentioned in the reviewed documents.

According the University Charter, universities and administrators are responsible for supporting lecturers' PLD rights. The common direction is to construct a strategic plan at different administrative levels for developing the teaching staff. For example, the faculty is required to build strategic plans to develop the teaching and research of staff as well as to organise activities for training and professional development to improve lecturers' expertise and professional skills. At a lower level, besides being responsible for implementing and managing academic activities, each department also has to plan for lecturer development.

\section{Reform initiatives and PLD supporting reform implementation}

Over the past decade the government and MOET have issued various educational reforms and directions to implement the reforms. The common objective of reforms is to boost $\mathrm{HE}$ quality in Vietnam, and to improve its competitive capacity in the Asian region as well as its position in the world. The HERA also emphasises the aim of improving student outcomes in terms of developing their potential for creative research, professional skills and competence, and working ability in the community. 
There has also been a call for innovation in the field of Teacher Education (TE), particularly stated in MOET's plan for developing TE programmes and TE institutions over the period of 2011-2020 (MOET, 2011). The plan aims to strengthen the capacity of TE faculties or institutions and make them a creative centre for innovation in TE throughout the country. To sum up, the reform documents highlight the role of HE lecturers and managers in reform implementation as well as the role of TE institutions in preparing and improving a teaching and management staff who will be capable of undertaking educational reforms in the school sector. There has been a call from MOET for innovations in the TE programmes and pedagogical approaches at an institutional level. Reform objectives centre on improving HE quality in general and students' outcomes particularly in terms of professional competence, self-regulated learning and research skills, and moral qualifications.

Reform documents raise the importance of developing human resources in $\mathrm{HE}$ in order to boost educational quality. The government' general aim is to develop sufficient HE staff with the quality and ability to implement reforms (MOET, 2011; Vietnamese Prime Minister, 2012). Specific plans are suggested to help achieve the aims for staff development. A key strategy for staff development involves lecturers studying towards an $\mathrm{MA}$ and $\mathrm{PhD}$ qualification either in Vietnam or in foreign countries. Table 4.9 presents the targets for university lecturers' expected qualifications by 2020 presented in various documents, with targets to ensure staff are qualified to doctoral level.

The reform documents are underpinned by the assumption that upgrading lecturers' degrees will result in upgrading lecturers' quality, and that teaching staff holding $\mathrm{PhD}$ degrees will help to improve educational quality and support the implementation of educational reforms. 
Table 4.9 Identified qualification targets for HE staff

\begin{tabular}{|c|c|c|c|c|}
\hline \multirow{3}{*}{ Policy documents } & \multicolumn{4}{|c|}{ Targets for staff development } \\
\hline & \multicolumn{2}{|c|}{ Ву 2015} & \multicolumn{2}{|c|}{ By 2020} \\
\hline & MA & $\mathrm{PhD}$ & MA & $\mathrm{PhD}$ \\
\hline $\begin{array}{l}\text { The basic and comprehensive reform in HE in } \\
\text { Vietnam, 2006-2020 (HERA) }\end{array}$ & & & $60 \%$ & $35 \%$ \\
\hline $\begin{array}{l}\text { Strategic plan for education development, } \\
2011-2020\end{array}$ & & & $100 \%$ & $25 \%$ \\
\hline $\begin{array}{l}\text { Project of training doctoral lecturers for } \\
\text { colleges and universities, 2010-2020 }\end{array}$ & & & & $\begin{array}{c}\text { at least } \\
20,000 \\
\text { more }\end{array}$ \\
\hline $\begin{array}{l}\text { Plan for developing the Teacher Education } \\
\text { programme and Teacher Education } \\
\text { institutions, 2011-2020 }\end{array}$ & $100 \%$ & $20 \%$ & $100 \%$ & $45 \%$ \\
\hline
\end{tabular}

There is also a focus on improving PLD for lecturers and educational managers in HE. For instance, HERA highlights the necessity of

Renewing strongly the content, programme and methods of training and developing lecturers and educational managers in $\mathrm{HE}$, focusing on upgrading expertise levels and pedagogical skills of lecturers, as well as the strategic visions, creative competence, and professionalism of managers.

Vietnamese MOET also suggests innovations in PLD programmes for lecturers in TE, with an emphasis on a combination of lecturer development and research activities, making research a criterion for developing and accessing lecturers' research ability (MOET, 2011).

Opportunities for PLD includes providing lecturers opportunities to attend seminars and workshops in Vietnam and overseas in order that they can share advanced knowledge and scientific innovations internationally (MOET, 2011). The government encourages high-quality collaborative training programmes for lecturers, as well as programmes for exchanging lecturers and experts with foreign institutions. However, PLD strategies, especially informal PLD forms such as lecturers' independent learning, or collaborative learning activities among lecturers, are not specified in the reviewed documents. 
In addition to strategies related to lecturers' formal qualifications, other strategies for improving lecturers' quality are provided, with a great focus on managing and assessing lecturers' teaching and research. The documents raise the need for policies about research duties and required research outcomes for lecturers holding different professional titles, and suggest a strict application of MOET regulations to lecturers' work (MOET, 2011; Vietnamese government, 2005). For example, MOET's plan for developing teacher education emphasises the importance of enhancing leadership and administration innovations. A strategy for this is

Identifying criteria and methods for assessing lecturers and managers of TE institutions in order to improve their sense of responsibility, teaching quality, and management effectiveness (MOET, 2011, p. 8).

There is a strong focus on strategies for upgrading lecturers' formal qualification across various documents, revealing a belief that upgrading lecturers' degrees will result in improving their teaching capability. Besides upgrading degrees, other aspects of expected lecturers' quality involve improved research ability, advanced professional knowledge and pedagogical skills, and good professional ethics (e.g., sense of responsibility, and morality). The documents also express a focus on providing innovative content in the PLD for lecturers, particularly by linking PLD to research, to ensure the quality of staff development. The documents suggest issuing policies related to managing and accessing lecturers and managers, as well as making research a criterion for staff assessment and development.

\section{Cultural perspectives on lecturers' professional roles and status}

The document analysis provided insights into the cultural values underpinning the professional status and professional roles of Vietnamese teacher educators. For example, the Education Law (Vietnamese Assembly, 2005) highlights that "The teaching staff have a decisive role in ensuring educational quality" (p. 5). The document also acknowledges the honour of the teaching profession when stating that the government needs policies to support lecturers to fulfil their roles, and to "maintain and develop the tradition of respecting the teaching staff and honouring the teaching profession" (p. 5). 
Lecturers have a professional responsibility to adhere to ethical and moral standards in addition to their academic responsibilities. Indeed, the documents (e.g., Tertiary Education Law, University Charter) outline specific academic duties for lecturers. Lecturers have to "maintain good character, prestige, and honour" as well as "respect students, treat students fairly, and protect students' reasonable rights and benefits" (Vietnamese Assembly, 2012, p. 28).

Consistently, reforms aim to improve lecturers' academic competence (e.g., having $\mathrm{PhD}$ degrees, improving knowledge, professional skills, and research ability) at the same time as improving their professional ethics. For example, the HERA (Vietnamese government, 2005) plans to develop teaching and managerial staff with "high expertise, advanced teaching and managing methods, moral qualifications and professional conscience (lưong tâm nghề nghiệp)" (p. 3).

There is an expectation that lecturers study continuously to improve themselves as well as to provide role models for students. Furthermore, lecturers' roles extend beyond teaching and academic aspects. Indeed, lecturers are expected to "contribute to the education of politics, morality, and ideology for students" (MOET, 2008, p. 3). In the field of TE, it is stated that the reformed TE programme will develop well-rounded students with both academic competence and moral values. The programme places an emphasis on "nurturing good character, morality, lifestyle, and professional ethics" for teacher trainees (MOET, 2011, p. 6).

The document review shows that the teaching profession and the role of teacher educators in education are highly respected by Vietnamese tradition. Lecturers are expected both to fulfil academic responsibilities and maintain moral standards as well as to be good role models for students. Some aspects of lecturers' professional identity such as professional status and professional ethics were identified across the documents. Professional identity was not a major theme in the document review; nonetheless, the cultural values expected of Vietnamese teacher educators and cultural expectations of teacher education were strong themes arising from the document analysis. 


\section{Case study findings}

The previous section captured the HE context and policies related to teacher educators' professional work and PLD as promoted in policy. This section examines how the educators in the three selected universities perceived and reported on their PLD experience in practice. As presented in Chapter 3, data from PLD observations and institutional document analysis were used to justify and triangulate findings from interviews rather than being analysed separately to generate their own themes or findings. An analysis of interview data, integrated with data from PLD observations and relevant institutional policy documents identified three key clusters of findings: the effects of PLD experience on individuals; the factors influencing PLD engagement; and the complexity of PLD experiences. While many participants shared similar experiences of PLD, their perceptions and reactions to the experiences were affected by different contextual and cultural factors at each site. In this section, the first two areas of the findings will be presented site by site to highlight individual reactions to PLD opportunities, as well as the social, cultural and contextual factors that impacted on the educators' PLD engagement at each site. Findings and analysis of the complexity of PLD experiences across the three sites will be presented in the next chapter to illustrate a holistic view of lecturers' PLD experiences in tertiary education in Vietnam.

\section{University site A}

As mentioned in Chapter 3, the study involved three university sites ${ }^{7}$ in the Mekong Delta of Vietnam. University site A is a traditional, regional university which was appointed by the MOET as a key university in the country. Site A has higher capacity and more resources than the other two sites. This section focuses on site A participants' reported changes as a result of their PLD engagement. These changes will be presented under two categories identified from the analysis of interview data and relevant institutional policy documents: professional knowledge and pedagogical practices, and professional identity.

\footnotetext{
${ }^{7}$ Demographic details about these universities are not provided for the purpose of protecting institutional and individual identities.
} 


\section{Professional knowledge and pedagogical practices}

All of the ten interviewed participants at site A perceived that a key role and function of PLD was to improve their knowledge and skills. This was associated with a perception of lecturers as experts in their specialisation:

As lecturers, we need to update our knowledge and teaching skills. We must be experts in our fields, and even for experts, learning is never complete. Besides experience we accumulate from teaching, we need to understand new trends in teaching. A.L2

The participants especially valued PLD that improved their understanding about government educational reforms, and developed their content knowledge and pedagogical skills to enact the reform. For example, a lecturer, A.L5, said that the training related to the language education reform and the implementation of the reform helped her to "understand more about the direction of EFL teacher education". Five lecturers in site A who were selected to attend this MOET training course valued both theoretical knowledge and practical experience in a new teaching field.

I learned about theories related to child psychology, various activities and techniques for teaching children, and understood the differences between teaching children and adults. A.L1

These lecturers also reflected on applying learned knowledge and skills in pedagogical practice. For example, A.L1 reported a positive effect of the MOET training course in her teaching. She explained that she paid more attention to psychological factors of young learners and applied various activities she learned from the course in her teaching, which increased the learners' motivation and her teaching effectiveness. Similarly, A.L4 confirmed positive changes in her classroom practices when she applied new ideas learned from the course.

I could apply what I learned in teaching. What I learned from the course changed the way I taught and made my classes more interesting. If I had not attended the course, my lessons would have been boring and I could not have explored the lessons in a meaningful way. A.L1. 
I learned a lot about effective ways to teach children. I learned from micro teaching and feedback. I could improve my lesson planning. Now when I teach, I always remember to apply the principles of varying classroom activities and use many games in my classes to increase students' concentration. A.L4

Lecturers also reported making pedagogical changes after attending external conferences or workshops. One lecturer, for example, reported improving her teaching when applying new ideas learned from an international conference on TESOL:

I attended sessions about methods for teaching listening and speaking which is my interest, and ways to teach English to children using puppets, songs and game-shows. I learned about these from the presenters. When I applied these methods in teaching my university students, it was very successful. A.L5

Lecturers' effort and flexibility to apply and adapt what they had learned into new working contexts was evident when they had to switch to a different teaching role. The lecturers believed that their learning from PLD and the ensuing pedagogical practices helped to enhance teaching effectiveness and students' learning. For example, A.L5, who had a role in running the English Speaking Club (ESC) valued this experience:

Regular attendance at the ESC had a great effect on my teaching. First, I liked sharing experience with the other members while discussing the club activities, and I could apply this experience in my teaching a lot. Second, I learned the skills to run the club such as how to instruct others, how to speak in public. My classes were effective when I applied these skills. A.L5

The participants also reported learning many other things when attending formal PLD events. Some enjoyed informal learning through conversations with colleagues from other universities during break time. Others valued the skills developed while working as facilitators of PLD projects designed for in-service teachers and lecturers in local areas.

I benefited a lot from the project. I learned how to write a proposal and manage the project, and have an overview of the project. I also learned important skills such as communicating and organising the activities. A.L1 
While six participants mentioned the role of PLD in improving understandings of their specialisation, two participants valued knowledge of broader areas beyond TESOL such as education in general, and economics. They believed that this kind of general knowledge would support their thinking about education and their teaching practices. A lecturer with a leadership role described his interest in learning about other disciplines:

I read broadly about different fields in order to improve my point of view and to have a new view and understanding of an issue. For example, I read not only about education but also other fields such as economics in order to find appropriate theories which can be applied in educational policy planning. After reading, I can speak and discuss about an issue and have a different view of education. A.AL2

The participants reported that attending PLD also changed their thinking about professional activities. For example, a leader indicated that his understanding of action research changed after he attended an educational project which aimed to develop lecturers' research and publications. He learned that it was necessary to do action research on a small and specific aspect of his regular teaching practices rather than focusing on something general but not practical.

Individual lecturers (A.L5, A.L2, and A.L3) varied in the ways they applied new teaching ideas learned from PLD sessions into their real-life teaching contexts. Some faced more challenges than others due to what they described as the low level of students' English proficiency and large class size. However, these lecturers seemed to go through a similar process of applying new ideas selectively (e.g., just in classes of English major students because these students had higher motivation in learning), adapting the ideas to suit available resources in their own institution (e.g., using alternative software supported by the university), observing outcomes and using students' feedback and collegial discussions (with another lecturer of the same course), to inform self-assessment and adapting their practices after each course.

\section{Professional identity}

In this study professional identity was defined as how the lecturers construct and understand their professional self, with particular attention to their professional and pedagogical commitments (Hiver, 2013). Although the participants did not explicitly use the term 
'professional identity', this concept was revealed from their reported changes in professional confidence, motivation, and sense of self through PLD activities. The term 'teacher's image' (hình ảnh của ngườ thầy) was used frequently when participants expressed their beliefs in what made an effective teacher educator.

The participants perceived a strong connection between improving expertise as a result of PLD and their self-image and professional confidence. That was why they emphasised the importance of gaining more specialised knowledge.

We have to identify what kind of knowledge we need to improve for our specialisation and teaching. Having more knowledge about something will make us more confident in teaching about it. A.L6

Five participants reported that attending formal PLD events built up their selfconfidence and affirmed their choice of profession. For example, A.L4 felt that she became more confident in her teaching ability after attending a training course.

Before the course I was not sure if I was suited to teach children or not, but after attending it, I am confident that I am able to teach children. A.L4

Being selected to attend important formal PLD events (e.g., a MOET training course or overseas conferences) enhanced the participants' professional pride and self-efficacy. One leader, A.AL2, reported that when being invited to be a facilitator for an international workshop, he "felt nervous but very proud". A young lecturer also expressed her pride:

I felt very happy, excited, and proud to be a representative of my university to attend this training course. At first I felt nervous about working with more experienced participants, but later on I became more relaxed and confident. A.L4.

The lecturers reported that they practised hard to enhance teaching effectiveness and develop self-confidence when delivering PLD for in-service teachers. This appeared to be more challenging for young and early-career lecturers who perceived the need to improve their teaching experience and skills.

I had to learn from experienced teachers how to teach at primary schools. Then I learned from the textbooks we received from the training course. Before teaching these 
classes, I had applied what I learned about teaching children into my classes of university students. I also taught children at a foreign language centre. Therefore, I have acquired experience in teaching children. After being able to apply these methods in my previous teaching, I felt more confident about presenting these methods to inservice teachers. A.L5

Lecturers also reported that attending PLD sessions enhanced their commitment to teaching and research.

After attending these workshops and training courses, I had a lot of motivation for selfdevelopment, and I loved research more. A.L4

There was consistence between findings from both institutional policy analysis and interviews that in addition to maintaining their academic performance, lecturers were required to adhere to professional ethics and moral standards. For example, institutional polices emphasised lecturers' responsibility to fulfil their teaching assignments and facilitate their students' learning. The regulations about morality standards for the staff, required lecturers to

- Be role models of personality, independent learning and creativity for students

- Undertake lifelong learning and demonstrate effort in learning and working

- Follow the university directions for studying higher to upgrade their qualifications

(University A - Document about lecturers' qualifications and responsibilities ${ }^{8}$ )

The interview responses showed that the participants were aware of these requirements and expectations, particularly for independent learning. Two leaders (A.AL2 and A.AL3) considered teacher educators as both leaders and role models in the classroom. This was consistent with questionnaire choices that showed leaders rated the role of PLD in enhancing leadership highly, possibly because they thought of leadership as inherent in

\footnotetext{
${ }^{8}$ For the purpose of protecting the university's identity, the title and official number of the reviewed documents were not presented. Instead, the documents were grouped according to their general objectives.
} 
lecturers' classroom practices. These leaders also raised the importance of lecturers furthering their qualifications in order to inspire students to learn.

A lecturer is seen as the leader in the classroom, and students are followers. In an educational environment, it is good to apply transformational leadership which means inspiring people rather than imposing on them. If we want students to learn we have to create a model by being punctual, giving practical activities, and speaking persuasively. The model of a lecturer will motivate students in learning and lifelong learning. They will follow their lecturers' models not only during university but also after their graduation. A.AL2

One of the leaders, however, commented that some lecturers did not practise independent learning, critical thinking, and problem-solving skills. This raised a dilemma for lecturers.

Some lecturers do not meet the standards of a teacher educator (thầy). They are acting as craft-workers $\left(t h o^{\prime}\right)$ rather than teacher educators (thầy). They cannot be a model for their students because of their limited thinking and point of view. A.AL3

While the above leader found limitations in lecturers' capability as teacher educators, the lecturers expressed their awareness of being good role models for students and considered this their professional duty. This awareness influenced their teaching and behaviours as well as reinforcing their motivation for further learning and selfimprovement. The participants believed that teacher educators and teachers in general have a profound effect on subsequent generations of students. Therefore, it was important for teacher educators to be good role models, as well as preparing pre-service teachers to gain qualifications. For instance, A.L2 considered it important for lecturers to develop life-long learning themselves before fostering this learning habit in students.

PLD helps lecturers develop a habit of independent learning and life-long learning. Only when lecturers have such learning can they share their experience with students, direct and encourage students to follow them. Especially for students in Education, this is useful not only for themselves but also for their pupils because they can transfer this ability to many generations of pupils. A.L2 
Another lecturer shared this view, and emphasised the importance of developing preservice teachers' learning behaviour and awareness of their future profession.

We need to remind students of their future role: being teachers who influence many generations of pupils. Therefore, they need to study harder. A small group of teachers cannot create changes. If all teachers are devoted to the profession, they will inspire their pupils. A.L4

Besides a sense of responsibility, the participants referred to ethics of care as they reflected on their teaching practices. Ethics of care refers to the participants' perception that an important feature of their teaching profession was caring for their students and supporting students in both personal and academic aspects. For example, a young lecturer ${ }^{9}$ reported that by caring about students' learning needs, strengths and weaknesses, she could motivate students in learning and development.

I found opportunities to have informal conversations with students and ask about their problems. This increased their learning motivation because they knew that I cared about them. I let them know my ideas about their strengths and weaknesses, and encouraged them to find ways to overcome their problems. A.L4

The participants also expressed an empathy with in-service teachers' learning problems, and a concern about the effect of the language reform on in-service teachers.

I tried to encourage the teachers to learn. Although the language reform project is good, implementing it is similar to giving teachers 'a good-health medicine' ${ }^{10}$ just for a short time. This will not have a long-lasting effect because when they return to their local schools and provinces, they will not have sufficient resources to apply what they have learned. A.L5

\footnotetext{
${ }^{9}$ In this study, 'young lecturers' refers to those who are at the 21-30 age group, and usually at their earlycareer stage (1-5 years of experience)

${ }^{10}$ Thuốc bố, refers to medicine for general good health (e.g. multivitamins), implying that PLD is a way of nurturing teachers/lecturers' professional capability
} 
Such reactions to their learners' needs motivated these participants to find ways to support their students' learning. The lecturers felt that PLD such as collegial discussions and research equipped them to respond to these problems.

If the in-service teachers cannot apply what they have learned in their local schools, we feel very concerned about this. Therefore, we are thinking about a research project to recommend the ways to maintain long-term effects of the reform project. A.L5

Engaging in PLD was reported to impact lecturers' sense of commitment and desire to make a better contribution to their institution or society in general. This perception was revealed by two young lecturers who expressed a very positive attitude toward PLD during the interviews. One of them, for instance, thought that it was a privilege for lecturers to be selected and funded by the university or MOET to attend training courses or further studying programmes. Therefore, these lecturers had to improve their professional ability and contribute to the development of their university in return for the support they received.

Lecturers have to do something after they finish the courses they are assigned to attend. First and foremost, they have to be more capable in their specialisation and able to apply what they have learned. Before thinking about contributing to the department and the faculty, they must improve their specialisation. A.L1

Another junior lecturer reported her desire to make a better contribution to the university, prompted after attending an international workshop.

The workshop motivated me a lot because I was impressed by many things other people did. I felt myself too small [insignificant]. They were just lecturers like me, but they could do research to contribute to their institutions and their community. This made me think that I should set aside time for doing research to find new things to support my colleagues and university. A.L4

This lecturer also justified her desire for further studying and pursuing her professional aspirations. Her sense of devotion and commitment to the teaching profession emerged clearly in the following response:

My viewpoint is that before I die, I must do something useful for education, at least for my university, or more widely for the Mekong Delta. A.L4 
This view was shared by two leaders who linked PLD roles and functions to institutional and social aspects.

At this university, we consider PLD as a strategic activity. By not learning further, lecturers limit their contribution to the university. PLD is not for individuals but for the institution and for social contribution. PLD is a social responsibility rather than for personal benefit. A.AL3

Overall, the interview data suggested that participants made an implicit connection between professional identity, and PLD motivation and engagement. Their PLD experience enhanced their awareness of self-improvement. These qualities informed their pedagogical practices and were reflected in their effort to become more effective lecturers as well as better contributors to the institution and society. However, in practice there were several factors influencing the lecturers' PLD engagement.

\section{Factors influencing PLD engagement}

Several cultural, social and contextual factors appeared to support or hinder EFL lecturers' PLD engagement in university A. These included institutional policies, the effects of complying with government and institutional initiatives, leadership, and personal factors.

\section{Complying with government and institutional initiatives}

As presented previously, educational policy in Vietnamese HE maintains a strong focus on developing lecturers' capacity and capability, especially through increasing the number of $\mathrm{HE}$ teaching staff with $\mathrm{PhD}$ degrees. A document review showed that university A issued various policy documents in response to the central directions. For example, an institutional strategic development agenda stated that by 2020 the university aimed to become a key multi-disciplinary university in the country and the biggest centre of research and technology transfer in the Mekong Delta. Ambitiously, the university aimed to be ranked as one of the leading universities in Asia, with certain training programmes reaching internationally recognised levels of quality. Key strategies for staff development were proposed in order to help the institution reach its goals as well as to address the national directives stated in HERA. These strategies focused on improving the quantity and quality of lecturers, research staff, and administrative staff. To increase the teaching resources, the 
institution prioritised the recruitment of graduates with excellent academic records as lecturers. The plan also specified strategies to provide PLD for lecturers and administrative staff, including:

- Sending lecturers and staff to overseas programmes to upgrade their qualifications

- Having policies to attract and invite leading experts in the country and overseas to teach administrators, lecturers, and students.

(University A, document about strategic development plans, issued in 2007, italic added).

The document highlighted that there would be funding for training lecturers over three stages (Table 4.10).

Table 4.10 Institutional targets for lecturers' qualifications (2007-2020)

\begin{tabular}{cll}
\hline \multicolumn{1}{c}{ Stage } & \multicolumn{1}{c}{ Targets } & \multicolumn{1}{c}{ Activities } \\
\hline 2007-2010 & $\begin{array}{l}\text { In 2010, 70\% lecturers would have at } \\
\text { least an MA degree }(25 \% \mathrm{PhD} \text {, and } \\
\text { 45\% MA) }\end{array}$ & $\begin{array}{l}\text { Annually send 100 lecturers to } \\
\text { postgraduate programmes (20\% of } \\
\text { them would be trained overseas) }\end{array}$ \\
2011-2015 & $\begin{array}{l}\text { In 2015, 85\% lecturers will have at } \\
\text { least an MA (40\% PhD and 45\% } \\
\text { MA) }\end{array}$ & $\begin{array}{l}\text { Annually send 120 lecturers to } \\
\text { postgraduate programmes }(20 \% \text { of } \\
\text { them will be trained overseas) }\end{array}$ \\
2016-2020 & $\begin{array}{l}\text { In 2020, 95\% lecturers will have at } \\
\text { least an MA (75\% of them have a } \\
\text { PhD) }\end{array}$ & $\begin{array}{l}\text { Training 250 more PhD, and 100 } \\
\text { more MA (30\% of them will be } \\
\text { trained overseas) }\end{array}$ \\
\hline
\end{tabular}

(University A, document about strategic development plans, issued in 2007)

The policy documents confirmed a strong focus on upgrading lecturers' qualifications. The strategies for staff development centred on providing formal PLD for lecturers through postgraduate programmes and training delivered by experts. When interpreting and implementing the government goals and directions in developing HE human resources, this institution set higher targets for lecturers' qualifications (e.g., having $75 \%$ of lecturers with a $\mathrm{PhD}$ degree by 2020 ) compared to the targets proposed in national 
policy documents (e.g., 35\% and 45\% as stated in HERA (Vietnamese government, 2005) and MOET's regulations of lecturers' work (MOET, 2008), respectively.

Interview responses showed that academic leaders expressed an awareness of the university mission and vision, as well as its goals. Leaders also highlighted lecturers' duties to help achieve the institutional goals. For example, a leader (A.AL3) believed that lecturers' higher qualifications would lift the university's rank and prestige. Lecturers' higher qualifications could support the university goals of improving graduates' outcomes to meet local and social needs for highly qualified personnel resources in the era of globalization. This leader also stated that besides lecturers' qualifications, their research and publications were also considered crucial for developing the university's prestige. He quoted the university goals and emphasised a need for having sufficient lecturers with $\mathrm{PhD}$ degrees to deliver advanced programmes.

The university aims to develop staff with $\mathrm{PhD}$ degrees to have sufficient personnel for MA and PhD programmes in Linguistics and in TESOL in the future. A.AL3

The directions for and objectives of upgrading lecturers' qualifications so that teaching staff had a $\mathrm{PhD}$ degree created motivation as well as pressure for both lecturers and academic leaders in relation to their PLD. Lecturers expressed an awareness that they had to study further to meet the reform requirements. However, requirements from the government and the institution also placed pressure on lecturers.

Lecturers have a higher desire to learn. However, they feel anxious and under pressure when their colleagues can attend PhD programmes, or study higher. A.AL3

A young lecturer reported feeling pressured to apply for a postgraduate programme to meet the university requirements of lecturers' standards. The pressure came from both the institutional policies and her peers' expectations.

I have been putting great effort into independent learning and research, but senior lecturers in the department think that I am focusing on teaching extra classes to earn money. Whenever they see me, they asked "Why don't you study further?" This puts more pressure on me. A.L4 
This junior lecturer quoted an institutional policy about lecturers' standards in order to justify that she was aware of her learning responsibility. The document clearly stated that lecturers were required to work towards higher degrees and/or qualifications within a certain timeframe from their recruitment. For example, one of the requirements for lecturers who were employed from 2008 onward was that:

After 4 years of being recruited, lecturers must be working towards or have completed a higher degree than the one they had when being recruited (e.g., from BA to MA, from $\mathrm{MA}$ to $\mathrm{PhD}$ ). (University $\mathrm{A}$, document about lecturers' qualifications and responsibilities, issued in 2009).

This document emphasised that it was the lecturer's responsibility to plan for further study to obtain higher qualifications and professional titles. Those who completed the requirements before the due date would be rewarded in the annual assessment of lecturers' work and considered for a salary raise. Those who failed to complete the requirements would be down-graded in these processes and possibly assigned to less prestigious professional posts.

Time and workload were ongoing factors at this site that negatively influenced lecturers' participation in PLD. Generally, these were exacerbated when lecturers' implemented pedagogical innovations concurrently with the language reform proposed by MOET. For example, three lecturers (A.L2, A.L6, and A.L4) reported working much harder than before when applying new teaching methods in order to improve students' motivation, active learning and self-regulated learning. These lecturers said they had to spend a great deal of time preparing more teaching activities, planning homework assignments, and assessing students' individual learning. Similarly, other participants (A.AL1, A.L4, A.L5, and A.L3) reported having to teach all day during the week at the same time as implementing the language reform project. Time limitations made it hard for lecturers to gather and share experience.

Sharing experience is not often done within the department because lecturers are very busy. The department has just organised some seminars although we have planned many seminars for the whole year. Because we have been intensively involved in B1, B2 classes for primary school teachers from Monday to Sunday, we have no free time at all, it is hard to gather many lecturers together to share experience. A.L5 
Time constraints and work overload appeared to influence lecturers' personal lives, well-being and work motivation. For example, one lecturer (A.L2) commented that she had to spend so much time on lesson planning and assessing students' learning that she had no time for entertainment. Working long hours particularly affected young lecturers:

My difficulty is that I have to spend lots of time preparing the lessons. When there is too much work, I have to stay up very late to finish it. As a result, I do not feel well when teaching in the classroom, or I am too tired to prepare an effective lesson. Because I have so much work, I sometimes feel exhausted and less interested in teaching. A.L4

Although all participants acknowledged the increased workload arising from enacting educational reforms, they all valued the learning opportunities associated with new teaching responsibilities the reforms proposed for them. For example, A.L6 reported being more reflective and better aware of her own PLD needs while implementing the reform.

The reform has influenced my PLD a lot. The reform requires school teachers to learn in order to meet the standards. This prompted me to assess how much knowledge I had. Also, the reform gave me a chance to teach a new field - teaching methods for primary school teachers - which made me do more independent learning to understand the learners and be able to teach them. A.L6

Similarly, A.L1 commented that the implementation of the language reform created many benefits for lecturers.

Despite the greater workload, the reform offers many benefits such as more classes to teach, more opportunities to learn, more funding and resources from MOET. A heavier workload, but more learning opportunities. A.L1

Besides individual learning opportunities, EFL lecturers reported that there were significant changes in collegial relationships among lecturers in the department. Changes derived from the process of lecturers working together to complete assigned tasks such as programme planning, material design, and discussions about other teaching issues. Academic leaders also appreciated these changes and commented that lecturers had become more collaborative and supportive than before. 
There has been an improvement in teamwork and group cohesion because lecturers have more opportunities to work together. They have also improved how they give feedback. A.AL3

Three young lecturers especially valued their learning when working with experienced colleagues to design a training programme for school teachers. They also reported having more opportunities to receive mentoring and coaching from the others.

We got to know each other more. Although we did not have time to meet each other face-to-face, we shared ideas and experiences more via email or cell-phone. There were more opportunities to collaborate and learn from each other, more opportunities for young lecturers to have mentoring and support from experienced ones. A.L1

The findings show that institutional policies greatly affected the participants' PLD engagement. For instance, three leaders and one lecturer believed that financial support was important to promote lecturers' research activities and publications. They appreciated the university policies that supported lecturers' research and publications.

Seminar presenters have financial support from the university or from the department. One seminar presentation is equivalent to 20 teaching periods. A.L6

Lecturers with publications are given payments in the form of additional teaching hours. For example, one paper in a national journal equals to 50 teaching hours, and to 100 teaching hours in an international journal. A.AL3

Although the participants valued financial support for some PLD activities, they noted limited funding for other situations and felt that greater financial support would maximise their PLD engagement. For example, they proposed more funding for conducting research at institutional level, attending workshops held in foreign countries, and inviting foreign experts to the university to provide training for lecturers.

Other institutional policies were also perceived as hindering lecturers' engagement in research. For example, A.L6 reported that lecturers were required to register their proposed research topics one year in advance, which she thought was not feasible. She wanted to be informed of the criteria for research assessment, and suggested more realistic 
timeframes for applying to undertake research. She also experienced problems in applying for research funding at institutional level, which caused her to lose interest in research:

There were unclear criteria for assessing research proposals. I was refused without any explanation. Priority is often given to lecturers who ask for big funding, or who have a PhD degree, or who are senior lecturers. A.L6

Two other lecturers raised the need for transparent criteria for selecting lecturers to attend PLD, particularly formal PLD opportunities provided by the university or by MOET. Young lecturers felt that they were at a disadvantage:

Young staff like us don't attend many training courses. That means we do not have many opportunities to attend specialised training courses. Only more experienced lecturers are given priority to attend them. We are mainly given opportunities to attend workshops. I've found that lecturers in other universities are younger than me, but they can participate in significant courses. I think there should be more support for young lecturers to attend training courses, and there should be no distinction between young and experienced lecturers. A.L5

They gave examples of inequitable policies for selecting candidates for formal PLD outside the university, especially overseas. These specialist courses were intended by MOET to prepare EFL lecturers to implement the language reform:

For training courses related to the project, only experienced lecturers were selected. I felt sad about this. They should have considered language competence as a criterion. An important thing I want is a change in criteria to select participants more fairly, rather than basing so much on degrees. A.L4

The responses from the lecturers, however, did not clearly show if these selection criteria were set by the PLD providers (MOET) or from their institutional policies.

Although expressing concern about the selection process for attending PLD, a young lecturer later commented that she was happy with the current practice of planning lecturers' PLD within the department. She found that lecturers' expectations of PLD were considered and integrated with the general development goals of the department: 
The department completes a form showing each lecturer's priorities within a certain professional field. For example, if I wish to develop IT skills, and skills for teaching children, whenever there are any related workshops, my name will be on the top of the list. This is because there used to be problems of lecturers competing with each other for professional development. Therefore, now the department has a clear direction. The lecturers state their expectations and the department will decide their priorities when there are related training courses, both inside and outside the country, run by the MOET. A.L5

The extract suggests that the departmental PLD plan focused on formal PLD such as training courses and workshops, provided either within or outside the country.

\section{Leadership}

The participants identified that academic leaders played an important role in supporting lecturers to attend PLD. An academic leader (A.AL3) perceived that leaders needed to provide timely directions and support for lecturers' PLD activities. He reported that he clearly informed lecturers about the university mission and vision, as well as the development plans of the university and of the faculty in staff meetings. This enabled lecturers to understand their responsibilities and plan their PLD. He reported closely supervising and directing research activities. He also attended seminars and professional meetings within the department in order to encourage and support EFL lecturers.

After we suggest a direction for change, we need to check how people follow it and support them when they have difficulty. A.AL3

Besides sharing information and giving encouragement, it was perceived to be important for leaders to mandate lecturers' PLD practices. This view was shared by both leaders and lecturers. Indeed, a lecturer commented that requirements were necessary because they pushed lecturers to move ahead. Without these expectations from leaders, lecturers might not try as hard as they could to make progress.

It is necessary to encourage as well as to require lecturers to do research or to present in faculty seminars. People usually do required things better, so requirement is good. Sometimes, people say they do not have time, or do not know how to do something, but when being required to do it, they can. Requirement here means being able to 
practise, to do, and to learn something' rather than forcing everyone to do something.

A.L6

Similarly, two leaders (A.AL1, A.AL4) mentioned that lecturers did not undertake tasks when there was no obligation to do so.

There is no requirement for peer observations and co-teaching, so lecturers see no need to do these. A.AL4

These leaders, therefore, proposed to make these activities obligatory to ensure that lecturers practised them regularly.

Reflecting on their leadership practices, all leaders perceived that it was important to be a role model to motivate lecturers in their PLD. Just as lecturers were expected to be role models for their students, leaders reported making an effort to set a good example in learning and teaching for lecturers, which they referred to as "transformational leadership".

Because I am in this position, I need to engage in research and independent learning, and have publications to encourage lecturers to do these things. A.AL1

A.AL3 also shared his view on qualifications of a good leader.

I am a good role model (tấm gưong) because 'people may doubt what you say, but believe what you do'. A good leader needs to have both tâm (good heart, or aspiration) and tầm (a clear vision ${ }^{11}$ ). I always do things wholeheartedly and fairly. A.AL3

This leader considered PLD as a social responsibility, and reported committing to ongoing professional learning to fulfil his leadership roles and contribute to the organisation.

Besides reporting on their leadership beliefs and practices which facilitated lecturers' PLD, some leaders admitted to having weaknesses which hindered lecturers' engagement

\footnotetext{
${ }^{11}$ In Vietnamese tâm (good heart) refers to characteristics more associated with emotions such as kindness, care, love, fairness, honesty, and devotion. Tầm (vision) refers more to intellectual qualification and expertise, particularly the competence for strategic planning.
} 
in PLD. For example, when justifying why lecturers were not actively engaged in research, one leader commented that:

The roles of academic leaders in research are not clear. We need to be involved more actively to encourage and promote lecturers' research activities. Leaders have to participate, monitor, and assess the effects of research activities. A.AL3

Similarly, another leader thought that leaders did not play a positive role in promoting lecturers' collaborative learning through activities such as co-teaching and peer observations.

Some academic leaders are not aware of the function and value of a learning community and collegial support, so they do not promote these activities. A.AL4

Within this university, the issue of leadership was reported both as support and as a barrier to lecturers' PLD more often by the leaders themselves rather than by lecturers. Most lecturer participants appreciated the support they received from their leaders regarding their PLD engagement.

\section{Individual factors}

Issues related to lecturers' beliefs, awareness, and capacity were identified as influencing lecturers' engagement in PLD. Two leaders commented that some lecturers did not invest sufficient time and effort in learning further. One of them explained that time was commonly used as an excuse for lecturers' lack of engagement in pedagogical changes and research, while the actual reason was likely to be lecturers' limited awareness of the value of these activities.

They usually say that they have no time to apply new things. They are not aware that by applying new things they will achieve better quality teaching. If they research and write publications, they will achieve financial rewards. A.AL4

Similarly, another leader commented that although the implementation of educational reforms and new teaching methods increased the lecturers' teaching load, it created opportunities for their learning and research. He thought that lecturers would engage more 
actively in research if they knew how to integrate research into their teaching and daily work.

They do not know how to take advantage of their chances at the moment; that is their teaching opportunities. As lecturers, they just need to do research related to their own work and their daily teaching, but they do not. A.AL3

This leader felt that at times lecturers' beliefs posed barriers to their efforts towards further learning and research. He gave example of two lecturers' lack of autonomy.

They think that everything needs training. They are not aware of their own initiative in learning and their ability to seek for help. Some lecturers have limited research ability, and ability to observe and identify research topics. A.AL3.

This leader also commented that some lecturers lacked vision about the positive impact of PLD as well as their role in supporting the university goals.

They tend to accept what they have at the moment rather than thinking about the future when the university needs $\mathrm{PhD}$ lecturers to staff $\mathrm{MA}$ and $\mathrm{PhD}$ programmes. Providing these postgraduate programmes is an important mission of the university. Therefore, by not learning further, they limit their contribution to the university. A.AL3

During the interview, this leader expanded his perception on the previously mentioned concept of thầy in Vietnamese. He commented that some lecturers were far from meeting the standards of a teacher educator.

We are training thầy (teachers), but lecturers are now just tho (craft-workers), so they tend to train their students as tho . Their teaching philosophy is 'teaching is going to class' rather than 'teaching is a creative career'. Therefore, they merely provide a mould, and train students rigidly to fit their given mould. For example, they do not exploit the internal competence of learners and encourage individual development. It's a danger because this relates to lecturers' beliefs. This teaching method kills learners' potential and reduces their competence for lifelong learning. A.AL3

He viewed an ideal teacher educator as one who is aware of and supports students' needs and potential and, is flexible in their teaching in order to facilitate and promote 
students' competence and life-long learning. His vision for teacher education conceived of the teaching profession as a creative career rather than a mechanical delivery of lessons.

In order to promote lecturers' engagement in research and other PLD, this leader (A.AL3) suggested that MOET and the university should have a clearer direction for managing lecturers' work, with clear requirements for each type of lecturer in terms of teaching and research responsibilities. He thought this would help to assess lecturers' performance at the end of the year more accurately. Those who did not meet the requirements could then be removed from the position of teacher educators. This idea again reveals that regulations and requirements were perceived as necessary to promote and assess lecturers' professional work. This also highlights the academic leaders' desire for transparency and feedback in staff management.

While academic leaders identified limitations related to lecturers' beliefs, awareness and competence as key factors hindering lecturers' research activities, the lecturers themselves (A.L2, A.L3, A.L4, A.L6) referred more frequently to contextual barriers (e.g., time, workload and policies regarding research assessment and funding), and their limited research experience. Another difference was that while one leader (A.AL3) suggested making research a criterion for lecturers' assessment, the lecturers seemed to think of research as a learning process. Two lecturers (A.L2 and A.L6) admitted that lecturers had limited confidence in and ability to research. Using the metaphor truyền lía (transferring the fire), A.L2 emphasised the importance of peer support and inspiration in promoting lecturers' research.

It is necessary to have someone who 'transfers the fire' to others to do research or to join a research project. This will create a movement or a wave for research which will spread from one lecturer to another. Collaboration in research will increase lecturers' confidence and motivation as well as share responsibilities. A.L2

In addition, lecturers' personal circumstances and other commitments beyond academic duties were identified as having a major influence on their availability to participate in PLD. Academic leaders doubted lecturers' PLD commitment. One leader complained that undertaking external teaching hindered lecturers' learning effort. This kind 
of additional work, or moonlighting, was informally referred to as chạ sô (running teaching shows).

Lecturers are busy with their 'teaching shows' to earn money, so they do not invest a lot into learning or applying for short or long courses overseas. A.AL4

In contrast, another leader expressed sympathy with lecturers' personal responsibilities, and explained that most lecturers preferred teaching to research because teaching they thought that teaching was less challenging and helped to increase lecturers' income.

Due to financial conditions and the day to day problems (com, áo, gạo, tiền $n^{12}$, they prioritise teaching over research. A.AL3

Lecturers themselves also identified family commitments and personal lives as factors that at times hindered their PLD engagement. A young lecturer reported that:

I give priority to family issues. I once had to turn down a learning opportunity although

I liked it very much. That was a chance to attend a course overseas. A.L5

Similarly, a lecturer (A.L3) who reported participating in very few PLD activities explained that he did not have time to attend these events because besides teaching, he had outside commitments to his family and running his own business.

A few young lecturers, in contrast, commented that they had the advantage of being single, and free from family commitments, which allowed them to seize learning opportunities. As one lecturer said, "I am still single, so I have more free time to attend workshops or training courses". A.L1

In general, the participants reported that PLD was influenced by cultural, social and contextual factors which functioned either as supporters or barriers to PLD. External factors included national as well as institutional policies and initiatives. Lecturers' PLD

\footnotetext{
${ }^{12} \mathrm{Com}$, áo, gạo, tiền (cooked rice, clothes, raw rice, money) is an expression in Vietnamese to refer to necessary issues in a person's material life
} 
engagement was also influenced by internal factors such as their beliefs, competence, as well as their personal circumstances.

\section{University site B}

University site B was a relatively new university which was established from a teacher training college. The university was located in a province, and it was under MOET's administration. University B was one of the universities appointed by MOET to provide training courses for EFL in-service teachers from several provinces in the region in response to the reform in foreign language education. In this respect site B was similar to site $\mathrm{A}$ in that it received supported PLD and resources from MOET. Similar to site A, some EFL lecturers at site $B$ reported having opportunities to attend official MOET training and overseas PLD to enhance their capacity to enact the reform.

The participants from university B acknowledged a number of changes resulting from their PLD engagement. The changes, either implicitly or explicitly expressed, involved improved professional knowledge and pedagogical practices, and impacted their professional identity.

\section{Professional knowledge and pedagogical practices}

The participants reported improving their professional knowledge and skills as a result of their PLD experience. This effect was particularly related to their engagement in formal training as well as independent learning. Improvement in knowledge and skills were highly valued by the participants because these were believed to enhance their teaching effectiveness. For example, the participants (B.AL5, B.AL1, B.AL3, B.L1) reported learning about theoretical issues and practical activities in the field of teaching English to children from MOET training related to the language reform. They believed that learning from the training supported their new responsibility of teaching in-service EFL teachers at primary schools in the local areas.

These participants acknowledged that PLD engagement impacted upon their pedagogical practices. They felt that most changes had occurred in the areas of selfreflection, adaptive teaching, and applying their learning to improve practices. For instance, most participants reported that reflection after attending formal PLD enabled them to 
identify teaching areas they needed to improve. For example, B.AL1 emphasised that she made an effort to vary the activities within a lesson in order to improve students' motivation and comprehension. B.AL3 and B.A2 reported applying the techniques they learned from the TOEIC workshop to simplify the teaching activities and provide authentic materials to facilitate learning for students with low levels of English.

A participant from the training course organised by MOET and the British Council experienced an 'aha moment' which changed her previous beliefs about good practice.

Before, I had always started a lesson with theories. During the course, when I planned activities and practised teaching, the instructor kept commenting that I was giving too much theory. I changed and realised that it was more effective to present theories through activities. Now I always apply this approach in my teaching. It helps students learn better. B.AL1

The participants made a conscious effort to apply their learning from formal training into their teaching practice. For example, after attending a course on teaching English to children, they reported adapting and applying this content for teaching university students. They appreciated the positive effect this had on students' motivation and outcomes.

I have become more active in teaching. I use a lot of games, chants, and songs in teaching the classes of university students. I even sing more frequently in the classroom. Before I was very shy and did not dare to sing in the classroom. The students are very motivated. They commented that I look younger and more cheerful. I think it is because they enjoy the activities. B.AL1

Another important impact was that lecturers who experienced meaningful PLD were eager to share their learning with colleagues. For example, B.AL1 and B.AL2 highly valued their learning from attending a training course by the British Council. They especially appreciated how giving and receiving feedback from the course facilitators and other attendees benefited their teaching practices. These two lecturers also reported changing their view of teaching errors: "I learned that making mistakes when we are teaching is not a bad thing because we can learn from our mistakes" (B.AL1). As a result, they planned to organise a workshop for their colleagues to share their learning experiences and discuss how to make teaching observations and feedback more effective within the department. 
From the course experience, B.AL1 added that she learned to be open-minded and self-reflective. Another important change she identified was the way she addressed teaching problems. She learned to take responsibility for the success as well as failure of a lesson. As she stated, "I often blame myself if the lesson is not effective and students are not motivated in learning. If they do not learn well, it is my fault, not theirs" (B.AL1).

Besides professional knowledge, teaching skills, and language proficiency, the participants (B.AL1, B.AL3, B.AL2) reported learning general presentation skills, workshop organisational skills, and time-management skills. This reflected that they were interested in learning many other things beyond their specialisation. The participants' PLD experience illustrated that meaningful PLD promoted positive changes in the pedagogical practices, professional confidence, and attitudes about teaching of individual lecturers.

\section{Lecturers'professional identity}

The participants reported that PLD experience enhanced their professional confidence. For example, B.AL1 revealed that her participation on a course made her become more confident in teaching and in socialising with other colleagues. She described feeling very anxious at the beginning of the course activities.

The other participants were very active. Some of them had studied abroad, so they were very confident. They talked and discussed a lot. During the first sessions, I mainly listened to their ideas. I was also not confident in teaching the in-service school teachers in Hochiminh city because they were very good. I was afraid they would ask me too many questions. B.AL1

However, she reported gaining self-confidence after a few sessions and becoming more eager to express her ideas during the course. B.AL1 believed that participating during the course empowered her to interact with professionals from other areas and made her enthusiastic about widening her network. Her agreement to participate in my research was an example.

If I had not attended this course, I would not have been confident enough to participate in this interview. When I was invited to join the research, I thought, "Why not? If I do it, I will have a new friend”. B.AL1 
This particular academic leader reported professional and personal transformations as a result of her participation in PLD. PLD participation also increased her motivation to teach and seek for further PLD opportunities. She acknowledged that: "The more workshops and training courses, the more motivated I become in teaching" (B.AL1).

There appeared to be a mutual influence between the participants' care for students' learning, their PLD, and their teaching practices. Observations of their students' challenges in learning motivated the participants to research ways to support their students better. For example, B.AL4 reported conducting an individual research project on students' mistakes on the course he was teaching.

Other participants expressed empathy with their learners - in-service teachers who were implementing the language reform in the school sector. They were aware of the contextual and psychological challenges these teachers experienced.

It is hard for them to improve their language because at schools they do not have good learning conditions. They are very upset when judged as lacking competence and looked down upon by parents and their colleagues who teach other subjects. Now they are under a lot of pressure to improve their proficiency in a limited time. B.AL1

Some participants questioned the feasibility of expecting local in-service teachers to immediately apply what they learned from the training at site B.

I'm concerned about their ability to apply what they learned here. There are a lot of problems in teaching facilities at schools. B.AL3

This care for their learners encouraged lecturers to take more responsibility for supporting learners' learning. The participants (B.L1, B.L2, B.AL3, and B.AL1) felt uncomfortable and responsible when the students did not learn well in their classes. To address these problems, the lecturers reported doing more self-reflection and discussing issues with their colleagues to find ways to teach more effectively. 


\section{Factors influencing PLD engagement}

The participants highlighted various factors that impacted upon their PLD engagement. This section will describe how the participants' PLD had been influenced by educational reforms from the government, institutional initiatives, leadership, and personal factors.

\section{Complying with government and institutional initiatives}

Similar to those at the first site, the participants from this site focused particularly on enacting the reform in foreign language education. This reform was reported to present challenges as well as opportunities for EFL teacher educators.

Although the reform was perceived to be necessary, many participants reported feeling under pressure to upgrade their knowledge and skills, especially in achieving the level of language competence to meet the standard set by the university. The term đạt chuẩn (meet the standard) was used repeatedly to indicate their PLD focus. Unlike site A where junior lecturers reported facing more pressure to upgrade their knowledge and skills, the pressure appeared to be greater for senior lecturers at site B managing cultural issues of face-saving and peer pressure.

The reform caused tension and anxiety for lecturers to meet the requirement, especially for middle-aged lecturers or lecturers with leadership because they were afraid that they could not get as good results as the younger ones when taking an English test. B.L3

Additionally, time and workload were identified as the two biggest challenges to lecturers' PLD attendance, as consistent with findings from site A. All participants reported that they had very busy teaching schedules since the reform implementation.

Lecturers have to teach too much. They do not want this, but this is because they have to teach the classes arising from the reform project. For me, after class time, I have to spend a lot of time assessing learners' work and responding to their questions. This affects my independent learning routine. B.L2 
Many participants (B.AL2, B.AL4, B.AL5, B.L1) revealed that they faced pressure to ensure that their learners met the outcomes set by the reform, which they perceived unrealistic.

\begin{abstract}
Implementing the reform causes pressure and a greater workload for both lecturers and school teachers. School teachers gather at the university to attend a two-month intensive course of English. By the end of the training, these teachers need to have upgraded their English by one level. It is very hard to achieve this over a short period of time. B.AL4
\end{abstract}

The above challenges led some participants (B.L1, B.L2, B.AL5) to think that the reform was too demanding.

It causes two burdens (gánh nặng): how to learn independently to meet the expected qualifications for lecturers, and how to train others to meet the standard for teachers' qualifications. These are our two biggest concerns. B.L1

However, all participants valued the learning opportunities associated with the reform. They found the training courses sponsored by MOET, both in Vietnam and overseas very helpful for improving their learning and teaching. A leader expressed a very positive attitude toward the reform:

Lecturers have learned and applied the new language standard, which was based on the CEFR. They have accessed various teaching materials and textbooks oriented to the CEFR standard, and can prepare themselves for the test. Their learning needs and awareness of independent learning have increased a great deal. B.AL4

The participants' increasing need for their PLD also resulted from their selfassessment and the feeling of uncertainty and inadequacy they experienced in their implementation of the reform. As one stated, "We feel that we are not good enough. Because we are inadequate, we have to learn more to be able to teach these classes" (B.AL5).

Some participants thought that the reform implementation also enabled lecturers to understand more about challenges and expectations of their learners who were in-service EFL school teachers. As a result, the lecturers were better equipped to develop a network 
with school teachers. The participants also indicated that the new teaching responsibilities promoted more collegial support and sharing of teaching experience and resources among EFL lecturers. For one lecturer, the reforms "helped to increase collegial conversations and sharing of teaching materials and teaching ideas. This helps us solve our problems and teach more effectively" (B.AL3). Overall, the reform in foreign language education was reported to create significant changes in the participants' working contexts. The new teaching responsibilities and requirements associated with the reform were considered to foster the participants' motivation to engage in various kinds of PLD, particularly to improve their competence in fulfilling their teaching responsibilities.

The participants frequently referred to policies (co chế) and innovations as both a supporting and hindering factor to their PLD engagement. In terms of formal training, the participants appreciated the financial support they received for attending external events. However, they all commented that the support was limited and wished for increased funding either for lecturers to attend outside training or for inviting experts to provide training within the university.

In addition to the limitation of funding, a leader referred to an institutional regulation that lecturers have an article published in workshop/conference proceedings in order to receive funding for attending the event. She noted "I want the university to eliminate this regulation because it is very difficult to write an article. Also, we do not have time to do it" (B.AL1). In contrast, one leader thought that this policy was an effective way to ensure that PLD opportunities were divided equally among the lecturers.

For the foreign language teaching reform, the opportunities to attend workshops and training courses were divided among lecturers within the department. Most lecturers attended at least one training session provided by the project. Therefore, I see no need to provide lecturers with more training or PLD support in their implementation of the reform because most of them have had enough training. B.AL4

The training provided by MOET was considered to be a formal qualification for teaching the reform-related classes. This may explain why lecturers valued formal training highly and considered it necessary for their teaching: 
Only those who have had the training from University $\mathrm{X}$ are eligible to teach the classes related to the language reform project. Some other lecturers have not been assigned to teach these despite their competence. B.AL2

Four participants referred to the difficulty of inviting foreign experts to come and organise PLD for lecturers within the university. These participants felt that politically related policies from the local authority restricted university lecturers' opportunities to engage in learning with foreign experts. In addition, one participant identified that a recent institutional initiative on the assessment of lecturers' professional performance had had a great impact upon their PLD. They explained that the initiative had only been enacted within the past six months. The new policy specified criteria for assessing lecturers' work and classifying lecturers' performance into various levels of achievement ${ }^{13}$. The policy rationale was to improve lecturers' teaching quality and research ability. The two participants (B.AL4 and B.AL3), who expressed a strong support for top-down requirements, perceived this new method of assessment as motivating for lecturers.

This policy has affected lecturers' independent learning a lot. One example is that it requires lecturers to have a personal PLD plan in order to gain good scores for this item. Research is identified as a key criterion, contributing to very high scores in the assessment. With this assessment, lecturers have to study hard and complete the research requirement in order to gain the highest merit grade. B.AL3

In contrast, other participants (B.AL2, B.L1, B.L2) pointed out challenges in implementing the criterion of lecturers' research engagement from this initiative. They explained that:

There are no standards for research assessment. The assessment focuses on formats rather than content. Sometimes, research committee members use conflicting methods to assess lecturers' research activities. B.AL2

\footnotetext{
${ }^{13}$ In this university, these levels were reported to include: chiến sĩ thi đua (competitive soldier), lao động giỏi (good labourer), and hoàn thành nhiệm vu (duty completer), raking from the highest to the lowest. The terms/titles of lecturers' performance may varied from one university to another, according to their institutional assessment schemes.
} 
Another barrier identified by many lecturers was the process and regulations required to ask for research funding. For example, B.L1 and B.L2 mentioned the complicated paperwork (thủ tục rườm rà) that required researchers to make detailed claims for expenses. It was also challenging to provide evidence when applying for funding. B.L2 expressed frustration and annoyance when talking about these requirements, which he called kim, chi, đá lư $a^{14}$ in Vietnamese. He highlighted that these regulations greatly discouraged lecturers' from engaging in research, especially for 'genuine researchers' who cared about the research quality. Additionally, if it was provided, the funding for research was perceived as insufficient.

\begin{abstract}
Research benefits us a lot and helps us improve our ability. It is an achievement if we have finished one research project and have it published. However, to tell the truth, I do not have a lot of motivation for research. Funding for research is too limited. For example, last year I had about 8 million $\mathrm{VND}^{15}$ to support research at the institutional level, but my actual expenditure was more than this. In economic terms, it is a big loss (lỗ nặng) to do research. B.L2
\end{abstract}

The pressure on lecturers to fulfil their research responsibility seemed to escalate when the university announced its intention to eliminate financial support for research beginning in the next academic year, due to a limited institutional budget.

We were informed that from next year, there would be no funding for research. I think without funding, people will not want to conduct research. People want payment for their PLD. There should be a good reward system. B.L2

It was important to note that this perception derived from his belief that providing good payment or financial reward was a way to acknowledge the lecturers' effort and appreciate their achievement, rather than a mere interest in how much money lecturers could earn from their PLD.

\footnotetext{
14 Tiny, detailed but not useful things. This expression refers to the action of paying too much attention to small and unimportant details.

$158,000,000$ VND is approximately equal to 470 NZD
} 
Some participants expressed different reactions to the university initiative on lecturer assessment and then the decision to stop research funding. While B.L2 believed that lecturers would lose their motivation to conduct research, he reported that some lecturers in the department felt pleased with the elimination of funding, mainly because "they will not need to do the complicated paperwork related to funding". Some believed that lecturers would continue to conduct research to meet the requirement.

Lack of funding will not affect lecturers a lot because with the new assessment scheme, they have to complete their research duty to achieve a high performance rank. B.AL3

One participant, B.AL2, shared the idea that the assessment initiative encouraged lecturers' research engagement, but questioned the quality of research conducted only to meet the requirement rather than out of a genuine desire for learning. She also referred to the fact that "not all lecturers are good at research because it requires skills and experience".

Reflecting on the effect of the initiative on non-professional aspects of lecturers' lives, B.A2 shared that "some lecturers feel anxious about not meeting the criteria of the new policy because the assessment result is related to their salary".

Overall, the participants perceived that the institutional initiative in lecturer assessment encouraged them to improve their professional performance and research engagement. However, they highlighted tensions and challenges arising when lecturers had to complete their workload and research duties without sufficient support. This complicated situation added to their anxiety and professional burden.

\section{Leadership}

Similar to the perception at site A, leadership was agreed to be an influential factor on lecturers' PLD. However, at this site, lecturers' obligations to complete PLD were mentioned very frequently, suggesting a top-down leadership style. The combination of encouragement and requirement was a key leadership strategy. It appeared that lecturers valued this kind of leadership although at times they challenged the feasibility of meeting the leaders' requirements. 
Many participants shared the belief that obligations were necessary and motivating for their learning (B.AL3, B.AL4, B.AL5, B.L3). These participants thought that requirements from leaders, together with lecturers' agency, enhanced lecturers' PLD engagement.

We are aware that we need to learn, but sometimes we postpone our learning due to time and workload. However, if we are required to do something, we will try harder to complete it. B.AL3

Sharing this view, B.L3 referred to imperatives from leaders as an external influence on lecturers' participation in PLD.

Lecturers try to learn and improve themselves to meet leaders' requirements. For example, in a meeting, the rector requested that lecturers attain higher qualifications in order to improve the university image, compared with the neighbouring universities. This made the lecturers try to study higher, as a way to express their respect for and their obedience to the rector's requests. B.L3

The practice of giving respect and obedience to leaders suggested by this lecturer reflects cultural aspects of Vietnamese hierarchical society which values obedience and authority.

The participants identified qualities of a good leader. There was a clear expectation that the leaders would provide a model of learning in order to motivate lecturers in their PLD.

Leaders should be 'one head higher' ${ }^{16}$ than the others. They must understand and sympathise with others, and inspire others to take action. Leaders have a very important role. If they want to require lecturers to study, they themselves have to do it first. B.L2

Lecturers and leaders alike, identified the roles of leaders in supporting PLD.

\footnotetext{
${ }^{16}$ Vietnamese expression cao hơn nguời khác một cái đầu, referring to someone who is significantly more knowledgeable than others / has a higher level of knowledge and expertise than others
} 
Our leader is highly qualified. He has done a lot of research. He is also very understanding and supportive. He encourages us to do research, and says that he would be willing to give feedback and advice on our research reports. B.L2

Because I am a manager, I have to be a role model for the others. I have to do these things first so that the others can follow me. It is not effective if I just say things without doing them. I need to have experience of these things before I can give the others directions persuasively. B.AL4

I always encourage and provide opportunities for lecturers to improve their PLD. My working principle is respecting the others in the department. If I find something suitable for a particular lecturer, I will recommend it to him/her, and let him/her make the final decision. I give lecturers orientation, and ask for ideas about it before carrying out something. It is not $100 \%$ obligatory. B.AL4

The description of leadership practices from B.AL4, especially the respect for lecturers' choices, appeared to contradict the lecturers' experience of obligatory PLD activities within the department such as observations, research, monthly staff meetings, and taking English language tests. However, most of these required activities were regulations set by the university and the MOET. This mismatch showed a tension between what this leader perceived effective in leadership, and what needed to be done in practice in order to meet the institutional and national requirements. This also showed a nesting relationship in which leaders at department level were influenced by rules and regulations from higher administrative levels in their leadership practice.

\section{Individual factors}

Individual factors had a strong influence on lecturers' motivation to take part in PLD. These related to lecturers' awareness, agency and effort, the desire to enhance their professional identity, and the challenge to achieve a balance between their work and personal lives.

Although they mentioned several external factors influencing lecturers' PLD practices, all participants emphasised that lecturers' self-awareness, agency and effort were decisive factors influencing their commitment to engage in PLD (B.AL1, B.AL3, B.AL4, B.AL5, B.L3). For example, one leader emphasised that it was the lecturers' responsibility 
to make full use of any internal forces to support their learning (phát huy nội lục) and supplement limited PLD opportunities.

Lecturers themselves play a core role in their PLD. Despite facing difficulties, they should think of PLD as their own need and duty. If they have awareness and determination, and are willing to take action, they will solve problems. For example, if they do not have a chance to study overseas, they can study within the country, or can practise their language using CDs, DVDs, or books in English. B.AL5

Similarly, another leader, B.AL4 also emphasised the necessity of self-management:

It is important that we regulate our own learning and research, and undertake our own

PLD. Because we do not have a lot of time, we need to focus on the issues that are most necessary to our teaching, or of most interest to us. B.AL4

Lecturers' perceptions of their professional identity and their sense of professional commitment were other personal factors that fostered their PLD engagement. All participants acknowledged their responsibility as teacher educators in the field of teacher education and educational reform implementation. Some of them described the profession as 'a pride' ( $v i n h d \varphi$ ). They perceived that teacher educators have an effect on subsequent generations of students they train. The lecturers, therefore, felt a strong responsibility to improve themselves: "Lecturers need to study hard to build their prestige and inspire students to learn" (B.L3). They also highlighted the necessity for lecturers to improve both professional knowledge and morality, two important qualities of teacher educators. This was expressed as a combination of tài (talent or expertise) and dức (morality) ${ }^{17}$. B.L3 explained it in this way:

There is a Vietnamese proverb: "có tài mà không có đức là người vô dụng; có đức mà không có tài làm việc gì cũng khó" (A talented but immoral person is a useless one; a moral but untalented person does everything with difficulty). Having good knowledge is not enough. If students respect a lecturer's morality, they will have more trust in the

\footnotetext{
${ }^{17}$ In Vietnamese, "tài”" refers to talent, or high level of expertise; " đức" refers to high moral standards. These two qualities are culturally considered as requirements of good leaders, or expected qualities for people who receive high social respects such as teachers and doctors.
} 
knowledge he/she transfers, be more convinced, and remember what they have learned from this lecturer longer. B.L3

This perception reflected the Vietnamese cultural expectation that teachers are models of knowledge and morality for their students. Good expertise and high moral standards were also identified as crucial qualities of teacher educators in national and institutional documents such as the University Charter, Tertiary Education Law, and University Self-report.

All participants acknowledged the significance of their roles in teacher education; however, they also perceived undertaking PLD to be 'a professional burden' (B.A1, B.A2, B.AL5) or 'a heavy duty' (B.AL3, B.AL1), particularly in the context of educational reforms. Despite this challenge, the participants expressed a sense of commitment to their profession.

Although we have a hard job, we are making a lot of effort to improve ourselves and carry out our responsibilities well. B.AL3

Lecturers want to improve themselves and confirm their ability. Their motivation to learn also derives from social needs. The language reform project is a social need, and lecturers have to improve their knowledge and skills to meet the need and fulfil their responsibility. Also, they want to maintain their profession. B. AL4

Like their colleagues at site A, a few lecturers in site B reported undertaking additional work outside the university to supplement their family income. B.L1 mentioned time and financial issues when explaining lecturers' limited research engagement.

Most EFL lecturers have a lot of 'teaching shows'. They are responsible for the family financial conditions. Like me, I am teaching too much outside the university, so I do not have time for research. B.L1

Lecturers indicated that their salary was not sufficient to support their families (B.L1, B.AL2). In particular, the participants perceived that the payment they received was not worth the effort they made, especially when teaching classes related to the reform. For instance, a leader cited a joke among lecturers: "European teaching standards but African payment standards" (dạy theo chuẩn Châu Âu, nhưng trả luoong theo chuẩn Châu Phi) to 
imply that they were required to teach to a high standard, according to the CEFR, but were not well-paid.

Besides the responsibility to support their family financially, some lecturers (B.AL3, B.L2, B.AL1) reported that they had to take care of their children, which affected their time for independent learning or planning for a post-graduate programme. One leader referred to the social pressure to take care of the family and attend to her children's education. She explained that "It is common for people to be judged on their family status and living conditions" (B.AL2). The lecturers with family commitments agreed that at times they needed to minimise their PLD in order to fulfil personal responsibilities.

At site B, lecturers' engagement in PLD was reported to be impacted by various contextual, cultural and personal factors. National and institutional policies and initiatives in education and professional management were perceived to create both opportunities and tensions affecting lecturers' PLD engagement. Leadership was another influencing factor. In addition to external forces, individual factors contributed to the lecturers' desire to enhance their professional identity and professional commitment by taking part in PLD.

\section{University site $\mathbf{C}$}

University site $\mathrm{C}$, like site $\mathrm{B}$, was a 'new' university upgraded from a teacher training college. However, site $\mathrm{C}$ was directly administered by the provincial government. That meant its financial budget, educational resources, and personnel were mainly decided by the local authority rather than MOET (who primarily gave directives on academic issues). Site $\mathrm{C}$ was required by MOET to implement current national reforms in education, including the reform in foreign language education, as were all other public universities. However, unlike the other two sites, this university was not appointed as one of the key universities to implement this reform. As a result, the university and its EFL lecturers did not receive as much support from funding, resources, and MOET training opportunities, compared with the other two sites.

This section presents the reported effects of PLD engagement upon individual participants. Similar to the participants at the previous two sites, PLD affected site C 
participants in two key areas: professional knowledge and pedagogical practice, and professional identity.

\section{Professional knowledge and pedagogical practice}

All participants at site $\mathrm{C}$ agreed that PLD engagement greatly enhanced their professional knowledge and teaching skills. For example, one lecturer, C.L4, described a collaborative activity which he found meaningful. This was working with other lecturers to design test questions for an English test bank. He especially valued the opportunity to review and improve his knowledge of and accuracy in using English, and the access this gave him to useful resources.

This helped me consolidate my content knowledge and gave me a deep understanding of certain issues so that I could avoid inaccuracy in the test bank. Besides, I could draw from many materials, both mine and other lecturers'. C.L4

Most of the participants reported improving their knowledge and professional skills through independent learning and preparing for their teaching lessons. They also reported learning general skills, which they referred to as 'soft skills' (kỹ năng mềm). These were skills related to working, feedback giving, time-management, and PLD event organisation. These skills were observed and learned while the participants were engaged in various PLD activities. For example, the participants (C.AL2, C.L3, C.L2) reported observing the presenters in formal PLD and learning about their presentation styles as well as the ways they organised the events.

When collaborating with and facilitating volunteers in organising workshops for the university lecturers and students, C.AL1 reported improving his cultural understanding and skills in communication, programme planning and problem solving. He also valued the opportunity to improve his language competence when working as a translator for the foreigners in these events.

In contrast to site $\mathrm{B}$, participants in site $\mathrm{C}$ did not strongly emphasise the effect of PLD on their language competence. Also, they did not report feeling under pressure to improve their language proficiency. This appeared to relate to the institutional regulations as well as their current teaching responsibilities. The participants did not mention any 
institutional regulations or targets set for lecturers' English proficiency. Another reason was that in this site, as the two academic leaders noted, the implementation of the language reform was at the beginning stage, and not all EFL lecturers within the department were involved in teaching in-service teachers. Therefore, the reform did not seem to influence their desire for language improvement.

The participants at this site also highlighted the effect of PLD on their pedagogical practices, as found in the previous sites. However, lecturers in site $\mathrm{C}$ particularly valued learning teaching experiences from their colleagues. For example, C.L1 considered that learning and sharing experience with colleagues was the most effective PLD for her. This was particularly helpful in preparing her for teaching the new subjects she was assigned. She could prepare better for the courses by learning from more experienced colleagues who were teaching these subjects.

Another unique feature of site $\mathrm{C}$ was that lecturers reported engaging in teaching observations more frequently. The lecturers who undertook observations of pre-service teachers' teaching practice in schools, and of EFL primary school teachers' lessons reported learning a lot from these observations. These lecturers considered observations to be useful learning which helped them to have better understanding about EFL teaching in school contexts. This also allowed them to identify how students applied what they had learned during their practicum. This understanding assisted these lecturers to modify their teaching at the university to make it more effective and relevant to school contexts. Their ultimate aim was to better prepare teachers for local schools.

\section{Professional identity}

Participants in site $\mathrm{C}$ felt that engaging in PLD enhanced aspects of their professional identity such as confidence, motivation, and self-image. For example, C.L1 greatly valued her experience in both attending and presenting her research at an international conference, the CamTESOL. She considered that it offered an important chance to widen her professional network and provided opportunities for further PLD events.

The experience made me feel more confident. I learned a lot from other participants. One participant was interested in my presentation and asked me to collaborate on a 
research project in which data will be collected in Vietnam, Indonesia, and the Philippines. I think this is a wonderful opportunity. C.L1

PLD could result in enhancing self-image and being recognised professionally according to individual lecturers. One lecturer, C.L4, willingly opened his classes to new lecturers who wanted to learn from his teaching experience. He commented that the new lecturers normally complimented his teaching rather than pointing out weaknesses. This might be, in his view, because he was more experienced than they were. Despite this, he had positive feelings about this activity, and considered it useful to gain peer-respect and recognition of good teaching from colleagues:

I feel happy because my teaching is recognised. When I am not observed, I still teach as usual, but feel that no one cares if I am teaching well or badly. C.L4

There was an indication that attending PLD encouraged positive changes in lecturers' understanding of the teaching profession. For example, C.AL1 valued the content of a workshop on building a teacher education network between universities and schools, presented by a foreign expert who was working as a volunteer at the university. C.AL1 perceived the presentation helped to raise lecturers' awareness of the interrelation between university and schools, and helped to create changes in lecturers' common beliefs about the roles of the university and of schools in teacher education.

We lecturers normally think that the university is the head of the train, pulling schools while schools do not think so. They [teachers] think that the university lecturers lack practical experience, and do not understand the curriculum in schools as well as they do. It is important for the two parties to collaborate with each other in order to provide teacher trainees with better learning environments where they can benefit from the strengths of each place. C.AL1

Participants felt that PLD enhanced their professional ethics, including care for the learners and sense of responsibility. For example, one leader valued a workshop presented by a foreign volunteer. The presentation was about special education in the USA, and the presenter shared her experience of teaching primary school students with special needs. C.AL1 commented that the presentation promoted lecturers' self-reflection and ethics of care for the students and sense of commitment to their teaching responsibility. 
Although we do not teach students with special needs, through the presentation we learned that we need to be more patient, enthusiastic, and sympathetic with students. The presenter was very determined and patient when working with disabled students. Compared with her, we have more advantages when teaching normal students. C.AL1

Of interest in this response is that although this leader appreciated the above internal workshop, it was not mentioned by the lecturer participants. My research observation notes of these two events at site $\mathrm{C}$ showed that few EFL lecturers attended these workshops. It would have been interesting to know if lecturers also found these workshops valuable.

The participants' responses showed that PLD promoted reflection on their professional practices and sometimes challenged their professional ethics. At this site, the participants expressed concern about an unspoken norm within the department of assessing lecturers as "all passed" after classroom observations. This practice reflected complex cultural issues such as showing respect for peers, avoidance of criticism, and maintaining collegial relationships. Although complying with this norm, the participants reported feeling a sense of conflict.

Although I agreed to conclude that the lessons were "effective", or "met the requirements", I felt uneasy due to the fact that actually some lessons did not meet the assessment criteria at all. C.AL2.

This response suggests a conflict between cultural practices or departmental norms and lecturers' professional conscience. A few participants in particular recommended ways to improve the effectiveness of observations and the reliability of assessments. Similar to the participants at site B, at this site participants suggested that there should be "a workshop to discuss the ways to observe and give feedback, with clear assessment criteria and a common observation form to ensure reliable and accurate assessment" (C.AL2).

Although lecturers at this site expressed positive growth in knowledge, pedagogy, and professional identity, they attributed fewer changes to PLD than the other participants. This limitation seemed to relate to the fact that site $\mathrm{C}$ participants did not have similar opportunities to attend training activities specifically related to the language reform project. These particular activities were perceived as valuable by lecturers at sites A and B. All participants at site $\mathrm{C}$ reported on the effects of independent learning on their professional 
development, whereas only three participants (C.AL1, C.L1, C.AL2) attributed changes in beliefs and practices to their collaborative PLD engagement.

\section{Factors influencing PLD engagement}

This section analyses various factors that influenced the participants' PLD engagement. These included national and institutional policies, resources, leadership, collegial support, and individual factors.

\section{Complying with government and institutional policies}

The participants found university policies to be both enablers and barriers to their PLD engagement. The participants acknowledged that they received financial support to attend workshops and conferences organised outside the university. However, they reported that limited funding meant that there were few places for lecturers to attend these events. They wished that opportunities for attending external PLD would be extended to all lecturers rather than to a few selected ones. For example, one stated "All lecturers have a right to attend workshops and conferences. It is not fair to assign a few to attend these events" (C.L2). This opinion was consistent with lecturers' rights for attending PLD sessions, as found in the analysis of policy documents.

In contrast to C.L2's suggestion for the university to send as many lecturers to PLD as possible, C.L4 thought that due to the institution's limited budget, it was appropriate that only a few lecturers were sent to these PLD events at a time. However, he did not feel that these opportunities should be awarded to only senior lecturers or lecturers with leadership. He also proposed a process to make those who were able to attend external PLD share the materials and their learning with the others within the department.

The document review showed that funding was allocated for certain PLD activities such as research, publications, material designed, programme evaluations and programme design, and course syllabi. Although these financial policies were set out in documents available from the university website, some participants (C.L3, C.L5) doubted that this support was actually available to them. This suggested that these lecturers were not fully aware of the policies at site $\mathrm{C}$. 
Besides financial support, most participants expressed concern about the institutional regulations related to annual lecturer assessment. They described how the head of the department selected a few lecturers to be assessed at the beginning of each year. It was more likely that the teaching and responsibilities of newly recruited lecturers would be assessed for compliance. The assessment involved a teaching evaluation by means of classroom observations, and the examination of many different professional documents (kiểm tra hồ sơ chuyên môn). One leader referred to the list of documents to be assessed:

The professional documents included about 7-8 items such as syllabi, teaching schedules, teaching plans (kế hoạch giảng dạy), lesson plans (giáo án), meeting agenda, form-lecturer agenda, student adviser's agenda, observation agenda. C.AL2

However, the participants who referred to this regulation did not view this assessment as PLD. They all agreed that those who were assessed faced pressure and an additional workload because they had to prepare the required documents, particularly the lesson plans which were supposed to be "detailed and neat". This concern was shared by an academic leader.

It is very time-consuming, especially when we teach so many subjects. We have to submit lesson plans, copies of teaching materials/course-books, syllabi, etc., which creates pressure on lecturers. C.L1

Lecturers are not happy when being asked to provide detailed lesson plans, which are very time-consuming and as detailed as those in the school sector. They refer to this issue as 'turning lecturers to school teachers' (phổ thông hóa giáo viên). They would prefer to submit the teaching notes they normally prepare before teaching. Also, each lecturer is teaching at least 4 classes (sometimes 5-7 classes). It is a lot of work for them to complete detailed lesson plans. C.AL2

The participants also identified other physical inconveniences such as the assessed lecturers having to carry several professional notebooks and lesson-plan books around the campus while they normally just needed to have electronic copies on their computers. Professionally, the requirements were not perceived to be relevant to all lecturers. One lecturer commented that making detailed lesson plans was more useful when lecturers were 
teaching new subjects, or for new lecturers, because in these cases lecturers needed to undertake more careful teaching preparation.

Normally, after several years of teaching I know how to teach, so I just need to jot down some things and plan the lesson in my mind. I usually write notes of my lesson plans, briefly and simply, in my own way. If I were asked, I would not dare to submit these to my boss. I would rewrite them clearly, and follow a clear structure. This would take a lot of time. C.L1

This response reveals that the assessment regulations were not in keeping with experienced lecturers' professional practices, and affected their flexibility and ownership of their pedagogical decisions. Cultural practices such as face-saving (e.g., making an effort to meet the requirement with high standards), and showing respect to the leaders (unwillingness to submit untidy or unreadable lesson notes) seemed to add to lecturers' pressure from this activity.

Another kind of annual assessment was conducted in the form of self-assessment (ty đánh giá). The participants reported that all lecturers were required to assess themselves using a form prepared by the faculty or university. Aspects of assessment included their teaching performance, other professional activities they had completed, and how they would rank their overall performance. The lecturers were uncertain about who would read these reports, and reported that they had not received any feedback on their self-reports. As a result, like the previous assessment requirement, this assessment was perceived as having little effect on lecturers' learning. This made them think of the assessment as a 'formatchecking activity' (hinh thúc) rather than a useful professional activity. An analysis of the documents showed that these annual assessments were intended to promote lecturers' teaching effectiveness and their PLD. However, the participants described them as having opposite the effect: these regulations caused tensions and extra workload rather than promoting their learning and pedagogical practices.

Distinct from sites $\mathrm{A}$ and $\mathrm{B}$, site $\mathrm{C}$ participants identified limited resources for teaching and learning as a barrier for their PLD. Four participants commented that a shortage of specialised books available in the university library made it challenging for them to prepare for their teaching or conduct independent learning. As C.L3 commented, 
lecturers did not have sufficient resources for redesigning the educational programmes to meet MOET's requirements and undertake institutional initiatives like upgrading HE teaching quality. In addition, the participants considered the lack of a staffroom designed just for EFL lecturers within the department as another barrier to their PLD. They strongly believed that a friendly staffroom would promote collegial relationships, professional dialogues, and peer learning among the lecturers.

At an institutional level, a review of related policies showed that the university encouraged lecturers to engage in course-book design and provided financial support for this activity. Also, the university library would order (using the university funds) necessary teaching materials and specialised books recommended by the lecturers for supporting teaching and learning. However, the interview responses showed that while one leader mentioned this kind of support from the university, lecturers did not seem aware of these supporting policies.

Similar to the other sites, all participants at site $\mathrm{C}$ indicated that that they faced tensions from time and workload, which greatly affected their willingness to engage in PLD. One academic leader confirmed that overwork caused pressure and hindered lecturers' learning opportunities.

Each lecturer teaches so many classes per semester. They sometimes teach without having enough time to prepare lessons. Many lecturers including me would like to study further, but we have too much work, and so feel stuck and think this is enough. We try hard, but this goal seems unrealistic because the current work alone makes us exhausted. C.AL2

From the lecturers' perspective, time and workload were key barriers to their engagement in independent learning and research. For example, C.L3 shared that she did not have much time for learning due to her busy teaching schedules both within and external to the university (e.g., moonlighting). Similarly, C.L1, a lecturer who showed high interest in research shared that "I am racing against time to complete my teaching. I have no time for research". Another lecturer raised the concern that lecturers were given tasks that did not relate to their teaching duties. This highlighted a tension in the distribution of work. 
We have to teach too many hours per year, about 500 hours, and do many additional duties which are not relevant to lecturers' main responsibilities. For example, we have to work as students' consultants (cố vấn học tập), and attend too many kinds of staff meetings. C.L5

A few participants (C.AL2, C.L1, C.L2), all females, mentioned that overwork and time pressure affected their well-being and inhibited their motivation for further learning.

At site $\mathrm{C}$, the participants reported very little engagement in research. The academic leaders identified barriers related to research regulations, lecturers' limited competence and confidence, and lecturers' beliefs about research. As one leader commented:

They are afraid of completing time-consuming and complicated paperwork, particularly related to asking for funding and claiming for expenses. Also, research is challenging, stressful, and unfamiliar. Doing research is like having a new burden, compared with teaching. C.AL1

The other leader shared the above idea, but emphasised that "some lecturers thought that there were no interesting research topics in the field of EFL teaching" (C.AL2). This comment was shared by a lecturer who stated that "it was difficult for lecturers to find relevant topics for research in the field of English or English teaching" (C.L6). These quotes suggest that the lecturers' perception of what might be suitable research topics restricted their research engagement and opportunities to investigate other educational areas.

One lecturer could not see the value of research for the sake of research. $\mathrm{He}$ emphasised the importance of ensuring research integrity.

I am not interested in research because after completing research, no one will care about it, or apply what I have researched. Due to my current teaching load, I do not have time to do 'genuine research' (khoa học chân chính). Doing 'research for fun' (nghiên cúu theo kiểu choi choi) may be ok, that means a research project that is not done seriously and may be based on unreliable data. C.L4

Although research was acknowledged to be a professional responsibility together with teaching, unlike in the other two sites, the participants in this site did not feel under the same pressure to undertake research. This appeared to be related to institutional 
regulations about research responsibility. Unlike those at site B, site $\mathrm{C}$ participants did not mention accruing any penalties if they did not complete their research responsibility. They reported that lecturers were allowed to transform their research hours into teaching hours and complete their responsibilities exclusively through teaching. This issue was confirmed by an academic leader who commented that "lecturers preferred to teach more rather than doing research" (C.AL1).

\section{Leadership}

Similar to the participants at the other two sites, site C participants agreed that leadership had a great influence on lecturers' interest in PLD. However, many lecturers at site C challenged leadership practices within the department in terms of work assignment, assessing lecturers' performance, and motivating lecturers to engage in PLD.

A few lecturers commented that leaders did not take account of lecturers' professional specialisation when allocating professional responsibilities. One lecturer expressed the challenge involved when lecturers were assigned to teach courses belonging to different sub-specialisations, and suggested that teaching assignment should be based on individual strengths.

Lecturers have to 'run' all the time, sometimes teaching linguistics, sometimes language skills, and sometimes translation. This is hard because of professional instability. If you specialise in linguistics, I should assign you to teach only linguistics. Besides teaching, you should do research and have publications in this field and share your research with others in your group. C.L5

Another aspect of work assignment questioned by the lecturers was that academic leaders tended to favour particular lecturers in the department. As a result, lecturers did not have equal opportunities to participate in professional tasks. For example, one lecturer reported on which lecturers had been nominated to give presentations at the previous departmental conference organised for new students.

Only a few lecturers, mainly experienced ones or those having a higher degree, were invited to give presentations at this event. Young lecturers were given fewer opportunities to present. This would have been better if we could have registered to 
present our ideas. Then the academic leaders could evaluate and select the best presentations for the conference. It was not a good idea to nominate someone to present on a particular topic. According to Vietnamese culture, other people would avoid competing with the recommended one, so they would not say that they wanted to do it. C.L4

The lecturers also expected a fairer allocation of places on external PLD.

It is necessary to provide opportunities to attend outside workshops to all lecturers rather than just assigning certain lecturers to attend most of these events. C.L4

The above responses show that this lecturer highly valued learning opportunities and believed that PLD should be open for all lecturers who were capable. Also, cultural aspects such as avoiding competition with colleagues, respecting decisions from leaders, and prioritising those with degrees and experience seemed to undermine a fair distribution of tasks and PLD opportunities to younger lecturers.

Although lecturers' assessment was supposed to follow the university guidelines and regulations, academic leaders appeared to play an important role in evaluating lecturers within the department. Four lecturers felt that the assessment of their annual performance was not fair or accurate. In order to promote effective leadership that would facilitate lecturers' PLD and teaching, the lecturers proposed some changes. One lecturer (C.L5) suggested making a plan for PLD activities relevant to the department's as well as the lecturers' needs at the beginning of each year. Another suggestion was to set specific standards for lecturers, and assess their performance based on these standards in order to ensure fair in professional assessment.

There needs to be a standard for university lecturers. Those who do not meet the standard will be assigned other jobs. There will be different policies for people who do a good job and those who don't. This is very necessary. It's unreasonable to assess hard-working people as at the same level as those who don't do anything. C.L5

This idea was in line with the comment by another lecturer (C.L4) who raised the need for having "clear and serious methods of giving awards and punishments". He highlighted the importance of building a fair and motivating workplace environment, which 
would help to promote lecturers' access to PLD, and improve their effectiveness and wellbeing.

If responsibilities are shared fairly, people will find it necessary to learn and contribute to the department and the university, and feel happy and motivated to work. C.L4

Academic leaders also reflected on leadership roles and leadership practices. One leader expressed an awareness of the important role of leadership in supporting lecturers' PLD. This leader reported encouraging lecturers to engage in PLD, especially to study for a higher degree to meet the goals of the department. This leader, however, reflected that over the past years the practices of leadership within the department seemed to focus more on managing paperwork and regulations which was time-consuming, rather than focusing on supporting lecturers' professional activities. The other leader admitted to not having received any leadership training since taking up the position. This person reported selfteaching leadership skills and knowledge, and 'learning by doing'. This leader also reported facing challenges and providing ineffective leadership at times.

Like lecturers at site $\mathrm{B}$, lecturers at this site were expected to complete many obligatory activities. For example, a few lecturers were assigned to redesign education programmes, conduct a programme assessment, and engage in observations and teaching assessments. Besides, a model of top-down decision making with multi-layers of leadership also appeared to prevail at site $\mathrm{C}$. The leader participants revealed that they were supposed to follow the directions from the leaders at higher administrative levels. At times, they were uncertain about how much power they had and to what extent they could modify the regulations from the university. Indeed, one leader shared her concern about the irrelevance of the regulations for lecturers' assessment, but was not sure whether departmental leaders could change these regulations or not. This raised the question of how much power resided with the departmental leaders and lecturers, and whether they had the authority to establish and review rules related to their professional activities and PLD.

Academic leaders were also uncertain about whether they were allowed to organise specialised workshops for EFL lecturers within the department. They realised the necessity of department-led PLD and the lecturers' need for this, but were aware of contextual barriers to promoting this kind of bottom-up PLD. 
At the departmental level, we may not have the rights to make these decisions. We want to organise workshops for the lecturers in the department, but it depends on the university policies and decision. We are still unsure about the extent we are allowed to do this. C.AL1

This uncertainty was related to the issue of complicated paperwork and the process of asking for permission to organise PLD at the department level. As C.AL1 commented, it was difficult for the department to deal with expenses related to airline tickets and allowances for invited experts, and other logistical issues. Another challenge was that the department had to ask for collaboration from other offices in the institution in organising a PLD event. Due to these complicated procedures, it was easier to leave PLD organisation and provision to the International Relations Office which was usually in charge of organising PLD for lecturers. However, the PLD provided by this office was not specific to EFL, and thus was not sufficiently tailored to EFL lecturers' needs.

Both leaders and lecturers agreed that in addition to training or expert-model PLD, it was necessary to promote other kinds of PLD which could be organised without being restricted by so many institutional regulations. They proposed informal PLD such as departmental seminars, professional specialised group meetings, and a TESOL club for lecturers.

The participants identified that collegial support had a great impact on lecturers' PLD. Their comments suggested an understanding that lecturers' collaborative learning was promoted when they were involved with a supportive group of like-minded members. For example, C.L1, C.L2, and C.L6 reported learning a great deal from engaging in classroom observations, and informal experience-sharing with colleagues who shared the same teaching courses and interests.

In contrast, lack of collegial support or fear of peer judgement was identified as hindering collegial learning. These issues were mentioned by several lecturers. For example, C.L5 referred to the issue of "each caring about his/her own work" (mạnh ai nấy lo) to justify a lack of mutual support among lecturers. Similarly, C.L6 commented that sharing was not appropriate when talking to or working with colleagues with a high level of self-confidence in their knowledge and skills. He was unwilling to put himself in the 
position of 'teaching the experts' (múa rìu qua mắt thọ ${ }^{18}$, performing with an axe in front of a carpenter). The fear of colleagues' criticism was shared by another lecturer, C.L4, who stated that lecturers were unwilling to give presentations in the department seminars because their sharing might be judged negatively rather than favourably. C.L4 referred to this issue as 'fear of being thrown stones' (sọ' bị ném đá) by the audience.

A leader highlighted another problem for group relationships. She quoted a Vietnamese saying 'happy face, unpleased heart' (bằng mặt, không bằng lòng) to describe the situation in which lecturers might show fake approval and collaboration in order to maintain group harmony.

At a surface level, everyone agrees to work with others in their group, but there are problems when they actually work together. One reminds another of the task, or some work more and some work less. They look happy, but in their mind they are not pleased. Therefore, the next time when there is another group task, they tend to avoid being in the same group with the person they were not pleased with, but they do not raise the issue directly. C.AL2

This problem is rooted in cultural practices of showing respect for peers, indirect communication, and avoidance of criticism. The practices of avoiding teaching the experts, fear of criticism, and showing fake approval to maintain group harmony when working and sharing experiences with colleagues implied a distance in the collegial relationship among some of the lecturers. This also suggested a lack of trust among those involved. These cultural behaviours seemed to hinder lecturers' real engagement in assigned professional teamwork.

\section{Individual factors}

In addition to contextual and social issues, personal factors (e.g., awareness, commitment, personal circumstances) were identified as greatly influencing lecturers' effort and

\footnotetext{
${ }^{18}$ A Vietnamese proverb, equivalent to "teaching a fish to swim". This refers to a situation in which a novice attempts to teach a more experienced person or a specialist in the field. Pragmatically, when referring to oneself, the proverb implies that the person is humble/ modest in expressing himself/herself. When referring to others, the proverb implies that these people want to show off.
} 
engagement in PLD. The participants agreed that the most decisive personal factor was lecturers' agency and independent learning.

First of all, lecturers must have agency in this activity. They must be aware of selflearning to improve their professional level and teaching skills. C.L4

The academic leaders expressed a positive view about lecturers' independent learning and willingness to share their professional knowledge.

I think all lecturers have a good awareness of learning. Although they may not attend workshops, they do a lot of self-study during the teaching process to improve teaching and students' satisfaction. They have a good sense of responsibility. Some regularly discuss teaching issues, and share experiences and course syllabi with each other, usually within their sub-specialist groups. C.AL1

Another crucial factor was lecturers' motivation for engaging in PLD. While all lecturers showed that they were motivated to learn, one academic leader observed that motivation for PLD varied between two groups of lecturers: the younger and the more experienced group (in terms of age and teaching experience, as defined by this leader).

Young lecturers seem to be more motivated in learning compared with older ones. Some lecturers feel satisfied with their current qualifications because they have MA degrees as required for university lecturers, so they are not interested to study further. They focus on taking care of their families instead. C.AL2

The participants' responses suggested that their understanding of professional identity (e.g., self-image, perception of professional roles) also influenced their PLD effort and engagement. All participants were aware of their social responsibilities as teacher educators. One noted, “Teacher educators have very important roles in training teachers whose qualifications will influence the quality of younger generations of students at schools" (C.AL1). This was similar to the perception of lecturers in the other two sites.

The participants reported that the context of educational reforms required them to take on more important roles. In fact, they were expected to concentrate more on helping pre-service teachers to develop ability for autonomous learning so that after graduating, the teachers would know how to update their own knowledge and skills in teaching. The 
increasingly demanding teaching made teacher educators study harder in order to fulfil their duties. The participants' awareness of their roles as teacher educators contributed to their desire for PLD. Most of them reported making an effort to engage in independent learning and teaching preparation to improve their teaching and students' learning.

Lecturers' attempts to improve their students' outcomes were aligned to their responses that they mainly implemented reforms in teaching methods and student assessment, rather than referring to general national reforms in education such as quality assurance in HE, or enhancing institutional autonomy. This suggested that lecturers' perceptions of their roles were associated with their daily practices and teaching objectives. These priorities also affected their choice of PLD (e.g., undertaking more independent learning, and seeking PLD to improve teaching).

The participants' desire to develop a positive reputation was another motivation for their PLD. For instance, a lecturer (C.L4) noted that his motivation for PLD was promoted by a desire to maintain the esteem given to teacher educators ( giũ sĩ diện của nhà giáo). He explained that it was particularly important for lecturers to be respected by their students.

Lecturers also considered lifelong learning as PLD that was crucial to the teaching profession (C.L1, C.L2, C.L5). This was in line with the perception of lecturers in site B about PLD as an essence or a core component of the teaching profession.

PLD is an ongoing and lifelong activity of a lecturer. As a lecturer, we have to study for our whole life. This is very necessary for lecturers because knowledge keeps changing, so we have to learn and update our knowledge in order to be able to teach. C.L5

Another important source of internal motivation for lecturers' PLD was their sense of professional responsibility which encouraged them to undertake further learning to find ways to support their students' learning. C.L1 was among the lecturers who expressed great care for the learners and concerns about the quality of teaching and learning quality. She reflected on her experience of teaching in-service teachers in a programme that addressed the language reform project. Her appreciation of her learners' needs encouraged her to adapt some of her pedagogical practices and the programme content. She decided to help 
the teachers improve their ability to learn independently and develop teaching resources to support their teaching in schools, rather than to focus on improving their IELTS scores.

Although lecturers at this site valued the role of PLD in their profession and their respected identity as educators, in practice, their PLD was affected by individual circumstances and family commitments. Most participants (six out of eight), confessed that family issues at times hindered their PLD opportunities and engagement.

Because the salary is low and not sufficient for lecturers and their families, we have to teach extra classes outside to increase our incomes. This distracts us from teaching and research. C.L5

Other family commitments such as raising children were also identified as distractors to lecturers' PLD (C.L3, C.L4, C.AL2). In contrast to the others, one lecturer (C.L2) expressed that she was very grateful for her family members who sympathised with her busy teaching and studying schedule, and took care of her child so that she could finish her postgraduate studies.

\section{Summary}

In summary, this chapter described key factors that influenced the participants' perceptions of and engagement in PLD. It illustrated how PLD was either supported or hindered by various personal, cultural, social and contextual issues. Within the HE contexts, educational initiatives and related policies introduced by the government, MOET and institution provided both opportunities and challenges to lecturers' PLD. Other stakeholders such as leaders, colleagues, and learners also influenced lecturers' desire to participate in PLD. Within each institution, top-down initiatives, policies and leadership, though providing some support, were challenged by participants who desired a fairer distribution of work and more transparent lecturer assessment. The chapter also revealed how cultural practices and beliefs, especially perceptions of teacher educator professional identity, as well as individual circumstances, influenced lecturers' motivation and engagement in PLD. 


\section{CHAPTER 5 \\ RESULTS: THE PLD CASE}

This chapter presents an analysis of the results identified in the previous chapter. It examines how PLD is conceptualised and experienced across the three sites using a CHAT analysis, and presents the dynamic and complex nature of the activity. While Chapter 4 highlighted the PLD activity within each university system, this chapter now explores what participants actually meant when they referred to different forms of PLD, including formal, collaborative, and informal PLD. Understanding what these mean to the participants is necessary before analysing the impact of PLD on a tertiary system. The first section describes the complexity of PLD the participants engaged in, and the second section analyses the findings within a CHAT analysis.

\section{The complexity of PLD}

This section analyses the participants' experiences of different aspects of PLD over the two year period. The analysis explores the three key forms of PLD: formal PLD, collaborative PLD, and informal PLD and how the participants perceived the meanings of their engagement in these forms.

Formal PLD primarily considered to be a significant way of upgrading lecturers' content knowledge and skills to support their teaching and policy enactment. This approach was facilitated by external expert-presenters, and could lead to qualifications. Formal PLD, however, tended to have limited relevance to the participants' needs and was unlikely to promote sustainable changes in their practices. Formal PLD was characterised by attending training such as specialised courses, conferences, workshops, and post-graduate programmes organised both within the participants' institutions and externally.

Collaborative PLD predominantly involved a focus on sharing experiences and solving teaching problems with colleagues. Collaborative approaches like mentoring and coaching were seen as leading to meaningful learning. Collaborative PLD required a 
trusting, open, and supportive learning environment in which members had a shared vision of effective collegial learning. It also required negotiation among cultural practices, institutional norms and regulations. Collaborative PLD was more informal and involved activities such as group work to complete given professional duties, teaching observations, departmental seminars, and professional conversations with colleagues.

Informal PLD was conceptualised as requiring the participants to manage their own learning. These approaches emphasised learning through trying new things, self-reflection and self-assessment. The participants perceived that informal PLD was most relevant to their learning needs and professional aspirations. Informal learning, particularly tw hoc (self-regulated learning), or tụ bồi duõng (self-developing), was reported to be the most frequent PLD form, and included learning from teaching, individual research, and practising to develop English language proficiency.

The analysis of the three forms of PLD was based on the participants' own definitions, classifications, and experiences of PLD in their contexts. The arrangement of specific PLD activities according to each PLD form is tentative given the blurred boundaries of these activities. For example, the participants' PLD experiences showed that a particular PLD activity (e.g., a departmental seminar) could occur either formally or informally and could be perceived as either an individual or collaborative activity. Therefore, there might be variations in how a particular PLD activity was classified and defined depending on the way different participants perceived and engaged in this activity.

Overall, the participants' perceptions and engagement in the three PLD forms facilitate the analysis of the complexity of PLD in HE. The descriptions below also highlight the roles these forms of PLD play within the activity system, and what make them effective or barriers to the participants' learning.

\section{Formal PLD}

As defined by the interview participants, formal PLD occurred in formal settings, focused on training, and provided specialised knowledge and skills, possibly leading to further qualifications. For example, one lecturer defined PLD as "attending training courses, or studying towards a higher degree" (A.L3). Identifying formal training as a key PLD model 
was consistent with the participants' view that PLD involved acquiring new knowledge and skills, as described in the previous chapter.

The participants' experiences of formal PLD revealed that PLD plays different roles and functions within the activity system. Formal PLD might serve as a mediating artefact, rules, and at times object. These roles and functions are justified below with specific examples of PLD events the participants experienced.

Across the three universities lecturers shared positive perceptions of formal PLD activities, and their reported PLD engagement showed that formal PLD, either organised within or outside their universities, was a dominant type of PLD. This finding was supported by data from my observations of PLD events in sites A and C. A summary of PLD observations (Appendix P) showed that ten out of the 13 observed PLD events were conducted formally in forms of one-off training courses, workshops, and conferences. The other three events were departmental seminars which were found to occur either formally or informally. Observational data justified common features of formal PLD events, namely one-off events, expert-led, and involving a large number and mixed types of attendees, as described above.

The participants reported that when training was provided by MOET (in essence becoming both a mediating artefact and a rule within the system), it served the purpose of supporting the universities and lecturers to implement current reforms in HE. The participants at sites A and B confirmed that they had many MOET-funded training opportunities, both within the country and in overseas, in order to enhance their ability to implement the reform in foreign language education. They particularly valued two MOETsponsored courses which aimed to improve EFL teacher educators' knowledge and skills so that these educators could support EFL school teachers to undertake the reform in teaching EFL in the primary sector.

All participants attending MOET training reported that the courses supported their new responsibility to provide training for school teachers in the field of teaching English to children. For example, a leader commented that the courses "met the needs of not only EFL school teachers but also of EFL teacher educators working at universities" (B.AL5). The 
participants acknowledged improving their theoretical knowledge, pedagogical practices, and language competence as the result of the course participation.

The experts presented many methods related to how children learn, classroom management, using songs and games, teaching all four skills. The content was very good. After that, we had school visits. They selected two leading primary schools in the area so that we could do classroom observations. Generally, it was well organised. A.L5.

Four participants, however, thought that the training sometimes presented challenges to them in applying what they had learned:

There were no clear demonstrations of how to teach each skill or lesson, such as writing and speaking in the currently used textbook. There should have been more discussions and clearer feedback on these issues. Because there was no standard to follow, we had to search for more materials, and learn how to teach these skills by ourselves. B.AL3

On the other hand, this formal PLD provided the opportunity to practise teaching and receive constructive feedback. For example, the participants reported learning useful and relevant practices for their own teaching when attending a training course offered by the British Council, in association with MOET. They enjoyed participating in lesson planning, micro-teaching, reflection, sharing experiences with and giving feedback to colleagues. In addition, the friendly and supportive environment among the attendees was identified as an important factor.

The content was related to real teaching contexts. During the course, I learn to teach, and learn how to improve my teaching thanks to feedback from the instructor and other friends. B.AL1

A key challenge reported by participants when attending formalised PLD sessions was the need to adapt content to their local context. For example, site B participants reported having difficulty in applying their learning when teaching local in-service teachers who had a low level of proficiency in English. These participants required further individual learning after the training. 
Training from the course was not adequate because the reality of my teaching is different. Therefore, I had to do a lot of independent learning. I also needed to discuss teaching issues with other colleagues, and to talk to in-service teachers about their teaching at primary schools in order to find out a better way to teach. B.A1

Another key issue for formal PLD is that the identified training did not always target the participants' specific needs, which contributed to tensions between the participants and their use of the training knowledge and skills (tools). For example, one leader participant reported that when he attended a two-day workshop on EFL test design, "its content was more relevant to EFL lecturers than to academic leaders" (A.AL2). This leader felt that MOET's decisions to provide PLD on particular aspects of lecturers' specialisation and pedagogy (e.g., a template for test design) appeared to restrict lecturers' professional autonomy and agency. Similarly, another leader commented that the directions and regulations (rules) from the MOET were sometimes confusing and caused tension for lecturers who were the main agents in the reform process.

MOET's directions and templates for implementing some aspects of the reform such as testing and assessment changed continuously. This confused lecturers a lot, especially those who are in charge of designing tests. A.AL1

Other forms of external training (which were more likely self-selected and internally driven compared to the above MOET-directed training) also served as mediating artefacts to support lecturers' teaching and students' learning (i.e., the object of their activity). All participants perceived that external workshops and conferences were useful for their teaching. The participants' responses showed that they especially valued external PLD on pedagogical practices. Formal PLD in this situation mediated the lecturers' high degrees of motivation for improving their teaching and students' learning. For example, one lecturer (B.A3) considered a workshop on using information technology (IT) in teaching organised by SEAMEO ${ }^{19}$ in Hochiminh city as the most effective one she had attended. She reported being able to apply these strategies in her teaching and share what she learned with students and other colleagues.

\footnotetext{
${ }^{19}$ Southeast Asia Ministers of Education Organisation
} 
Formal PLD was not always about receiving information or knowledge but also about teaching and presenting one's own research. Individual lecturers reported an important form of formal PLD in HE which was presenting their own work publicly. The participants' motives for presenting their research at external workshops and conferences were both academic (e.g., learning about teaching and research from the presenters and other participants, sharing teaching experience, and having a chance to network with colleagues and experts) and personal (e.g., traveling to new places). For example, one participant, like others, was willing to personally fund the costs to attend an international conference annually. Her response reveals a strong internal motive for attending the event in order to support both her professional and personal growth (i.e., object of her activity):

I want to attend this conference in order to learn new approaches in education, meet other lecturers, and listen to various accents in English spoken by people from different countries. I can also improve my language and confidence and learn the way people organise the workshop. B.AL1

The data also show that tensions might occur in formal PLD when the participants attempted to apply their learning in teaching a local community of students with different characteristics from those with whom the foreign experts (PLD providers) worked. Indeed, while 14 other participants expressed a preference for attending workshops and conferences presented by foreign experts, four participants (B.L2, B.AL1, C.L6, C.AL2) questioned the relevance and implications of the training provided by these experts. For example, B.AL1 reported attending a workshop on teaching English cultures provided by an Australian expert. Although valuing new cultural understanding she gained from the workshop, she could not apply the workshop content and materials in her teaching because they were not suitable with her students' developing level of English.

Another leader, C.AL2, shared a similar experience when attending a workshop presented by an American expert. Although learning some teaching techniques from the presenter, she commented that the presentation focused on free-writing techniques for secondary students in the United States. In practice, these were not relevant to her teaching of university students in an exam-oriented teaching context. These examples suggested that although foreign experts (PLD facilitator mediating lecturers' learning) were often favoured by the lecturers, these experts sometimes did not appreciate or understand the 
local contexts (rules and sociocultural practices of lecturers) and the lecturers' real needs and aspirations (object of their learning). The mismatch between the lecturers' learning motive and expectation and the knowledge and skills delivered by the external experts caused tensions within the PLD activity system.

Across the three sites, there was a shared perception that overseas training offered a unique PLD opportunity for EFL teacher educators. Five participants recalled attending courses and workshops in foreign countries in the past that were very meaningful to them. One participant cited the value of being actively involved in teaching and learning activities at an overseas institution. He considered that this brought about meaningful learning, especially in relation to improving his English which for him, was 'real learning':

I was sent to an international school of English for the practicum. I participated in the class activities as a real student. At the meantime, I observed and learned about the teaching methods and classroom management. I was involved in various activities of the school. I could greatly improve my language and learn experience in teaching. This was real learning. I think it will be very useful for lecturers if they can attend such a course, even just for one month. B.AL5

The response showed that although the PLD event was formal (i.e., a training course), the participant engaged in it informally, and his active engagement in meaningful activities resulted in effective learning experience.

The idea that overseas training was necessary for EFL lecturers was expressed by many participants in the three sites $(7,6$, and 4 , in site $\mathrm{A}, \mathrm{B}$, and $\mathrm{C}$, respectively). They explained that in addition to getting a qualification, lecturers would improve their language competence, widen knowledge and skills, gain practical life experiences which could be applied in teaching, and improve their professional confidence. One participant, B.A3, perceived that learning in an English speaking country would help lecturers 'standardise' (chuẩn hóa) their language proficiency, and enhance their ability and confidence in teaching English specialised courses.

The participants considered language accuracy and proficiency crucial for being teacher educators in English and enhancing their professional self-efficacy. Thus, having an opportunity to attend a training course overseas was their professional goal. 
I wish to attend a one-year course overseas. I will feel reassured about my language competence after that. Not only I, but also all lecturers in the department expect to be able to attend courses in foreign countries. B.AL3

Preparing for and taking international English tests was explicitly emphasised as an imperative PLD activity for the lecturers. Five participants reported preparing for an English test in order to get a certificate of English proficiency. They found it motivating when their leaders required them to gain qualifications for English proficiency.

In the last staff meeting, the leader required all lecturers to take the exam at the end of this year in order to have $\mathrm{C} 1$ or $\mathrm{C} 2$ certificate. He said we must try to take the exam now because later on all university lecturers' English competence will be officially tested [by MOET]. B.AL3

In above response B.AL3 appreciated the leader's insistence because she thought it encouraged lecturers to manage their time and make an effort to meet the standard set for lecturers (the rule). Lecturers also perceived that getting a certificate showing their high level of English proficiency was a prerequisite to apply for a scholarship to study abroad (their object).

A questionnaire finding was that the participants expected to have opportunities to study overseas, or attend PLD sessions in English speaking countries. The data from document analysis and individual interviews supported this finding, and expanded it further by showing that overseas training, as a kind of formal PLD, played different roles within the tertiary activity system depending on who defined it. As presented in Chapter 4, national and institutional policy documents identified providing overseas postgraduate programmes for university lecturers as an important strategy to improve educational quality and human resources to enact the HERA. MOET also sponsored overseas training courses for selected lecturers to upgrade their knowledge and skills in relation to the EFL teaching reform. Additionally, findings of document analysis and individual sites (see Table 4.9 and Table 4.10) showed that tertiary lecturers were required to upgrade their qualifications through MA and PhD programmes (either from within Vietnam or preferably overseas institutions) in order to maintain their teaching position and meet the official lecturers' standards set by MOET. Formal PLD, in this respect, played a key part within the rules of the tertiary 
activity system. These above accounts show how formal (and overseas) training was seen by MOET and policy makers as a mediating artefact for policy enactment, and at times as a rule that lecturers had to comply with.

From a different perspective, the interview data highlight that most lecturers aspired to gaining qualifications from an English-speaking country. They shared a strong motive for this, closely connected to their object of improving language proficiency, being role models of successful EFL learners and teachers for their students, and thus enhancing their self-image and professional identity. Since overseas training was their object, they reported engaging in self-study to maximise this opportunity (e.g., by taking an IELTS test, or preparing to apply for a scholarship to study further).

The above analysis shows that overseas training was viewed differently by MOET or institutional leaders and by lecturers. From a CHAT analysis, MOET and institutional leaders were more likely to perceive lecturers' attending overseas training as either a rule or mediating artefact, whereas the lecturers considered it as the object of their activity. However, the lecturers showed a commitment to upgrading their qualifications, which matched both the leaders' and their own plans. In this situation, leaders' and lecturers' different perspectives on the role and function of this kind of PLD did not seem to result in tensions or contradictions because the PLD, either seen as artefact, rule, or object within the activity system, was nonetheless relevant and supportive to the lecturers' teaching and professional aspirations.

Formal PLD sessions organised within the participants' institutions were identified as artefacts to support their teaching and their students' learning. In comparison to external training, the participants across all three sites reported having more opportunities to attend courses, workshops, and conferences organised within their institutions. The common features of these internal formal PLD events included following an expert-led PLD model, short-term PLD, involvement of attendees with different specialisations, and organisation at the faculty or institutional level rather than at the departmental level.

Participants described several formal PLD events organised by their own institutions that they found effective. For example, B.A2 reported learning from a workshop on TOEIC 
organised for EFL lecturers in the university and local EFL high school teachers. He valued the opportunities for experience-sharing.

It was good because it was done at the time when we were required by the university to teach TOEIC for students. It helped us to understand more about typical features of TOEIC, and plan our teaching better than before. The most important thing was that the participants had a chance to discuss with each other about the good things and problems in their teaching. B.A2

My research observations of PLD sessions support the lecturers' reported desire to share teaching experience and current problems in a formally structured PLD session. Data from an observation of a training course on Teaching English to Children at site $\mathrm{C}$ showed the teacher attendees' great interest and active participation in the course activities (University C, Observations 7). The attendees shared their teaching problems and discussed solutions with their colleagues and the presenter who was a foreign expert. These features matched the participants' definitions of effective training. As one of them described, it should provide both theory and practice.

There are demos or practical activities for lecturers to observe and participate in. The content is practical and specific. It enables participants to learn practical experience from the trainer. C.L3

On the other hand, like external formal PLD, institution-based formal PLD events were at times perceived as ineffective due to the lack of follow-up support from the experts when the lecturers tried to apply what they had learn into their local teaching contexts. As one lecturer expressed:

For the workshops organised here, most of the presenters were from Hanoi. They were also busy with their work, so sometimes they did not reply to my emails. That happened many times. After the workshops, they let us 'swim by ourselves' (tu' boi) [i.e., apply the skills without further support or coaching]. C.L2

There were also examples of internal training which was considered ineffective or irrelevant by the participants. For example, participants reported attending a training course on how to use an interactive whiteboard and related software in teaching. An academic leader commented that despite several sessions, the training did not provide lecturers with 
sufficient practice, nor was there any follow-up support from the experts after the course. This resulted in it being more challenging for the lecturers to apply the new skills into their teaching. This leader also thought about PLD as peer teaching and learning.

Most lecturers were not able to operate the software and use the resource after the training. Some lecturers, particularly those teaching ELT methodology, were assigned to teach in the lab-room and apply this equipment in their teaching, but they were not confident and still needed further directions and practice. I think some young lecturers who are good at IT should practise more and then show the others how to use it. C.AL2

Data from my research observations of this training course were consistent with this leader's comments. During the training, the lecturer attendees mainly listened to the information and demonstration from the presenter who was also the programme provider. There was minimal interaction or discussion among the attendees about the application of the equipment in their own teaching (University $\mathrm{C}$, Observation 6).

The data showed that lecturers decided not to go to formal PLD sessions that they found irrelevant to their needs. They wanted more agency to plan and organise their own formal PLD events within the department to maximise the relevance of the training to their teaching. As one lecturer suggested:

It is necessary to have workshops exclusively for EFL lecturers, rather than for a big group of lecturers from various departments. The content needs to be related to lecturers' teaching contexts, and involve both theory and tasks for participants to do. It is expected to have in-depth discussion about presented issues to find out a good way to apply them into teaching. C.L1

Leaders, in contrast, expressed a more positive view about the availability and relevance of formal PLD events organised for EFL lecturers within their institutions. For example, while seven lecturers felt that few internal workshops were relevant to their learning needs, their leaders asserted that EFL lecturers had many PLD opportunities within the university. This disconnect may have arisen because academic leaders interpreted PLD as contributing to broader roles and functions beyond lecturers' daily teaching practices. The lecturers, in contrast, tended to seek PLD that directly supported their teaching roles. 
When contradictions arose between a leader's perceptions of what would be useful for lecturers' PLD and what lecturers believed to be relevant to their needs, these tended to be because the training sessions were planned by the institutional leaders and relied on the external experts' decisions about delivered content. As reflected from the interview findings, lecturers had limited agency in planning these PLD sessions and their professional needs were not always recognised. The differences between the views of leaders and lecturers on the relevance of internal PLD events revealed a lack of a shared vision on the role and function of these PLD activities. This disjunction of beliefs suggests a need for institutional PLD to be negotiated between the academic leaders and lecturers (to achieve a shared understanding between the subjects and their community).

\section{Collaborative PLD}

Collaborative PLD can be defined as PLD activities (sometimes formal, but largely informal) in which lecturers learn and work collaboratively with their colleagues, or with other members of their community. This way of learning reportedly encouraged qualitative changes in the participants' knowledge, skills, and beliefs about their teaching and students' learning, and changes in their pedagogical practices.

The participants reported engaging in a variety of collaborative PLD activities, including working in groups to fulfil assigned professional duties, conduct peer observations, and share experiences through departmental seminars and informal professional dialogues. Groups formed among EFL lecturers who shared interests and/ or professional responsibilities or those teaching in the same sub-departments ${ }^{20}$. The participants reported undertaking obligatory and voluntary collaborative activities. The focus of collaborative PLD varied, including to complete teaching and research commitments, enact educational reforms, comply with institutional policies (e.g., peer observation, research), or share teaching ideas and content knowledge with each other (e.g., departmental seminars).

\footnotetext{
${ }^{20}$ Within a department of foreign languages, or department of EFL teacher education, there are several subdepartments, or specialised units, such as ELT Methodology, English Skills, General English, Translation, and Linguistics.
} 
An example of collaborative PLD was evident when a group of lecturers worked together to design a PLD programme to share with local in-service teachers what they had learned from the MOET training course. Five participants reported their engagement in this complex activity, as described in detail by one lecturer.

We met many, many times, to discuss whether we could reuse the framework from University $\mathrm{X}$, or how to adapt it. After we agreed on the modules in the programme, we divided the tasks of collecting materials. After that, we got together to compile and check all modules and make changes if needed. A.L5

Diverse teaching experiences and professional knowledge among the group resulted in collegial support in the forms of mentoring and coaching. A more experienced member valued learning through mentoring and working with the others.

I explained and shared what I learned [from a training course by the British Council] with the other lecturers in the group. The group work was very useful because everyone could learn new things and share experience. A.L6

Less experienced lecturers (having from three to five years of teaching experience) also acknowledged learning from more experienced ones.

During this work, some lecturers were attending a training course by British Council, so they had good knowledge. For example, they showed us how to design something. At first, we designed something very general, not specific. These lecturers instructed us how to redesign the programme to ensure that our learners would study both in the classroom and do the reading assignments. A.L5

The response showed that this teamwork involved many components such as demonstration, instructions, actions, reflections and adaptation. The activity had two clear aims: (1) to fulfil their team duty (i.e., to design a PLD programme for in-service teachers), and (2) to maximise the learners' outcomes. The extract also revealed that the formal training the participants received from University $\mathrm{X}$ could be considered as a stimulus for this follow-up collaborative PLD. Learning occurred when the lecturers were committed to the task, worked together to adapt the training into their local contexts, and viewed the process as a meaningful learning experience for all members. The participants' responses showed that the lecturers' collaborative endeavour and shared understanding of the object 
of the activity, and their effective use of the provided artefact (MOET's training course and resources) contributed to the accomplishment of this team work.

Another example of collaborative work was showed when lecturers attempted to address an aspect of national educational reform. This particular reform was perceived challenging because they were not clear about what the task involved and how to undertake it. For example, MOET required tertiary institutions to undertake self-assessments of their teacher education programmes with the aim of revising and improving these programmes. Two lecturers at one site reported being assigned to work with colleagues to complete a self-assessment of the EFL teacher education programme in their university. With neither sufficient training on how this issue nor resources (tools) to support this process, one of the team noted, "We were required to do this, but we found it very hard during the process. We felt like we were doing something beyond our ability" (C.L3). Therefore, although these lecturers reported their collective attempts to comply with the requirement, this teamwork did not result in a learning process. The example reveals a tension resulting from lecturers' enacting a top-down initiative (i.e., object of their activity) without favourable resources (mediating artefacts). This experience suggests that for national reforms in education to be implemented successfully and promoting lecturers' learning for making the changes, lecturers need to understand clearly the reform rationale as well as to be provided with necessary skills and on-going support.

Other opportunities for collegial discussions, experience sharing, and experimental learning were identified as crucial for effective peer learning. These features were clearly demonstrated in a collaborative professional activity which involved a group of junior lecturers working together to run an English Speaking Club (ESC) for students. These lecturers considered this an effective PLD experience.

We normally discuss activities and share experiences when we participate in the ESC. For example, I can say 'Ah, in my class, I use this warm-up activity'. The ESC mainly focuses on speaking and listening skills, so it is very comfortable for us to share ideas. We usually bring to the ESC what we find interesting in our classrooms. We share all things we know when we sit together to plan the programme for ESC. A.L5 
Another lecturer acknowledged that the ESC was a place for her to apply new pedagogical practices she learned through formal training.

I apply the ways to organise games, songs that I learned from the training course at University X when planning activities for ESC. Sometimes I create new games and tried them in ESC. Whenever I have new ideas, I try them in the ESC and evaluate their effectiveness or how to improve them. A.L4

The extracts revealed that ESC was considered as a small community of practice where members were willing to share their teaching experiences and ideas for completing the shared duty. Although running the English Speaking Club was an assigned duty, the lecturers valued the collegial support and learning they received. They also reported applying the skills they gained from organising ESC into their classroom practices. This showed that there was a connection between these lecturers' additional roles and their main roles of EFL teaching.

There is evidence that collaborative learning was effective when lecturers engaged in their professional activities collaboratively and voluntarily for the purpose of learning, rather than for formal assessment of their own or their colleagues' performance. This was manifested in the participants' experiences of teaching observations and feedback, which they identified as a form of collaborative PLD.

Twelve participants perceived the importance of peer observations and feedback as PLD. For example, an academic leader who was responsible for planning and providing PLD for lecturers put a high value on these activities.

These are very necessary activities. By doing these, lecturers can build a learning community for their PLD. They can receive feedback and advice from peers who observe their teaching. The observers can also apply new ideas. A.AL4

Junior lecturers in particular were willing to be observed:

I really want my teaching to be under examination. I want to get feedback on what is good and what is not good so that I can improve my teaching. B.L1 
However, eight participants, particularly those from sites B and C where teaching observation was obligatory, believed that observations and feedback were poorly structured, and thus failed to promote authentic peer learning. One lecturer (B.A2) commented that he did not learn much from observers' feedback because it was too general. He noted that observers usually avoided pointing out weaknesses in their peers' teaching, which he perceived as a Vietnamese cultural practice of showing peer-respect ( $c a ̉$ nể). Sharing this view, one leader stated that observations and feedback did not work in practice. She raised the issue that lecturers conducted them only 'to comply with' (đối phó) the regulations rather than being fully committed to these as learning activities.

Observations were organised just to respond to the university requirements. Lecturers tend to avoid conflicts, so they don't give real feedback. B.AL2

This cultural issue was also mentioned by other participants. Both lecturers and leaders questioned the reliability of evaluative observations rooted within a cultural practice of peer respect:

There has been an 'unspoken norm' within the department for a long time. This is a tradition of the department that the observing group would give an 'all passed' assessment (tất cả đều đạt) to the observed lecturers. C.AL2

The participants also referred to a contrasting cultural practice, 'no peer respect' (không nể nhau), which was opposite to showing 'peer-respect' (cả nể) as an additional reason why observations might be unwelcome. For example, B.AL2 and B.AL1 explained if lecturers were of a similar age, or in a similar position, it was more likely that they would exercise 'no peer respect' in giving feedback after the classroom observations. As a result, the observed lecturers would feel very uncomfortable because the feedback was likely to be overly negative and not constructive. A lecturer referred to this phenomenon as a reason for lecturers' low engagement in observations as a form of PLD:

Lecturers do not have time for this, and they tend to avoid criticism because observers might give negative comments rather than constructive feedback. A.L2

The participants identified conditions that would ensure that observations and feedback would provide fruitful PLD. 
Classroom observations are beneficial when they are voluntary, involve discussions and sharing ideas, and when a new lecturer needs to learn experience from more experienced ones. A.AL2

There was evidence of voluntary classroom observations and feedback that promoted collegial learning among a small group of lecturers within their sub-specialised groups. For example, one lecturer reported that she sometimes invited others, including foreign volunteers and Vietnamese lecturers to observe her lessons. She described an active learning experience when she had a chance to observe others, including preparing for the observation by making her own plan for the lesson she was going to observe, observing, and taking notes. She compared how the observed lecturer taught with how she planned to teach the same points. This lecturer also reported what happened when she met with her colleagues after this observation when they shared their feedback.

The feedback sessions were useful because I could learn a lot from giving feedback to others and from listening to their clarifications or responses to my feedback. This discussion helped me to avoid making subjective comments. This was a two-way interaction and learning. C.L1

The process of reflecting on teaching issues as described above deepened the understanding of lecturers who were involved in this learning. Even so, these lecturers reported making a great effort to prepare for a model lesson. As one lecturer reported:

I often feel uncomfortable when being observed. I usually prepare the lesson thoroughly before teaching. However, despite these issues, I still want others to observe my lessons and give me suggestions for improvement, especially for new subjects that I am teaching. C.L1

The response showed that this lecturer's need for observations and feedback derived from her motive to improve teaching effectiveness. The need for learning appeared to outweigh her anxiety and other psychological issues related to being observed.

It was interesting to find that most participants used the term bi dụ giơ in Vietnamese to refer to being observed. Pragmatically, $b i$ indicates a state of suffering or having to undergo something unpleasant or unfavourable. This implied meaning was relevant to 
many participants' experience of anxiety or reluctance to be observed by peers, which was more likely to occur when lecturers were required to provide open class for teaching observations and assessment (obligatory collaborative PLD, seen as a rule), contrasting with the feeling of dươc dur giờ (e.g., seeing being observed as a favour, or honourable task) they often quoted when talking about more informal and voluntary ways of observations. The use of bị dụ giò or dươc dụ giò to talk about the same PLD activity also reflected different views and meanings individual lecturers held in relation to their experience of this PLD form which functioned as either rule or an artefact within the lecturers' PLD activity system.

Although the participants referred to teaching observation as a form of collaborative PLD, their experience of this activity showed that obligatory teaching observation was not in fact collaborative but rather a formal process of observation and professional assessment. In this respect, obligatory observation was very much a formal PLD activity. Alternatively, voluntary incidents of peer observation were viewed as collaborative and informal learning in which a lecturer could learn effective teaching practices from their colleagues or receive useful feedback to improve their own teaching. These two examples show the complexity of this particular PLD activity.

Discussing teaching or research ideas within departmental seminars was identified by the participants as another form of collaborative PLD. The lecturers expressed positive attitudes toward attending or presenting at these seminars.

The seminars are useful because of the informal atmosphere and opportunities for lecturers to meet and share experience with each other. A.L2

My research observations of three seminars in site A showed that departmental seminars, similar to teaching observations as presented above, occurred in both formal and informal ways. The first two seminars included six EFL lecturers (one presenter and five attendants) and were conducted in informal styles with a similar procedure. Each seminar started with a short presentation of about 20-30 minutes, followed by 10-20 minutes for discussions. Seminar one aimed at sharing the presenter's experience in using technology in teaching English to children. The participants actively asked the presenter about designing and delivering the course, and then discussed obstacles as well as strategies for 
teaching effectively with this approach. Similarly, the purpose of seminar two was to share the learning and materials the presenter obtained when attending an overseas course. The participants actively discussed how to use the materials effectively. The discussion was practical particularly when the participants reflected on their experience of supervising and assessing students' research, and then suggested using the materials and ideas learned from the course to design a detailed set of guidelines for research assessment within the faculty. Generally, the first two seminars involved a great deal of professional discussion and collegial support. The attendees showed interest in the presentations, actively engaged in sharing their teaching practices, and discussed teaching problems (University A, Observations 1, 2).

The third observed seminar was conducted more formally. The seminar aimed at sharing experience of using a software package to manage data in qualitative research. Unlike the other seminars, this seminar included four EFL lecturers and more than 20 students. The presentation took about 45 minutes including: the theoretical grounds of qualitative research, data analysis, and how to use the software. The participants mainly listened to the presenter, watched the demonstrations and took notes, and sometimes answered the presenter's questions (University A, Observation 3).

The observational data showed that seminars within a department were conducted in different ways, varied in purpose, and involved different participants. Reporting on their experience of this type of PLD, the interviewed participants preferred informal seminars, and valued an informal environment which offered opportunities for learning from colleagues, reflections on their practices and discussions about teaching problems and solutions. This differentiated the kinds of learning in formal and informal settings.

A key aspect of collaborative PLD was how individual members perceived the role played by others within their community in their learning. The study highlighted different views held by lecturers about learning from internal experts. One lecturer considered it was more convincing and motivating to listen to lecturers from the same context sharing experience. 
It is easier for attendees to be convinced about the effectiveness of the presented teaching techniques because the presenters are colleagues who share the same teaching context. We will have motivation to keep up with other colleagues. A.L2.

However, in a slightly contradictory way, this lecturer added that it would be more persuasive to listen to outside experts sharing experiences because they came from different contexts and thus provided new ideas. She believed that lecturers could learn more from external experts and colleagues than from their local peers. In these instances, she valued networking with colleagues from other institutions for experience sharing and learning. To explain this, she quoted a Vietnamese proverb 'Bụt chùa nhà không thiêng' (The Buddha in a domestic pagoda is not holy), which implies people from the same university are not as recognised by their peers as they would from other universities.

We can learn more from experts from other universities. Lecturers from the same university may feel satisfied with their present situations, so they feel no need for changing their teaching. A.L2

This perception was shared by another lecturer who also seemed to have contradictory opinions about peer learning among lecturers within the department. On the one hand, he reported learning good teaching practices from colleagues. On the other hand, he explicitly expressed his preference for outside experts over inside ones. He believed that lecturers would not learn a lot from colleagues from the same department.

We [lecturers within the department] can organise workshops by ourselves, but 'closing the door and teaching each other' (đóng cưa dạy nhau ${ }^{21}$ ) is not useful. We understand our contexts and we know each other well, so there is nothing new to learn from each other. B.A2

This attitude toward 'closing the door and teaching each other' expressed by B.A2 was congruent with A.L2's perception of 'the Buddha in a domestic pagoda is not holy', as presented previously. Although both lecturers' ideas of internal experts appeared to be contradictory, they related to the different contexts in which PLD took place, and to the

\footnotetext{
${ }^{21}$ This Vietnamese expression refers to a situation of members teaching each other or solving internal problems without the interference of outsiders.
} 
lecturers' learning purposes. This also reveals that tensions might occur within the learning community if there is a lack of shared vision on peer learning and how community members could contribute to the learning of others.

Experience sharing with colleagues through informal dialogue was identified by the participants as an important PLD experience embedded in their daily practice. One leader used the term nói chuyện chuyên môn (professional dialogue) to emphasise the informality of these conversations which he perceived very effective for lecturers' PLD. He explained that the informal environment allowed lecturers to feel comfortable about discussing teaching issues and sharing experience with each other. He also raised the importance of establishing a shared vision or an agreement (đồng thuận) among lecturers about how to address an issue.

It is not a formal meeting. It is like a professional dialogue. It must be open and not cover too many issues. Lecturers share a problem in teaching, discuss it and seek agreement. B.AL5

This leader distinguished between two kinds of agreement. One was an agreement arising from peer-respect implying that no matter what their actual opinion was, people might agree with each other in order to show peer respect and avoid conflict. The other was an agreement resulting from a shared vision when people agreed with each other because they all shared the same view and purpose of getting something necessary done. This leader especially valued the contribution of new staff members.

Agreement (đồng thuận) here is not from peer respect (cả nể), but from a scientific view that it is necessary for us to do something to solve the problem. People share experience and then agree on how to do something, such as how to exploit a teaching material. Experience can come from not only old but also young lecturers. B.AL5

Another experienced lecturer who had an additional role in facilitating research activities within the department was equally open to learn from others. She was eager to talk with other lecturers who had research experience to discuss research problems and learn about researching from them. She acknowledged that this learning improved her ability to fulfil her role. 
I learn from everyone who has experience in research and research management, such as from the Head of the faculty, lecturers with $\mathrm{PhD}$ degrees, normal lecturers, and even students. A.L6

New lecturers were equally keen to learn from their colleagues. A junior lecturer shared that when having difficulty in teaching, she sought advice from more experienced colleagues through informal telephone conversations.

When I am not sure about how to teach some aspects in the programme, I call them [more experienced lecturers] to ask for advice and they show me how to teach these.

A.L1

Most lecturers valued PLD that came about through sharing experiences informally with like-minded colleagues:

I usually share experience with lecturers who are close, like-minded (tâm đầu ý hơp), have the same views about teaching, and sometimes teach the same subjects. This is a good learning experience. We feel comfortable to share all things we know about teaching, and we are happy to observe each other. C.L1

However, some reported that this happened infrequently due to time constraints and workload. Issues of trust and availability were mentioned as barriers to sharing.

Learning from sharing experience was very limited because I found few people who would be willing to share, and share honestly. I can share with people who play with me [i.e., have close relationship], like Y., because we are at the same age. A.L5

Overall, discussing their practice informally was the most commonly reported form of collaborative PLD. Several factors appeared to play an important role in promoting collaborative learning. These included maintaining a focus on addressing teaching problems, promoting learning and experience sharing in informal and voluntary settings rather than formally as an obligation for staff assessment. The lecturers also concluded that PLD was most successful when it promoted mutual support between like-minded lecturers with shared interests. Factors that were perceived to hinder collaborative learning were the practice of peer-respect or lack of peer-respect in feedback giving, and unfavourable 
attitudes towards learning from insider presenters (i.e., when PLD was initiated by insiders).

\section{Informal PLD}

Informal learning was perceived to play a crucial role in the lecturers' PLD experiences. The Vietnamese terms lecturers normally used, tụ học (self-regulated learning), and tụ bồi duõng (self-developing), as briefly mentioned at the beginning of this chapter, reflected a greater sense of personal control on their learning. In this study the term 'self-regulated learning' is used to refer to tụ hoc which takes place when lecturers decide by themselves what they need to learn and how they learn it based on their own needs and available resources. The lecturers reported mainly undertaking tu hoc independently and individually. However, they also gave examples of tụ hoc which occurred when a small group of lecturers got together and learned something of their interest such as practising their English speaking skills. In the latter situation tụ hoc can be seen as collaborative learning, but it is managed entirely by the lecturers themselves. Because it involves lecturers' self-regulation and agency in their learning, tụ hoc is presented as a critical form of informal PLD in this study.

The participants perceived self-regulated learning as an obligatory commitment of lecturers, or an essence of their profession: "a typical feature of a teacher's job is selfregulated learning" (B.A2). They believed that self-regulated learning including agency and self-regulation in their own learning was the most effective way for teacher educators to fulfil their roles.

Self-regulated learning means learning what I like, or learning to self-equip me with what I lack. A.L6

I think self-regulated learning is the most useful activity. We know our own need and inadequacy, and how to improve ourselves. B.A2

The participants across the three sites agreed that informal learning should be ongoing and lifelong, and undertaken frequently because it was flexible and relevant to their needs. Recurring examples of informal learning involved: learning from teaching and 
experiencing new ideas; learning through individual reading and research; and practising their own English skills.

A key purpose for lecturers' informal learning was to update content knowledge and professional skills, which they viewed as critical mediating artefacts for effective teaching and students' learning (i.e., the object of their activity). Reflection and self-assessment were identified as core components of lecturers' informal learning. For example, the participants reported using various strategies to improve their teaching such as using teaching journals, students' feedback, and self-assessment which enabled them to reflect on their teaching and learning experience after each lesson. Others sought feedback on their teaching by asking students for written anonymous feedback.

For self-regulated learning or self-developing, I usually keep a teaching log to reflect on my teaching effectiveness and what needs improvement. I decide what I need to learn more and what kind of knowledge I need for my major or for teaching, and learn it. B.AL1

Informal learning often resulted from teaching dilemmas and was undertaken in order to address lecturers' professional concerns. Lecturers' learning needs were reported to derive from their teaching responsibilities, especially teaching specialised courses (e.g., English or American Literature, Linguistics, Translation), or ESP (e.g., English for Business, Tourism, Banking) which they perceived as 'hard to teach'.

I have to update my knowledge regularly because there are new terms and concepts in both Vietnamese and English language. I have to learn and read a lot to improve my teaching and support students' ability in translation. B.A2

The above response also highlights the unique role of EFL lecturers, and teacher educators, as language learners. Seven participants reported practising and completing the English exercises in the courses they were teaching by themselves before giving these to their students. From this, they could experience challenges the learners might face. This teaching practice was particularly evident when the participants were implementing the foreign language reform which required them to teach a new programme for in-service school teachers. 
The teaching contents in the programme designed for in-service teachers were related to international English language tests such as IELTS and TOEFL. These are quite difficult. If we do not study and prepare well, we cannot teach these things. It takes a lot of time and effort because we have to practise and study these things before being able to teach them. B.AL5

The teaching content in this example seemed to be test-oriented, which required lecturers' practice and preparation to familiarise themselves with the tests and test-taking strategies before being able to teach and share experiences with their learners. Additionally, teaching a new type of learners, in-service teachers, as a part of the reform implementation, also pushed lecturers, especially junior lecturers, to undertake more self-regulated learning to improve their own ability.

Because the learners are experienced in-service teachers, I have to learn and practise my own teaching skills before teaching them. A.L4

Experiential learning was an important form of informal PLD experienced lecturers reported learning from classroom experiences when they attempted to apply new skills in daily practice and review the impact of these changes. For example, lecturers reported applying more motivational strategies to engage students in learning, or trying new ideas when teaching evening classes before using them to teach university students. These were powerful learning experiences which informed their teaching and apparently resulted in improved student outcomes.

Across all sites, lecturers' individual research was conducted in different forms, such as individual research at MOET level, provincial level or institutional level, designing course-books and teaching materials, presenting their research at professional workshops or conferences, and writing articles for publication. Generally, the participants valued the importance of research in their teaching. However, they expressed different levels of commitment to research, as presented in individual site findings (Chapter 4).

All participants perceived that it was necessary for lecturers to improve their own language competence, and to meet the standard of language officially set for lecturers. These participants were interested in seeking opportunities to improve their language proficiency such as learning with foreign experts in formal and/or collaborative activities, 
or studying in an English speaking country, as described in the previous sections. However, due to the limitations of these PLD opportunities, 24 out of 26 participants reported taking the initiative and practising the language by themselves, using English books, CDs, news, media, and other resources to improve their skills. For example, B.AL5 reported that in his free time, he listened to English tapes, and practised his pronunciation and oral skills. Another participant reported individual learning to improve English and teaching skills.

I studied from online resources. I also watched English films, practised IELTS, and learned more about how to teach English. C.L6

The participants shared a desire to improve their language competence. They believed that their English proficiency could be enhanced through various PLD activities, as illustrated in Figure 5.1.

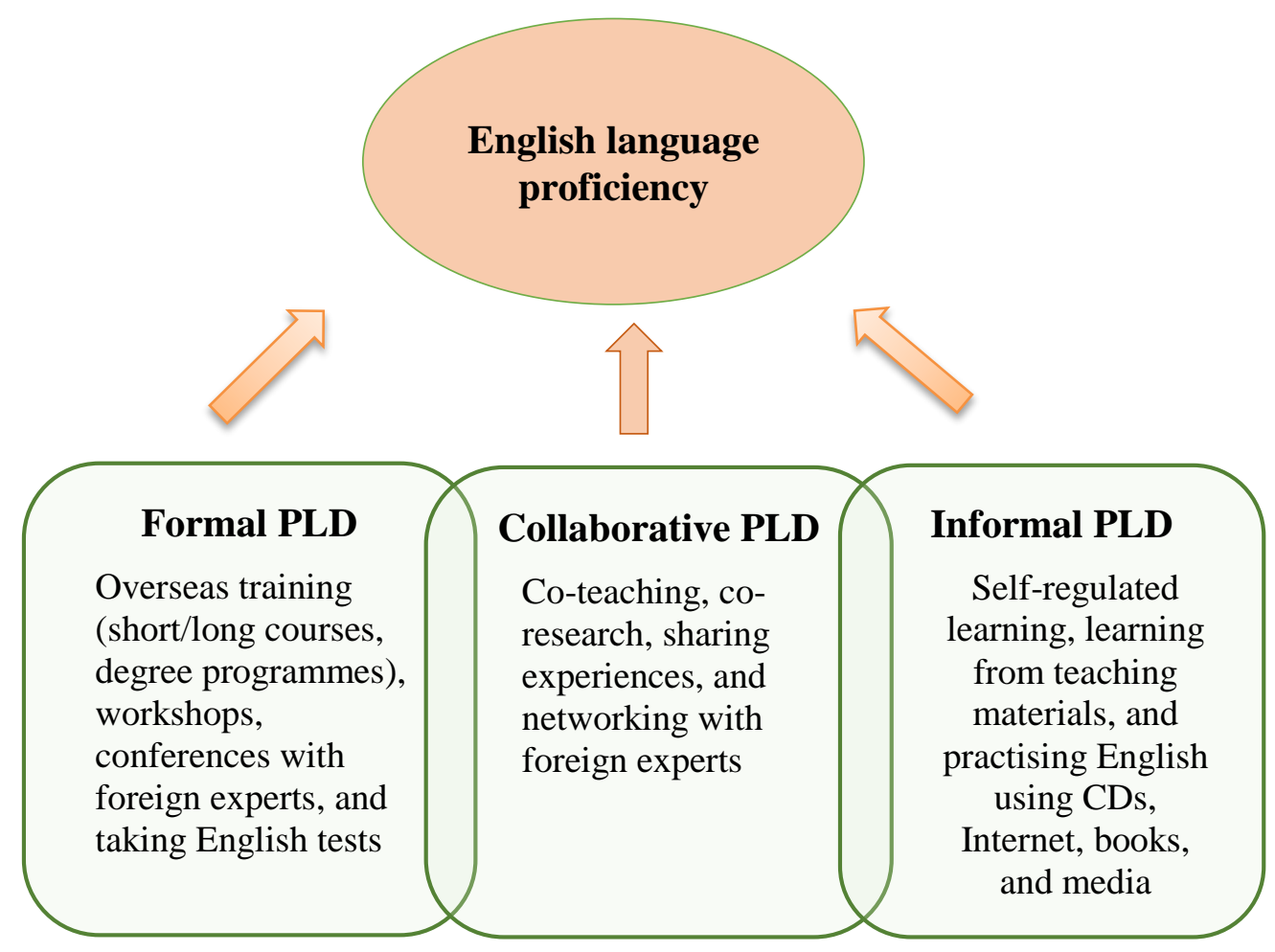

Figure 5.1 PLD for improving English proficiency

Among the strategies to enhance their language, independent PLD was reported as the most accessible activity. Although the figure reflects general perceptions and 
experiences of participants across all sites, the desire to improve language proficiency was expressed most strongly in site B. The participants' responses showed that informal PLD occurred both inside and outside the lecturers' classrooms or institutions, and was more likely to be incidental or unplanned. This included daily talks with colleagues or their students at break time, reading news in Vietnamese, chatting with a foreign volunteer working at the university, and even during a formal PLD session when the lecturer picked up something they found interesting or relevant for their personal life while watching the presenters. It centred on learning from different members within the lecturers' community. Given that learning tended to be tacit and implicit, and incidental or unplanned, lecturers appeared not to be aware of this learning, and they did not explicitly indicate this as a key PLD model. Their reported learning experiences, however, suggest that informal PLD played a key role in these lecturers' professional lives.

Overall, participants' perceptions of PLD were informed by a complex amalgam of their expectations of PLD roles and functions, and through their experiences of different forms of PLD. Lecturers at times differentiated formal, informal, and collaborative PLD, yet these kinds of learning operated simultaneously. Even when attending formal events such as training courses, workshops, and conferences, collaborative and informal learning occurred through lecturers' explicit or implicit reflections on their own practices and beliefs, and through self-assessment of their own competences, leading to some ideas for self-improvement. Overall, the participants shared a perception that self-regulated learning was an essential mode of PLD for members of the teaching profession, a professional responsibility, and the most effective type of informal PLD available. They reported selfregulated learning through the process of teaching preparation and reflection, conducting individual research, preparing for post-graduate studies, and language proficiency practice.

In summary, this section integrated findings from both quantitative and qualitative phases. These show that PLD for the Vietnamese teacher educators occurred in diverse ways (e.g., formal, collaborative, and informal PLD) and for different purposes. A summary of these forms of PLD and their common features is presented in Table 5.1. 
Table 5.1 Participants' experiences of PLD

PLD forms $\quad$ Common features

Formal Occurring in formal settings; with an expert model; one-off events, involving large numbers and mixed types of participants; employing few or very general forms of PLD evaluation; few or no follow-up activities

Collaborative Mainly occurring within the department; mostly assigned tasks; involving sharing and discussing ideas; practising and reflecting on practices; peersupport; learning through working with others

Informal Mainly occurring individually and in informal settings; involving selfreflection, self-assessment, self-regulation

In practice, PLD appeared to be a fluid phenomenon experienced by the participants in different ways according to how they engaged in PLD and their motives for engaging in PLD. Therefore, there were no fixed classifications of PLD forms and PLD activities. Also, none of the reported or observed PLD activities was entirely formal, informal or collaborative. There might be formal, informal, and/or collaborative elements within a particular PLD activity. For example, seminars could be either formal or informal, and/or collaborative depending on how they were actually organised and engaged in. Similarly, there is an example of how shared research activities could be undertaken individually without much peer discussion or collaboration (i.e., members worked individually to finish their sections which would be compiled later to create the final product). Lecturers also reported different levels of engagement and learning within a specific PLD event. For example, they reported more meaningful learning when engaging in informally-designed activities (e.g., discussions of teaching practices, practices new teaching techniques) within a formal PLD session (e.g., a training course). This highlights an interplay among the three 
forms of PLD as well as among different specific PLD activities, as illustrated in Figure 5.2 .

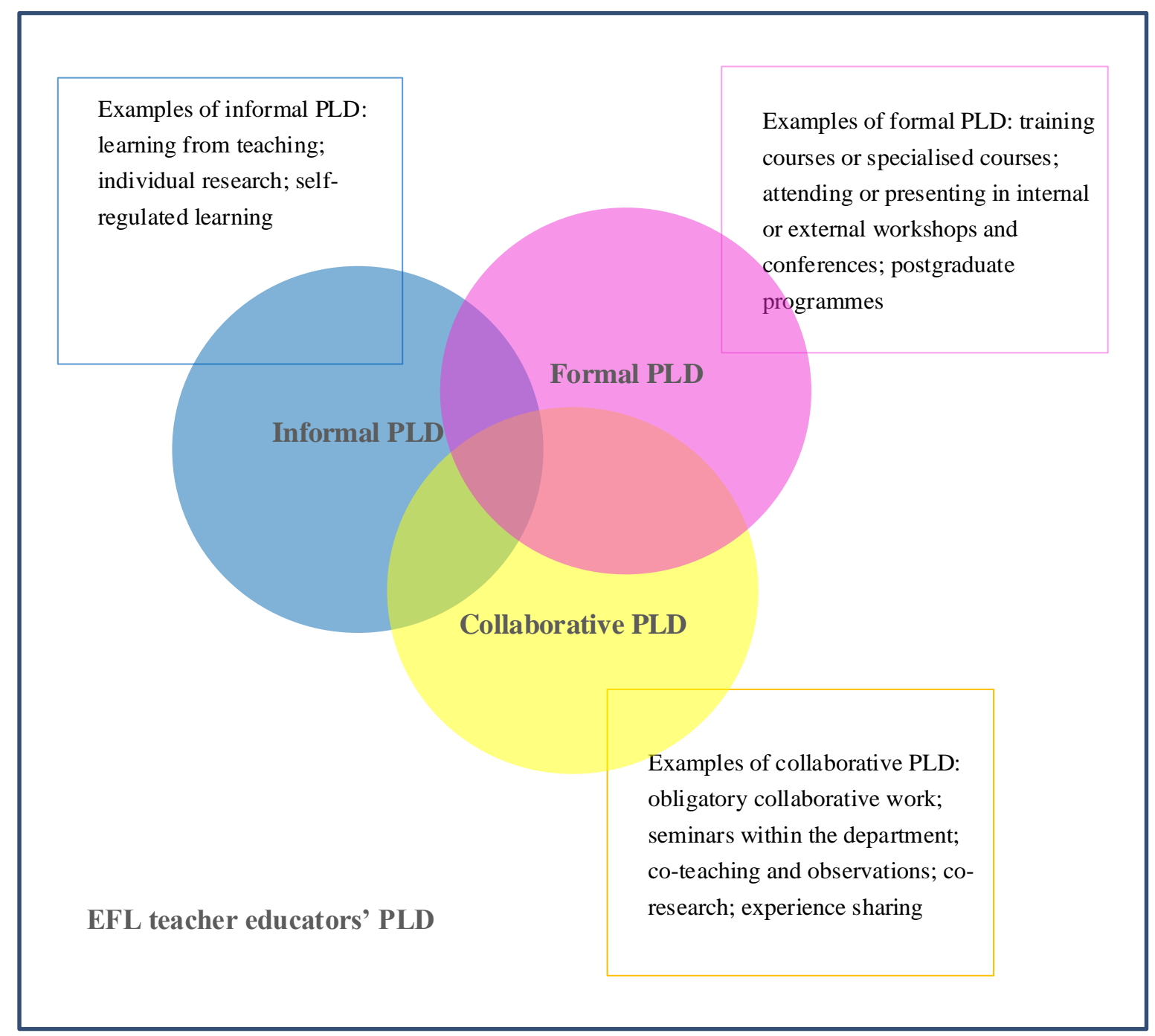

Figure 5.2 Interplay among PLD forms

The classification of PLD activities according to these three main forms, as illustrated in Figure 5.2, is tentative and based on how these activities were defined and experienced by the participants in the Vietnamese contexts. This study explored how the participants engaged in different PLD activities and the meanings they attributed to their experiences. However, it aimed for a holistic understanding of the PLD phenomenon rather than evaluating each type of PLD and drawing conclusion about which kind of PLD can be considered as the most effective. 
Although the teacher educators valued all forms of PLD, contextual factors (e.g., time, workload, leadership) and cultural practices (e.g., peer respect, indirectness in communication) might at times hinder their engagement in some PLD activities. In the next section, a CHAT analysis presents how the lecturers' PLD took place, and explores when and why tensions and contradictions occurred within the PLD activity systems in the three sites.

\section{CHAT analysis of the three sites}

The previous section draws together findings from all data sources and presents how PLD for the EFL teacher educators was experienced by the participants. This section utilises a CHAT lens to further explore dimensions of PLD for the lecturers in their tertiary contexts, and to focus more on how PLD was operationalised at a system level. The analysis highlights the complex interactions among different elements of the PLD activities systems. The CHAT analysis of the three sites captures different perspectives of the PLD activity systems in their contexts. The analysis identifies both distinctive features of PLD within each site activity system and commonalities in relation to PLD across the three university settings.

\section{Exploring dimensions of PLD through a CHAT analysis of each site}

Although the three university sites were all public universities, they had their own regulations, prioritised initiatives, resources, and cultures which influenced the operation of PLD for the lecturers within their organisations. The CHAT analysis of PLD in each site will explore further different aspects of the PLD activity system in its specific context and highlight the influence of contextual and cultural factors on PLD for the lecturers. The following CHAT analysis of each site offers more insights into the complexity of the PLD phenomenon and the dynamic systems within which PLD took place.

\section{A CHAT analysis of site A}

In addition to shared features related to PLD as presented in the earlier section, the CHAT analysis of site A highlights tensions in the lecturers' experiences of working within their community, and the impact of institutional regulations on the lecturers' PLD engagement. 


\section{Tensions for lecturers' working within their community}

At this site, there seemed to be some confusion around the delineation of roles between the academic leaders and the EFL lecturers. For example, the academic leaders commented that most lecturers did not meet the standards (e.g., qualifications and research ability) of tertiary teacher educators. The leaders believed that lecturers' 'craft-workers' approach (i.e., following a rigid teaching style, not being creative in facilitating students' selfregulated learning) made students into passive learners. The lecturers were expected to enhance their own agency through learning and research rather than seeking training from outside experts.

Taking a contrasting perspective, all of the six interviewed lecturers reported making an effort to engage in $t \underline{r}$ hoc (self-regulated learning) and updating their knowledge and skills. The lecturers were confident that they could facilitate and improve students' lifelong learning skills. These lecturers highlighted the importance of formal training as a way to enhance their confidence and qualifications to teach and research.

The power imbalance between the senior and junior lecturers was a cultural influence on the lecturers' experiences of PLD. Two junior lecturers reported feeling more comfortable sharing their teaching experience with peers of the same age and position rather than with senior colleagues. Their hesitance in asking for assistance or instructions from more experienced colleagues arose from their reluctance to take up time in these senior lecturers' busy schedules. Another culturally influenced example was of a junior lecturer who reported listening to the opinions of senior colleagues and accepting their decisions rather than contributing her own ideas to the team. This behaviour is consistent within Vietnamese culture where the young are expected to obey and show respect to the more experienced in a group. This junior lecturer also reported facing pressure when the senior colleagues kept urging her to attend a postgraduate programme without taking into account her heavy teaching load and her desire to apply for a postgraduate course. The habitual indirectness in communication between the young and experienced lecturers may have caused tensions and inhibited meaningful collegial support for the young lecturers' PLD. 
Such differences between leaders and lecturers, as well as junior and senior lecturers, created tensions for the lecturers individually and collectively, and made it difficult for a group to work effectively when lecturers did not understand others' the expectations of them. In Figure 5.3, the tension between the lecturers and other members of their organisation is illustrated by the jagged line between the lecturers (i.e., subjects) and the community within which they work.

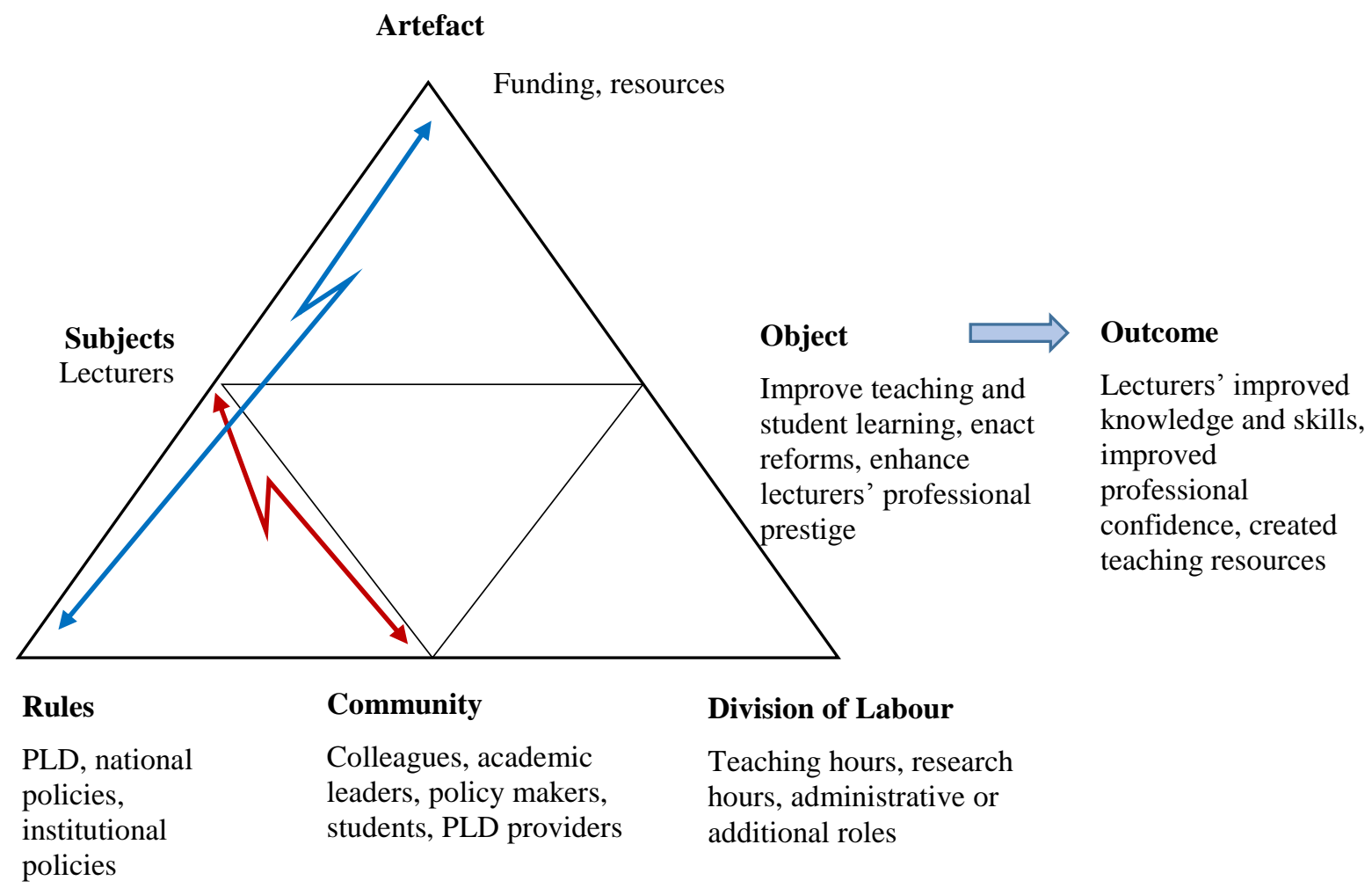

Figure 5.3 The influences of PLD within this system (Site A)

\section{Tensions from policies applied to PLD}

At site A there was a tension inherent in the selection process for lecturers to attend PLD events (i.e., rules), and the PLD opportunities (i.e., the artefact), as depicted by a jagged line between the rules and artefact in Figure 5.3. This tension was felt particularly strongly by young members of staff. The junior lecturers reported that they had limited opportunities to participate in formal PLD, especially in intensive specialised courses, compared to their more experienced peers. The young lecturers also suggested more appropriate selection criteria which were not only based on formal qualifications and experience. 
Regulations related to assessing research projects were also perceived as problematic by one experienced lecturer. This lecturer commented that approval of research proposals and funding were more likely to be given to applicants with a PhD degree, or to researchers on big projects which generating large funds rather than those working on small research projects. This unspoken selection criterion, together with complicated paperwork and registration processes for research and funding application, hindered the lecturers' motivation for research.

Two leaders emphasised changes within the department initiated to better support the lecturers' PLD engagement. They gave examples of encouraging and funding collaborative learning through organising seminars in which lecturers could share teaching experience with each other. The leaders also reported having a strategic plan designed at 'bottom-up' level, by the lecturers within the department. The plan allowing the lecturers to state their PLD goals would be used to facilitate the provision of PLD relevant to individual lecturers' needs and preferences. The leaders' reports were confirmed by three lecturers who appreciated their increased PLD opportunities.

Within site A, institutional and departmental regulations (rules) were found to create both challenges as well as enablers to the lecturers' PLD experiences (artefacts). The analysis highlighted how a bottom-up PLD plan was likely to ensure that lecturers could access relevant PLD.

\section{A CHAT analysis of site B}

The second site-specific example highlights the influence of institutional regulations on the lecturers' PLD experiences, as well as the lecturers' reports of their limited access to PLD opportunities. Findings from site B add insights into the interrelations between PLD and the social, cultural, and political context in which it was embedded.

\section{Contradictions in institutional PLD regulations}

Within site B, PLD such as research and self-regulated learning was identified as an obligatory professional activity, and as such, was viewed as the rule. The institution had introduced a new policy in which research engagement was the key criterion for assessing lecturers. The purpose, or object, was to improve lecturers' research and qualifications. 
However, other institutional rules, such as those related to managing and evaluating lecturers' research were perceived by both the lecturers and academic leaders as inhibiting their engagement in research. For example, the lecturers reported that the paperwork and application process for research funding were complicated, and that in their experience, funds were limited.

The contradiction between the objective of enhancing lecturers' research engagement (object) and the institutional regulations to support research activities (rules) became marked when the institution planned to eliminate research funding in the coming year. As seen in Figure 5.4, this tension was depicted as a jagged line between the object and rule of the activity system. As a result, these lecturers worried about their ability to meet the demands to research without favourable supporting regulations. The new policies created an external force that obligated all lecturers to conduct research if they wanted to achieve good annual assessment. This was exacerbated by the cultural expectation of respecting and obeying authority. However, these lecturers believed that eliminating funding would reduce their motivation and actual commitment to conducting research. They also questioned the possible quality of research when all lecturers were required to do research regardless of their ability, experience and other related skills.

The CHAT analysis of site B highlights how the new policies appeared to create unintended consequences or outcome (i.e., reducing lecturers' motivation and support for their research rather than promoting their research capability). This also revealed tensions within the institutional policies themselves. Tensions inherent in the institutional policies were depicted by a circle with a jagged arrow within the rule component in the diagram.

These contradictions inherent in the regulations contributed to the reported tensions between the lecturers' engagement in collaborative learning such as collaborative research (i.e., artefact) and the institutional aim of promoting lecturers' research (object). The lecturers reported that collaborative research was not encouraged or undertaken simply because they preferred to conduct individual research during mandatory research hours. As a result, in this university community, the conditions for research did not favour or encourage collaborations. 


\section{Limited PLD opportunities as artefacts}

Within university site B, the lecturers reported limited access to PLD opportunities, both within and external to their institution. They noted that lecturers lacked financial support from the university to attend external PLD. Site B lecturers expressed a strong desire to attend training overseas, which they believed essential to their teaching and the enhancement of their professional skills and confidence as EFL teacher educators. The lecturers wished that the institutional leaders would support them by providing information about postgraduate scholarships or training overseas.

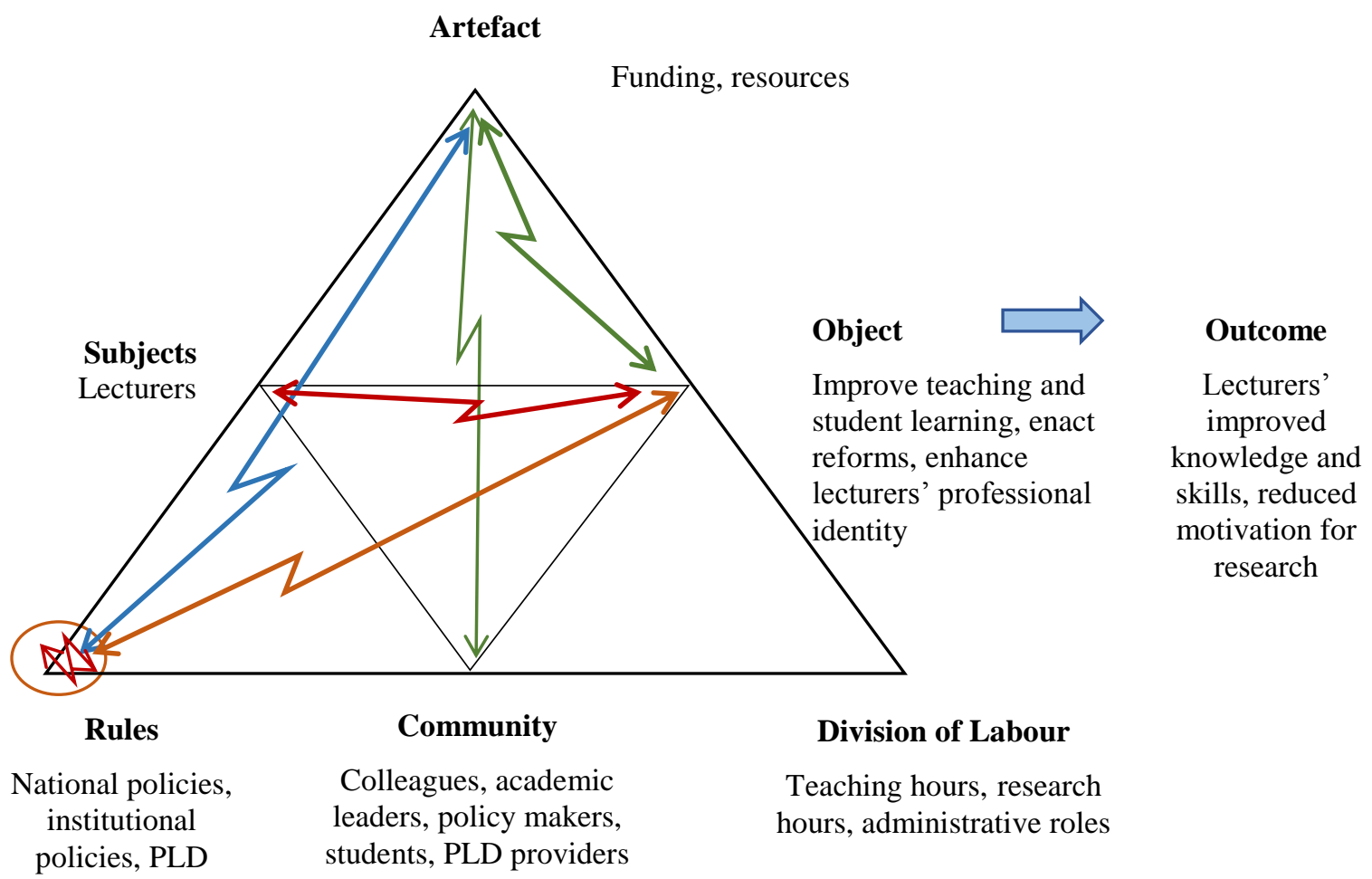

Figure 5.4 The influence of institutional regulations on PLD (site B)

Within the institution, conferences and workshops for lecturers were usually organised at institutional level by the International Relations Office, or the Centre of Foreign Languages rather than at departmental level. Therefore, the lecturers reported that they were not involved in the PLD planning process, and provided PLD events were not always relevant to their needs. Clearly these lecturers wished to have more agency in organising their own PLD within the department. They also proposed the implementation 
of collaborative PLD like seminars or experience-sharing led by the lecturers within the department. However, they highlighted that for such a model of PLD (i.e., lecturer-led PLD at departmental level) to take place, there needed to be support from the institution as well as a shared vision among the lecturers in the department.

It was important to note that while most lecturers would have liked to attend more PLD events and engage in on-going learning opportunities, a leader commented that the lecturers had sufficient PLD (e.g., training within and external to the institution) for the implementation of the reform in foreign language teaching. These opposing views indicated tensions resulted from a mismatch between the leader and lecturers in interpreting the lecturers' PLD needs and preferences.

The tensions and contradictions within the PLD activity system in site B were closely associated with the implementation of institutional regulations, especially since PLD was identified as an obligation. These tensions and contradictions acted more as barriers than motivators for new lecturers to engage in PLD. Four lecturers perceived their roles as a professional burden or a challenging responsibility because of the increasing professional demands from the institution. As a result, these lecturers faced the dilemma of dividing their time and resources between their own personal PLD and their other professional responsibilities. Three lecturers reported having to delay their postgraduate studies and independent learning so as to prioritise their teaching responsibilities. These contradictions created a great deal of tension within the PLD activity system in site B which was unlikely to be resolved without a shift in the rules to support the lecturers' PLD engagement.

\section{A CHAT analysis of site C}

The third site provided further insight into the complexity of PLD within a tertiary environment. Within site $\mathrm{C}$, the CHAT analysis revealed complex interactions among different elements of the lecturers' PLD activity system. The findings highlighted three key aspects: (1) the tension facing lecturers to comply with the institutional regulations, (2) contradictions arising from leadership, and (3) the lecturers' uncertainty about mandated rules. 


\section{Tension from complying with the institutional regulations}

Within site $\mathrm{C}$, the participants reported the challenges from institutional regulations about the annual assessment of their academic and teaching performance. The objective of the assessment was to improve lecturers' teaching quality and ensuring that they fulfilled their responsibilities. However, as described in Chapter 4, the participants reported a critical tension: the assessment regulations within the university created pressure and in their view unnecessary additional work, rather than promoting meaningful learning. For example, lecturers were required to submit multiple documents for the courses they taught. This was time-consuming and these lecturers tried to comply with the regulations rather than being really committed to these activities.

The above regulations made assessment into a burden (i.e., unexpected outcome), rather than promoting lecturers' learning and developing quality teaching (i.e., intended outcome set by the institutional leaders). The assessment exercise took time away from engaging in self-regulated learning or research which lecturers perceived as more relevant and important for their professional growth. Ironically, one interviewed leader reported being aware of this problem yet was unsure about challenging the institutional regulations. The combination of lecturers' sense of responsibility for complying with competing regulations, and the academic leader's hesitance about raising problems in the policies reinforced a Vietnamese cultural expectation that subordinate members should show respect and obedience to authority within their organisation. Within the university activity system, PLD as an 'artefact' revealed tensions within the institutional regulations themselves (the rules), and the influence of these regulations on lecturers' learning (the object), as illustrated by a jagged line between the rules and artefact in Figure 5.5. 


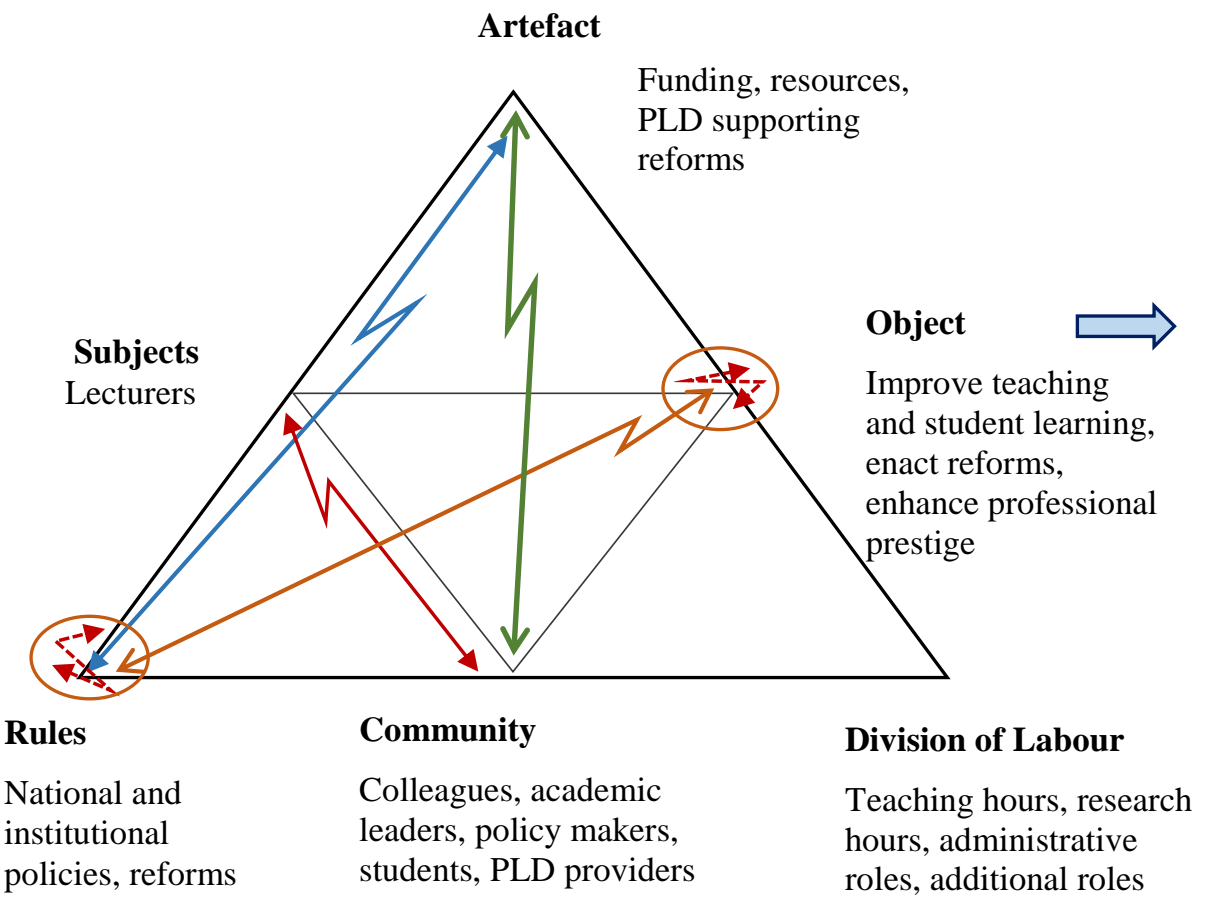

Figure 5.5 The interactions among components of the PLD activity system (Site C)

\section{Contradictions arising from leadership}

Leadership was identified as an important consideration in how PLD was conceptualised and experienced. A typical finding from site $\mathrm{C}$ was that the lecturers expressed a concern about the effectiveness of leadership in supporting their PLD. The issue of fairness in allocating work and assessing lecturers was raised by three lecturers. They reported that within the department, hard-working lecturers were assessed as performing to an equal standard as their colleagues who appeared to be less conscientious. Additionally, some lecturers had more teaching and departmental professional responsibilities than their peers, even though there was no recognition of this increased responsibility. These lecturers commented that the lack of transparency and fairness in assessing lecturers' performance reduced their motivation and commitment to engage in PLD and other professional tasks. Site $\mathrm{C}$ lecturers wanted more equitable work division and better recognition of their contribution within the department.

This issue of unequal work division directly impacted on lecturers' collegial relationships and engagement in collaborative PLD. As one leader noticed, when asked to 
work in small teams to complete certain professional tasks, lecturers tended to avoid including those colleagues whom they believed were not productive. The metaphor 'happy face, unhappy heart' (bằng mặt nhưng không bằng lòng) alludes to avoiding showing direct disapproval of other members.

The two leaders, however, appeared to be unaware of the lecturers' expectations of fairness in the workplace, perhaps because the lecturers did not express their opinions about this issue directly. One lecturer described his declining motivation in reaction to the unfair evaluation of lecturers' performance:

I have lost the motivation to work. I still complete the assigned tasks, but do not make an effort to complete it to a high standard. C.L4

The two leaders acknowledged that they were uncertain about their power and possibilities to challenge or modify particular institutional regulations in order to support the lecturers' PLD. Furthermore, because the leaders also had teaching responsibilities at the university, they reported facing pressure in engaging in PLD that supported both their teaching and management roles. One of the two leaders admitted that she had not received any PLD on leadership. She reported learning management skills through her daily practices. This leader's responses highlighted that she relied on informal PLD to manage her new leadership role.

At this site, on the one hand the lecturers wanted more effective leadership practices and support, while on the other hand the leaders struggled with the scope of their roles and were unsure how much power they had to enact institutional regulations within the department. These controversial issues had the potential to cause tension, as depicted by a jagged line between the lecturers (subject) and their leaders (community members), when collaborating on PLD activities. For the tension to be resolved, it was necessary to develop a shared understanding of the roles and expectations of each of the two groups.

\section{Uncertainty about mandatory rules and reform object}

This research took place in a context of government reforms where lecturers essentially had little choice but to engage with these changes. However, for top-down reforms in education to be effectively enacted, all who were involved in the change process needed to have a 
shared understanding of the reforms and how to implement them. At site $\mathrm{C}$, three out of six lecturers reported having only a vague understanding about the rationale of the reform in foreign language teaching or how to implement it. One lecturer asserted that the department had not undertaken any actions to address MOET's expectation, and noted that few lecturers in the department were actively engaging with the reform initiatives.

In contrast to the lecturers' perceptions of reform implementation, the two leaders reported completing an official strategic plan including several stages to enact the reform. They also reported assigning the lecturers to undertake initial activities of the reform enactment. These activities included redesigning the educational programmes, selecting new teaching materials, and designing teaching syllabi. Two lecturers confirmed that they had been assigned by the Head of the Department to participate in these activities, which in turn had become a meaningful PLD experience for them.

The differences in the participants' responses revealed a lack of shared understanding about the reform rationale and enactment (i.e., object). Also, within the department, the lecturers had different levels of awareness and commitment to PLD related to the reform (i.e., artefacts that mediated the implementation of the reform). That a lecturer was not aware of the process and activities involved in the reform implementation showed a mismatch in communication between members of the department regarding the reform and related PLD activities.

Additionally, this issue seemed to derive from the fact that site $\mathrm{C}$ did not receive many resources like MOET training to support the lecturers' implementation of the reform whereas the other two sites did. The lack of MOET training and supporting resources (artefacts) and feasibly the lack of clarity around the reforms from institutional leaders may have led to some lecturers' confusion. Within the activity system, this referred to the tensions caused by the object of the activity itself (ambiguous object), as well as tensions between the lecturers' ability to enact the reform (rules) without sufficient support and PLD opportunities (artefacts). In Figure 5.5, tensions within the object itself was illustrated by a jagged arrow within a circle at the object component.

The above analysis of PLD within individual sites reveals that variations in institutional policies, structures, resources, and developmental plans influenced the 
lecturers' PLD opportunities and engagement. However, the differences across the three sites were not clear-cut because the universities shared the general Vietnamese tertiary educational context, cultural values, and impacts from the government's educational policies.

\section{Commonalities across the three university sites}

Across the three sites, there were common features of lecturers' experiences of PLD, factors affecting their PLD engagement, and tensions and potential contradictions within the PLD activity systems. Key commonalities included (1) multiple voices and perspectives of PLD role and function, (2) tensions around roles and division of labour, and (3) contradictions between lecturers' collaborative learning and cultural practices.

\section{Multiple voices and perspectives of PLD role and function}

The different stakeholders' interpretations of the role and function of PLD were influenced by their own roles within the organisation. The diversity of these perspectives on PLD role and function created some tensions and even uncertainties within the organisations. When PLD acted as artefact within the system, it was valued differently by different stakeholders who varied in their object. Indeed, the different objects prioritised by MOET/ policy makers, the lecturers, and institutional leaders led to differences in the ways they saw PLD as a means to achieve their objects. For example, the analysis of national policy documents in Chapter 4 showed that policy makers were more likely to link PLD to national educational reforms, national goals in education, and the improvement of tertiary lecturers' formal qualifications and research. When MOET or policy makers' object was to support the government reforms, they wanted the outcome to be reform enactment, lecturers' higher qualifications and research ability. Professional learning and development from this perspective appeared to be more formal, leading to higher qualifications. Such PLD was more likely to be used as a tool for assessment of lecturers' performance rather than encouraging informal and collaborative learning among the lecturers.

The data show that the institutional leaders shared these broad views when emphasising the roles of PLD in enacting national and institutional initiatives. In addition, PLD was also considered as a requirement for lecturers so that they were more capable of 
supporting the institutional goals and missions. For example, an academic leader in site A viewed PLD as 'social responsibility' (trách nhiệm xã hội), indicating that lecturers needed to engage in PLD to meet the social need of providing better education quality. This leader also emphasised that the lecturers were expected to get a doctoral qualification because the university needed a sufficient number of staff with doctorates to introduce postgraduate programmes in the future. For these leaders, an increase in the number of lecturers with $\mathrm{PhD}$ degrees would also help to raise the rank of their university nationally and internationally, as stated in the university goals. This reflected the object of the institutional activity system.

Taking a pedagogical perspective, most lecturers across the three sites expressed an interest in PLD that directly supported their teaching and students' learning. When the lecturers were aiming to develop their professional image, they saw PLD as a mechanism to support both personal and professional growth (i.e., the object of lecturers' activity system). For example, they all considered self-regulated learning meaningful and useful PLD because it helped them to improve knowledge and skills for better teaching. They highlighted the importance of PLD in enhancing their confidence and self-efficacy. The lecturers across the three sites engaged in collegial discussions and experience sharing to support the implementation of reforms. They considered these as meaningful and necessary professional learning activities. Therefore, the lecturers' PLD engagement revealed that they valued and prioritised informal and collaborative PLD which directly supported their responsibilities in teaching and reform enactment.

Although there was a shared outcome of using PLD to enhance teaching and learning quality in tertiary education, the different views among the policy makers, institutional academic leaders, and lecturers regarding PLD role and function seemed to create tensions within the lecturers' PLD activity system. Tensions occurred when the lecturers sometimes had to postpone their own personal and preferred PLD to invest their time and effort in required PLD to meet the expectations from the leaders and policy makers (i.e., the rule lecturers had to follow).

The different views of the role of PLD and tensions across the three sites can be illustrated through Figure 5.6 that shows, although the intent for the PLD as a mediating 
artefact was often the same, the object was quite different dependent on the perspectives and roles of those involved.

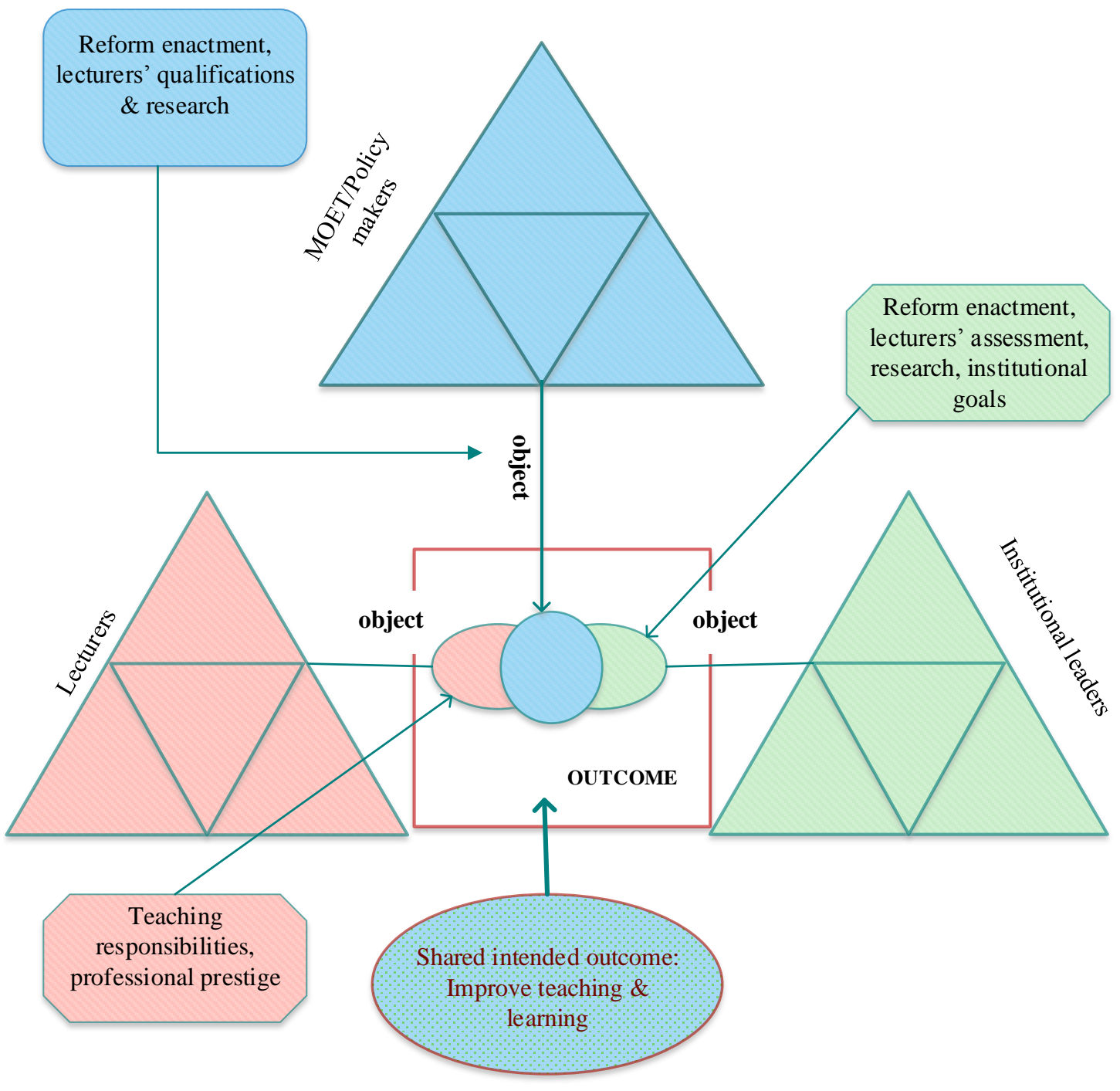

Figure 5.6 Different perspectives on PLD role and function (PLD as artefact)

\section{PLD created questions around division of labour}

Aiming to enact national reforms in education, the institutions issued several regulations requiring the lecturers to engage in research, study for higher degrees, and meet English proficiency standards. In this situation, PLD became a part of the rules within the lecturers' activity system. In Vietnam, there is a cultural imperative for lecturers to follow their 
leaders' directions and to avoid actively questioning authority or government regulations. Consistent with this cultural norm, then, these cultural features of respecting and obeying authority influenced how the lecturers viewed the requirements as rules. Most of the lecturers considered their leaders' directives as motivational, and an expression of the leaders' care for their PLD.

In contrast, the lecturers faced the challenge of complying with institutional regulations without supporting policies. This created tensions for the lecturers in terms of when to complete PLD, and for what reason. Indeed, findings from both quantitative and qualitative phases showed that all lecturers identified workload and time constraints as the two biggest barriers to their enactment of educational reforms and participation in PLD activities. Their allocated workload reportedly increased as a direct consequence of implementing education reforms. All lecturers reported having to spend extra time on teaching preparation, assessing students' learning, and facilitating in-service teachers' learning, which negatively affected their time for independent learning and other PLD activities.

Besides their teaching and research responsibilities, eight lecturers reported being assigned to undertake additional work such as being learning advisors, and attending meetings and activities which were not related to their teaching (e.g., activities of the Labour Union and Youth Union ${ }^{22}$ ). Commitment to these additional roles prevented them from exploring some PLD options.

\section{Contradictions between collaborative learning and cultural practices}

Given that PLD is a complicated phenomenon embedded in the social, cultural, and historical context in which it took place, it is important to understand the influence of cultural practices on the lecturers' engagement in PLD. A key finding in sites B and C was that the lecturers' cultural practices of avoiding conflicts, maintaining group harmony, and showing respect for peers appeared to hinder their full engagement in collaborative learning. As explained in Chapter 4, observations and feedback were made obligatory to

\footnotetext{
${ }^{22}$ Labour Union (Công đoàn), Youth Union (Đoàn Thanh niên): social organisations within a university that facilitate labour rights and organise entertainment and community service activities for lecturers.
} 
promote the lecturers' collaborative learning as well as improving teaching. However, in practice, although valuing collaborative learning, participants commented that these PLD activities did not enhance their peer learning. Conversely, the practice of following an implicit rule called 'all-passed assessment' undermined the reliability of peer assessment and violated professional ethics when lecturers glossed over weaknesses in their colleagues' teaching.

Although the lecturers' attitudes and behaviours related to the implementation of peer observations (the practices of either showing peer respect or no peer respect) conformed somewhat to Vietnamese cultural values, these practices appeared to conflict with the lecturers' professional ethics and desire for authentic collegial learning. This issue led to contradictions between collaborative PLD (as an artefact to support the lecturers' teaching) and inter-relationships among those were involved in this kind of PLD (the community within which it took place).

\section{Summary}

Overall, the study findings show that PLD was perceived by the participants as an essential aspect of their profession and a crucial tool to support their roles of being teacher educators in Vietnamese HEIs. Lecturers reported a diversity in their engagement of PLD occurring across formal, collaborative, and informal forms for different individual and professional purposes. The CHAT analytical lens reveals the complexity of the sociocultural, political and institutional contexts within which PLD for lecturers was conceptualised and operationalised. It highlights multiple voices, perspectives, interrelated factors, and potential sources of tensions and contradictions within and across the PLD activity systems. This enables an insightful understanding of the phenomenon of PLD for Vietnamese teacher educators. A synthesis of the study results, described in Chapters 4 and 5, and a discussion of the study findings will be presented in the next chapter. 



\section{CHAPTER 6 DISCUSSION}

The results from this study challenge the traditional understanding of PLD as top-down initiatives or activities designed by external experts merely for upskilling or 'fixing' lecturers' deficiencies in knowledge and teaching skills. Instead, the study positions PLD as a multifaceted phenomenon which is shaped by educational policies, lecturers' practices and teaching, and cultural values. This conception of the phenomenon of PLD is considerably broader and integrated within the lecturers' real-life working context. The study aimed to understand the complexity of PLD for tertiary lecturers at both system and individual levels, as well as the interrelations among all elements of the activity systems in a Vietnamese dynamic tertiary educational context. The results facilitate a more sophisticated way of looking at PLD by foregrounding the rich qualitative accounts of these PLD lecturers, to reveal the different motivations for their engagement in PLD and the outcomes of this engagement.

In terms of methodology, the first phase of the research captured an overall picture of PLD for EFL tertiary lecturers through a quantitative data analysis. The case study across three sites then explored in-depth the lecturers' perceptions and experiences of PLD, and meanings held about PLD engagement in their authentic tertiary settings. Specifically, the policy document analysis highlighted contextual features and imperatives in Vietnamese tertiary education. The analysis of interviews and PLD observations further exposed the multiple dimensions of the lecturers' experiences of PLD. The CHAT analysis of the three university sites took into consideration the complex, interrelated physical and social factors embedded in the PLD activity systems and highlighted tensions and contradictions within and between the activity systems.

The study findings foreground PLD as a core component of the lecturers' profession, and a driver for their professional commitment and identity enhancement. The CHAT analysis, as described in the previous chapter, provides further understanding of the interdependent relationships operating within and across the lecturers' PLD activity 
systems, as well as the influence of the wider Vietnamese sociocultural, political HE environments on lecturers' PLD experiences. The following sections discuss three fundamental and interrelated concepts underpinning EFL teacher educators' PLD engagement and understanding of their PLD: the sociocultural context of tertiary education in Vietnam, the professional identity of EFL teacher educators, and the nature of EFL lecturers' learning. The final section in this chapter revisits the research questions and offers an overall description of the responses to these questions.

\section{The sociocultural context of tertiary education in Vietnam}

To understand how PLD for Vietnamese EFL lecturers was conceptualised by different stakeholders (e.g., lecturers themselves, academic leaders, and policy makers), and then subsequently operationalised, it was important to explore in depth the sociocultural and political context in which PLD occurred. The results from both the quantitative and qualitative phases of the study highlighted that cultural values in Vietnamese society were a major influence on lecturers, and on the educational system and institutional structures within which they worked, as also found in previous studies (Hayden \& Lam, 2007b; Tran, 2015; Truong, 2013). These cultural values shaped the lecturers' engagement in their profession. This section centres on key sociocultural features within this dynamic environment. A critique of the educational policies and innovations in Vietnamese HE, lecturers' responses to mandatory initiatives, and impact of institutional features on lecturers' PLD engagement also adds insight into the PLD context.

The study revealed the influence of hierarchy, centralisation, and collectivism within the Vietnamese tertiary context. The hierarchical system, MOET power, and top-down policies inherent in enacting educational reforms in Vietnam are consistent with characteristics of reform implementation and challenges faced by other Southeast Asian countries (Hallinger, 2010). These issues were revealed by the lecturers' adherence to policies and practices expected of them, and their peer interactions with those in superior positions. This impacted on their experiences of PLD because at times, they undertook PLD to either please their leaders or to support their own promotion prospects. 
The cultural and social expectation of giving respect and obedience to authority was evident in the study and often marked the power differential within organisations. As noted in previous studies in Vietnam and other Asian contexts (House, Hanges, Javidan, Dorfman \& Gupta, 2004; T. H. Pham, 2014; Tran, 2015; Truong, 2013), power is a cultural outcome afforded to people with leadership, seniority, experience and age. These cultural features of a hierarchical society impact on the operation of tertiary institutions, their policies and leadership styles. Qualitative findings showed that within a multi-layered administrative environment, subordinates were expected to follow requirements from the higher level leaders. Educational changes and initiative decisions were typically decided by the leaders, which subsequently restricted lecturers' agency in their own PLD as well as in shaping their professional trajectories.

In Vietnam, MOET plays a decisive role in educational programmes and mandatory policies applied in tertiary education. The case study findings (Chapter 4) show that this centralisation is another typical feature of the Vietnamese educational system. The three institutions, although varied in the ways they interpreted and implemented central policies, strictly followed MOET's directives and requirements for establishing professional duties and standards for lecturers. In this respect, PLD was conceptualised by the policy makers and institutional leaders as a mechanism for generating credentials and implementing topdown polices, as also shown in previous studies (Pedder et al., 2010). Centralisation has also emerged a key theme in previous studies on HE in Vietnam (Fry, 2009; T. H. Pham, 2014; Truong, 2013) which stress the importance of developing institutional autonomy and enhancing lecturers' agency in identifying their own learning needs if educational quality is to be improved in local contexts (Hayden \& Lam, 2007b).

The findings showed that MOET and the universities played a dominant role in deciding the forms of PLD provided to lecturers, the official roles of PLD, and allocating resources for lecturers' teaching and learning. As a result, lecturers experienced limited ownership of PLD policies and processes. Lecturers' autonomy in their learning was solely manifested in their ability to choose which PLD options to engage in. However, while the policies tended to emphasise formal PLD, lecturers' learning in this study also took place in informal and self-directed settings. This is consistent with other studies, such as Tallerico's (2005), which argue that teachers are in the best position to understand their 
own learning needs and they learn best when self-regulating their learning rather than being told what to learn. Therefore, to increase the likelihood that PLD for Vietnamese lecturers will be transferred into meaningful learning, lecturers would benefit from exercising more autonomy and having increased agency in their own PLD process (Bourke, McGee \& O’Neill, 2008; Hargreaves et al., 2013).

The impact of Vietnam's collectivist society on educational governance as well as interpersonal relationships among different stakeholders in these tertiary contexts was identified in this study. Cultural practices related to collectivism were evident in the lecturers' ethics of avoiding group conflicts and showing peer-respect. Individually, lecturers across the three sites acknowledged contradictions and irrelevances within the institutional regulations (e.g., research assessment, lecturers' assessment, salary scheme), but yet they conformed to these rules. These culturally ingrained responses to top-down policies echoed previous research which showed that tertiary lecturers may comply with government educational reforms without fully being committed (T. H. Pham, 2014). The practice of such cultural values seemed to hinder subordinate members from engaging in meaningful discussions and critiques of the policies and decisions made by their leaders, congruent with findings from other studies that showed lecturers' reluctance to express their ideas and question leaders' directives in Vietnamese HE contexts (Tran, 2015; Truong, 2013). This cultural practice resulted in lecturers' voices sometimes remaining unheard, which in turn tended to reinforce the existing centralisation in educational policy making and management.

Leadership is an important factor that mediates how national policies are interpreted and enacted at institutional levels. The above cultural features also affected leadership practice at institutional levels. The institutional and departmental leaders in this study experienced some tensions where they strove for successful implementation of national and institutional initiatives and showed a reluctance to challenge top-down policies. This reveals that within a Vietnamese hierarchical and collectivist society it is challenging for academic leaders as well as lecturers to critique MOET policies. The implication for PLD opportunities is that there can be a mismatch between what educators at all levels value for their own learning, and the PLD they are expected to engage in to meet national and organisational needs. As a result, PLD provision may not meet lecturers' or leaders' needs 
and interests. This study supports the findings from other studies that effective leaders are able to connect lecturers' performances and professional goals to the institutional policies, strategies, and goals (Blackmore \& Blackwell, 2006; Youngs \& King, 2002). Leaders, particularly at departmental levels, need to have the capacity as well as permission to critique or question national and institutional policies and strategic objectives if they are to address lecturers' professional concerns.

Collegial relationships are critical in Vietnamese culture. This is particularly relevant within the PLD context where lecturers perceived that it would be culturally inappropriate to express disapproval of a colleague's performance. In contrast to Western culture that values diversity and individualism (House et al., 2004), Vietnamese, like other Asian peoples, may suppress their own opinions to achieve a group agreement. Therefore, members of collectivist cultures may restrict their individual voice for the benefit of the larger group. The expression 'happy face, unhappy heart' illustrates how the group harmony may actually indicate a more fundamental issue around power and control. This means, on the surface lecturers might appear to get along well with each other (happy face), but this might coexist with implicit disapproval of individual group members (unhappy heart). From this perspective, lecturers' indirectness in communication and avoidance of conflict may hinder authentic collegial collaboration. This study, therefore, invites a more nuanced view of group harmony in a Vietnamese educational context than "constructive, positive collegial learning communities" which enhance lecturers' learning through "challenging and supporting each other towards a shared vision of improved practice" (Lamont, 2011, p. 63). A challenging, supportive and trusting environment is a crucial prerequisite for promoting lecturers' meaningful and reflective learning from group tasks without undermining their professional and interpersonal relationships. However, this was not always achieved by participants in this study.

In Vietnam, teaching is culturally perceived as an honourable profession, and teachers and teacher educators receive a high social status as well as facing high expectations from Vietnamese society. As highlighted in previous studies in Vietnamese educational contexts, there is a tradition of honouring teaching and respecting teachers (K. D. Nguyen \& McInnis, 2002; Phan \& Phan, 2006). In return for accepting prestige and social status, teachers are expected to be role models both in terms of knowledge and morality. These social 
expectations are rooted in Confucian culture which emphasises the crucial role of teachers in shaping students' knowledge and moral standards (K. D. Nguyen \& McInnis, 2002; T. H. T. Pham, 2011; Truong, 2013). The lecturers in this study, as in others, reported their pride in the role as teacher educators, but also stressed the pressure they felt to meet the high social expectations (Phan \& Phan, 2006). Also, the implementation of the foreign language education reform and demands for higher levels of English proficiency in almost all sectors of the labour market made them aware of the high stakes involved in their teaching role. These were powerful factors that motivated the lecturers to improve themselves and fulfil their professional roles. Therefore, the lecturers highly valued PLD that supported their teaching roles as well as enhancing their professional confidence and sense of self as teacher educators.

\section{Context of Vietnamese higher education}

The government has high expectations of Vietnamese tertiary institutions and lecturers in enhancing teaching and learning quality in the country (Vietnamese Prime Minister, 2012). In this respect, Vietnamese educational reforms shared key features with those of other countries in Southeast Asia (Bai \& Hudson, 2010; Cheng, 2009; Hallinger, 2010; Zhu, 2010) also participating in the international movement towards educational change to meet the challenges of globalisation and international competition. Tertiary institutions in Vietnam must address increasing social demands for a qualified labour force to serve the national process of industrialisation, modernisation, and globalisation.

Several key imperatives in tertiary education in Vietnam were identified in this study. The Vietnamese government has specified the goal of enhancing the quality and calibre of tertiary academics to ensure the success of its reform agenda (Vietnamese Prime Minister, 2012). The government's prioritising of staff development in the reform process was in line with educational policies in other contexts which promoted teachers' PLD as an educational reform strategy (Borko et al., 2002; Frost, 2012). This commonly held stance stresses that "the quality of a university is of course critically dependent on the quality of its academic staff, who perform the research and teaching and interact with students" (Wilson, 1998, p. 156). In responding to reform directives from the government, all three universities prioritised upgrading lecturers' qualifications as a key strategy for achieving higher 
educational quality. Research productivity has become a key criterion for assessing lecturers' performance, as also found in other studies (Hwang, 2014; Lai et al., 2014). As a result, lecturers perceived the tertiary context as a challenging environment which increased the pressure on their individual learning and academic performance. Accordingly, PLD was perceived by these lecturers as the essence of their profession and a means of sustaining their teaching effectiveness.

The analysis of policy documents showed that policy makers associated lecturers' doctoral degrees with higher teaching quality. Educational projects that provided funding for tertiary lecturers to gain $\mathrm{MA}$ and $\mathrm{PhD}$ degrees from overseas training showed the government's high commitment to enhance lecturers' qualifications. In this respect, PLD was construed as adding to academics' credentials. However, this common belief that a higher academic degree means better quality teaching and research was challenged by some lecturers. This reflects T. H. Pham's (2014) observation that tertiary academics may hold different views on what constitutes quality compared to their leaders and policy makers. Watty (2003) too argues that a lack of a consensus between different key stakeholders' perceptions of quality may potentially cause tensions within the activity system. Such tensions were evident in my study where EFL lecturers faced pressure to quickly upgrade their academic qualifications and increase the number of research publications. These tensions appeared to increase for lecturers from newer tertiary institutions with fewer resources and capacity (e.g., site B and C). Lecturers suggested that these pressures would be manageable if they could choose when and how to undertake further learning (i.e., to support institutional goals) so that this learning also suited their personal goals and preferences.

The influence of English as a global language has made Vietnam, like other countries in Southeast Asia, enact reforms to improve the quality of EFL teaching and learning and the English proficiency of the labour force. As Nunan (2003) showed, Vietnam faces challenges in improving EFL teacher education and meeting social and economic demands for higher proficiency in English. Mandated initiatives in foreign language education across all sectors complicated the EFL teacher educators' roles and the nature of their PLD engagement. H. T. M. Nguyen (2011) studied EFL teaching in primary schools in Vietnam and found that the teachers were in great need of relevant PLD and professional support 
from EFL teacher educators in order to meet new EFL standards. My research provides evidence that the new policy has also created pressure for EFL teacher educators at the universities. The teacher educators in this study, like in-service EFL teachers, expressed anxiety about improving their own language proficiency, and this occurred strongly as their immediate professional concern. This finding suggests that the reform challenged these teacher educators' sense of self-efficacy about their language, and arguably undermined their professional confidence since they were aware that they had to acquire high English proficiency to be considered an effective language lecturer and teacher educator. A focus on English language proficiency and content knowledge was found as a distinctive feature of PLD for the EFL teacher educators in this study. This is consistent with a previous study (Hiver, 2013) indicating that for EFL teachers "a lack of language self-efficacy was found to be near synonymous to lack of teaching self-efficacy" (p. 1). The lecturers' desire to obtain higher qualifications in English was a strong motivation for them to take initiative and engage in PLD on language improvement, as with EFL lecturers in Thai universities (Wichadee, 2012). Like EFL teachers in Korea, these lecturers were "haunted by perfect English", indicating the crucial role of English proficiency in these teachers' selfconfidence (Cho, 2014, p. 58).

Favouring PLD opportunities in English speaking countries, as well as PLD that involves learning with or from native speakers of English is another unique feature of PLD for the EFL teacher educators. This is reflected through all lecturers' perceptions of overseas training as their 'professional dream', or a 'must-do' desire to become more confident and effective EFL lecturers and teacher educators. They also reported effort in practising English with native speakers of English, listening to CDs or news in English and learning from native speakers' pronunciations and language use. This finding implies that the Vietnamese EFL teacher educators seemed to strive for perfect and native-like English, which would add to their pressure in enhancing their own English proficiency within an EFL context where there was little exposure to English outside their classrooms.

Previous studies show that PLD plays an importance role in enhancing language teachers' content knowledge as well as developing leaders with skills to support English language teaching (McGee, Haworth, \& MacIntyre, 2015). This is especially critical in EFL educational contexts such as Vietnam where EFL lecturers struggle to improve language 
competence for themselves and for their students without access to an English speaking environment. These EFL teacher educators felt that they needed better support and more resources to improve their own language proficiency if they were to fu lfil their responsibility of teaching pre- and in-service school teachers how to teach EFL effectively.

\section{Impact of institutional features on PLD}

There was evidence that institutional developmental histories, structures and cultures have influenced how PLD for lecturers is perceived and practised, as consistent with previous research (H. T. M. Nguyen, 2011; Wichadee, 2012). The three universities had different historical backgrounds, which resulted in differences in their institutional goals, policies and resources. The types and developmental status of the universities influenced the opportunities, policies and priorities of PLD for their EFL lecturers.

This finding parallels findings from other Southeast Asian countries that lecturers' PLD relates to university types and that formal PLD is a dominant form (Wichadee, 2012). Wichadee's study (2012) found that lecturers from government and private universities had more access to self-development than those from universities which used to be colleges and had recently upgraded to university status. The findings from my study are consistent with this view, although mine offers further insights into how different institutional contexts shape their lecturers' perceptions of PLD and their experiences and prioritisation of PLD activities. This study shows that recent educational initiatives in HE in Vietnam, especially the implementation of new language policies offered more PLD opportunities for the lecturers. However, there were significant variations in teaching and learning resources and PLD opportunities, particularly MOET-sponsored PLD (e.g., workshops, training courses, and overseas training) the EFL lecturers in the three universities accessed to. The CHAT analysis of University $\mathrm{C}$ highlighted tensions and uncertainty the EFL lecturers faced when having to enact the language education reforms with limited understanding, resources, and PLD support, compared with their colleagues in the other universities. This raises the importance of ensuring that lecturers across different institutions are well-informed of new top-down initiatives, sufficiently supported, and able to access to PLD resources within and across institutions. For PLD to be meaningful for lecturers, it needs to be related both to institutional developmental goals and lecturers' own learning needs and responsibilities in 
their daily practices. Even these are shaped by the institutional and cultural contexts, so ultimately PLD becomes at once a personal, professional and institutional endeavour.

\section{Lecturers' responses to mandatory reforms: Transferring the fire}

The EFL lecturers in this study went to considerable effort to undertake what was expected of them. The crucial role of leadership and collegial support in facilitating their effort was also highlighted. When lecturers used metaphors such as 'transferring the fire' (i.e., inspiring each other in doing research) they indicated the importance of 'others', either in a collegial or leadership capacity, when engaging in research, PLD, teaching, and reform enactment in tertiary education in Vietnam.

As the study highlights, lecturers were open to change, and highly aware of their responsibilities for implementing innovations. Indeed, their positive responses to reforms in this study run counter to the assertions from previous research where lecturers were resistant to change (T. H. Pham, 2014). The academic leaders and lecturers valued and supported government and institutional goals for improving educational quality. However, lecturers were concerned about the feasibility of achieving some objectives within a limited timeframe. These lecturers, like those in other studies, felt that the goals of the reforms were too ambitious (Cheng, 2009; Hallinger, 2010; K. D. Nguyen et al., 2009). They questioned the sustainability of the reform in foreign language education when there was little follow-up support or ongoing PLD opportunities for both university and school EFL teachers. These issues reflect a common situation in Vietnam and other Asian countries, described as 'bottle-neck effect' in the reform process (i.e., a sequence of reforms with little support and impact in practice) in Hong Kong schools (Cheng, 2009, p.76). Vietnamese educators in this study would probably agree that "deep or meaningful change takes time and this is often considerably longer than anticipated" (McGee, 2011, p. 57). Like McGee, this study suggests that policy-makers and change-initiators need to re-imagine educational change as a long and challenging process in which the lecturers receive on-going support both personally and professionally. A careful consideration of the challenges and pressure lecturers face in implementing top-down innovations may prompt institutional leaders and policy makers to reassess the reform objectives and allow an achievable time for full implementation. Also, given that the successful implementation of proposed initiatives 
depends on available resources and capability, any reform must take into account the need for lecturers' flexibility and autonomy in their practices, as emphasised in previous studies (Hiver, 2013). In addition, leadership teams need to be aware that barriers to reform implementation or unintended consequences may arise in practice and at the local level (Bourke et al., 2013).

Research engagement emerged as a critical and obligatory form of PLD in HEIs in Vietnam. However, it was evident that lecturers struggled to balance research and teaching responsibilities. Most lecturers in this study did not actively engage in research due to wellrecognised obstacles such as time constraints, heavy workload, and limited funding, which echoed findings of previous studies (Bai \& Hudson, 2010; Borg, 2010; Lai et al., 2014; H. H. Pham, 2006). Lai et al. (2014) found that a stressful and competitive tertiary context developed when research became a significant indicator for academics' employment and promotion in Chinese HE. The pressure of complying with new employment policy which favoured research-active academics was so high that Chinese academics were forced to conduct research even to the detriment of their teaching commitment. Lai et al.'s (2014) study suggests that obligating lecturers to engage in research without reducing workload or providing support can negatively affect their teaching quality. However, unlike the Chinese academics' experiences, all lecturers in this study valued their teaching role and considered teaching to be their prime commitment. This also shows the Vietnamese educators' strong professional identity as teaching lecturers, which greatly influenced their choice of PLD and their motive for engaging in PLD. This finding indicates a clear link between the lecturers' sense of professional identity and their agency in their PLD and practices, which is consistent with previous studies that emphasise the inter-relationships between professional identity and professional agency (Edwards, 2015; Hiver, 2013).

To support the ultimate aim of enhancing teaching and learning quality in tertiary education, as stated in the HERA, it is important for MOET and institutional leaders to take into consideration lecturers' perceptions of their professional roles and their learning needs. This may include supporting Vietnamese lecturers to engage in research practices for the purpose of enhancing their teaching. Lecturers in this study shared the aspirations of their international colleagues (Hwang, 2014; Lai et al., 2014) for a reduced workload and resources such as funding and specialised materials to enhance their research engagement. 
Support and inspiration from leaders and colleagues are commonly identified as crucial factors in promoting lecturers' research (Bai \& Hudson, 2010; Borg, 2010; McGee, 2011).

The metaphor truyền lưa (transferring the fire) highlighted influence from peers and leaders as an external source of motivation for lecturers to engage in research. These suggestions are valuable for informing policies that facilitate lecturers' research engagement.

\section{Teacher educators' professional identity: A role-model of 'tài' and 'đức'}

It was evident that cultural values attached to the teaching profession and the teacher educators' professional roles shaped their sense of professional identity and affected the quality of their PLD experience. Teacher educators' professional identity is an intricate and multifaceted concept which is neither fixed nor static (Ben-Peretz et al., 2010). The teacher educators perceived their profession in diverse ways, often torn between critical tensions of professional pride and burden. Their views of themselves as role models, both for students and other social agents, enhanced the educators' strong sense of professional commitment and motivation for PLD. A notable finding is the educators' dual desire to pursue their personal and professional goals alongside meeting their external responsibilities as EFL teacher educators in a reform context.

\section{PLD: Maintaining the pride and managing the burden}

The teacher educators in this study understood their important role in teacher education and strove to maintain their professional pride. They acknowledged the high status and prestige which were culturally and socially given to them merely by being in the teaching profession. This finding contradicts that from a study which showed that in the United States, teacher educators and teachers alike perceived their professional status as low as a result of the dominant social belief that teaching was easy although the educators themselves viewed teaching as a challenging task (Labaree, 2005). Culturally opposed perceptions of teaching and teachers' roles might explain such a contrast between Labaree's findings and those from this study.

The cultural and social value attached to the teaching profession was also a motivation for these lecturers' professional commitment. Awareness of the importance of 
their profession in teacher education enhanced lecturers' sense of responsibility in effective teaching to prepare well-qualified school teachers. The teacher educators perceived that their teaching was important because it would affect ongoing generations of future teachers and these teachers' students across the school sector. This perception was consistent with the so-called 'double commitment' experienced by teacher educators in previous studies (Ben-Peretz et al., 2010, p. 118) when describing their dual roles of being responsible for the quality of in-service teachers as well as these teachers' students. Accordingly, PLD for the teacher educators in this study had at once a present and future focus, and intergenerational goals of supporting not only themselves as teacher educators, but also the school teachers, and the younger generation.

\section{Striving to be a role-model}

From an Asian perspective this is a critical link to understanding PLD as lecturers work especially hard to merit their status as role model. As with 'silkworms', known to diligently spin their silk thread until death, or the metaphor of 'candles' that are seen to burn selflessly to bring light to others (Gao, 2008, p. 156), the dedication and focus teacher educators in this study brought to their role is significant in understanding their perspectives on PLD. The lecturers' teaching commitments and professional aspirations seemed to reflect a cultural image attached to Vietnamese teachers, 'ngườ lái đò thầm lặng' (silent sailors), who work wholeheartedly to take other people to new places, just as teachers support and contribute to their students' learning journeys.

Most lecturers used the expression of role-model to capture their self-image as a teacher educator. This desire to be role models for students, particularly academically, was aligned with expectations of teacher educators in other contexts including Western cultures (Ben-Peretz et al., 2010; Smith, 2003) which also highlight teacher educators' desire to be a pedagogical model for their student teachers. However, Vietnamese educators highlighted that they were striving to be role-models in morality, and not just in pedagogical and academic performance. This perception was consistent with other studies of Vietnamese education (K. D. Nguyen \& McInnis, 2002; Phan \& Phan, 2006), and seems to be more relevant to Asian cultures where teachers in general are expected to be caregivers, moral guides, or 'soul engineers' of students (Gao, 2008; Kumazawa, 2013). As one educator 
emphasised, teacher educators had to possess two key qualities: tài (talent), and đúc (good heart, or morality). Tài referred to knowledge and skills in their specialisation, which were the major focus of the educators' PLD. The other quality, díc, was obligatory, and even culturally considered to outweigh tài. The educators expressed empathy with in-service EFL teachers. Such empathy drove their commitment to teaching and supporting in-service teachers' learning and teaching. This was a clear example of how teacher educators viewed PLD as beneficial not only for themselves but also for their learners. The ethics of care emerged as a typical characteristic of the teacher educators in this study, and a demonstration of these educators' dúc commitment. Therefore, PLD is seen to be pivotal to achieving both tài and đức and gaining professional prestige from students as well as colleagues. This also reflects the lecturers' effort to meet the officially required competencies of EFL teachers as specified in governmental policies (MOET, 2014), as presented in Table 2.1.

An important finding was the link between the teacher educators' perspective of themselves as role-models and their desire to be effective teachers and to gain trust and respect from students. Their effort to create positive changes in students' learning and attitudes seemed to be stronger than their need to implement departmental or institutional practices. This finding parallels other Vietnamese studies where tertiary academics valued students' respect as the greatest reward in their profession (T. H. Pham, 2014). In their teaching, lecturers strove to nurture their professional knowledge and moral practices through responding to PLD and students' feedback. This showed their awareness of social expectations of teacher educators, and helped to explain why they valued pedagogical knowledge and skills almost as highly as personal qualities enhanced through PLD.

Classroom experiences played a critical part in lecturers' informal learning and their professional initiatives. There were references to lecturers' emotional intelligence (Day, 1999; Hargreaves, 2003), suggesting that nurturing personal relationships was an important component of their teaching skills (Day \& Lee, 2011). As described in Chapter 5, lecturers valued their learning through teaching experiences, for example, from observing students' emotional behaviours, or from heart-to-heart talks with in-service teachers, which enabled them to identify their students' concerns, learning needs, and expectations. These characteristics are consistent with those of school teachers who were observed by O'Neill 
(2008) to be "conscientious workers who do their best every day to meet the cognitive and affective needs of all students in their care” (p. 29). Supporting pre- and in-service teachers' learning was at the heart of the EFL teacher educators' professional aspirations, which provided insights into the influential role students played in these lecturers' motivation for engaging in PLD. This finding also expands our understanding of teacher educators as active agents in their teaching context whose expertise, coupled with professional conscience (luong tâm), empowers them to transform their students' learning. The teacher educators' cultural knowledge, expertise, experiences, and learning needs must be taken into account when planning PLD that is relevant and useful within their cultural context (Labone \& Long, 2014; Lawler \& King, 2000).

Although nurturing the lecturer-student relationship was perceived as integral in the lecturers' pedagogical practices, it was also evident that lecturers wanted to look good in other people's eyes. Indeed, they were concerned about how they were judged by their leaders, colleges, and people in the society. Within a culturally hierarchical structure, a person in a higher position is expected to be a role-model, and has the potential to be a teacher for others in a lower or less rated position. In this respect, the study reveals tensions experienced by superiors to maintain face and avoid shame or negative judgements form subordinates. This issue is similar to the 'paradox of power' described by Gao (2008, p. 163) as an implication of face and shame in a Confucian and hierarchical culture. The relationships between young and early-career tertiary teacher educators and experienced in-service teachers was complicated and at times contradictory. These lecturers were in a higher academic position, yet in a lower position in terms of age and teaching experience, compared to in-service teachers. The paradox of power added pressure for these young lecturers to undertake PLD to improve their teaching, maintain face and enhance the prestige of being teachers of teachers, and avoid shame and vulnerability that may have occurred from less effective teaching. The changing teaching context and new roles seemed to make the teaching profession more challenging and demanding for young lecturers. This resulted in their desire for more PLD opportunities, as also highlighted in previous studies on PLD for novice teacher educators (Boei et al., 2015; Davey \& Ham, 2010; Murray, 2010; H. T. M. Nguyen, 2008). From this cultural perspective, my study contributes to current understandings of the role of PLD as a learning tool to mediate complex learning patterns and interrelationships among different stakeholders in a hierarchical culture. 
The desire to provide role models was inherent in interrelationships among all stakeholders within the organisation: lecturer-student, senior lecturer-young lecturer, and leader-lecturer. The lecturers overtly described their efforts to model language proficiency and effective pedagogical practices for pre- and in-service teachers, as well as using their expertise and moral quality to inspire learners to learn. In an implicit way, senior lecturers attempted to provide examples of effective teaching when being observed by their younger peers. Similarly, the leaders in this study reported engaging in PLD and research in order to be role-models for lecturers, consistent with a common perception of the qualities of effective leaders (McGee et al., 2015; Truong, 2013). Besides modelling academic behaviours, leaders also wanted to inspire their colleagues by their work commitment, and the selfless fulfilment of their professional responsibilities.

Such selflessness was also found in lecturers, but for slightly different purposes. While academic leaders were focused on optimising policy and initiative enactment, lecturers placed teaching and students' learning at the heart of their commitment. All lecturers reported working long hours, over seven days a week, and often at the expense of their personal lives, to deal with the demands of their increasing teaching load. The lecturers' work ethic was consistent with their ideals of a teacher who is devoted wholeheartedly to teaching and their students (Robinson \& McMillan, 2006), or a Confucian ideal of a teacher who is culturally described as a dedicated sailor (Le, 2014), silkworm, and candle (Gao, 2008). This study foregrounds the strong link between cultural values and lecturers' sense of professional identity. The teacher educators' dedication in this study should be recognised as an important driver towards self-improvement and professional commitment.

Like teacher educators internationally (Ben-Peretz et al., 2010), the educators in this study played multiple roles. They taught EFL, prepared EFL teachers, supported in-service EFL teachers, and engaged in research to improve their teaching and student learning. Some were also assigned formal leadership roles and responsibilities. However, this study highlighted additional roles outside the normal remit of a lecturer. As a result, the educators struggled to engage in PLD to support teaching and researching roles while managing these additional requirements. The tensions were more marked for early-career lecturers and similar to those reported by novice EFL school teachers in Japan (Kumazawa, 2013). 
Young educators working within hierarchical societies struggle to directly express their need for support from their senior colleagues. This at times hindered meaningful professional discussion that might have resulted in support. My study, therefore, suggests reconsideration of the workload and support mechanisms available to less experienced members of the tertiary institutional community.

The multiple roles and responsibilities expected of the lecturers as agents of reform to improve teaching quality was perceived by some lecturers as a heavy duty, and at times their profession felt like a burden. These feelings and experiences echo findings from earlier studies (Cheng, 2009; Gao, 2008; Kumazawa, 2013; Robinson \& McMillan, 2006) that noted how policy changes contributed to teachers' stress and burn-out resulting from overcommitment, time pressure, and demanding responsibilities. However, while prior studies indicated that pressure and workload made teachers in general lose motivation and commitment to teaching (Cheng, 2009; Gao, 2008), this study offers a more hopeful stance in that the educators, despite the pressure and workload, expressed a strong sense of responsibility and commitment to their teaching.

Having to undertake a wide range of responsibilities greatly restricted the educators' time and energy to engage in learning to enhance their teaching and professional image. This created tensions for the educators when negotiating between their possible selves (Dörnyei, 2009; Higgins, 1987): ought-to selves (who they were expected to be to fulfil their responsibilities and meet the institutional and social expectations) and their ideal selves (who they would ideally like to become, and what they were internally striving for), a finding consisting with those in previous studies (Kumazawa, 2013). Dörnyei (2009) stresses that the possible selves can be future guides for people's learning and actions when there is an overlap between their perceived ought-to selves and their ideal selves. In this study there was a shared vision between the educators' perceptions of their ought-to selves and ideal selves which centred on improving educational quality and students' learning. Unlike educators in other contexts who resisted change (Hu \& McGrath, 2011), the educators in this study were engaged in implementing top-down reforms, possibly because they found these reforms relevant, desirable, and likely to improve teaching and student learning (Robinson \& McMillan, 2006). From this perspective, it can be interpreted that despite demanding responsibilities, the teacher educators' perception of their possible 
selves was a drive for them to strive to enhance their teaching and qualifications through PLD.

\section{Transformative professional identity}

In this study, despite being implicitly expressed by the participants, professional identity emerged as an unexpected theme which shaped and was shaped by lecturers' PLD experiences. Although professional identity was not part of my original thinking, it is presented and discussed in this chapter as an emerging issue.

Previous studies showed that HE educators employed different strategies to manage lecturers' heavy workload and the dual duties of teaching and research. These strategies included reducing their teaching commitments to prioritise research outputs, gaining research grants, and promotion (Hwang, 2014; Lai et al., 2014), working after hours and over weekends to keep up with work (Robinson \& McMillan, 2006), or even "stealing time for teaching" by taking time for research to excel in teaching (Hemer, 2014, p. 488). The Vietnamese lecturers in this study employed the two last strategies, which demonstrated that they prioritised quality teaching as a core element of their professional identity and thus made PLD about teaching their main concern, as found by Hemer (2014) and Robinson and McMillan (2006).

However, the Vietnamese educators in this study also aspired to engage in research. Unlike previous studies which showed that tertiary academics undertook research mainly for external motivation including promotion, financial incentives, or meeting employment criteria (Hwang, 2014; Lai et al., 2014), Vietnamese teacher educators reported conducting research mainly for solving teaching problems, enhancing teaching effectiveness, and supporting student learning. They reported that they engaged in research in response to teaching problems associated with the implementation of reforms. This is an important point because it highlights the cultural context for PLD, and also foregrounds the value of identifying PLD as a tool for pedagogical practice.

The findings revealed that EFL teacher educators in this study possessed a range of different identities: identity as EFL high school teachers, as EFL tertiary lecturers, as EFL 
teacher educators, as researchers, and as EFL learners. These identities were interrelated and complementary, reflecting their understanding of the complexity of their profession.

Although being trained to be high school teachers of English, few lecturers had worked at schools before starting their academic career in HE. Therefore, the teacher educators in this study did not struggle to transform an established identity and expertise as school teachers into a new identity as tertiary academics, as widely discussed in studies on PLD for teacher educators in other countries such as New Zealand, Australia, and the UK (Davey \& Ham, 2010; Hill \& Haigh, 2011; Murray, 2010). The Vietnamese educators in this study, especially the novice educators, however, wished to receive more PLD on teaching and learning in HE.

This study highlights a significant characteristic of the professional identity of EFL teacher educators, that is, they perceived themselves as concurrently EFL educators and EFL learners. Previous research in school settings showed that EFL teachers' experience as language learners was a resource for their teaching because they could provide their students with a model of effective language learning (Cho, 2014). Similarly, the current study showed that Vietnamese EFL tertiary lecturers' on-going experiences as foreign language learners had a strong impact on their pedagogical practice and informed their approach to providing PLD for pre- and in-service teachers.

This study also revealed that the teacher educators were beginning to perceive themselves not only as teaching lecturers, but also as research-active lecturers. This transformation of lecturers' professional identities has been widely investigated in earlier studies on the nexus of academics' teaching and research (Bai \& Hudson, 2010; Hill \& Haigh, 2012; Lai et al., 2014). The Vietnamese lecturers reported gaining a higher awareness of their research responsibility and trying to engage more in research. This change derived from the increasing demands in $\mathrm{HE}$ as well as international competition in education, which requires tertiary lecturers to undertake new roles and responsibilities. Vietnamese tertiary education shares this international trend in education towards enhancing academics' research capacity in HE (Bai \& Hudson, 2010; Hwang, 2014; Lai et al., 2014). 
Other Vietnamese studies have also noted that EFL lecturers valued research that was classroom-based and teaching-oriented (H. H. Pham, 2006). Clearly, lecturers' new teaching-research professional identity builds on their strong existing teaching professional identity (Hill \& Haigh, 2012; Robinson \& McMillan, 2006). An implication for PLD is that facilitating lecturers' engagement in self-study research (i.e., researching their own practices) would enable research-informed teaching as well as developing lecturers' research ability. Many studies illustrate the positive impact of self-study and collaborative research on educators' professional practices and identity (Boei et al., 2015; Gallagher et al., 2011; McGee \& Lawrence, 2009; Murray, 2010). These studies also emphasise the importance of collaborative learning and leadership support in educators' research engagement, which aligns with the perception the EFL teacher educators in this study held of leaders and colleagues 'transferring the fire' and supporting their research engagement.

Besides seeing research as PLD to support pedagogical practices, a few early-career educators in this study viewed research as an avenue to meet professional goals of receiving a scholarship to attend postgraduate programmes overseas. This finding highlights how research was meaningful to Vietnamese EFL teacher educators in terms of both professional and personal growth. Additionally, lecturers' motivation for research, despite identifying research as an obligatory form of PLD, could derive from both internal and external sources, as also identified in other studies (Leibowitz, Schalkwyk, Ruiters, Farmer, \& Adendorff, 2012).

\section{The nature of tertiary lecturers' learning: Introducing a PLD model}

This study identifies the integrated roles and functions of PLD for tertiary EFL teacher educators in Vietnam, and highlights the importance of understanding the complex phenomenon of PLD within an organisation. A key message from the findings is that PLD is inherent within organisations and individuals and needs to be well articulated so that relevant opportunities can be created.

Lecturers' professional learning took place through formal, collaborative, and informal PLD means, and their learning varied from intentional to unintentional, structured to unstructured, and explicit to tacit. These findings build on a current body of literature 
that emphasises the dynamic nature of teacher learning (Grosemans, Boon, Verclairen, Dochy, \& Kyndt, 2015; Jones \& Dexter, 2014; Knight et al., 2007; Opfer \& Pedder, 2011; Steyn, 2010). As learners in wider professional learning communities within and outside their institutions, lecturers' professional learning occurred in different ways. These included learning as doing (e.g., through their daily practice and experimenting new ideas), as experience (e.g., making sense of their experience), as belonging (e.g., through participating in collective activities as members within their community), and as becoming (e.g., enhancing their professional identity, and being the most effective lecturers they could), as outlined by Wenger (2009). Understanding learning across these dimensions allows for deeper understanding, and more sustainable changes in lecturers' beliefs and practices.

Key principles of effective PLD for these EFL teacher educators include: relevant, meaningful learning (linked to their learning needs and teaching practices, and applicable to improve teaching); reflective learning (involving self-assessment of their own practices, and critical and constructive feedback from peers and students); and active learning (where lecturers are self-regulated learners). These PLD principles were also identified in previous studies across different contexts (Labone \& Long, 2014; Opfer \& Pedder, 2011; Smith, 2003; Villegas-Reimers, 2003). However, the CHAT analysis of the case study provides evidence of the multiple-voicedness and dynamic interactions between and among different stakeholders within and across the PLD activity systems. Based on this finding, my study highlights another principle for effective PLD which proposes that PLD purposes and roles are negotiated between and among all stakeholders involved in PLD and supporting PLD for teacher educators.

Relevance is a key principle for all forms of PLD. Official PLD was important in the lecturers' view when linked to mandated policies, and when it helped to improve lecturers' knowledge and skills to implement changes in a new field of teaching. Across the three universities, there was evidence that PLD enhanced lecturers' understanding of government and institutional policies and support their implementation of mandated initiatives. Lecturers valued certain official training sessions from MOET because they were relevant and timely, and involved opportunities for practising and applying new skills and knowledge in their teaching. Such PLD was perceived by the lecturers as good health 
medicine (thuốc bổ) which helped to enhance their ability and self-efficacy in responding to new professional duties. This finding was different from other studies (Chaudary, 2011; Hu \& McGrath, 2011; Steyn, 2010) which showed that teachers perceived formal PLD a waste of time because the PLD they received was irrelevant to their needs and the teaching contexts.

It is widely agreed that lecturers' learning mostly occurs informally and is embedded in their everyday practices (Jones \& Dexter, 2014; Knight et al., 2007). This study also showed that the lecturers prioritised PLD which was responsive to their own daily practices and their immediate teaching and learning needs. Such PLD can be described as authentic PLD (Opfer \& Pedder, 2011; Webster-Wright, 2009), which likely results in lecturers' meaningful learning and deeper understanding of their practices, and promoted changes in their pedagogical practices, attitudes, and beliefs.

In this study authentic learning also occurred when lecturers worked collaboratively and shared teaching experiences with each other. However, the case study findings showed that lecturers' efforts to establish collaborative learning seemed to be fragmented and inconsistent, and depending on the instructional cultures and leadership. Previous studies also found that collaborative learning was not frequently undertaken by teachers, or lecturers (H. T. M. Nguyen, 2008; Wichadee, 2012). Effective relationships based on trust, openness and constructive feedback are crucial to optimise meaningful collaborative learning among lecturers, as highlighted in this study and other PLD research (McGee, 2011; Smith, 2003; Teräs, 2014; Vo \& Nguyen, 2010). Therefore, for on-going and authentic PLD, it is necessary for the administrators and lecturers to nurture a trustful and collaborative learning environment within the department as well as the institution.

Lecturers' learning was enhanced when they were required to implement changes in their practices which challenged their professional confidence. This created a desire for further learning in order to respond to new responsibilities. There was evidence that inner tensions and contradictions within the department and institution resulted from mandating innovations and lecturers' new responsibilities were a catalyst for lecturers' learning and change. This is consistent with other studies using CHAT to understand PLD initiatives (Bourke et al., 2013; Engeström, 2001; Yamagata-Lynch \& Smaldino, 2007), where these 
studies found that expansive learning occurred when the members within the community made changes in order to resolve inner contradictions within the activity system. For example, dealing with tensions arising from negotiating between lecturers' professional ethics and cultural practices also fostered authentic learning. The lecturers proposed internal workshops to allow lecturers to discuss effective ways to give constructive feedback and authentic peer support. As evident in the literature (Vo \& Nguyen, 2010), such models initiated by the lecturers themselves within their department offer relevant, useful and practice-based PLD which can enhance the participants' ownership of their own PLD.

Choices of PLD were affected by both internal factors (e.g., lecturers' beliefs, teaching experience and career stage, and their family circumstances) and external factors (e.g., sociocultural and institutional factors, leadership, and collegial relationships). Time and workload were the two biggest barriers to lecturers' learning, as consistent with other studies internationally (Kennedy, 2011; H. T. M. Nguyen, 2008; Smith, 2003; Teräs, 2014; Wichadee, 2012). The contextual impacts on lecturers' PLD participation helped to explain why there were marked discrepancies between lecturers' positive perception of PLD and their low participation in PLD in practice, as clearly shown in the questionnaire and interview findings.

A dilemma between imposed, institutional PLD and self-regulated, personal PLD was identified. Lecturers navigated tensions between official PLD which mainly focused on policy implementation and institutional goals and unofficial PLD which targeted their personal needs and professional aspirations. Consistent with findings from other Vietnamese studies (K. D. Nguyen \& McInnis, 2002; T. H. Pham, 2014) tertiary academics did not support the use of students' formal assessments of lecturers' teaching because this ran counter to the Vietnamese culture of students' showing respect to lecturers. They also believed that such formal assessment could expose lecturers to criticism from their students, which would negatively affect their professional motivation (T. H. Pham, 2014).

In contrast, lecturers valued students' feedback when it was undertaken informally and initiated by the lecturers themselves for self-improvement. This meets the criterion for effective informal learning that is voluntary and relevant to the learner's choice, and does 
not involve external assessment (Callanan et al., 2011). This raises the necessity of enhancing lecturers' agency and autonomy in deciding PLD activities which work best for their need and teaching contexts. Lecturers' learning is likely to be meaningful when they assume ownership of their own PLD, as this improves their capacity for transformative practice, and increases their motivation to engage in PLD (Fraser, Kennedy, Reid, \& Mckinney, 2007; Hargreaves et al., 2013; Kennedy, 2014; McGee, 2011).

A fundamental condition for informal learning, particularly collaborative learning among lecturers, is a departmental climate of trust and openness. This emerged as an integral factor for authentic peer learning. A collegial learning community seemed to work well when it was voluntary, practice-based, and involved self-selected members who had shared goals and like-mindedness, as clearly found in both this study and in previous research (Kennedy, 2011; Lamont, 2011; Vo \& Nguyen, 2010).

This study builds on a premise that learning is socially constructed (Rogoff, 2003; Vygotsky, 1978; Wenger, 2009) within networks of activity (Engeström, 2001), and the principles of PLD reflect this sociocultural activity. From the findings of this study, a model of PLD for EFL teacher educators in Vietnamese tertiary environment is proposed. The model is contextualised in the Vietnamese context, reflecting the influences of both the wider Vietnamese HE environment and the lecturers' professional learning community and networking on PLD. The model highlights PLD and the role it plays in the lecturers' profession, as perceived by the lecturers themselves, capturing the way in which all forms of PLD have value. Combined, these address a diversity in lecturers' motives, learning needs, and working contexts.

The model outlines three essential components of the PLD (see Figure 6.1):

1. the motives and/or expected outcomes of PLD across both the system/institutional and individual levels (presented in the central elements of the model),

2. the professional competencies required for being effective EFL teacher educators expertise and vision (tài and tầm), and professional ethics and aspiration (đức and tâm) - as seen in the right outer elements, and

3. PLD supporting structures, including the PLD principles and supporting systemlevel factors for PLD (the outer elements on the left of the model). 


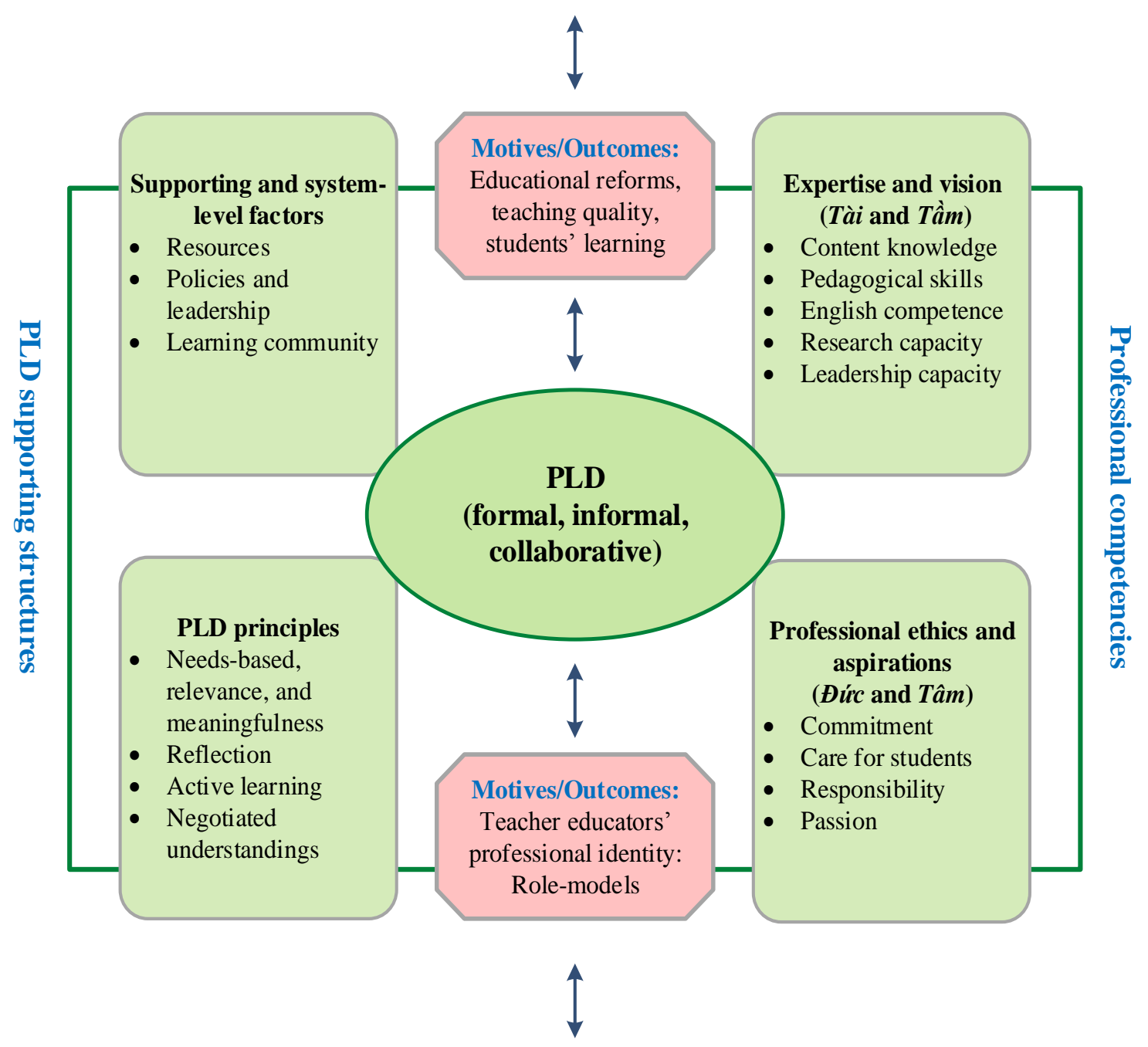

Networking and learning communities

(colleagues, pre- and in-service teachers, students, PLD facilitators, academic leaders)

Figure 6.1 PLD model for EFL tertiary teacher educators in Vietnam

The motives or expected outcomes of PLD are captured in the central parts of the model. These include supporting educational reforms, improving teaching and student learning, and enhancing lecturers' professional identity. These motives or expected outcomes are presented at governmental, institutional, and professional and personal levels. At policy level, PLD targets the implementation of central initiatives in education and 
reform agendas. Within the tertiary setting, PLD plays a key role in supporting institutional goals, missions, and visions, and enhancing the quality of teaching and students' learning. At a professional and personal level, in addition to its role and function in supporting lecturer teaching and student learning as previously mentioned, PLD is highly valued as a means to foster lecturers' professional identity and enhance their effectiveness. Lecturers' PLD motives and engagement are shaped by their sense of professional identity (i.e., 'ideal selves'), and socio-cultural values attached to the teaching profession and the role of teacher educators (i.e., 'ought-to selves'). Indeed, it is the lecturers' desire to be role-models for their students and others, and the cultural values of respecting the teaching profession in the Vietnamese context that drive their PLD commitment and professional aspirations. Within the dynamic and complicated tertiary environment, motives for PLD and expected outcomes of PLD are inter-related, and one can be the driver for the other. Given that lecturers are the key agents of their own PLD as well as in the process of educational changes, their motives for PLD and expected outcomes from PLD need to be fully understood and supported. The role and function of PLD in enhancing lecturers' meaningful learning and their sense of selves need to be viewed as important as in supporting the government's and their institutions' policies and agendas.

The professional competencies required for being effective EFL teacher educators, as presented on the left outer of the model (Figure 6.1), include expertise and vision (tài and tầm), and professional ethics and aspiration (đúc and tâm). These competencies are specified in policy documents, social and cultural expectations, and the lecturers' own perceptions of themselves as EFL teacher educators. Specifically, PLD is perceived as a powerful means to foster these two important and culturally expected competencies of teacher educators. This highlights distinctive features of PLD for EFL teacher educators and reflects typical characteristics of EFL teaching and learning in the Vietnamese context. For the EFL teacher educators, English competence, content knowledge, and pedagogical skills are essential aspects of their professional competencies, and are central to their PLD motivation, decisions and engagement. Within the changing EFL context in Vietnam, PLD associated with these aspects is especially valued because it enables EFL teacher educators to enact mandated initiatives in ELT, and address the challenges in their teaching. It also provides the means to fulfil the dual commitments of teaching EFL effectively and helping pre- and in-service teachers to learn about and improve their EFL teaching at school. It is 
also necessary that PLD addresses the other expectations of being teacher educators and role-models, professional ethics (đúc and tâm) which is typical of the Vietnamese Confucian-oriented culture. PLD that is congruent with lecturers' professional ethics is also integral in fostering lecturers' aspirations, commitment, and vitality throughout their career.

The model also outlines the essential structures for supporting PLD (i.e., the outer edge on the left of the model) including the key principles of PLD, and supporting systemlevel factors. For PLD to be effective, it must involve the key principles outlined in the study findings. It must: (1) be needs-based, relevant, and meaningful, (2) involve reflection, (3) encourage active learning, and (4) have understandings of the purpose and function of PLD negotiated with all stakeholders. The key principles of PLD are at the centre of this PLD model (designed for EFL teacher educators). These principles can offer guidelines for self-initiated PLD (e.g., independent learning, informal and collaborative learning within their network and professional learning community). These principles also need to be taken into consideration by academic leaders' and PLD facilitators when planning or promoting PLD for EFL lecturers. Beside PLD principles, supporting and system-level factors also determine the effectiveness of PLD for EFL lecturers. These factors refer to resources, policies and leadership, and professional learning community.

Overall, this model conceptualises PLD as mediated by sociocultural, political and contextual factors which can either facilitate or hinder lecturers' engagement in PLD and the impact of PLD on their professional and personal growth. The areas at the top and at the bottom of the model refer to contextual influences on PLD for EFL lecturers (i.e., the Vietnamese socio-cultural and political context, and lecturers' networking and learning communities). Different stakeholders can see their roles within the model and draw practical implications for themselves. However, it is crucial to establish reciprocal relationships and promote negotiated understandings among different people involved in the PLD context in order to obtain shared understandings of PLD roles and functions and to ensure that PLD approaches are fully negotiated. This will enable PLD designs that support institutional and national needs, as well as having the potential to empower lecturers as change agents within the changing HE context. Given that there have not been any PLD models that capture the holistic nature of PLD for EFL teacher educators in Vietnam, this model has significant implications for the field of PLD in HE in Vietnam. 


\section{Addressing the research questions}

This study investigated the forms of PLD used by EFL university lecturers, and the role and function PLD played in their professional lives. It then considered how PLD was positioned within the broader context of governmental reforms. This section captures the complexity of the PLD phenomenon for these educators and provides holistic answers to the research questions, as stated at the end of Chapter 2. A summary of key findings responding to these research questions is presented in Table 6.1.

Table 6. 1 Research questions and key findings

\section{Questions}

\section{Key findings}

1 .

What role and function does professional learning and development (PLD) play in EFL teacher educators' learning in tertiary education settings?
- PLD played multiple roles and functions, particularly in supporting national and institutional initiatives in education, the quality of teaching and student learning, lecturers' professional knowledge and skills, and the enhancement of lecturers' professional identity. Specifically, PLD was crucial in fostering professional competencies culturally expected for teacher educators: (1) tài and tầm (expertise and vision) and (2) đức and tâm (professional ethics and aspirations).

- PLD was both for development and learning. The roles and functions of PLD were perceived differently depending on the roles different stakeholders played within the HE context. MOET/ policy makers and HEI leaders linked PLD to broader issues related to policy enactment, achieving national and institutional goals and needs, staff assessment and qualification upgrading. The lecturers valued PLD which directly supported their self-image, teaching and professional duties and concerns, and their students' learning.

- Within the CHAT lens, PLD was perceived as a fluid phenomenon which played different roles and functions within and across the HE contexts. It could be artefacts supporting lecturers' teaching, learning, and implementation of educational initiatives, or could be conceived as rules, or policies lecturers must adhere to, or at times the object lecturers were striving for.

\section{2.}

Why do EFL teacher educators in Vietnam access particular models of
- The lecturers accessed a variety of PLD forms, ranging across formal, collaborative, and informal learning settings. Their motives for engaging in PLD varied from internal or personal, to external or institutional.

- Lecturers valued all kinds of PLD as long as it was relevant to their needs, promoted meaningful learning, and was applicable. They particularly valued PLD that enhanced their professional knowledge and skills and their 


\section{Questions}

PLD? And

what PLD do

they value?

\section{Key findings}

English language competence. This was a distinctive feature of PLD for EFL teacher educators and was consistent with their strong desire to be role-models of students in EFL teaching and learning for their students.

- Lecturers' preferred PLD included overseas training and PLD opportunities which allowed them to learn from and/or with native speakers of English. They believed this kind of PLD enhanced their language competence, cultural understandings, and professional confidence which were seen as critical in becoming effective EFL lecturers.

- Self-regulated learning was perceived as the most meaningful and relevant in the lecturers' daily teaching contexts.

\section{3.}

How do the educational reforms in

Vietnam influence the forms of PLD promoted and accessed by EFL lecturers?
- Educational reforms provided opportunities for all kinds of PLD for EFL lecturers, particularly:

○ More formal training opportunities sponsored by MOET, especially opportunities for overseas training

- More collaborative learning and experience sharing

- Meeting lecturers' increasing needs for independent learning and self-improvement to meet the expectations and requirements identified in reform objectives

- Educational reforms and the socio-cultural and political context also put pressure on the lecturers' professional practices and PLD engagement. They reported encountering:

- More workload and pressure from reform implementations, which hindered their learning time and wider PLD access.

○ Uneven access to PLD opportunities, teaching and learning resources, and expertise support across different HEIs.

- Self-directed learning focusing on English proficiency (especially test-based practice) and pedagogical content knowledge was greatly promoted across three institutions. This addressed EFL lecturers' professional concerns and their changing roles when enacting the national reform in foreign language education.
4.

How does PLD

support

educators'

capacity to

implement

these

educational

reforms?
- The lecturers who undertook MOET-sponsored PLD reported meaningful learning that supported their implementation of the national reform in foreign language learning and teaching. Positive impacts of their experiences included increasing understanding of the reforms and how to enact them, gaining necessary knowledge and skills that supported the implementation of new EFL curricula (e.g., teaching English at primary schools, test design, material design), and improving their professional confidence. However, these PLD opportunities were more accessible to the lecturers in sites $\mathrm{A}$ and $\mathrm{B}$. Lecturers at site $\mathrm{C}$ who received fewer supports 
from MOET reported uncertainty about the reform rationales and lower engagement in the reform enactment.

- Collaborative and informal PLD practices (e.g., experience sharing, researching their teaching practices, independent learning) initiated by the lecturers within their departments also facilitated their teaching practices and implementation of the reform. However, collaborative PLD activities appeared to be ad-hoc and scattered, and were undertaken primarily to address lecturers' immediate needs or institutional regulations rather than as on-going professional practices for authentic learning.

- PLD impacts on reform implementations varied according to contextual features and capacities of each HEI.

Overall, the EFL lecturers in the three studied universities engaged in a variety of PLD forms including formal PLD, collaborative, and informal PLD. There was an interplay between the different forms, and these forms of PLD contributed to an interwoven PLD experience. All of these PLD forms played a role in lecturers' learning, supported different aspects of their learning, and served different learning needs. Key roles and functions of PLD, as valued by the participants, included: upgrading their knowledge, skills, and qualifications; improving their teaching effectiveness and student learning; enhancing lecturers' self-image and professional confidence in being a language teacher educator; and supporting lecturers' ability to implement national and institutional initiatives. Culturally, it was crucial that PLD enhanced professional competencies of lecturers: tài and tầm, and dức and tâm.

The study also identified distinctive features of PLD for EFL teacher educators. First, the lecturers' PLD had a strong focus on enhancing their subject knowledge, teaching skills, and especially language competences. Subject knowledge was an especially demanding aspect of PLD for EFL lecturers who were in charge of teaching English specialised courses and ESP. Second, authenticity and opportunities to practise and communicate in the language was an integral feature for effective PLD for EFL lecturers. Overseas training and PLD delivered by foreign experts and/or English native speakers was strongly favoured. In this respect, PLD played a crucial role in enhancing lecturers' professional confidence and sense of selves as EFL teacher educators. This explained why lecturers had a very positive attitude towards PLD delivered by foreign experts and overseas training, even when the 
content presented by foreign experts were sometimes perceived by the lecturers as having little relevance. Finally, EFL lecturers and teacher educators explicitly perceived themselves as life-long language learners whose self-regulated PLD helped to foster their language knowledge and proficiency, and language learning skills and experiences. These characteristics informed their EFL teaching practices and ability to support pre- and inservice EFL teachers in learning and teaching EFL.

Key features or conditions for effective learning across different forms of PLD for the EFL lecturers were identified from the study. The lecturers valued PLD which was meaningful, practical, and relevant to their learning needs and teaching context. They perceived that PLD was effective when it also engaged lecturers as active, reflective and self-regulated learners. In addition, they preferred PLD that promoted collaborative learning and accommodated negotiated outcomes among members of the learning activity. Combined, these appeared to bring about sustainable changes in lecturers' professional thinking, beliefs and practices. These features for effective PLD need to be taken into account to better support and promote lecturers' learning, rather than the current focus on implementing PLD that is notionally considered best for the lecturers.

There is evidence that educational reforms and top-down initiatives in the Vietnamese tertiary environment created tensions and challenges for the lecturers in enacting the policies and improving their own competence to fulfil their increasingly demanding roles. These tensions, however, promoted opportunities for change and learning when the participants made the effort to resolve challenges and address new demands in their daily work. In this respect, despite causing workload and adding pressure on lecturers, educational initiatives were perceived by the lecturers as factors promoting their learning need and learning opportunities and as mediating artefacts supporting their ability to fulfil their roles.

In this study the PLD activity system in a Vietnamese tertiary context was complicated by how PLD was perceived and what function it played for each person depending on their role within the organisation. While the policies seemed to focus on official PLD, the case study showed that unofficial PLD also played an important role in 
lecturers' learning, and this needs to be seen as a legitimate form of PLD in the tertiary context.

The CHAT analysis illustrated that PLD could move between different elements within the tertiary activity system. This shows that PLD served multiple roles and functions within these organisations. In addition to supporting lecturers' capacity to enact teaching and learning innovations, PLD had the potential to become a motivating force for change. At times it was an activity lecturers strive for (object), and at other times was merely one of the rules that lecturers were expected to follow. For example, while the reform in foreign language education mainly aimed at improving teaching and learning quality across all educational sectors, the lecturers focused especially on improving their own language proficiency in order to meet the standard of language teachers described in the reform. The phenomenon of changing objects supports the assertion that an object in an activity system is ambiguous and changing (Engeström, 2001). The teachers interpreted government policies and practices differently to MOET, and as demonstrated in other research these tensions resulted in teachers creating their own vision for their practice, and thus creating a 'runaway' object (Bourke et al., 2013, p. 274). This finding extends current literature on PLD function and offers a nuanced understanding of PLD in tertiary education as a complex and multi-faced phenomenon. Looking at PLD from different perspectives and its relationships with the other elements of the activity system would allow preparation of a holistic strategic plan for PLD that could support both policies and individual lecturers' professional goals.

It is important to note that in the context of this study, a lack of a shared understanding of the reform objectives and how to enact the reform at departmental level led to lecturers' feelings of confusion and anxiety. This finding is congruent with the concept that reform success is dependent upon a shared vision of reform initiatives among the key stakeholders of the community (Bourke et al., 2013). Therefore, this study indicates how crucial it is to establish a shared understanding among different stakeholders in order to maximise reform success.

This study found that lecturers engaged in PLD (e.g., working towards accomplishing a task) for different motives and to achieve objects which sometimes did not align with the 
motives and objects of the other stakeholders. This expands our understanding that different stakeholders, as well as different activity systems, have their own roles to play, and there needs to be a negotiation of goals and interrelationships for a success in accomplishing a collaborative task. Relational agency, or the ability "to work alongside others towards negotiated outcomes" in a joint activity (Edwards, 2010, p. 61), offers direction for PLD in such a complex and multidimensional context. Exercising relational agency in PLD would enable an understanding of each member's motives, and enable negotiation of outcomes shared by the whole group. It could assist in establishing common knowledge (e.g., an agreed working protocol, group norms and regulations, ways of interactions) that mediates an individual's capacity to share resources and expertise they bring to the collective activities to work toward the negotiated outcome. Given that relational agency involves adjusting to each other's purposes, expertise, and ways of working, it would promote more flexible, responsive, and purposeful interactions when different people work together toward a shared outcome, as in the case of supporting and engaging in PLD for EFL lecturers in this study.

This chapter discusses how this study contributes to a revised understanding of PLD in Vietnamese tertiary education. A model of PLD for EFL teacher educators in Vietnamese HE is proposed from the study findings. The final section of the chapter revisits the research questions and unpacks the complexity of PLD for EFL lecturers. The next chapter discusses implications from the study findings, limitations and suggestions for further research. 



\section{CHAPTER 7 \\ CONCLUSION}

This study offers insights into PLD for EFL teacher educators at tertiary level in Vietnam, an area that is recognised as important for those in tertiary settings. The study employed a mixed-methods research methodology with a focus on qualitative approach, and an instrumental case study design involving three HEIs. The CHAT analytical lens offers an in-depth understanding of these lecturers' PLD as a multidimensional phenomenon within the Vietnamese sociocultural and political contexts. The previous chapter provided an overview of the study findings and a discussions of the findings within the current knowledge base of PLD in education. A model for PLD for teacher educators in Vietnamese context was also proposed, which suggested a nuanced view on PLD in tertiary education. This chapter provides implications of the study, identifies its limitations and areas for further research, and ends with some concluding remarks.

The study findings suggest several implications for policies and practices at central government, institutional and individual levels. These implications are both specific to the Vietnamese context, and to some extent universally applicable in relation to PLD for educators in general. They include issues related to the government's educational policies, institutional and departmental policies and practices, and suggestions for PLD facilitators and individual teacher educators.

\section{Government's educational policies}

This study indicates that PLD plays a key role in supporting national educational reforms in Vietnam. However, there are different interpretations of how these reforms should be operationalised and what kinds of PLD best target the different needs of lecturers and leaders. Clearly, the rationale for and processes of reforms need to be understood by all, and communicated with the institutions and lecturers. Lecturers need to understand the reforms, how to implement them, and what and how PLD could mediate the implementation of PLD at institutional levels. 
Lecturers need to receive on-going and relevant support so that they can engage in PLD if they are to be capable of enacting top-down innovations. Effective implementation of policies is more likely to occur if lecturers have clear and consistent directives and policies related to reform implementation. It is also important to encourage autonomy within tertiary institutions and in individual lecturers to enable then to decide how to address the reforms in their own contexts and use resources available to them.

The study shows that lecturers understood their students' needs and had sufficient expertise to make pedagogical decisions on how to facilitate their students' learning. However, lecturers sometimes faced a dilemma when undertaking a mandated curriculum change which they considered ineffective to meet their students' (i.e., in-service teachers) real needs. This suggests that educational reforms need to take account of the voices of institutional leaders, teacher educators, as well as students, in order to have a holistic understanding of how policies may be translated into practice at local and classroom level. Within the dynamic tertiary environment in Vietnam, each member (lecturers, PLD facilitators, MOET, institutional leaders) has a role to play within the activity system, and each activity system (lecturers' activity system, MOET's activity system, institution activity system) has a role to play when interacting with others in joined activity systems. A holistic understanding of the collaborative learning activity would be obtained by considering key questions for encouraging relational agency in lecturers' collaborative learning: Who is involved in the activity? What expertise and resources does each bring to the activity? What is the motive of each member? What is the shared object/outcome among the community? What common knowledge and relationships can mediate the collective work to achieve this shared/ negotiated object? An understanding of the others' perspectives would support collaborative work among lecturers and other stakeholders toward effective PLD for educational reforms and professional growth. In this respect, this study suggests adopting a broader view that draws on the expertise and collaboration of all stakeholders to inform PLD for tertiary lecturers. In this way tensions that may arise from applying the proposed PLD model to address government policies, institutional imperatives, and the lecturers' working circumstances can be mitigated.

In Vietnam's hierarchical culture, as analysed in the previous chapters, it may be challenging and take time to encourage conditions for relational agency and an alignment 
of different motives and perspectives when people in different positions (e.g., MOET, institutional leaders, lecturers, PLD facilitators, students) work together towards an educational innovation (the object of their activity systems). This process can be facilitated by "openly discussing expectations, roles and protocols for interactions" (Lamont, 2011, p.63) within the lecturers' community. Promoting a fluid and supportive tertiary environment to encourage a form of relational agency will enable all members to work resourcefully (e.g., sharing their resources and using others' resources), share responsibility and contribute to the accomplishment of a negotiated outcome (e.g., undertaking educational initiatives, improving teaching quality, and enhancing lecturers' professional identity). As Edwards (2010) stresses, relational agency in professional practice "offers the opportunity for an enhanced form of practice" (p. 61), which would also enhance the collective competence of a community.

A reconceptualisation of PLD so that PLD addressed lecturers' real learning needs, as well as national and institutional goals, would inform effective policies to support lecturers' PLD and professional work in tertiary education. Lecturers' professional efforts also need to be taken into account. It is necessary for the government and policy makers to understand and take into consideration the complexity of lecturers' learning and their working contexts. This would require educational policies to foreground the role and function of PLD for learning, rather than merely emphasising accountability and credential purposes. PLD for learning purposes as shown in this study and previous studies (Knight et al., 2007; Webster-Wright, 2009) is more likely to bring about authentic and sustainable learning and transformation of practice.

\section{Institutional and departmental policies and practices}

This study also invites a reconceptualisation of PLD at institutional and departmental level. PLD needs to be seen as a complex, multi-faceted phenomenon which occurs in diverse forms, settings and processes (e.g., formal, collaborative, and informal learning) given all PLD forms are important for lecturers' personal and professional growth, and for supporting institutional goals. As highlighted in previous studies (Labone \& Long, 2014), coherence in PLD policies, which enables a balance between institutional and individual needs, is a crucial factor in planning PLD for lecturers. 
Further direction for PLD could include allocating funding across different domains of formal/collaborative/informal PLD to enable lecturers' engagement in a wider range of PLD activities which better suit the institutional goals as well as individual interests. Although lecturers' heavy workload is a common and unavoidable problem in Vietnam, this study suggests that this can be reduced by promoting specialised roles for lecturers and allocating teaching assignments more strategically. For example, PLD needs to fit within the lecturers' limited time so it should focus on professional tasks that lecturers perceive to be valuable such as improving teaching practices, materials design, and action research rather than on duties which they perceive as time-consuming and unsuited to their expertise (e.g., being official student advisers). These changes would enable a better use of lecturers' time and expertise and more chances for lecturers to engage in PLD. Additionally, rather than focusing on formal PLD as at present, more investment in PLD towards informal PLD activities is likely to promote lecturers' self-regulation, research engagement, and learning communities that encourage lecturers to reflect on and examine their practice. Further, it is important to promote a holistic PLD approach involving organising and evaluating lecturers' learning through the three development planes, e.g., personal, interpersonal, and institutional planes (Rogoff, 1995). Given the interdependencies among these three planes, changes at institutional and system level in terms of policies, resources, and leadership are needed to support changes at personal and interpersonal levels.

There were variations in the ways the different universities in this study interpreted and enacted the national reform in foreign language education. This was arguably due to the differences among the institutions in terms of their status, roles in and capacities for teacher education in the region, as well as the support received from the government. It is, therefore, important to encourage a wider network among lecturers from different universities to promote lecturers' PLD, pedagogical changes, and sharing expertise and resources within and across institutions. Specifically, lecturers who received training and resources from MOET should be encouraged to share their learning and expertise with colleagues from other universities who did not have access to this training. Such a learning network within and across institutions would optimise lecturers' understanding and ability to enact mandated reforms. 
Cultural values attached to the teaching profession added to the lecturers' pride and their teaching motivation. However, increasing demands and expectations of lecturers' performance and qualifications at times created pressure on the lecturers' professional life, as also found in other studies showing that teachers in a Confucian culture perceived high sociocultural expectations of them as cultural burden (Gao, 2008). Given the Vietnamese government's policy which identified education development as the first priority for the overall aim of enhancing the national sociocultural, economic, and political development, educators are supposed to assume heavy responsibilities in supporting the government goals. This official and cultural expectation has created more pressure on lecturers, particularly teacher educators to fulfil their social responsibility. These contextual and cultural accounts offered insights into the meanings underlying lecturers' view of PLD as a social responsibility (i.e., serving and contributing to national development) rather than personal benefit. Importantly, this study suggests that high cultural expectations of Vietnamese lecturers, despite causing pressure on their profession, are still meaningful because the lecturers valued them and tried to meet these expectations through engaging in PLD. However, to continue as a powerful motivational force, these cultural values need to be used to empower lecturers rather than as criteria for judging their quality or competence.

The study foregrounds that institutional and departmental culture also greatly influenced lecturers' PLD engagement and their collegial relationships. Sometimes there were contradictions between lecturers' professional values and cultural values, particularly in collaborative learning such as peer observation and feedback. The practices of showing peer respect, face-saving, and conflict avoidance appeared related to Vietnamese culture, but at times challenged lecturers' professional ethics and values. For meaningful collegial learning, a negotiation between cultural norms and reflective professional practices needs to be taken into account. It is important to encourage lecturers to welcome constructive feedback from their colleagues, and become critical friends of their colleagues to support and enhance each other's professional practice. Also, nurturing a friendly learning environment of mutual trust, openness and shared visions would promote a PLD approach which is lecturer-driven, voluntary, collaborative, reflective and practice-based. A further direction for PLD could be through promoting 'learning departments', or 'learning teams' which promote learning, as well as enhancing lecturers' ownership and agency in their PLD and are supported to engage in meaningful and collaborative PLD activities (Knight et al., 
2007). Previous studies have widely supported the benefits of professional learning communities, or informal learning clusters in fostering teachers' authentic, reflective and collaborative learning (Hargreaves et al., 2013; Vo \& Nguyen, 2010).

Since leadership has an influential role in supporting lecturers' PLD, it is necessary to support leadership development through PLD designed for academic leaders, especially middle and junior leaders, to enable them to understand and fulfil their roles effectively. Such leadership would support institutional and departmental leaders to exercise their professional autonomy, influential capacity, and critical reflections on the effectiveness of top-down policies when needed. This is likely to empower leaders to clearly communicate national and institutional regulations, innovations, goals and vision with lecturers, as well as to support their collaboration with lecturers to work out PLD strategic plans for both individual and institutional growth.

The lecturers in this study did not highly value the role of PLD in enhancing their own leadership. This may derive from their perception of leadership as a formal administrative role associated with power and authority within the institution. This study proposes an expanded view of leadership which also involves fostering lecturers' ability to influence others, to lead the changes in pedagogical practices, and to promote a community of learning within their institutions. Such leadership may be sought from lecturers who do not hold official positions within the institution but are highly committed to education. These should be willing to take opportunities that allow them to learn from and learn with others, or to lead others' learning through mentoring and coaching. Such lecturers deserve recognition for their role in transfer the fire for learning to their peers and students. Therefore, a future direction for PLD could be fostering lecturer leadership, which seems to have been currently neglected in Vietnamese tertiary contexts, and empowering potential lecturer leaders to lead the change process at grass-root levels. This implication is relevant to other international contexts in which PLD has not been exploited as a tool for enhancing teacher leadership (Alexandrou \& Swaffield, 2012; Baecher, 2012).

The study findings indicate that PLD is a complex, political and culturally situated phenomenon that plays a key role in supporting the professional aspiration of lecturers. Lecturers' authentic learning is more likely to be optimised when they engage in PLD 
which includes the following four key principles arisen from the study findings: (1) being meaningful, applicable, and relevant to their needs, teaching context and responsibilities, (2) allowing reflective learning, (3) engaging lecturers as active learners, and (4) encouraging a negotiation for a shared vision and outcome among all involved stakeholders within a supportive and reflexive environment. These principles need to be taken into account when designing and facilitating PLD programmes for tertiary lecturers. Given that PLD is not only for reform enactment and accountability but also for lecturers' individual and professional growth, it is necessary that PLD initiatives for lecturers be promoted across all three PLD forms and able to accommodate diverse learning needs and preferences. Possible tensions may arise from the application of the suggested PLD model to address government policies, institutional imperatives, and the reality of the lecturers' circumstances. However, to address these tensions, it is necessary to achieve negotiated understandings of PLD, and ability to work toward relational agency in planning and supporting PLD for EFL lecturers. A reciprocal relationship among different stakeholders across the HE systems would allow the lecturers and other members within their community to give input and reflections on the policies and on their own working circumstances.

\section{PLD facilitators}

This study indicates that PLD for the EFL teacher educators was provided or initiated by a wide range of facilitators such as external experts, internal institutional leaders, internal colleagues, or the lecturers themselves. As lecturers' learning needs and required support (e.g., resources and expertise) vary when they engage in different forms of PLD, or are at different stages of reform enactment, it is necessary that PLD facilitators also vary their roles to support lecturers' learning effectively. The design of PLD also needs to be appropriate for the stage of reform implementation, as suggested from previous studies (Starkey et al., 2009).

Effective learning will likely be hindered if there are mismatches between lecturers and their PLD facilitators, especially international experts, in terms of PLD role and function, content, and process. For learning to take place, PLD facilitators and lecturer participants need to share an understanding and vision of PLD. Understanding lecturers' 
perceptions of PLD and the motives for their PLD engagement would allow facilitators to adjust their roles in order to match the lecturers' PLD needs. At present PLD facilitators' roles belong toward more formal PLD activities, mainly through delivering and transmitting knowledge and skills to lecturer participants. It is, therefore, suggested that PLD facilitators' roles need to include the collaborative and informal PLD types to respond to lecturers' learning needs and objectives. The PLD model (Figure 6.1) is a useful reference for PLD facilitators to consider when planning, organising, and supporting lecturers' PLD.

This study identifies the following five factors that PLD facilitators could consider to collaborate and support lecturers' learning:

1. Contextualise and localise PLD to meet lecturers' needs

2. Consider features of lecturers' learning, their prior experience and expertise when planning and organising PLD for lecturers, and consciously incorporate these into PLD programmes or PLD initiatives for lecturers

3. Promote mentoring/coaching and collaboration in a learning community among lecturers within and across institutions.

4. Provide on-going support and follow-up activities to give prompt feedback and support lecturers' application of new ideas into their teaching.

5. Work resourcefully to facilitate lecturers' learning across all forms of PLD.

\section{EFL teacher educators}

As suggested for the other stakeholders, EFL lecturers in this study also need to reconceptualise their understanding of PLD. It is important that they appreciate that meaningful learning can take place through informal PLD. This understanding would encourage their agency in identifying or promoting a wider range of potential learning opportunities they could access. EFL lecturers can consider the PLD model (Figure 6.1) when planning and engaging in PLD, particularly PLD activities initiated by the lecturers themselves within their network and learning communities. 
The lecturers highly valued formal PLD, but the learning from this approach seemed to be short-term and at a surface level. Therefore, it is important that lecturers take initiatives to deepen their learning. This could be obtained through various natural and voluntary activities such as talking to colleagues about their learning, applying formal learning in practice, reflecting on their experiences, and collaborating in problem-solving and researching their practices. There is strong evidence that learning from such collaborative and non-formal settings can be fruitful and enhance sustainable changes (Hargreaves et al., 2013; McGee \& Lawrence, 2009; Teräs, 2014).

There is a potential for promoting professional learning communities, or lecturers' learning groups in the Vietnamese tertiary education (Vo \& Nguyen, 2010). As the lecturers in this study suggested, it is important that PLD supports not only lecturers' professional knowledge and skills but also ways for them to learn and work effectively together. Lecturers can establish an online learning community, or a professional association within or beyond their institution. Participation in these communities of learners would enhance their learning opportunities and collegial support. This would also foster informal and authentic learning among lecturers.

The study showed that mentoring or coaching was uncommon in all three university sites although lecturers highly valued it. Mentoring or coaching requires a trustful and supportive learning environment, as previously discussed. Previous studies (Bartell, 2005; Davey \& Ham, 2010; Murray, 2010) suggest a combination of both formal and informal mentoring to enhance lecturers' learning. A formal and obligatory model may be effective in monitoring and supporting the performance of lecturers, especially the juniors, whereas a voluntary mentoring model would allow lecturers to approach a more experienced colleague for further learning. These variations of mentoring can be taken into consideration in Vietnamese tertiary context. Cultural features related to hierarchical relationships between juniors and seniors, or mentors and mentees, also need to be considered in order to create friendly and effective learning for both. A shared understanding and vision of collaborative learning and an agreed working protocol based on trust and openness could facilitate lecturers' co-learning processes. 
It may also benefit EFL teacher educators to reconceptualise their perceptions of research. The concept of 'transferring a fire' highlights the value and effect of collaborative support in inspiring lecturers to view research engagement as a form of PLD. Research mentoring and collaborative research have been proven to be productive and supportive ways to build research capacity, especially for beginning lecturer researchers (Hill \& Haigh, 2012; Jones et al., 2011; McGee, 2011; Murray, 2010; Robinson \& McMillan, 2006). The lecturers in this study valued research that directly supported their pedagogical practice and addressed teaching problems, therefore, they would probably appreciate the chance to engage in practitioner research. Researching their own practice would support lecturers' professional identity as teachers, which would empower them to undertake researchinformed teaching. Gradually, their research ability as well as professional identity as teacher-researchers would be enhanced (Hill \& Haigh, 2012; Robinson \& McMillan, 2006).

Teacher educators play an important role in teacher education, and need to collaborate with and support school teachers. However, the only interaction teacher educators in this study had with local schools was through delivering EFL methodology courses and supervising student teachers' practicums. There needs to be a stronger university-school partnership in which teacher educators support and facilitate EFL school teachers' action research and school-based PLD. A wider collaboration and professional network would foster mutual learning, and enable meaningful changes at both theoretical and practical aspects in teacher education not only in EFL but also in other disciplines. The PLD model proposed from this study can be a promising framework for teacher educators to consider not only for planning and promoting their own PLD but also for PLD of pre- and in-service teachers within their teaching and professional network.

\section{Limitations and recommendations for further research}

This section acknowledges some limitations of the research, and then suggests areas for further research. This study has the following limitations. First, it only involved a group of EFL teacher educators at three universities. This small sample is not representative of a wider population of Vietnamese tertiary lecturers in various HEIs. The study findings, therefore, should not be generalised for lecturers of other disciplines or from other HEIs. However, it was not the purpose of this current case study to provide generalisation. 
Second, the study could not involve internal PLD providers from all three universities, or external PLD providers, or PLD experts. The perceptions of PLD for tertiary lecturers and the experiences in PLD provision from this group were not explored despite their considerable impact on the lecturers' PLD experiences. Third, the study involved observations of PLD sessions in only two of the three universities, and there was limited access to incidences of informal and collaborative PLD such as professional dialogues, team work, or co-research. Due to ethical considerations where individuals within organisations could be identified, there were also limitations in presenting findings from PLD observations which would have added insights into typical features of PLD in practice. Additionally, policy documents such as departmental PLD plans, records of PLD activities, and lecturers' individual plans for PLD and reflections on their learning were not accessible. Limited data in these aspects prevented a deeper understanding of the departmental context and its culture and how these affected lecturers' opportunities for PLD. Finally, this study did not examine the impact of lecturers' PLD experiences on their students' learning, or how lecturers' PLD engagement was actually transferred into their classroom practices.

More research is needed on the role and function of PLD for tertiary lecturers in general, and tertiary teacher educators in particular. This study focused on PLD experienced by a particular group of tertiary teacher educators training EFL school teachers at three universities in one region, the Mekong Delta, in Vietnam. Professional learning and development for lecturers from other universities and other regions (in the central and north of Vietnam), or for lecturers specialising in other disciplines may be different, and thus would be an area for further research.

There were variations in the perceptions and experiences of PLD reported by different groups of lecturers (e.g., junior and senior lecturers, lecturers with and without leadership roles). However, these were just tentative findings because this study aimed to obtain a holistic understanding of PLD for the selected group of lecturers who were EFL teacher educators, rather than to explore deeply how PLD varied in the experiences of lecturers from wider backgrounds. Further research could focus on PLD for lecturers at different career stages, or in different professional roles within their institutions in order to inform PLD polices that support on-going PLD for lecturers across their career. 
The study found that although lecturers perceived individual and collaborative research as important forms of PLD for tertiary educators, they did not actively engage in these activities due to personal as well as contextual barriers. Further research is needed to explore further how lecturers' research, particularly practitioner research (e.g., lecturers researching their own teaching practice) could be promoted so as to enhance tertiary educators' quality teaching and professional identity.

The participants in this study reported a commitment to supporting local in-service teachers' teaching and learning, but their support seemed to take place primarily within university-based PLD programmes for these teachers. Previous studies on PLD for teacher educators showed that PLD initiatives involving university-school partnership have positive impacts on both tertiary educators' and local teachers' learning and changes in practice (Buczynski \& Hansen, 2010; Flint, Kurumada, Fisher, \& Zisook, 2011; Flint, Zisook, \& Fisher, 2011; McGee, 2011). To date, there has not been any research in this area in Vietnam so far, and it is worth investigating to shed light on how learning is promoted through such a network.

The teacher educators valued agency and autonomy in their own PLD, and wanted to promote a form of PLD which was initiated and directed by the lecturers themselves within their departments to maximise the relevance of PLD to their learning needs and professional concerns. Further research is needed around the implementation and impact of lecturers' self-regulated and informal learning (e.g., mentoring/coaching, lecturers' teaching club, collaborative research) within lecturers' community of learning in tertiary contexts. Arguably, PLD facilitators and mentors have a great influence on the effectiveness of PLD promoted and provided for tertiary lecturers. Further research could explore further the role and function of PLD for PLD facilitators and how their PLD could be promoted. Additionally, further research could focus on PLD that supports leadership capacity for academic leaders, potential leaders, or informal lecturer leaders who play important role in facilitating and promoting lecturers' learning and teaching at departmental levels. 


\section{Concluding remarks}

This study demonstrates PLD as a multidimensional and complex phenomenon that both supports and challenges teacher educators' roles in a Vietnamese dynamic, changing, and demanding tertiary environment. While PLD can enhance lecturers' implementation of educational reforms in a Vietnamese tertiary context, an interesting finding is that the roles and functions of PLD go beyond supporting reform agenda. PLD is found to have a powerful impact upon lecturers' teaching commitment and enhancing their perceptions of professional identity, and thus is integral to their personal as well as professional growth.

The study provides evidence that Vietnamese teacher educators' professional identity is influenced by deeply held cultural values attached to the teaching profession and the role of teacher educators, as well as mandated initiatives within a dynamic tertiary context. This in turn shapes and is shaped by their PLD motives and engagement. Key features of PLD for Vietnamese teacher educators include a strong focus on content knowledge, pedagogy, and English language competence, and aspirations for overseas training and PLD opportunities. As an important mechanism to enact mandating reforms in HE, PLD is also a means for enhancing teaching effectiveness, supporting students' learning, and strengthening lecturers' professional image and identity.

The findings show that PLD is a complicated and culturally, socially and politically bound phenomenon, and that it should not be conceptualised in a single way. As presented in Chapter 2, current literature proposes replacing the term PLD by PL in order to foreground the learning component as a core focus of teachers', as well as, lecturers' PLD (Webster-Wright, 2009). However, this study supports the use of PLD given the multiple roles and functions PLD plays in a Vietnamese tertiary context of educational reforms, highlighting both learning and development. Lecturers' PLD takes place in diverse ways depending on their own learning motives and focus. When learning is foregrounded, questions such as when? why? how? for whom (the subject's roles) might be asked. There needs to be a match between the why (e.g., for learning), the how (e.g., what types of PLD supports this goal), and the who (e.g., the learners and their roles) in order to support and foster lecturers' sustainable, meaningful, and effective learning which targets their personal and professional growth as well as national and institutional goals in educational changes. 
This study raises critical questions of what might need to be done within HE institutions and by policy makers to provide a supportive PLD environment to foster educators' capacity to bring about changes at both personal and institutional levels. The study contributes to the knowledge base of EFL teacher educators' PLD in an Asian context, and some of its implications are also relevant to PLD for tertiary lecturers in a wider international context.

Lecturers' PLD engagement is greatly influenced by national and institutional policies, leadership, lecturers' personal attributes, and sociocultural values. Therefore, for PLD to be further promoted and become effective, there needs to be a mutual understanding of the complexity of PLD for lecturers, and an alignment of motives and goals among different stakeholders involved in PLD activity systems in Vietnamese educational context.

From the study findings, PLD for the lecturers was both an individual and collaborative endeavour, and the lecturers' agency and motivation played a key role in their learning commitment, as consistent with findings from previous studies (Hiver, 2013). In other contexts, research has shown that PLD is effective when it targets the needs and goals of the teaching staff (Starkey et al., 2009; Tallerico, 2005). In this perspective, to optimise lecturers' learning, PLD needs to be reconceptualised to address both institutional goals and lecturers' own personal and professional goals, as also suggested from other studies (Labone \& Long, 2014; Opfer \& Pedder, 2011). This requires a shared vision and effort between individuals and their organisations. By legitimising the values of different PLD forms, and different ways lecturers learn and develop, MOET and institutional leaders could create a more transformative environment which supports both lecturers' learning and institutional changes (Engeström, 2015).

A further direction for PLD in tertiary institutions could be reallocation of funding and resources across all forms of PLD, rather than primarily on formal PLD to increase the number of staff with credentials. Indeed, PLD is far more powerful than merely gaining credentials, and it is considered by the lecturers as meaningful when it fosters lecturers' teaching and scholarship, and ultimately sustainable changes in lecturers' teaching and students' learning. Additionally, if the division of labour is adjusted to give lecturers more time for informal PLD such as research, collaborative learning, and networking with their 
colleagues, lecturers will be empowered to undertake their role as change agents in a complex and dynamic tertiary environment. By understanding, acknowledging and supporting lecturers' PLD need, and giving them more agency in their own PLD and opportunities to negotiate and align institutional and personal goals, there would be a potential for 'transformative agency' which occurs "when a group of people collaboratively take initiatives to develop their activity" (Haapasaari, Engeström, \& Kerosuo, 2014, p. 4). Such collective change efforts would evolve over time and bring about significant changes and transformations within tertiary institutions. As Scribner (1999) identified, this study shows that PLD needs to be viewed as "more than a vehicle for reform", but rather as "a reform in and of itself' (p. 263). In this respect, it is essential that PLD become an integral part of lecturers' professional practice and their institutional culture. 



\section{EPILOGUE}

I started my $\mathrm{PhD}$ with an initial interest in finding ways to improve the quality of current PLD for tertiary lecturers. My understanding of PLD at that time was restricted to independent learning and formal PLD activities such as workshops and training courses that my colleagues and I were provided, mainly from external experts. However, the results from this research identify PLD as a complex and multidimensional phenomenon occurring both formally and informally throughout lecturers' professional lives. I have gained more insights into how PLD shapes and is shaped by lecturers' daily practice, and how PLD is bounded within a dynamic social, cultural, and political context of lecturers' learning. As many of my colleagues participating in this study, I believe that PLD is essential and lifelong.

The PhD research journey is a meaningful learning experience for me. Through this process I have been inspired by the lecturer participants, my supervisors, and other $\mathrm{PhD}$ student researchers who 'transfer the fire' to foster my learning and research. Having now received the fire from the participants, upon accomplishing this research, I hope to be able to 'transfer the fire' to other lecturers and stakeholders in Vietnamese tertiary contexts who are willing to undertake a collective endeavour towards sustainable changes in education through supporting lecturers' learning.

In concluding my thesis, I reflect on a sociocultural image attached to the roles of teachers (as well as teacher educators) in Vietnam: 'a silent sailor' (người lái đò thầm lặng). In Vietnam, teachers are considered as metaphorical sailors who have knowledge (e.g., about weather, water currents, and directions) and navigational skills to direct the boat and take their passengers to their destinations safely. In the same way, teachers navigate and guide students' learning to prepare them for a good future. As humble and hardworking sailors take passengers to a new land, teachers take care of and teach generations of students and make a silent contribution to these students' future success.

The image of teachers as 'sailors' in Vietnamese culture still retains its powerful meaning in terms of reflecting teachers' commitment, effort, and dedication. However, in the current fast changing sociocultural and political context, this cultural image can be 
challenged in relation to whether it sufficiently captures teaching as a creative profession. As reflected in this study, the Vietnamese teacher educators are still playing their traditional role of sailors but in a modern, changing and demanding educational context. They are committed to and passionate about leading the young generations to a diversity of destinations, and doing the best to prepare their students for successful future journeys. These lecturers did not consider their students as passive passengers, but rather as active companions whose voices and learning needs are integral to the lecturers' teaching and learning efforts. During the course of their service, these teacher educators not only sail the boat with their students, but also with their peer lecturers, and at times support the students to sail their own boats. Similar to sailing, lecturers' teaching and their PLD in a Vietnamese tertiary context emerge from this study as a meaningful, cultural and collective activity system which has its own values, rules, and resources and embraces learning opportunities for all involved in the activity system.

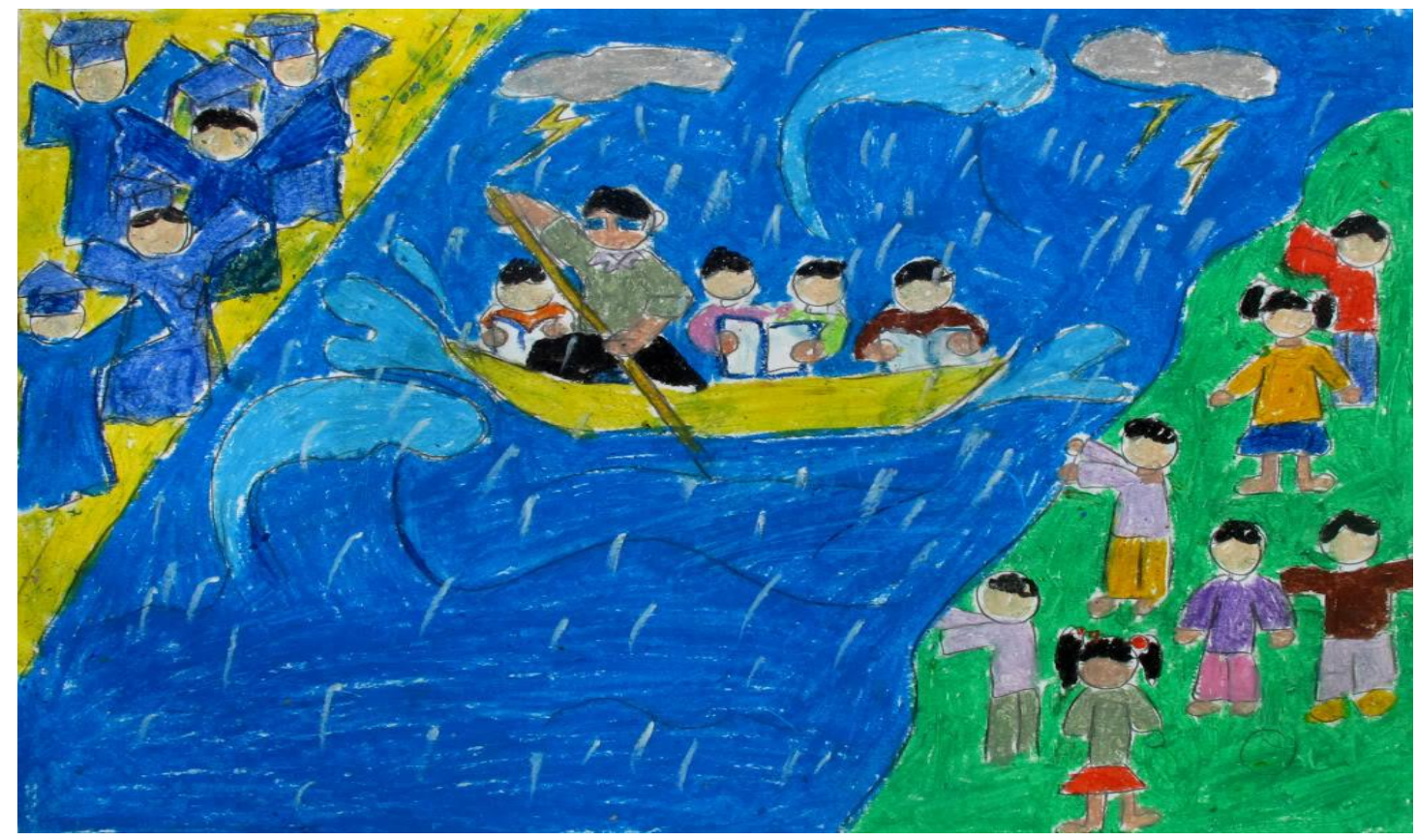

A dedicated sailor ${ }^{23}$ (Source: http://luongthevinh.com.vn/home/?p=239)

\footnotetext{
23 This drawing was created by a high school student for a drawing competition organised by the student's school to celebrate Vietnamese Teachers' Day (20 November). On this occasion students express their gratitude for their current and former teachers, a demonstration of expressing Vietnamese cultural practice.
} 


\section{REFERENCES}

Ahn, K. (2009). Learning to teach within the curricular reform context: A sociocultural perspective on English student teachers' practicum experience in South Korea (Doctoral thesis). The Pennsylvania State University. Retrieved from ProQuest database.

Alexandrou, A., \& Swaffield, S. (2012). Teacher leadership and professional development: Perspectives, connections and prospects. Professional Development in Education, $38(2), 159-167$.

Baecher, L. (2012). Pathways to teacher leadership among English-as-a-second-language teachers: Professional development by and for emerging teacher leaders. Professional Development in Education, 38(2), 317-330.

Bai, L., \& Hudson, P. (2010). Understanding Chinese TEFL academics' capacity for research. Journal of Further and Higher Education, 35(3), 391-407.

Bartell, C. A. (2005). Cultivating high-quality teaching through induction and mentoring. California: Corwin Press.

Basit, T. N. (2013). Ethics, reflexivity and access in educational research: Issues in intergenerational investigation. Research Papers in Education, 28(4), 506-517.

Bell, B., \& Gilbert, J. (1996). Teacher development: A model from science education. London: Falmer Press.

Ben-Peretz, M., Kleeman, S., Reichenberg, R., \& Shimoni, S. (2010). Educators of educators: Their goals, perceptions and practices. Professional Development in Education, 36(1-2), 111-129.

Blackmore, P., \& Blackwell, R. (2006). Strategic leadership in academic development. Studies in Higher Education, 31(3), 373-387.

Boei, F., Dengerink, J., Geursen, J., Kools, Q., Koster, B., Lunenberg, M., \& Willemse, M. (2015). Supporting the professional development of teacher educators in a productive way. Journal of Education for Teaching, 41(4), 351-368. 
Bolam, R., \& McMahon, A. (2004). Literature, definitions and models: Towards a conceptual map. In C. Day \& J. Sachs (Eds.), International Handbook on the Continuing Professional Development of Teachers (pp. 33-63). Berkshire: Open University Press.

Borg, S. (2010). Language teacher research engagement. Language Teaching, 34(4), 391429.

Borko, H., Elliott, R., \& Uchiyma, K. (2002). Professional development: A key to Kentucky's educational reform effort. Teaching and Teacher Education, 18(8), 969987.

Bourke, R., \& McGee, A. (2012). The challenge of changes: Using activity theory to understand a cultural innovation. Journal of Educational Change, 13(2), 217-233.

Bourke, R., McGee, A., \& O’Neill, J. (2008). Facilitating teacher learning. In R. Bourke, A. Lawrence, A. McGee, J. O’Neill \& J. Curzon (Eds.), Talk about learning: Working alongside teachers (pp. 65-71). North Shore: Pearson Education New Zealand.

Bourke, R., Mentis, M., \& O’Neill, J. (2013). Analysing tensions within a professional learning and development initiative for teachers. Learning, Culture and Social Interaction, 2(4), 265-276.

Bourke, R., \& St. George, A. (2008). Understanding learning through theory. In R. Bourke, A. Lawrence, A. McGee, J. O’Neill \& J. Curzon (Eds.), Talk about learning: Working alongside teachers (pp. 13-26). North Shore: Pearson Education New Zealand.

Brislin, W. R. (1970). Back-translation for cross-cultural research. Journal of CrossCultural Psychology, 1(3), 185-216.

Buczynski, S., \& Hansen, C. B. (2010). Impact of professional development on teacher practice: Uncovering connections. Teaching and Teacher Education, 26(3), 599-607.

Burton, D., \& Bartlett, S. (2009). Key issues for education researchers. London: Sage

Callanan, M., Cervantes, C., \& Loomis, M. (2011). Informal learning. Wiley Interdisciplinary Reviews: Cognitive science, 2(6), 646-655. 
Canagarajah, A. S. (2006). Negotiating the local in English as a lingua franca. Annual Review of Applied Linguistics, 26, 197-218.

Chaudary, I. A. (2011). A new vision of professional development for tertiary teachers in Pakistan. Professional Development in Education, 37(4), 633-637.

Cheng, Y. C. (2009). Hong Kong educational reforms in the last decade: Reform syndrome and new development. International Journal of Educational Management, 23(1), 6586.

Cho, J. H. (2014). Teachers' perceptions of changes to teaching practice and the influence of professional development: Experienced EFL teachers in South Korea (Unpublished master's thesis). Victoria University of Wellington, New Zealand.

Creswell, J. W. (2009). Research design: Qualitative, quantitative, and mixed methods approaches. California: Sage.

Creswell, J. W. (2014). Educational research: Planning, conducting and evaluating quantitative and qualitative research (4th ed.). Harlow: Essex Pearson.

Creswell, J. W., \& Miller, D. L. (2000). Determining validity in qualitative inquiry. Theory into Practice, 39(2), 124-130.

Creswell, J. W., \& Plano Clark, V. L. (2011). Designing and conducting mixed methods research (2nd ed.). Los Angeles: Sage.

D'Andrea, V., \& Gosling, D. (2005). Improving teaching and learning in higher education: A whole institution approach. Berkshire: Open University Press.

Davey, R., \& Ham, V. (2010). 'It's all about paying attention!' ... but to what? The '6 Ms' of mentoring the professional learning of teacher educators. Professional Development in Education, 36(1-2), 229-244.

Day, C. (1999). Developing teachers: The challenges of lifelong learning. London: Falmer Press.

Day, C., \& Lee, J. C. K. (Eds.). (2011). New understandings of teacher's work: Emotions and educational change (Vol. 6). New York: Springer. 
Day, C., \& Sachs, J. (2004). Professionalism, performativity and empowerment: Discourses in the politics, policies and purposes of continuuing professional development. In C. Day \& J. Sachs (Eds.), International Handbook on the Continuing Professional Development of Teachers (pp. 2-32). Berkshire: Open University Press.

Denscombe, M. (2002). Ground rules for good research: A 10 point guide for social researchers. Phildelphia, PA: Open University.

Denzin, N. K., \& Lincoln, Y. S. (Eds.). (2000). Handbook of qualitative research ( $2^{\text {nd }}$ ed.). Thousand Oak, California: Sage.

Diaz-Maggioli, G. (2004). Teacher-centered professional development. Alexandria, Va.: Association for Supervision and Curriculum Development.

Dörnyei, Z. (2009). The L2 motivational self system. In Z. Dörnyei \& E. Ushioda (Eds.), Motivation, language identity and the L2 self (pp. 9-42). Bristol, UK; Buffalo, NY: Multilingual Matters.

Dudzik, D. L., \& Nguyen, Q. T. N. (2015). Vietnam: Building English competency in preparation for ASEAN 2015. In R. Stroupe \& K. Kimura (Eds.), ASEAN integration and the role of English language teaching (pp. 41-70). Phnom Penh: Language Education in Asia.

Ebert-May, D., Derting, T. L., Hodder, J., Momsen, J. L., Long, T. M., \& Jardeleza, S. E. (2011). What we say is not what we do: Effective evaluation of faculty professional development programs. BioScience, 61(7), 550-558.

Edwards, A. (2010). Being an expert professional practitioner: The relational turn in expertise (Vol. 3). Dordrecht: Springer Netherlands.

Edwards, A. (2015). Recognising and realising teachers' professional agency. Teachers and Teaching: Theory and Practice, 21(6), 779-784.

Eisner, E. W. (1998). The enlightened eye: Qualitative inquiry and the enhancement of educational practice. New Jersey: Prentice-Hall, Inc.

Engeström, Y. (1999). Expansive visibilization of work: An Activity-Theoretical perspective. Computer Supported Cooperative Work, 8(1), 63-93. 
Engeström, Y. (2000). Activity theory as a framework for analysing and redesigning work. Ergonomics, 43(7), 960-974.

Engeström, Y. (2001). Expansive learning at work: Toward an activity theoretical reconceptualization. Journal of Education and Work, 14(4), 134-156.

Engeström, Y. (2009). Expansive learning: Toward an activity-theoretical reconceptualization. In K. Illeris (Ed.), Contemporary theories of learning: Learning theorists... in their own words (pp. 53-73). New York: Routledge.

Engeström, Y. (2015). Learning by expanding: An activity-theoretical approach to developmental research. Helsinki: Orienta-Konsultit Oy.

Engeström, Y., \& Miettinen, R. (1999). Introduction. In Y. Engeström, R. Miettinen \& R.L. Punamaki (Eds.), Perspectives on activity theory (pp. 1-16). Cambridge; New York: Cambridge University Press.

Fiszer, E. P. (2004). How teachers learn best: An ongoing professional development model. Maryland: ScarecrowEducation.

Flick, U. (2006). An introduction to qualitative research (3rd ed.). London: Sage.

Flint, A. S., Kurumada, K. S., Fisher, T., \& Zisook, K. (2011). Creating the perfect storm in professional development: the experiences of two American teachers and a university research team. Professional Development in Education, 37(1), 95-109.

Flint, A. S., Zisook, K., \& Fisher, T. R. (2011). Not a one-shot deal: Generative professional development among experienced teachers. Teaching and Teacher Education, 27(8), 1163-1169.

Flyvbjerg, B. (2011). Case study. In N. K. Denzin \& Y. S. Lincoln (Eds.), The Sage handbook of qualitative research, (pp. 301-316). Thousand Oaks: Sage.

Forde, C., McMahon, M., McPhee, A. D., \& Patrick, F. (2006). Professional development, reflection and enquiry. London: Paul Chapman Publishing.

Fraser, C., Kennedy, A., Reid, L., \& Mckinney, S. (2007). Teachers' continuing professional development: Contested concepts, understandings and models. Journal of In-service Education, 33(2), 153-169. 
Frost, D. (2012). From professional development to system change: Teacher leadership and innovation. Professional Development in Education, 38(2), 205-227.

Fry, G. W. (2009). Higher Education in Vietnam. In Y. Hirosato \& Y. Kitamura (Eds.), The political economy of educational reforms and capacity development in Southeast Asia (pp. 237-261). Springer Science + Business Media B.V.

Gallagher, T., Griffin, S., Parker, D. C., Kitchen, J., \& Figg, C. (2011). Establishing and sustaining teacher educator professional development in a self-study community of practice: Pre-tenure teacher educators developing professionally. Teaching and Teacher Education, 27(5), 880-890.

Gao, X. (2008). Teachers' professional vulnerability and cultural tradition: A Chinese paradox. Teaching and Teacher Education, 24(1), 154-165.

Gray, D. (2009). Doing research in the real world (2nd ed.). London: Sage.

Green, A. (2010). Teachers' continuing professional development and higher education. Changing English, 17(2), 215-227.

Green, J. C. (2007). Mixed methods in social inquiry (1st ed.). San Francisco, CA: JosseyBass.

Grosemans, I., Boon, A., Verclairen, C., Dochy, F., \& Kyndt, E. (2015). Informal learning of primary school teachers: Considering the role of teaching experience and school culture. Teaching and Teacher Education, 47, 151-161.

Guba, E. G. (1990). The alternative paradigm dialog. In E. G. Guba (Ed.), The paradigm dialog (pp. 17-30). Newbury Park, California: Sage.

Guskey, T. R. (2000). Evaluating professional development. California: Corwin Press.

Haapasaari, A., Engeström, Y., \& Kerosuo, H. (2014). The emergence of learners' transformative agency in a Change Laboratory intervention. Journal of Education and Work. Advance online publication. doi: 10.1080/13639080.2014.900168

Hall, S. J. (2015). A past before a blueprint: Malaysia's challenges in English language teaching. In R. Stroupe \& K. Kimura (Eds.), ASEAN integration and the role of 
English language teaching (pp. 149-168). Phnom Penh: Language Education in Asia.

Hallinger, P. (2010). Making education reforms happen: Is there an "Asian" way? School Leadership and Management, 30(5), 401-418.

Hamano, T. (2008). Educational reform and teacher education in Vietnam. Journal of Education for Teaching, 43(4), 397-410.

Hamid, M. O., Nguyen, H. T. M., \& Baldauf Jr, R. B. (2013). Medium of instruction in Asia: Context, processes and outcomes. Current Issues in Language Planning, 14(1), 1-15.

Hamid, M. O., \& Nguyen, H. T. M. (2016). Globalization, English language policy, and teacher agency: Focus on Asia. The International Education Journal: Comparative Perspectives, 15(1), 26-44.

Hargreaves, A. (2003). Teaching in the knowledge society: Education in the age of insecurity. Philadelphia: Open University Press.

Hargreaves, E., Berry, R., Lai, Y. C., Leung, P., Scott, D., \& Stobart, G. (2013). Teachers' experiences of autonomy in Continuing Professional Development: Teacher Learning Communities in London and Hong Kong. Teacher Development, 17(1), 19-34.

Hayden, M., \& Lam, Q. T. (2007a). A 2020 vision for higher education in Vietnam. International Educator, 16(1), 14-17.

Hayden, M., \& Lam, Q. T. (2007b). Institutional autonomy for higher education in Vietnam. Higher Education Research and Development, 26(1), 73-85.

Hayes, D. (2016). The value of learning English in Thailand and its impact on Thai: Perspectives from university students. Asia Pacific Journal of Education, 36(1), 7391.

Hemer, S. R. (2014). Finding time for quality teaching: an ethnographic study of academic workloads in the social sciences and their impact on teaching practices. Higher Education Research \& Development, 33(3), 483-495. 
Higgins, E. T. (1987). Self-discrepancy: A theory relating self and affect. Psychological Review, 94(3), 319-340.

Hill, M. F., \& Haigh, M. A. (2012). Creating a culture of research in teacher education: learning research within communities of practice. Studies in Higher Education, 37(8), 971-988.

Hiver, P. (2013). The interplay of possible language teacher selves in professional development choices. Language Teaching Research, 17(2), 210-227.

House, R. J., Hanges, P. J., Javidan, M., Dorfman, P. W., \& Gupta, V. (2004). Culture, leadership, and organisations: The GLOBE study of 62 societies. California: Sage.

Hu, Z., \& McGrath, I. (2011). Innovation in higher education in China: Are teachers ready to integrate ICT in English language teaching? Technology, Pedagogy and Education, 20(1), 41-59.

Hwang, H. (2014). The influence of the ecological contexts of teacher education on South Korean teacher educators' professional development. Teaching and Teacher Education, 43, 1-14.

Israel, M., \& Hay, I. (2006). Research ethics for social scientists: Between ethical conduct and regulatory compliance. London: Sage.

Johnson, R. B., \& Christensen, L. (2008). Educational research: Quantitative, qualitative, and mixed approaches (3rd ed.). Los Angeles: Sage.

Johnson, R. B., \& Christensen, L. (2012). Educational research: Quantitative, qualitative, and mixed approaches (4th ed.). Thousand Oaks, California: Sage.

Johnson, R. B., \& Christensen, L. (2014). Educational research: Quantitative, qualitative, and mixed approaches (5th ed.). Thousand Oaks, California: Sage.

Johnson, R. B., \& Onwuegbuzie, A. J. (2004). Mixed methods research: A research paradigm whose time has come. Educational Researcher, 33(7), 14-26.

Jones, M., Stanley, G., McNamara, O., \& Murray, J. (2011). Facilitating teacher educators' professional learning through a regional research capacity-building network. AsiaPacific Journal of Teacher Education, 39(3), 263-275. 
Jones, W. M., \& Dexter, S. (2014). How teachers learn: The roles of formal, informal, and independent learning. Educational Technology Research and Development, 62(3), $367-384$.

Kam, H. W. (2002). English language teaching in East Asia today: An overview. Asia Pacific Journal of Education, 22(2), 1-22.

Kelchtermans, G. (2004). CPD for professional renewal: Moving beyond knowledge for practice. In C. Day \& J. Sachs (Eds.), International handbook on the Continuing Professional Development of teachers (pp. 217-237). Berkshire: Open University Press.

Kennedy, A. (2011). Collaborative continuing professional development (CPD) for teachers in Scotland: Aspirations, opportunities and barriers. European Journal of Teacher Education, 34(1), 25-41.

Kennedy, A. (2014). Models of continuing professional development: A framework for analysis. Professional Development in Education, 40(3), 336-351.

King, M. B., \& Newmann, F. M. (2001). Building school capacity through professional development: Conceptual and empirical considerations. The International Journal of Educational Management, 15(2), 86-93.

Kirkpatrick, A. (2011). English as an Asian lingua franca and the multilingual model of ELT. Language Teaching, 44(2), 212-224.

Klassen, R. M., Usher, E. L., \& Bong, M. (2010). Teachers' collective efficacy, job satisfaction, and job stress in cross-cultural context. The Journal of Experimental Education, 78(4), 464-486.

Knight, P., Tait, J., \& Yorke, M. (2007). The professional learning of teachers in higher education. Studies in Higher Education, 31(3), 319-339.

Knight, S. L., Lloyd, G. M., Arbaugh, F., Gamson, D., McDonald, S. P., \& Nolan Jr., J. (2014). Professional development and practices of teacher educators. Journal of Teacher Education, 65(4), 268-270. 
Kumazawa, M. (2013). Gaps too large: Four novice EFL teachers' self-concept and motivation. Teaching and Teacher Education, 33, 45-55.

Kwakman, K. (2002). Factors affecting teachers' participation in professional learning activities. Teaching and Teacher Education, 19(2), 149-170.

Labaree, D. F. (2005). Life on the margins. Journal of Teacher Education, 56(3), 186-191.

Labone, E., \& Long, J. (2014). Features of effective professional learning: A case study of the implementation of a system-based professional learning model. Professional Development in Education. Advance online publication. doi:

$10.1080 / 19415257.2014 .948689$

Lai, M. (2011). Teacher development under curriculum reform: A case study of a secondary school in mainland China. International Review Education, 56(5-6), 613-631.

Lai, M., Du, P., \& Li, L. (2014). Struggling to handle teaching and research: A study on academic work at select universities in Chinese Mainland. Teaching in Higher Education, 19(8), 966-979.

Lamont, M. (2011). An environment of collegial reflective dialogue for inservice teacher educators. In J. Higgins, R. Parsons \& L. Bonne (Eds.), Processes of inquiry: Inservice teacher educators research their practice (pp. 63-88). Rotterdam: Sense.

Lawler, P. A., \& King, K. P. (2000). Planning for effective faculty development: Using adult learning strategies. Florida: Krieger Publishing Company.

Le, N. (2014). Thầy cô giáo - Người lái đò tận tụy [Teachers - Dedicated sailors]. Trang Thông tin điện tử Thành phố Vũng Tàu. Retrieved from http://vungtau.bariavungtau.gov.vn/web/guest/tin-tuc/-/brvt/extAssetPublisher/content/1131517/thayco-giao-nguoi-lai-do-tan-tuy

LeCompte, M., \& Goetz, J. (1982). Problems of reliability and validity in ethnographic research. Review of Educational Research, 52(1), 31-60.

Lee, C.-j. G. (2012). Reconsidering constructivism in qualitative research. Educational Philosophy and Theory, 44(4), 403-412. 
Leibowitz, B., Schalkwyk, S. v., Ruiters, J., Farmer, J., \& Adendorff, H. (2012). “'It’s been a wonderful life": Accounts of the interplay between structure and agency by “'good” university teachers. Higher Education, 63(3), 353-365.

Leont'ev, A. N. (1981). Problems of the development of the mind. Moscow: Progress.

Lim, C. P., \& Hang, D. (2003). An activity theory approach to research of ICT integration in Singapore schools. Computers and Education, 41(1), 49-63.

Lincoln, Y., \& Guba, E. (1985). Naturalistic inquiry. Newbury Park, California: Sage.

Little, J. W. (1992). Teacher development and educational policy. In M. Fullan \& A. Hargreaves (Eds.), Teacher development and educational change. London: The Falmer Press.

Liu, K. Y. (2012). A design framework for online teacher professional development. Asia Pacific Education Review, 13(4), 701-711.

Liu, M.-H. (2009). Exploring the impact of EFL teacher professional development on student learning experience in context. The International Journal of Learning, 16(10), 521-535.

Loughran, J. (2014). Professional developing as a teacher educator. Journal of Teacher Education, 65(4), 271-283.

Marlow, M. (2009). Supporting teacher professional identity through mentoring activities. Research in Higher Education Journal, 2, 1-9.

Maskit, D. (2011). Teachers' attitudes toward pedagogical changes during various stages of professional development. Teaching and Teacher Education, 27(5), 851-860.

Mason, J. (2006). Mixing methods in a qualitatively driven way. Qualitative Reseach, 6(1), $9-25$.

McGee, A. (2011). Building collaborative professional learning within an organisation. In J. Higgins, R. Parsons \& L. Bonne (Eds.), Processes of inquiry: Inservice teacher educators research their practice (pp. 45-62). Rotterdam: Sense. 
McGee, A., Haworth, P., \& MacIntyre, L. (2015). Leadership practices to support teaching and learning for English language learners. TESOL Quarterly, 49(1), 92-114.

McGee, A., \& Lawrence, A. (2009). Teacher educators inquiring into their own practice. Professional Development in Education, 35(1), 139-157.

McNicholl, J. (2013). Relational agency and teacher development: A CHAT analysis of a collaborative professional inquiry project with biology teachers. European Journal of Teacher Education, 36(2), 218-232.

Merriam, S. B. (1988). Case study research in education: A qualitative approach. San Francisco, California: Jossey-Bass.

Merriam, S. B. (2001). Qualitative research and case study applications in education. California: Jossey-Bass.

Merriam, S. B. (2009). Qualitative research: A guide to design and implementation. San Francisco, California: Jossey-Bass.

Miles, M., \& Huberman, A. M. (1994). Qualitative data analysis. Thousand Oaks, California: Sage.

Miles, M., Huberman, A. M., \& Saldana, J. (2014). Qualitative data analysis: A methods sourcebook (3rd ed.). California: Sage

MOET. (2007). Tiêu chuẩn đánh giá truờng Đại học [Standards for assessing universities]. (65/2007/QĐ-BGDĐT). Hanoi: Vietnam.

MOET. (2008). Quyết định ban hành quy định chế độ làm việc đối với giảng viên (Decision on issuing the regulations of lecturers' working conditions). (64/2008/QĐ-BGDĐT). Hanoi: Vietnam.

MOET. (2011). Quyết định phê duyệt chuoong trình phát triển ngành su phạm và các truờng sư phạm tù̀ năm 2011 đến năm 2020 (Decision on a plan to develop teacher education programmes and teacher education institutions 2011-2020). (6290/QĐ-BGDĐT). Hanoi: Vietnam.

MOET. (2013). Thông tu ban hành quy định bồi duõng chuyên môn, nghiệp vụ cho giảng viên các cơ sở giáo dục đại học (Circular of issuing regulations about professional 
development for lecturers of higher education institutions). (20/2013/TT-BGDĐT). Hanoi: Vietnam.

MOET. (2014). Hướng dẫn v/v thưc hiện Yêu cầu co bản về năng lục giáo viên tiếng Anh phổ thông (Instructions for implementing the basic requirements of professional competencies for EFL school teachers). (792/BGDĐT-NGCBQLGD). Hanoi: Vietnam.

Mundry, S. (2005). Changing perspectives in professional development. Science Educator, 14(1), 9-15.

Murray, J. (2010). Towards a new language of scholarship in teacher educators' professional learning? Professional Development in Education, 36(1-2), 197-209.

Ngo, T. T. (2011). Một số giải pháp khuyến khích giảng viên đổi mới phương pháp giảng dạy [Some solutions for encouraging lecturers to improve teaching methods]. Giáo dục và thời đại. Retrieved from http://www.gdtd.vn/channel/3063/201107/Mot-sogiai-phap-khuyen-khich-giang-vien-doi-moi-phuong-phap-giang-day-1949396/

Nguyen, H. T. M. (2008). Mentoring beginning EFL teachers at tertiary level in Vietnam. The Asian EFL Journal, 10(1), 111-132.

Nguyen, H. T. M. (2011). Primary English language education policy in Vietnam: Insights from implementation. Current Issues in Language Planning, 12(2), 225-249.

Nguyen, K. D., \& McInnis, C. (2002). The possibility of using student evaluations in Vietnamese Higher Education. Quality in Higher Education, 8(2), 151-158.

Nguyen, K. D., Oliver, D. E., \& Priddy, L. E. (2009). Criteria for accreditation in Vietnam's higher education: Focus on input or outcome? Quality in Higher Education, 15(2), 123-134.

Nguyen, T. Q. T. (2015). Conducting semi-structured interviews with the Vietnamese. Qualitative Research Journal, 15(1), 35-46.

O’Neill, J. (2008). Putting teacher learning in context. In R. Bourke, A. Lawrence, A. McGee, J. O’Neill \& J. Curzon (Eds.), Talk about learning: Working alongside teachers (pp. 27-38). North Shore: Pearson Education New Zealand. 
O’Brien, J., \& Jones, J. (2014). Professional learning or professional development? Or continuing professional learning and development? Changing terminology, policy and practice. Professional Development in Education, 40(5), 683-687.

Opfer, V. D., \& Pedder, D. (2011). Conceptualizing teacher professional learning. Review of Educational Research, 81(3), 37-407.

Parks, E. (2011). Vietnam demands English language teaching 'miracle', The Guardian Weekly. Retrieved from http://www.guardian.co.uk/education/2011/nov/08/vietnamunrealistic-english-teaching-goals

Pattie, L. Y. Y. (2009). Teachers' stress and teachers' development course in Hong Kong: Turning 'deficits' into 'opportunities'. Professional Development in Education, 35(4), 613-634.

Patton, M. Q. (2002). Qualitative research and evaluation methods (3rd ed.). California: Sage.

Pedder, D., Opfer, V. D., McCormick, R., \& Storey, A. (2010). 'Schools and continuing professional development in England - State of the Nation' research study: Policy context, aims and design. The Curriculum Journal, 21(4), 365-394.

Pham, H. H. (2006). Researching the research culture in English language education in Vietnam. TESL-EJ, 10(2), 1-19.

Pham, T. H. (2014). Quality Culture in Vietnamese Universities: A multiple case study of quality assurance and quality culture of Business English undergraduate programmes at three universities in Vietnam (Unpublished doctoral thesis). Victoria University of Wellington, New Zealand.

Pham, T. H. T. (2011). An investigation of perceptions of Vietnamese teachers and students toward Cooperative Learning (CL). International Education Studies, 4(1), 3-12.

Pham, T. N. (2014). Foreign language policy. In L. Tran, S. Marginson, H. Do, Q. Do, T. Le, N. Nguyen, T. Vu, T. Pham, \& H. Nguyen (Eds.), Higher Education in Vietnam (pp. 169-183). 
Phan, L. H., \& Phan, V. Q. (2006). Vietnamese educational morality and the discursive construction of English language teacher identity. Journal of Multicultural Discourses, 1(2), 136-151.

Richer, D., Kunter, M., Klusmann, U., Ludtke, O., \& Baumert, J. (2011). Professional development across the teaching career: Teachers' uptake of formal and informal learning opportunities. Teaching and Teacher Education, 27(1), 116-126.

Robinson, M., \& McMillan, W. (2006). Who teaches the teachers? Identity, discourse and policy in teacher education. Teaching and Teacher Education, 22(3), 327-336.

Rogoff, B. (1995). Observing sociocultural activity on the three planes: Participatory appropriation, guided participation, and apprenticeship. In J. V. Wertsch, P. D. Rio \& A. Alvarez (Eds.), Sociocultural studies of mind (pp. 139-164). New York: Cambridge University Press.

Rogoff, B. (2003). The cultural nature of human development. New York: Oxford University Press.

Roth, M. W., \& Lee, Y. J. (2007). "Vygotsky neglected legacy": Cultural historical activity theory. Review of Educational research, 77(2), 186-232.

Sales, A., Traver, J. A., \& Garcia, R. (2011). Action research as a school-based strategy in intercultural professional development for teachers. Teaching and Teacher Education, 27(5), 911-919.

Schneider, E. W. (2014). New reflections on the evolutionary dynamics of world Englishes. World Englishes, 33(1), 9-32.

Sharp, J. L., Mobley, C., Hammond, C., Withington, C., Drew, S., Stringfield, S., \& Stipanovic, N. (2012). A mixed methods sampling methodology for a multisite case study. Journal of Mixed Methods Research, 6(1), 34-54.

Shawer, S. (2010). Classroom-level teacher professional development and satisfaction: Teachers learn in the context of classroom-level curriculum development. Professional Development in Education, 36(4), 597-620. 
Shumack, K. A., \& Forde, C. M. (2011). Business educators' perceptions of the impact of their professional development on classroom instruction. The Delta Pi Epsilon Journal, 3(1), 1-13.

Silverman, D. (2011). Interpreting qualitative data: A guide to the principles of qualitative research (4th ed.). Los Angeles: Sage.

Smith, K. (2003). So, What about the professional development of teacher educators? European Journal of Teacher Education, 26(2), 201-215.

Stake, R. E. (1995). The art of case study research. Thousand Oaks, California: Sage.

Stake, R. E. (2008). Qualitative case study. In N. K. Denzin \& Y. S. Lincoln (Eds.), Strategies of qualitative inquiry (3rd ed., pp. 119-150). California: Sage.

Starkey, L., Yates, A., Meyer, L. H., Hall, C., Taylor, M., Stevens, S., \& Toia, R. (2009). Professional development design: Embedding educational reform in New Zealand. Teaching and Teacher Education, 25(1), 181-189.

Steyn, G. M. (2010). Educators' perceptions of continuing professional development for teachers in South Africa: A qualitative study. Africa Education Review, 7(1), 165179.

Stroupe, R. (2012). Culture and context: Challenges to the implementation of English language curricula in Asia. Language Education in Asia, 3(2), 126-131.

Swennen, A., \& Bates, T. (2010). The professional development of teacher educators. Professional Development in Education, 36(1-2), 1-7.

Tallerico, M. (2005). Supporting and sustaining teachers' professional development: $A$ principal's guide. Thousand Oaks, California: Corwin Press.

Teddlie, C., \& Tashakkori, A. (2009). Foundations of mixed methods research: Integrating quantitative and qualitative approaches in the social and behavioural sciences. Los Angeles: Sage.

Teräs, H. (2014). Collaborative online professional development for teachers in higher education. Professional Development in Education, Advance online publication. doi: $10.1080 / 19415257.2014 .961094$ 
Thanh Binh. (2010, August 11). Cần đổi mới cách tập huấn, bồi dưỡng giáo viên [Necessity of reforming teacher professional development], Dân Trí. Retrieved from http://dantri.com.vn/ban-doc/can-doi-moi-cach-tap-huan-boi-duong-giao-vien1281767801.htm

Thomas, D. R. (2006). A general inductive approach for analysing qualitative evaluation data. American Journal of Evaluation, 27(2), 237-246.

Tran, T. B. T. (2015). The role of leadership in promoting and supporting the basic English curriculum design and delivery at two Vietnamese universities (Unpublished doctoral thesis). Victoria University of Wellington, New Zealand.

Truong, D. T. (2013). Confucian values and school leadership in Vietnam (Unpublished doctoral thesis). Victoria University of Wellington, New Zealand.

Vietnamese Assembly. (2005). Luật Giáo dục (Education Law). (38/2005/QH11). Hanoi: Vietnam. Retrieved from http://www.moet.gov.vn/?page=6.3\&type=documents\&view=2741.

Vietnamese Assembly. (2012). Luật Giáo dục Đại học (Tertiary Education Law). (08/2012/QH13). Hanoi: Vietnam.

Vietnamese government. (2005). Nghị quyết về đổi mới co bản và toàn diện giáo dục đại học Việt Nam giai đoạn 2006-2010 (Resolution of a basic and comprehensive reform in HE in Vietnam 2006-2020, HERA). (14/2005/NQ-CP). Hanoi: Vietnam.

Vietnamese Prime Minister. (2010). Quyết định ban hành Điều lệ trương Đại học (Decision on issuing the University Charter). (58/2010/QĐ-TTg). Hanoi: Vietnam.

Vietnamese Prime Minister. (2012). Chiến lược phát triển giáo dục 2011-2020 (Strategic plan for educational development 2011-2020). (711/QĐ-TTg). Hanoi: Vietnam.

Vietnamese Prime Minister. (2008). Quyết định Phê duyệt Đề án "Dạy và học ngoại ngũu trong hệ thống giáo dục quốc dân giai đoạn 2008 - 2020” (Decision on "The project of teaching and learning foreign languages in the national educational system 2008-2020”). (1400/QĐ-TTg). Hanoi: Vietnam. 
VietNamNet Bridge. (2011, January 1). A call to improve education in Mekong Delta, VietNamNet Bridge. Retrieved from

http://english.vietnamnet.vn/en/print/education/4461/a-call-to-improve-educationin-mekong-delta.html.

VietNamNet Bridge (2012, October 1). Local teachers of English not up to standard, VietNamNet Bridge. Retrieved from http://english.vietnamnet.vn/en/education/17546/local-teachers-of-english-not-upto-standard.html.

Villegas-Reimers, E. (2003). Teacher professional development: An international review of the literature. Paris: UNESCO: International institute of educational planning.

Vo, L. T., \& Nguyen, H. T. M. (2010). Critical friends group for EFL teacher professional development. ELT Journal, 64(2), 205-213.

Vu, N. T. T., \& Burns, A. (2014). English as a medium of instruction: Challenges for Vietnamese tertiary lecturers. The Journal of Asia TEFL, 11(3), 1-31.

Vu, T. P. A. (2010). University graduates' failure to communicate after ten years of learning English: Causes and solutions. Paper presented at the Conference on EFL Teaching in Higher Education, HCM National University.

Vygotsky, L. S. (1978). Mind in society. Cambridge, MA: Harvard University Press.

Walker, W. (2007). Ethical considerations in phenomenological research. Nurse Researcher, 14(3), 36-45.

Watty, K. (2003). When will academics learn about quality. Quality in Higher Education, 9(3), 213-221.

Webster-Wright, A. (2009). Reframing professional development through understanding authentic professional learning. Review of Educational Research, 79(2), 702-739.

Wenger, E. (2009). A social theory of learning. In K. Illeris (Ed.), Contemporary theories of learning: Learning theorists...in their own words (pp. 209-218). New York: Routledge. 
Wichadee, S. (2012). Factors related to professional development of English language university teachers in Thailand. Journal of Education for Teaching, 38(5), 615-627.

Widiati, U., \& Hayati, N. (2015). Teacher professional education in Indonesia and ASEAN 2015: Lesson learned from English language teacher educational programs. In R. Stroupe \& K. Kimura (Eds.), ASEAN integration and the role of English language teaching (pp. 149-168). Phnom Penh: Language Education in Asia.

Wiles, R. (2013). What are qualitative research ethics? London; New York: Bloomsbury Academic.

Wilson, H. W. (1998). Examining the fabric of academic life: An analysis of three decades of research on the perception of Australian academics about their roles. Higher Education, 36(4), 421-435.

Yamagata-Lynch, L. C. (2003). How a technology professional development program fits into teachers' work life. Teaching and Teacher Education, 19(6), 591-607.

Yamagata-Lynch, L. C. (2010). Activity systems analysis methods: Understanding complex learning environments. New York: Springer Science+Business Media.

Yamagata-Lynch, L. C., \& Smaldino, S. (2007). Using activity theory to evaluate and improve K-12 school and university partnerships. Evaluation and Program Planning, 30(4), 364-380.

Yin, R. K. (1994). Case study research (2nd ed.). Thousand Oaks, California: Sage.

Yin, R. K. (2003). Applications of case study research. Thousands Oaks, California: Sage.

Yin, R. K. (2009). Case study research: Design and methods. California: Sage.

Yin, R. K. (2014). Case study research: design and methods (5th ed.). Los Angeles: Sage.

Yoon, K. S., Duncan, T., Lee, S. W. Y., Scarloss, B., \& Shapley, K. L. (2007). Reviewing the evidence on how teacher professional development affects student achievement. Issues \& Answers. REL 2007-No.033. Regional Assistance, Regional Educational Laboratory Southwest (NJ1). 
Youngs, P., \& King, M. B. (2002). Principal leadership for professional development to build school capacity. Educational Administration Quarterly, 38(5), 643-670.

Yuwono, G. I., \& Harbon, L. (2010). English teacher professionalism and professional development: Some common issues in Indonesia. Asian EFL Journal, 12(3), 145163.

Zhu, H. (2010). Curriculum reform and professional development: A case study on Chinese teacher educators. Professional Development in Education, 36(1-2), 373-391. 


\section{APPENDICES}

\section{Appendix A. QUESTIONNAIRE FOR EFL LECTURERS}

This questionnaire is for a $\mathrm{PhD}$ thesis entitled "Professional learning and development for EFL teacher educators in the context of educational reforms in Vietnam", conducted by Tran Thi Thanh Hue, a lecturer at Angiang University and a $\mathrm{PhD}$ student at Victoria University of Wellington, New Zealand. The questionnaire aims to investigate Vietnamese EFL lecturers' engagement in professional learning and development (PLD) and factors that affect their PLD in the context of educational reforms.

Please allow about 25 minutes to complete the questionnaire. By completing this questionnaire, you indicate your consent to participate in the research. Your responses will be confidential. No institutions or individual participants will be identified in any reports or publications arising from this thesis.

Thank you for contributing your time and thoughtful responses to this questionnaire. Your participation in this research helps to acknowledge lecturers' views on PLD. I also hope that reflecting on your PLD experiences through this questionnaire may support your own professional learning.

\section{Section A: Demographics}

Could you please provide some information about your background by ticking the relevant box or writing the answers on the blanks?

- Gender: $\square$ Female $\square$ Male

- Please indicate your age group
20-30
$31-40$
$41-50$
$>50$

- How long have you been teaching in tertiary education? years

- What are your formal qualifications?
Bachelor
Master
$\mathrm{PhD}$
Other:

- Besides teaching, what is your other post of responsibility, if any?

- What English programmes have you been teaching over the past two years?
General English
English for Specific Purposes (ESP)
English teacher education
Others: 


\section{Section B: Your perceptions and experiences of PLD}

1. Please tick one box only for each statement below.

\begin{tabular}{|c|c|c|c|c|}
\hline $\begin{array}{l}\text { How important are the following roles and } \\
\text { functions of PLD in your learning and } \\
\text { teaching? }\end{array}$ & $\begin{array}{c}\text { Not } \\
\text { important } \\
1\end{array}$ & $\begin{array}{l}\text { Of little } \\
\text { importance } \\
2\end{array}$ & $\begin{array}{c}\text { Important } \\
3\end{array}$ & $\begin{array}{l}\text { Very } \\
\text { important } \\
4\end{array}$ \\
\hline $\begin{array}{l}\text { 1) Update my content knowledge and } \\
\text { teaching skills }\end{array}$ & $\square$ & $\square$ & $\square$ & $\square$ \\
\hline $\begin{array}{l}\text { 2) Change my beliefs and attitudes of } \\
\text { teaching and learning }\end{array}$ & $\square$ & $\square$ & $\square$ & $\square$ \\
\hline 3) Improve my teaching effectiveness & $\square$ & $\square$ & $\square$ & $\square$ \\
\hline 4) Improve my student learning outcomes & $\square$ & $\square$ & $\square$ & $\square$ \\
\hline 5) Enhance my leadership & $\square$ & $\square$ & $\square$ & $\square$ \\
\hline 6) Support my professional needs and goals & $\square$ & $\square$ & $\square$ & $\square$ \\
\hline $\begin{array}{l}\text { 7) Improve my teaching motivation and } \\
\text { confidence }\end{array}$ & $\square$ & $\square$ & $\square$ & $\square$ \\
\hline 8) Improve my research ability & $\square$ & $\square$ & $\square$ & $\square$ \\
\hline $\begin{array}{l}\text { 9) Enhance collaboration and collegial } \\
\text { support }\end{array}$ & $\square$ & $\square$ & $\square$ & $\square$ \\
\hline 10) Address institutional needs and goals & $\square$ & $\square$ & $\square$ & $\square$ \\
\hline $\begin{array}{l}\text { 11) Build a learning community in my } \\
\text { institution }\end{array}$ & $\square$ & $\square$ & $\square$ & $\square$ \\
\hline 12) Address national educational reforms & $\square$ & $\square$ & $\square$ & $\square$ \\
\hline $\begin{array}{l}\text { 13) Improve my ability to facilitate EFL } \\
\text { school teachers' teaching and learning }\end{array}$ & $\square$ & $\square$ & $\square$ & $\square$ \\
\hline $\begin{array}{l}\text { 14) Meet professional standards stated by the } \\
\text { institution and MOET }\end{array}$ & $\square$ & $\square$ & $\square$ & $\square$ \\
\hline
\end{tabular}

Others: 


\section{There are two response columns for each statement in this question. Column $A$ is}

\section{about your view on PLD activities. Column B is about your PLD practices over the}

past two years. Please tick one box only in each column for each statement.

\begin{tabular}{|c|c|c|c|c|c|c|c|c|c|}
\hline \multicolumn{4}{|c|}{$\begin{array}{c}\text { A. } \\
\text { How important are the following } \\
\text { PLD activities for your learning } \\
\text { and teaching? }\end{array}$} & \multirow{3}{*}{\multicolumn{2}{|c|}{ PLD activities }} & \multicolumn{4}{|c|}{$\begin{array}{c}\text { B. } \\
\text { How often have you } \\
\text { participated in these activities } \\
\text { in the past two years? }\end{array}$} \\
\hline $\begin{array}{l}\text { Not } \\
\text { im- } \\
\text { portant }\end{array}$ & $\begin{array}{l}\text { Somewhat } \\
\text { im- } \\
\text { portant }\end{array}$ & $\begin{array}{l}\text { Im- } \\
\text { portant }\end{array}$ & $\begin{array}{l}\text { Very } \\
\text { im- } \\
\text { ortant }\end{array}$ & & & \multicolumn{4}{|c|}{ Never Sometimes Often Always } \\
\hline 1 & 2 & 3 & 4 & & & 1 & 2 & 3 & 4 \\
\hline$\square$ & $\square$ & $\square$ & $\square$ & & $\begin{array}{l}\text { Workshops, seminars, } \\
\text { conferences within your } \\
\text { institution }\end{array}$ & $\square$ & $\square$ & $\square$ & $\square$ \\
\hline$\square$ & $\square$ & $\square$ & $\square$ & & $\begin{array}{l}\text { Workshops, seminars, } \\
\text { conferences outside your } \\
\text { institution }\end{array}$ & $\square$ & $\square$ & $\square$ & $\square$ \\
\hline$\square$ & $\square$ & $\square$ & $\square$ & & $\begin{array}{l}\text { Short training courses within or } \\
\text { outside your institution }\end{array}$ & $\square$ & $\square$ & $\square$ & $\square$ \\
\hline$\square$ & $\square$ & $\square$ & $\square$ & & $\begin{array}{l}\text { Participating in a teaching club } \\
\text { or a lecturers' association }\end{array}$ & $\square$ & $\square$ & $\square$ & $\square$ \\
\hline$\square$ & $\square$ & $\square$ & $\square$ & & $\begin{array}{l}\text { Mentoring or coaching other } \\
\text { lecturers in your institution }\end{array}$ & $\square$ & $\square$ & $\square$ & $\square$ \\
\hline$\square$ & $\square$ & $\square$ & $\square$ & & $\begin{array}{l}\text { Observing other lecturers' } \\
\text { classroom practice in your } \\
\text { institution }\end{array}$ & $\square$ & $\square$ & $\square$ & $\square$ \\
\hline$\square$ & $\square$ & $\square$ & $\square$ & & $\begin{array}{l}\text { Co-working with other lecturers } \\
\text { in doing research }\end{array}$ & $\square$ & $\square$ & $\square$ & $\square$ \\
\hline$\square$ & $\square$ & $\square$ & $\square$ & & $\begin{array}{l}\text { Organising PLD programmes } \\
\text { for EFL school teachers }\end{array}$ & $\square$ & $\square$ & $\square$ & $\square$ \\
\hline$\square$ & $\square$ & $\square$ & $\square$ & & $\begin{array}{l}\text { Observing lessons by EFL } \\
\text { school teachers }\end{array}$ & $\square$ & $\square$ & $\square$ & $\square$ \\
\hline$\square$ & $\square$ & $\square$ & $\square$ & 10) & $\begin{array}{l}\text { Supervising EFL teacher } \\
\text { trainees' research or teaching } \\
\text { practicum }\end{array}$ & $\square$ & $\square$ & $\square$ & $\square$ \\
\hline$\square$ & $\square$ & $\square$ & $\square$ & 11) & $\begin{array}{l}\text { Formal postgraduate courses } \\
\text { leading to a degree or diploma }\end{array}$ & $\square$ & $\square$ & $\square$ & $\square$ \\
\hline$\square$ & $\square$ & $\square$ & $\square$ & & $\begin{array}{l}\text { Independent study by reading } \\
\text { books, research reports, and } \\
\text { journals }\end{array}$ & $\square$ & $\square$ & $\square$ & $\square$ \\
\hline$\square$ & $\square$ & $\square$ & $\square$ & 13) & Conducting research by yourself & $\square$ & $\square$ & $\square$ & $\square$ \\
\hline$\square$ & $\square$ & $\square$ & $\square$ & & $\begin{array}{l}\text { Committee or task force (e.g., } \\
\text { programme design, curriculum } \\
\text { development, course-book } \\
\text { design, programme assessment) }\end{array}$ & $\square$ & $\square$ & $\square$ & $\square$ \\
\hline
\end{tabular}

Others: 
3. How important do the following reasons in YOUR decision to participate in the PLD activities in the last two years (2010-2012)? Please tick one box only for each reason.

\begin{tabular}{|c|c|c|c|c|}
\hline $\begin{array}{c}\text { I participated in PLD activities in order to / } \\
\text { because... }\end{array}$ & $\begin{array}{c}\text { Not } \\
\text { important } \\
1\end{array}$ & $\begin{array}{c}\text { Somewhat } \\
\text { important } \\
2\end{array}$ & $\begin{array}{c}\text { Important } \\
3\end{array}$ & $\begin{array}{c}\text { Very } \\
\text { important } \\
4\end{array}$ \\
\hline 1) Gain certificates and formal qualifications & $\square$ & $\square$ & $\square$ & $\square$ \\
\hline 2) Improve my teaching motivation & $\square$ & $\square$ & $\square$ & $\square$ \\
\hline $\begin{array}{l}\text { 3) Get new knowledge and skills related to } \\
\text { my major }\end{array}$ & $\square$ & $\square$ & $\square$ & $\square$ \\
\hline $\begin{array}{l}\text { 4) Find solutions to improve my teaching } \\
\text { effectiveness }\end{array}$ & $\square$ & $\square$ & $\square$ & $\square$ \\
\hline $\begin{array}{l}\text { 5) Have opportunities to meet other } \\
\text { colleagues }\end{array}$ & $\square$ & $\square$ & $\square$ & $\square$ \\
\hline $\begin{array}{l}\text { 6) Follow up previous professional learning } \\
\text { activities }\end{array}$ & $\square$ & $\square$ & $\square$ & $\square$ \\
\hline $\begin{array}{l}\text { 7) Improve my understanding of educational } \\
\text { reforms }\end{array}$ & $\square$ & $\square$ & $\square$ & $\square$ \\
\hline 8) Improve my students' learning outcomes & $\square$ & $\square$ & $\square$ & $\square$ \\
\hline $\begin{array}{l}\text { 9) These activities were relevant to my PLD } \\
\text { needs }\end{array}$ & $\square$ & $\square$ & $\square$ & $\square$ \\
\hline $\begin{array}{l}\text { 10) The institution/faculty/department required } \\
\text { me to participate. }\end{array}$ & $\square$ & $\square$ & $\square$ & $\square$ \\
\hline
\end{tabular}

Others: 
4. Please tick one box only for each statement below.

\begin{tabular}{|c|c|c|c|c|}
\hline $\begin{array}{l}\text { How often did these practices happen in your } \\
\text { informal PLD over the past two years? }\end{array}$ & $\begin{array}{c}\text { Never } \\
1\end{array}$ & $\begin{array}{c}\text { Sometimes } \\
2\end{array}$ & $\begin{array}{c}\text { Often } \\
3\end{array}$ & $\begin{array}{c}\text { Always } \\
4\end{array}$ \\
\hline $\begin{array}{l}\text { 1) I discussed teaching problems and share } \\
\text { teaching practices with my colleagues in } \\
\text { informal conversations. }\end{array}$ & $\square$ & $\square$ & $\square$ & $\square$ \\
\hline $\begin{array}{l}\text { 2) I read research reports as one source of useful } \\
\text { ideas for improving my practice. }\end{array}$ & $\square$ & $\square$ & $\square$ & $\square$ \\
\hline $\begin{array}{l}\text { 3) I planned PLD activities together with other } \\
\text { colleagues. }\end{array}$ & $\square$ & $\square$ & $\square$ & $\square$ \\
\hline $\begin{array}{l}\text { 4) I modified my teaching based on self- } \\
\text { evaluations of my classroom practice. }\end{array}$ & $\square$ & $\square$ & $\square$ & $\square$ \\
\hline $\begin{array}{l}\text { 5) I modified my practice based on feedback from } \\
\text { my academic leaders and other colleagues. }\end{array}$ & $\square$ & $\square$ & $\square$ & $\square$ \\
\hline $\begin{array}{l}\text { 6) I modified my teaching practice based on my } \\
\text { students' feedback. }\end{array}$ & $\square$ & $\square$ & $\square$ & $\square$ \\
\hline $\begin{array}{l}\text { 7) I engaged in collaborative learning (e.g., lesson } \\
\text { planning, material design, action research) with } \\
\text { other colleagues to improve my teaching and } \\
\text { learning. }\end{array}$ & $\square$ & $\square$ & $\square$ & $\square$ \\
\hline
\end{tabular}

Others:

Section C: Your perceptions of major education reforms in your institution

5. What major educational reforms in higher education have you been implementing over the past two years? Please list them here: 


\section{Please tick one box only for each statement below.}

\begin{tabular}{|c|c|c|}
\hline $\begin{array}{l}\text { From the list below, what barriers have you experienced when } \\
\text { implementing educational reforms in your institution over the past two } \\
\text { years? }\end{array}$ & Yes & No \\
\hline $\begin{array}{l}\text { 1) Limited understanding about the content and how to implement the } \\
\text { reforms }\end{array}$ & $\square$ & $\square$ \\
\hline 2) Lack of relevant knowledge and skills & $\square$ & $\square$ \\
\hline $\begin{array}{l}\text { 3) Lack of resources (materials and facilities) for your learning and } \\
\text { teaching }\end{array}$ & $\square$ & $\square$ \\
\hline 4) Lack of relevant PLD opportunities & $\square$ & $\square$ \\
\hline 5) Full workload & $\square$ & $\square$ \\
\hline 6) Tension from assessment of lecturers' work & $\square$ & $\square$ \\
\hline 7) Time limitation & $\square$ & $\square$ \\
\hline 8) Lack of support from leaders & $\square$ & $\square$ \\
\hline 9) Lack of support from colleagues & $\square$ & $\square$ \\
\hline 10) Lack of financial support & $\square$ & $\square$ \\
\hline
\end{tabular}

Others:

7. What kinds of PLD do you need or expect to participate in order to implement educational reforms better at your institution?

Comments: If you wish to add any further information about your experience of PLD, to clarify or expand your answers, or to provide other information useful to the study, please comment here: 
I would like to invite you to participate in a follow-up individual interview in the next stage of the study. If you are willing to do that, please leave your contact information on the blank below, and I will contact you later to provide further information about the interview.

Name:

Institution:

Email:

Contact number:

Thank you very much for your participation 


\section{Appendix B. INFORMATION SHEET FOR QUESTIONNAIRE PARTICIPANTS}

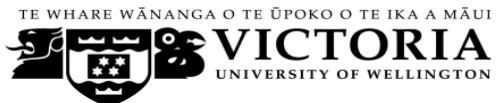

Faculty of Education

Date:

\section{INFORMATION SHEET}

(To EFL lecturers at the selected tertiary institutions)

\section{"Professional learning and development for EFL teacher educators in the context of educational reforms in Vietnam”}

I am Hue Tran, a PhD student in the School of Educational Psychology and Pedagogy, Faculty of Education, Victoria University of Wellington - New Zealand, and an EFL lecturer at Angiang University - Vietnam. As part of my doctoral study, I am conducting research to examine the practice of professional learning and development (PLD) for English lecturers in Vietnam. The purpose of the study is to obtain in-depth understanding of the practice of PLD for EFL teacher educators in order to gain insights into how to promote and support EFL teacher educators' PLD and capacity to implement educational reforms in Vietnamese tertiary context.

My study will be conducted in three public tertiary institutions. The research process will be undertaken in the following manner:

- Visiting the university: Initially, I will visit each university to have a meeting with the Rector and administrative staff to discuss the research and ask for their permission to conduct the research in the institution.

- Selecting participants: I will invite about 30-35 people from each university to participate in the research. My research will involve two groups of participants: one group of 30-35 lecturers of English (for the questionnaire and the individual interview) and one group of 2 administrators (for the individual interview) from each institution. Eligible participants are EFL lecturers who have at least two years of teaching experience in their current institutions, and have been involved in training school teachers of EFL and/or of other disciplines.

- Collecting data:

- Questionnaires: I would like to conduct a questionnaire involving about 30-35 lecturers of English from each university. The questionnaire will ask about the lecturers' perceptions and experiences of PLD and the implementation of educational reforms in higher education over the past two years.

- Interviews: I would like to conduct individual interviews with 6 EFL lecturers and 2 administrators at each university. The 6 EFL lecturers will be purposively selected to vary in gender, teaching 
experience, and academic roles. Each interview session will take up to one hour. The interviews will be semi-structured and audio-recorded for the purposes of maintaining an accurate record of the participants' responses.

- Observations: I will conduct 2-3 observations of PLD sessions (e.g., workshops, conferences) and informal PLD events (e.g., inquiry-based activities, mentoring) for EFL lecturers in the institutions to gather supplementary data for the research. I will take notes about the process and activities during these sessions, but not about individual participants. These observations will be done during my data collection from November 2012 to April 2013.

- Documents: I would like to examine documents relating to the university strategic plan, self-review report, EFL education programmes, decisions or any other items related to staff development and reform implementation and professional activities within EFL department at each university.

I am inviting you to participate in this study. If you volunteer to participate in the study, you will be asked to complete a questionnaire which may take up to 25 minutes of your time. At the end of the questionnaire, you will be invited to participate in one semi-structured individual interview at the later stage of the research, and to include your contact information if you are willing to take part in the interview.

The questionnaire is attached to this letter. If you are willing to take part in the study, please complete the questionnaire. You can put the completed questionnaire in the envelope provided (without any identifying details), and put the envelope in to my mail box in your staff-room. I will come and collect them one week later.

Among EFL lecturers who volunteer to be involved in the interview, I will purposively select 6 participants from each university to represent different genders, teaching experiences, academic roles and responsibilities for the interview. I will contact you via email or phone to confirm if you will be selected for the interview and provide you further information about it within two weeks of the questionnaire collection. The interview will be scheduled at the most convenient time for you.

Your participation is voluntary, and you will be free to withdraw at any time without any disadvantage and without having to explain why. Your responses will be translated into English for data discussion in the research report. Any responses that you give will be treated confidentially. Your identity will be protected through the use of a pseudonym and the removal of any identifying details. No information in the study will be discussed with anyone outside me, my supervisors and the participants. All research data will be securely stored in password protected files or/and in locked cupboards and will be destroyed using a pager shredder or/and electronically wiped within five years after the completion of the research.

When completed, the doctoral thesis will be submitted to the School of Educational Psychology and Pedagogy and deposited in the WJ Scott Library, and will be available online. The research data will also be used for conference papers and/or publications in scholarly journals. 
This research has been approved by the Victoria University Faculty of Education Ethics Committee, No. SEPP/2012/75 RM19494. If you have questions about the way the research is being conducted you may contact the Chair of the Victoria University of Wellington Human Ethics Committee, Dr. Allison Kirkman at Allison. kirkman@vuw.ac.nz.

If you have any questions or would like to receive further information about the project, please feel free to contact me at hue.tran@vuw.ac.nz. You can also contact my supervisors, Dr. Roseanna Bourke at Roseanna.bourke@ vuw.ac.nz, and/or Dr. Margaret Gleeson at Margaret.gleeson@ vuw.ac.nz.

Hue Tran

Signed: 


\title{
Appendix C. LETTER TO THE RECTORS OF SELECTED TERTIARY INSTITUTIONS
}

\author{
TE WHARE WÃNANGA O TE ÚPOKO O TE IKA AMĀUI \\ Faculty of Education
}

Date:

\section{Letter to the Rectors of selected tertiary institutions}

Subject: Asking for permission to conduct research

\section{"Professional learning and development for EFL teacher educators in the context of educational reforms in Vietnam"}

Dear .......,

I am a PhD student in School of Educational Psychology and Pedagogy, Faculty of Education, Victoria University of Wellington - New Zealand, and an EFL lecturer at Angiang University - Vietnam. As part of my doctoral study, I am conducting research to examine the practice of professional learning and development (PLD) for English lecturers at three tertiary institutions in Vietnam.

The purpose of the study is to obtain in-depth understanding of the practice of PLD for EFL teacher educators in order to gain insights into how to promote and support EFL teacher educators' PLD and capacity to implement educational reforms in Vietnamese tertiary context.

I am writing to request your permission to conduct research in your institution from 11/2012 to 04/2013.

The research process will be undertaken in the following manner:

- Visiting the university: Initially, I will visit your university to have a meeting with you and your administrative staff to discuss the research.

- Selecting participants: I will invite 30-35 people from the university to participate in the research. My research will involve two groups of participants: one group of 30-35 lecturers of English (for the questionnaire and the individual interview) and one group of 2 administrators (for the individual interview). Prior to selection, all potential participants will be provided with information about the research for their consideration. For the questionnaire, the participants will show their consent by completing the questionnaire. For the interviews, the participants will be required to sign a "Consent Form" to formalize their willingness to participate. Participation will be voluntary and each participant may withdraw from the research at any time before data analysis begins without any disadvantages.

- Collecting data:

- Questionnaires: I will conduct a questionnaire involving about 30-35 lecturers of English from your institutions. The questionnaire will ask about the lecturers' perceptions and experiences of PLD and the implementation of educational reforms in higher education over the past two years. 
- Interviews: I will conduct individual interviews with 6 EFL lecturers and 2 administrators in your institution. The 6 EFL lecturers will be purposively selected to vary in their age, gender, qualifications and academic roles. Each interview session will take up to one hour. The interviews will be audiorecorded for the purposes of maintaining an accurate record of the participants' responses.

○ Observations: I will conduct 2-3 observations of PLD sessions (e.g., workshops, conferences) and informal PLD events (e.g., inquiry-based activities, mentoring) for EFL lecturers in the institutions to gather supplementary data for the research. I will take notes about the process and activities during these sessions, but not about individual participants. These observations will be done during my data collection from November 2012 to April 2013.

○ Documents: I will review documents relating to the university strategic plan, institutional self-review report, EFL education programmes, decisions and any other items related to staff development, reform implementation and professional activities within EFL department at your university.

This research has been assessed and approved by the Victoria University Faculty of Education Ethics Committee, No. SEPP/2012/75 RM19494. I will make every effort to ensure that the participants' identities will remain confidential through the use of pseudonyms and the removal of any identifying details of the institutions and the participants. The audio recordings will be kept secure for a period of up to 5 years before being deleted. No information in the study will be discussed with anyone outside me, my supervisors and the participants. All research data would be securely stored in password protected files or/and in locked cupboards and will be destroyed using a pager shredder or/and electronically wiped within five years after the completion of the research. If you have questions about the way the research is being conducted you may contact the Chair of the Victoria University of Wellington Human Ethics Committee, Dr. Allison Kirkman at Allison. kirkman@vuw.ac.nz.

When completed, the doctoral thesis will be submitted to the School of Educational Psychology and Pedagogy, and deposited in the WJ Scott Library, and will be available online. The research data will also be used for conference papers and/or publications in scholarly journals.

If you have any questions or would like to receive further information about the project, please feel free to contact me at hue.tran@vuw.ac.nz. You can also contact my supervisors, Dr Roseanna Bourke, at Roseanna.bourke@vuw.ac.nz, and/or Dr. Margaret Gleeson, at Margaret.gleeson@vuw.ac.nz.

Your permission to conduct the research at your university is highly appreciated. I will call you next week to organise a time to meet to discuss the research and consent form which is attached to this letter.

Thank you very much for your support.

Yours sincerely, Hue Tran 


\section{Appendix D. CONSENT FORM FOR RECTORS}

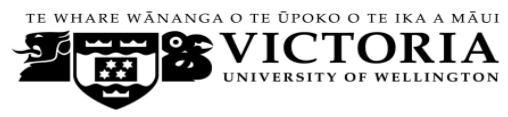

\section{Faculty of Education}

\section{CONSENT FORM FOR RECTORS}

\section{"Professional learning and development for EFL teacher educators in the context of educational reforms in Vietnam”}

Please tick each box to indicate that you understand each point and you are willing to allow Hue Tran to conduct her doctoral research at your university.

I have been given information about this project and discussed the research project with Hue Tran. I have had an opportunity to ask questions and have them answered to my satisfaction.

$\square \quad$ I understand what is required of the participants from this university who take part in the research.

$\square \quad$ I understand that participation in the research is voluntary and the participants may withdraw from it during the data gathering (before data analysis begins) without having to give reasons and without penalty.

$\square \quad$ I understand that the researcher will give my institution a pseudonym.

I understand that the participants' identities will be kept confidential.

I understand that all research data will be stored in password protected files and will be destroyed within five years after the completion of the research.

I consent to the researcher conducting her project in this university.

I understand that the data collected from my university will be used for a doctoral thesis, for conference papers and/or publications in scholarly journals, and I consent for it to be used in that manner.

$\square$ I consent to the researcher having access to relevant documents including the university strategic plan, self-review report, EFL education programmes, decisions and any other items related to staff development, reform implementation and professional activities within EFL department at my university. The researcher may translate these documents into English for data analysis and discussion in her thesis, and I consent for this.

I consent to the researcher observing any workshops, conferences and other events related to EFL lecturers' professional learning and development in this university provided that the researcher withdraws from any event if requested by the chair.

Would like a copy of the summary of findings of this research in English forwarded to you at the conclusion of the research?

Yes No $\square$

Signed:

Date: (The Rector will be given a copy of this after signing) 


\section{Appendix E. INTERVIEW PROTOCOL FOR EFL LECTURERS}

\section{Background information}

Could you provide an overview of your teaching career in terms of teaching experiences, qualifications, and academic roles?

\section{Research issues}

Part 1: Models of professional learning and development (PLD) EFL lecturers accessed and their motives

1. How do you define professional learning and development?

2. What forms of PLD have you engaged in in the past two years?

What was the most frequent form? Why did you participate in these activities?

3. What process is used to plan PLD activities for EFL lecturers?

Who is responsible for this? To what extent are you involved in planning PLD activities? Are your needs considered? Do the university and the department have a strategic PLD plan for educators?

4. How has PLD for EFL lecturers been implemented in your department?

Please describe the location, the length, facilitators, participants' engagement, follow-up activities, PLD evaluations

5. To what extent have you engaged in collaborative learning with other lecturers? How has this been done? What forms of informal PLD have been practiced?

\section{Part 2: Role and function of PLD in EFL lecturers' personal and professional growth}

1. What is the value of PLD in your work? What motivates you to engage in PLD?

2. In what ways (if any) has PLD influenced your personal growth (e.g., motivation, beliefs, self-regulation, well-being)? How might PLD address these issues?

3. In what ways (if any) has PLD influenced your professional growth (e.g., knowledge, teaching skills, research capacity, leadership)? How might PLD address these issues?

4. How would you define effective PLD? Could you describe a particular PLD experience which was effective for and meaningful to you? 
Part 3: Influence of educational reforms in Vietnamese tertiary sector on the forms of PLD promoted and practised by EFL lecturers

1. What major reforms in higher education have you been implementing? How have you learned about these reforms?

2. How have these reforms affected your working and learning? Have they changed the way you think about your role as a teacher educator?

3. In what ways (if any) have PLD practices in your department changed to address the reform requirements? What have you and other colleagues done to implement these reforms?

4. To what extent have PLD opportunities enabled you to implement national and institutional initiatives? How have the PLD activities changed your understandings, perceptions, and ability to implement education reforms? Please give an example of an effective PLD activity that supported you to implement a reform?

5. What personal and contextual factors might support and/or hinder your PLD and your ability to implement reforms?

\section{Part 4: EFL lecturers PLD needs and expectations}

1. How do you identify your PLD needs? Who/ What influences your PLD needs? How does the provision of PLD meet your needs? How are your PLD needs and the institutional needs aligned?

2. What has been the focus of your learning currently? What are your plans for PLD?

3. What might the institution and the department do to better support your PLD in the future?

\section{Ending questions:}

1. What do you think about yourself and/or your work as an EFL teacher educator?

2. Is there anything else you think I should know to understand your PLD better? 


\section{Appendix F. INTERVIEW PROTOCOL FOR ACADEMIC LEADERS}

(Heads of Education Faculty and Heads/ Deputy-heads of EFL Department)

\section{Background information}

Could you provide an overview of your working experiences, qualifications, positions and responsibilities?

\section{Research issues}

Part 1: Models of professional learning and development (PLD) EFL lecturers accessed and their motives

1. How do you define professional learning and development?

2. Tell me about a typical range of PLD activities for EFL lecturers in your institution in the last two years? What were the purposes for these activities?

3. What is your role in providing and supporting PLD activities for EFL lecturers?

4. How have PLD activities usually been planned and implemented? (How are decisions made concerning the content and organisation of PLD activities? Please describe location, length, facilitators, content, follow-up activities, PLD evaluations)

5. To what extent have EFL lecturers engaged in collaborative learning? (How has this been done? Why has this been practiced? What forms of informal PLD have been practised? How do you evaluate the impacts of these activities?)

Part 2: Role and function of PLD in EFL lecturers' personal and professional growth

1. Tell me what value PLD has in EFL lecturers' work? What motivates EFL lecturers to engage in PLD?

2. In what ways (if any) do you think PLD has influenced EFL lecturers' personal growth (e.g., motivation, beliefs, self-regulation, well-being)?

3. In what ways (if any) do you think PLD has influenced EFL lecturers' professional growth (e.g., knowledge, teaching skills, research capacity, leadership)? How might PLD address these issues?

4. How do you define effective PLD? Could you describe a particular PLD experience which you think was effective and meaningful to EFL lecturers in your institution? 
Part 3: Influence of educational reforms in Vietnamese tertiary sector on the forms of PLD promoted and practised by EFL lecturers

1. What major reforms have EFL lecturers been implementing in your university? Do you think that EFL lecturers have sufficient understanding of the reforms and of their responsibilities to implement the reforms? What makes you believe so?

2. How have these reforms affected EFL lecturers' working and learning? In what ways have PLD practices in your department changed to address the reforms? What have you done to support EFL educators to enact these reforms?

3. To what extent have PLD opportunities enabled EFL lecturers to implement national and institutional initiatives? (Have you provided any PLD related to these reforms? How have the PLD activities changed educators' understandings, perceptions, and ability to implement education reforms? Can you give an example of an effective PLD activity that addressed a reform?)

4. What personal and contextual factors might support or hinder PLD for EFL lecturers? How might these affect their ability to implement reforms?

5. As an administrator, how have these reforms affected your own work and PLD? Can you describe your PLD? Do you receive any support for your own PLD?

\section{Part 4: EFL lecturers' PLD needs and expectations}

1. How do you identify EFL lecturers' needs in your department? How does PLD meet lecturers' needs? How are the lecturers' needs and the institutional needs aligned?

2. What has been the focus of EFL lecturers' learning in your department recently?

3. In your opinion, what might the institution and the department do to better support yours and other educators' PLD in the future? Do you have any plans for EFL lecturers' PLD in your department?

\section{Ending questions:}

1. What do you think about your role in providing and supporting PLD for EFL teacher educators in your institution?

2. Is there anything else you think I should know to better understand PLD for EFL teacher educators in your institution? 


\title{
Appendix G. INFORMATION SHEET FOR INTERVIEWED LECTURERS
}

\author{
TE WHARE WĀNANGa O TE ŨPOKO O TE IKA A MĀU

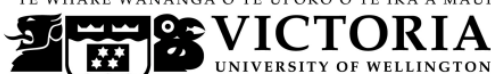 \\ Faculty of Education
}

Date:

\section{INFORMATION SHEET}

(To EFL lecturers at the selected tertiary institutions)

\section{"Professional learning and development for EFL teacher educators in the context of educational reforms in Vietnam”}

I am Hue Tran, a PhD student in the School of Educational Psychology and Pedagogy, Faculty of Education, Victoria University of Wellington - New Zealand, and an EFL lecturer at Angiang University - Vietnam. As part of my doctoral study, I am conducting research to examine the practice of professional learning and development (PLD) for English lecturers in Vietnam. The purpose of the study is to obtain in-depth understanding of the practice of PLD for EFL teacher educators in order to gain insights into how to promote and support EFL teacher educators' PLD and capacity to implement educational reforms in Vietnamese tertiary context.

My study will be conducted in three public tertiary institutions. The research process will be undertaken in the following manner:

- Visiting the university: Initially, I will visit each university to have a meeting with the Rector and administrative staff to discuss the research and ask for their permission to conduct the research in the institution.

- Selecting participants: I will invite about 30-35 people from each university to participate in the research. My research will involve two groups of participants: one group of 30-35 lecturers of English (for the questionnaire and the individual interview) and one group of 2 administrators (for the individual interview) from each institution. Eligible participants are EFL lecturers who have at least two years of teaching experience in their current institutions, and have been involved in training school teachers of EFL and/or of other disciplines.

- Collecting data:

○ Questionnaires: I will conduct a questionnaire involving about 30-35 lecturers of English from each university. The questionnaire will ask about the lecturers' perceptions and experiences of PLD and the implementation of educational reforms in higher education over the past two years. 
- Interviews: I will conduct individual interviews with 6 EFL lecturers and 2 administrators at each university. The $6 \mathrm{EFL}$ lecturers will be purposively selected to vary in gender, teaching experience, and academic roles. Each interview session will take up to one hour. The interviews will be semistructured and audio-recorded for the purposes of maintaining an accurate record of the participants' responses.

○ Observations: I will conduct 2-3 observations of PLD sessions (e.g., workshops, conferences) and informal PLD events (e.g., inquiry-based activities, mentoring) for EFL lecturers in the institutions to gather supplementary data for the research. I will take notes about the process and activities during these sessions, but not about individual participants. These observations will be done during my data collection from November 2012 to April 2013.

○ Documents: I will examine documents relating to the university strategic plan, self-review report, EFL education programmes, decisions or any other items related to staff development and reform implementation and professional activities within EFL department at each university.

I am inviting you to participate in this study. If you volunteer to participate in the study, you will be asked to complete a questionnaire which may take up to 25 minutes of your time. At the end of the questionnaire, you will be invited to participate in one semi-structured individual interview at the later stage of the research, and to include your contact information if you are willing to take part in the interview.

The questionnaire is attached to this letter. If you are willing to take part in the study, please complete the questionnaire. You can put the completed questionnaire in the envelope provided (without any identifying details), and put the envelope in to my mail box in your staff-room. I will come and collect them one week later.

Among EFL lecturers who volunteer to be involved in the interview, I will purposively select 6 participants from each university to represent different genders, teaching experiences, academic roles and responsibilities for the interview. I will contact you via email or phone to confirm if you will be selected for the interview and provide you further information about it within two weeks of the questionnaire collection. The interview will be scheduled at the most convenient time for you.

Your participation is voluntary, and you will be free to withdraw at any time without any disadvantage and without having to explain why. Your responses will be translated into English for data discussion in the research report. Any responses that you give will be treated confidentially. Your identity will be protected through the use of a pseudonym and the removal of any identifying details. No information in the study will be discussed with anyone outside me, my supervisors and the participants. All research data will be securely stored in password protected files or/and in locked cupboards and will be destroyed using a pager shredder or/and electronically wiped within five years after the completion of the research.

When completed, the doctoral thesis will be submitted to the School of Educational Psychology and Pedagogy and deposited in the WJ Scott Library, and will be available online. The research data will also be used for conference papers and/or publications in scholarly journals. 
This research has been assessed and approved by the Victoria University Faculty of Education Ethics Committee, No SEPP/2012/75 RM19494. If you have questions about the way the research is being conducted you may contact the Chair of the Victoria University of Wellington Human Ethics Committee, Dr. Allison Kirkman at Allison. kirkman@vuw.ac.nz.

If you have any questions or would like to receive further information about the project, please feel free to contact me at hue.tran@vuw.ac.nz. You can also contact my supervisors, Dr. Roseanna Bourke at Roseanna.bourke@ vuw.ac.nz, and/or Dr. Margaret Gleeson at Margaret.gleeson@ vuw.ac.nz.

Hue Tran

Signed: 


\section{Appendix H. INFORMATION SHEET FOR INTERVIEWED LEADERS}

\section{势 \\ Faculty of Education}

Date:

\section{INFORMATION SHEET}

(For administrators in the HEIs)

\section{"Professional learning and development for EFL teacher educators in the context of educational reforms in Vietnam"}

I am Hue Tran, a PhD student in the School of Educational Psychology and Pedagogy, Faculty of Education, Victoria University of Wellington - New Zealand, and an EFL lecturer at Angiang University - Vietnam. As part of my doctoral study, I am conducting research to examine the practice of professional learning and development (PLD) for English lecturers in Vietnam. The purpose of the study is to obtain in-depth understanding of the practice of PLD for EFL teacher educators in order to have insights into how to promote and support EFL teacher educators' PLD and capacity to implement reforms in Vietnamese tertiary context.

My study will be conducted in three public tertiary institutions. The research process will be undertaken in the following manner:

- Visiting the university: Initially, I will visit each university to have a meeting with the Rector and administrative staff to discuss the research and ask for their permission to conduct the research in the institution.

- Selecting participants: I will invite about 30-35 people from each university to participate in the research. My research will involve two groups of participants: one group of 30-35 lecturers of English (for the questionnaire and the individual interview) and one group of 2 administrators (for the individual interview) from each institution. Eligible participants are EFL lecturers who have at least two years of teaching experience in their current institutions, and have been involved in training school teachers of EFL and/or of other disciplines.

- Collecting data:

- Questionnaires: I will conduct a questionnaire involving about 30-35 lecturers of English from each university. The questionnaire will ask about the lecturers' perceptions and experiences of PLD and the implementation of educational reforms in higher education over the past two years.

- Interviews: I will conduct individual interviews with 6 EFL lecturers and 2 administrators at each university. The 6 EFL lecturers will be purposively selected to vary in gender, teaching experience, 
and academic roles. Each interview session will take up to one hour. The interviews will be semistructured and audio-recorded for the purposes of maintaining an accurate record of the participants' responses.

- Observations: I will conduct 2-3 observations of PLD sessions (e.g., workshops, conferences) and informal PLD events (e.g., inquiry-based activities, mentoring) for EFL lecturers in the institutions to gather supplementary data for the research. I will take notes about the process and activities during these sessions, but not about individual participants. These observations will be done during my data collection from November 2012 to April 2013.

- Documents: I will examine documents relating to the university strategic plan, self-review report, EFL education programmes, decisions or any other items related to staff development and reform implementation and professional activities within EFL department at each university.

I am inviting you to participate in this study. As a participant, you will take part in one interview about your perceptions of PLD for lecturers of English and your role in providing and evaluating PLD for EFL lecturers. The interview will be semi-structured and will take up to one hour. The interview will be in Vietnamese and audio-recorded to ensure an accurate record of your responses.

Your participation is voluntary, and you will be free to withdraw at any time before data analysis begins without any disadvantage and without having to explain why. Your responses will be translated into English for data discussion in the research report. Any responses that you give will be treated confidentially. Your identity will be protected through the use of a pseudonym and the removal of any identifying details. No information about your identity will be shared with anyone except my supervisors. All research data will be securely stored in password protected files or/and in locked cupboards and will be destroyed using a pager shredder or/and electronically wiped within five years after the completion of the research.

When completed, the doctoral thesis will be submitted to the School of Educational Psychology and Pedagogy and deposited in the WJ Scott Library, and available online. The research data will also be used for conference papers and/or publications in scholarly journals.

This research has been assessed and approved by Victoria University Faculty of Education Ethics Committee, No SEPP/2012/75 RM19494. If you have questions about the way the research is being conducted you may contact the Chair of the Victoria University of Wellington Human Ethics Committee, Dr. Allison Kirkman at Allison. kirkman@vuw.ac.nz.

If you have any questions or would like to receive further information about the project, please feel free to contact me at hue.tran@vuw.ac.nz. You can also contact my supervisors, Dr. Roseanna Bourke at Roseanna.bourke@vuw.ac.nz, and/or Dr. Margaret Gleeson at Margaret.gleeson@vuw.ac.nz.

Hue Tran

Signed: 


\section{Appendix I. CONSENT FORM FOR INTERVIEW PARTICIPANTS}

\section{TE WHARE WĀNANGa O TE ŪPOKO O TE IKA A MĀU 59: \\ Faculty of Education}

\section{CONSENT FORM FOR PARTICIPANTS}

(For both leaders and lecturers participating in the interviewees)

\section{"Professional learning and development for EFL teacher educators in the context of educational reforms in Vietnam”}

Please read the following statements and tick if you agree.

$\square$ I have been given information about this project and discussed the research project with Hue Tran.

$\square$ I agree to participate in the research under the conditions set out in the information sheet.

$\square$ I understand that I may withdraw myself (or any information I have provided) from this project during the data gathering without having to give reasons or without penalty of any sort.

$\square$ I understand that the interview will be audio-recorded and transcribed. I will have an opportunity to check the transcript of the interview in Vietnamese for verification.

I understand that my responses will be translated into English for data discussion in the research report.

$\square$ I understand that any information I provide will be kept confidential and that my identity will not be revealed.

$\square$ All interview data would be stored in password protected files and will be destroyed within five years after the completion of the research.

$\square$ The data collected from my participation will be used for a doctoral thesis, for conference papers and/or publications in scholarly journals, and I consent for it to be used in that manner.

Would you like a copy of the summary of findings of this research in English forwarded to you at the conclusion of the research?

Yes No $\square$

Signed:

Name:

Date: 


\section{Appendix J. INFORMATION SHEET FOR PLD PROVIDERS}

\section{TE VIIVESITY OF WELLINGTON}

Faculty of Education
Date:

\section{INFORMATION SHEET}

(For PLD Chairs or PLD providers)

\section{"Professional learning and development for EFL teacher educators in the context of educational reforms in Vietnam"}

I am Hue Tran, a PhD student in the School of Educational Psychology and Pedagogy, Faculty of Education, Victoria University of Wellington - New Zealand, and an EFL lecturer at Angiang University - Vietnam. As part of my doctoral study, I am conducting research to examine the practice of professional learning and development (PLD) for English lecturers in Vietnam. The purpose of the study is to an obtain in-depth understanding of the practice of PLD for EFL teacher educators in order to gain insights into how to promote and support EFL teacher educators' PLD and capacity to implement educational reforms in a Vietnamese tertiary context.

My study will be conducted in three public tertiary institutions. The research process will be undertaken in the following manner:

- Visiting the university: Initially, I will visit each university to have a meeting with the Rector and administrative staff to discuss the research and ask for their permission to conduct the research in the institution.

- Selecting participants: I will invite about 30-35 people from each university to participate in the research. My research will involve two groups of participants: one group of 30-35 lecturers of English (for the questionnaire and the individual interview) and one group of 2 administrators (for the individual interview) from each institution. Eligible participants are EFL lecturers who have at least two years of teaching experience in their current institutions, and have been involved in training school teachers of EFL and/or of other disciplines.

- Collecting data:

- Questionnaires: I will conduct a questionnaire involving about 30-35 lecturers of English from each university. The questionnaire will ask about the lecturers' perceptions and experiences of PLD and the implementation of educational reforms in higher education over the past two years.

- Interviews: I will conduct individual interviews with 6 EFL lecturers and 2 administrators at each university. The $6 \mathrm{EFL}$ lecturers will be purposively selected to vary in gender, teaching experience, and academic roles. Each interview session will take up to one hour. The interviews will be semi- 
structured and audio-recorded for the purposes of maintaining an accurate record of the participants' responses.

- Observations: I will conduct 2-3 observations of PLD sessions (e.g., workshops, conferences) and informal PLD events (e.g., inquiry-based activities, mentoring) for EFL lecturers in the institutions to gather supplementary data for the research. I will take notes about the process and activities during these sessions, but not about individual participants. These observations will be done during my data collection from November 2012 to April 2013.

- Documents: I will examine documents relating to the university strategic plan, self-review report, EFL education programmes, decisions or any other items related to staff development and reform implementation and professional activities within EFL department at each university.

I would like to ask for your permission to observe the PLD session on (date) that you will facilitate/chair. The purpose of the observation is to explore the natural context of PLD practices for EFL lecturers. During the observation, I will take notes about the structure, content and activities of PLD, the kinds of materials and resources, but I will not use data generated by or about particular participants or attribute any information to any individual. I would withdraw from any meeting or event as requested by the chair (e.g., if the discussion was sensitive). A summary of the observation will be sent to you via email for verification.

I attach an Observation guide to this email for your reference. If you consent to my attendance at the event, please complete the attached consent form and send it back to me at hue.tran@ vuw.ac.nz before (date).....

Your participation is voluntary, and you will be free to withdraw at any time before data analysis begins without any disadvantage and without having to explain why. The observational data will be treated confidentially. Any ideas or contributions that you give during the meeting will be kept completely confidential. The attendees' identities will be protected through the removal of any identifying details. All research data will be securely stored in password protected files or/and in locked cupboards and will be destroyed using a pager shredder or/and electronically wiped within five years after the research completion.

When completed, my doctoral thesis will be submitted to the School of Educational Psychology and Pedagogy and deposited in the WJ Scott Library, and available online. The research data will also be used for conference papers and/or publications in scholarly journals.

This research has been assessed and approved by Victoria University Faculty of Education Ethics Committee, No SEPP/2012/75 RM19494. If you have questions about the way the research is being conducted you may contact the Chair of the Victoria University of Wellington Human Ethics Committee, Dr. Allison Kirkman at Allison.kirkman@vuw.ac.nz.

If you have any questions or would like to receive further information about the project, please feel free to contact me at hue.tran@vuw.ac.nz,. You can also contact my supervisors, Dr. Roseanna Bourke at Roseanna.bourke@vuw.ac.nz, and/or Dr. Margaret Gleeson at Margaret.gleeson@ @uw.ac.nz.

Hue Tran

Signed: 


\section{Appendix K. CONSENT FORM FOR PLD PROVIDERS}

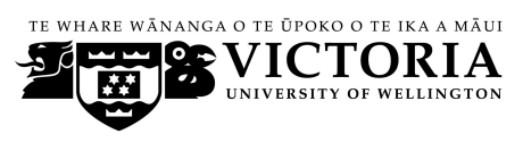

\section{Faculty of Education}

\section{CONSENT FORM}

(For the Chairs of PLD sessions)

\section{Professional learning and development for English as a foreign language (EFL) teacher educators in the context of Vietnamese educational reform}

Please tick the boxes on this form to show that you have read and understood each statement and you allow Hue Tran to observe the PLD session you will hold on (date) at (place)

I have been given information about the purpose of the observation and discussed this with Hue Tran.

I understand that Hue Tran will take notes during the event using the observation protocol she has shown me.

$\square \quad$ I understand that the attendee's identities will be kept confidential. Hue Tran will not disclose the identity of any of the attendees in the event.

I I understand that any information I and other participants provide during the meeting will be kept confidential by Hue Tran. In the published results no opinions will be attributed to me or any other participants.

I understand that I will have an opportunity to check a summary of Hue Trans' observation notes in Vietnamese and make any corrections.

$\square \quad$ I understand that all research information will be stored in password protected files and will be destroyed within five years after the completion of the research.

The data collected from the observation will be used for a doctoral thesis, for conference papers, and/or for publications in scholarly journals, and I consent for it to be used in that manner.

By signing below,

I give Hue Tran permission to come to the event.

I allow Hue Tran to copy and use the materials of the PLD sessions for her research.

Signed: Name: Date: 
Appendix L. ObServation GUIDE

\begin{tabular}{|c|c|}
\hline Observed issues & Observer's comments \\
\hline 1. Date: & \\
\hline 2. Place: & \\
\hline 3. PLD form: & \\
\hline 4. Duration: & \\
\hline 5. Participants: & \\
\hline 6. Facilitator(s): & \\
\hline 7. Content \& purpose: & \\
\hline 8. Activities: & \\
\hline 9. Participants' engagement: & \\
\hline 10. Resources: & \\
\hline 11. Evaluation: & \\
\hline Others:... & \\
\hline
\end{tabular}


Appendix M. Summary OF A PLD obServation

Observation notes ${ }^{24}$

1. Date: $28 / 12 / 2012$, Duration: 40 minutes

2. Place: Meeting room 2

3. PLD form: Department seminar

Sharing experience from participating in an overseas course on "Proposal writing for international researchers"

4. Presenter: An EFL lecturer (teacher educator) who completed the course

5. Participants: 06 (EFL lecturers)

6. Content \& purpose:

- The presenter shared the knowledge, skills and materials she learned from the course, and suggested how to use the materials within the department

- The presentation content: (1) main issues covered in the materials, (2) overview of proposal writing, (3) quality criteria, (3) 5 criteria to evaluate a project, (4) sponsor organisation, (5) proposal judgement, (6) conclusion

- Presentation: 20 minutes

- $\mathrm{Q} / \mathrm{A}$, discussion: 20 minutes

7. Participants' engagement and behaviours:

- Friendly, informal atmosphere

- The presenter also shared her experience in applying for a grant from DAAD to attend the course. She encouraged the other to apply for short courses overseas like hers.

- The participants actively asked the presenter many questions about the course and the materials

\footnotetext{
${ }^{24}$ Details related to the venue/location of the PLD session and backgrounds of the presenter and attendees were removed to protect the identities of the site and the participants
} 
- The participants discussed the implementation of the course and how to use the materials: introducing the materials to lecturers in the school, from these materials identifying components / criteria for assessing a research proposal to facilitate lecturers' research assessment / supervision of students' research at department level

- Some participants shared their personal experience and expressed disagreements among lecturers when supervising / assessing students' research.

- The participants raised problems in the lack of clear criteria in assessing students' research / proposals, and suggested having a clear and detailed guidelines.

8. Resources: A folder of materials from the course and CDs shared by the presenter

9. Evaluation: N/A

\section{Others:}

The participants showed interest in the presentation, actively engaged in discussion, eager to share their experience, raise problems / challenges and make recommendations about the use of the materials and related professional activities in the department. 


\section{Appendix N. NATIONAL POLICY DOCUMENTS FOR REVIEW}

\begin{tabular}{|c|c|c|}
\hline No. /date & Document name & Categories \\
\hline $\begin{array}{l}\text { National Assembly, } \\
\text { No. 38/2005/QH11 }\end{array}$ & Education laws & $\begin{array}{l}\text { Lecturers' standards; professional duties; } \\
\text { professional rights }\end{array}$ \\
\hline 2005 & & PLD for lecturers \\
\hline \multirow[t]{2}{*}{$\begin{array}{lr}\text { National } & \text { Decision } \\
\text { No. 58/2010/QD-TTg }\end{array}$} & University Regulation & $\begin{array}{l}\text { Lecturers' standards; professional duties; } \\
\text { professional rights }\end{array}$ \\
\hline & & PLD for lecturers \\
\hline \multirow[t]{2}{*}{$\begin{array}{l}\text { MOET Decision No. } \\
\text { 64/2008/QD-BGDDT }\end{array}$} & Policies of lecturers' work & $\begin{array}{l}\text { Lecturers' standards; professional duties; } \\
\text { professional rights }\end{array}$ \\
\hline & & PLD for lecturer \\
\hline \multirow[t]{2}{*}{$\begin{array}{l}\text { National Assembly, } \\
\text { No. 08/2012/QH13 }\end{array}$} & HE Law & $\begin{array}{l}\text { Lecturers' standards; professional duties; } \\
\text { professional rights }\end{array}$ \\
\hline & & PLD for lecturer \\
\hline National & The 1 & Reform objectives and targets \\
\hline $2005 / \mathrm{N}$ & $\mathrm{HE}$ & $\begin{array}{l}\text { Strategies for staff development } \\
\text { PLD for lecturers }\end{array}$ \\
\hline $\begin{array}{l}\text { MOET Direction No. } \\
\text { 1374/BGDDT- } \\
\text { GDDH } \\
2012 \\
\end{array}$ & $\begin{array}{l}\text { Implementing the reform in } \mathrm{HE} \\
\text { administration in } 2010-2012\end{array}$ & $\begin{array}{l}\text { Reform objectives and targets } \\
\text { Strategies for staff development } \\
\text { PLD for lecturers }\end{array}$ \\
\hline $\begin{array}{l}\text { MOET Decsion No. } \\
\text { 6290/QD-BGDDT, } \\
2011\end{array}$ & $\begin{array}{l}\text { Plan for developing Teacher Education } \\
\text { programmes and Teacher Education } \\
\text { institutions in 2011-2020 }\end{array}$ & $\begin{array}{l}\text { Development objectives and targets } \\
\text { Strategies for staff development } \\
\text { PLD for lecturers }\end{array}$ \\
\hline 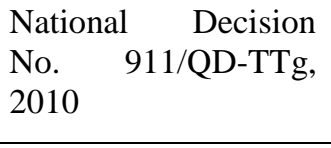 & $\begin{array}{l}\text { A project for training lecturers for a } \mathrm{PhD} \\
\text { degree in colleges and universities in } \\
2010-2020\end{array}$ & $\begin{array}{l}\text { Development objectives and targets } \\
\text { Strategies for staff development } \\
\text { PLD for lecturers }\end{array}$ \\
\hline $\begin{array}{l}\text { MOET Decision No. } \\
\text { 6639/QD-BGDDT, } \\
2011\end{array}$ & $\begin{array}{l}\text { Strategic plan for developing human } \\
\text { resources in Education }\end{array}$ & $\begin{array}{l}\text { Development objectives and targets } \\
\text { Strategies for staff development } \\
\text { PLD for lecturers }\end{array}$ \\
\hline $\begin{array}{l}\text { National } \begin{array}{l}\text { Decision } \\
\text { No. }\end{array} \text { 711/QD-TTg, } \\
2012\end{array}$ & $\begin{array}{l}\text { Strategic plan for education development } \\
\text { in 2011-2020 }\end{array}$ & $\begin{array}{l}\text { Development objectives and targets } \\
\text { Strategies for staff development } \\
\text { PLD for lecturers }\end{array}$ \\
\hline $\begin{array}{l}\text { National Decision } \\
\text { No. } 1400 / \text { QD-TTg }\end{array}$ & $\begin{array}{l}\text { Project "Teaching and learning foreign } \\
\text { languages in the national educational } \\
\text { system in 2008-2020" }\end{array}$ & $\begin{array}{l}\text { Reform objectives and targets } \\
\text { Students expected outcomes } \\
\text { Strategies for staff development } \\
\text { PLD for lecturers }\end{array}$ \\
\hline $\begin{array}{l}\text { MOET Report No. } \\
760 / \text { BC-BGDĐT }\end{array}$ & $\begin{array}{l}\text { Report on the development of } \mathrm{HE} \text {, and } \\
\text { strategies to ensure and improve training } \\
\text { quality }\end{array}$ & $\begin{array}{l}\text { Development objectives and targets } \\
\text { Strategies for staff development } \\
\text { PLD for lecturers } \\
\text { Students' expected outcomes }\end{array}$ \\
\hline $\begin{array}{l}\text { MOET Circular No. } \\
\text { 20/2013/TT-BGDĐT }\end{array}$ & $\begin{array}{l}\text { Regulations about professional } \\
\text { development for lecturers of higher } \\
\text { education institutions }\end{array}$ & $\begin{array}{l}\text { PLD descriptions, purposes and contents } \\
\text { PLD activities } \\
\text { Lecturers' rights and responsibilities for } \\
\text { PLD }\end{array}$ \\
\hline
\end{tabular}




\section{Appendix O. A translated INTERVIEW TRANSCRIPT}

\section{Researcher}

Can you tell me about your academic responsibilities?

\section{Interviewee}

I'm mainly in charge of teaching. I'm not involved in management. Currently, I have been involved in: teaching English skills for English-majors, and general English for non-English majors. (...). ${ }^{25}$

\section{Researcher}

Besides teaching, have you participated in other activities of the department?

\section{Interviewee}

Last year, I participated in a project of teaching English for children by MOET. I joined a 2-week training course at University $\mathrm{X}$. After the course, the participants from our university were responsible for designing a course book to train EFL teachers at local primary schools. We spent nearly a year to do that, and we started the $1^{\text {st }}$ course in August. We trained all methods for primary school teachers. Each course lasted for 1 month, and we have finished two courses so far.

\section{Researcher}

My research is about "professional learning and development" (PLD) for EFL lecturers. Can you give me your own definition of this phrase?

\section{Interviewee}

For me, besides teaching, lecturers have to participate in courses, workshops or projects to learn more about their majors. We need to learn more to improve our professional knowledge.

\section{Researcher}

Beside professional knowledge, what are other aspects you think lecturers can improve through engaging in these activities?

\section{Interviewee}

While learning, lecturers will find out directions for research. They will find out interesting things for research or things that need researching, so they can develop their research skills.

\footnotetext{
${ }^{25}$ Deleted details (e.g. personal and identified information, names of people or universities, and sensitive information) to protect the identities of the universities and of the interviewee, as well as to avoid creating potential disadvantages the interviewee may feel or face when revealing sensitive information.
} 


\section{Researcher}

What PLD activities have you participated in over the past 2 years?

\section{Interviewee}

I participated in workshops inside and outside the country, such as workshops by Vietnam-USA Centre (VUS) in HCM city, or CamTESOL in Cambodia, just these workshops. The biggest training course I've had was at University X. Young staff as us didn't attend many training courses. (...). We mainly had opportunities to attend workshops.

\section{Researcher}

Who organised workshops that you attended?

\section{Interviewee}

Sometimes people from HCM city came here to organise some workshops such as workshops to introduce new textbooks by Oxford publisher. We could attend these workshops. The university also gave us opportunities to attend outside workshops that required registration. However, we did not have a chance to attend training courses which were more specialised.

\section{Researcher}

Were you assigned to attend these workshops?

\section{Interviewee}

Yes, or I registered to attend the ones I found interesting. Also, I paid by myself to attend workshops that I found interesting. For example, I paid my own money to attend the CamTESOL because at that time we did not have enough experience to give a presentation. We had to pay because we were just attendants in the workshop. Next year we will give a presentation there, and the university will give us financial support to attend it.

\section{Researcher}

Why did you decide to spend your own money on this event?

\section{Interviewee}

Because I heard that we could learn a lot of experiences from this. And after that workshop it was true that I learned a lot of experiences after attending only three sessions. These sessions were very good. I applied them in my teaching as soon as I got back, and this was very effective.

\section{Researcher}

Give me some examples of the things you applied in your teaching. 


\section{Interviewee}

For example, I attended sessions about methods for teaching listening and speaking which is my interest, and ways to teach English to children using puppets, songs and game-shows. I learned experiences about these from the presenters. When I applied these methods in teaching my university students, it was very successful.

\section{Researcher}

In your opinion what is an effective PLD activity?

\section{Interviewee}

First, in terms of organisation, there need to be enough time for learning effectively, about 1 week or more. This also depends on the types of participants or trainees. In addition to time, it is the content the presenter provides. For example, I once attended a 5-day training course in HCM city. This could be called a long course. The presenter was an American, having a PhD with 30 years of experience in teaching children, but I did not learn anything during those 5 days. Actually, she seemed to be in a hurry and was not well prepared. We found her confusion in presenting, and the things she presented were not new. I think with such duration of time, if there had been good preparation and organisation, we could have learned a lot. But the way she presented was not effective.

\section{Researcher}

You have mentioned a training course at University X. Could you describe it in details?

\section{Interviewee}

It was provided by MOET. There were lecturers from 18 colleges and universities throughout the country, from 8 to 10 lecturers from each institution. It lasted for 2 weeks. The training group, who were lecturers at University X, had been trained by the British council before. Then they trained us all the methods they had learned. Some staff from the British Council came and observed some sessions, and they also taught in a few sessions, but mainly for lecturers at University X. They presented many methods related to how children learn, classroom management, using songs and games, teaching all four skills. The content was very good.

After that, we had school visits. They selected two leading local primary schools so that we could do classroom observations. Then they provided us a tour to visit the city there. Generally, it was well organised, but because it was not original (that means being provided by a third party); it was not as professional as the way British Council trained. 


\section{Researcher}

How much could you apply what you had learned from the course?

\section{Interviewee}

We could use about $70-80 \%$ of all materials and videos because the MoET said that they were standards. While using, we made some changes to make them easier and have more activities. We reused these contents and added new materials. We made changes to make the programme better.

\section{Researcher}

As you mentioned, after the training course the group worked together to design a programme. How did you work on this task?

\section{Interviewee}

We had several meetings, many, many times, to discuss whether we could reuse the framework at University X or how to adapt it. After we agreed on the modules in the programme, we divided the tasks and collected materials. We found materials based on the agreed criteria of designing the module. After finishing this task, we got together to compile and check all modules to make changes if needed. We spent about 1 year designing the programme, a very long time. I can say that we were "crazy" with this! (laugh...). But it was not finished when we started teaching the first class. Therefore, we had to revise it and teach it at the same time. The course book was not completed until the second class.

\section{Researcher}

How did your participation in this process affect your professional development?

\section{Interviewee}

Of course it was good for me. During this work, some lecturers were attending a training course by British Council, so they had good knowledge. They showed us how to design the tasks. At first, we designed something very general, and we copied the course at University $\mathrm{X}$ because that was how we were trained. From the course at University X, we were given materials for reading, but actually we did not read at all. Therefore, these lecturers instructed us how to redesign the programme to ensure that our learners would study both in the classroom and do the reading assignments. We had to be flexible and change the materials by adding many tasks such as gap-filling, multiple choice, etc. Then we realised that it was better to add such activities. We've delivered 2 courses for teaching English at primary schools. Besides, there have been classes to upgrade language proficiency such as B1, B2 levels for teachers at primary schools and secondary schools, but we did not receive training to teach these courses. We mainly teach based on text-books. 


\section{Researcher}

What challenges did you have when teaching these teachers?

\section{Interviewee}

For classes of teaching methods at primary schools, first, what we had learned was very "ideal", while in reality, classes in Vietnamese primary schools are very different. For example, we learned that a noisy class was an interesting class. However, in primary schools, classes must be quiet. When a class is a bit noisy, the next door one gives a complaint. Therefore, when teaching, we faced a "negative" attitude of the teachers because they usually thought that they could not apply what we were teaching them. We had to encourage them by telling them that like taking a kind of "goodhealth medicine" (thuốc bổ), they would benefit by a certain way. We provided evidence that some teachers had applied new methods in their extra classes. Others applied these methods when they gave model lessons for classroom observations, and the lessons were very exciting and successful. After realising these effects, the teachers complained less often. At first, they were not pleased to learn something opposite to their common beliefs. And they thought that it was the Heads of Education departments and academic leaders who need to learn new teaching methods so that these people understand what makes a good English lesson. Otherwise, these leaders will blame the teachers for making noise when having the children play a game or sing a song.

\section{Researcher}

As a young lecturer, how did you learn and improve your teaching skills so that you could be able to teach these experienced in-serviced teachers?

\section{Interviewee}

First, I had to learn from experienced teachers how to teach at primary schools. Then, I learned from the textbooks we received from the training course. Before teaching these classes, I had applied what I learned about teaching children into my classes for university students. I also taught children at an English centre. I have more experience in teaching children than in teaching students because I have spent more time teaching children than teaching students. After being able to apply these methods in my previous teaching, I felt very confident to present these methods to in-service teachers.

\section{Researcher}

What reforms in higher education have you implemented over the past two years?

\section{Interviewee}


(pause) Now we change our teaching method from teacher-centre to student-centre. Since I graduated and started teaching, I have used this method, (pause) ... but I am not sure if I have applied this reform or not. When teaching English, we really need to create opportunities for students to speak more and participate more in class activities. I do not know if I have applied any reforms but since my first teaching, I have taught in such ways, not the way in which the lecturer speaks and students copy the information. I mostly teach listening and speaking, so (pauses and smiles) I don't know if I have implemented any reforms or not. I'm not sure...

\section{Researcher}

How did you often assess your teaching effectiveness?

\section{Interviewee}

I often asked students to write down their feedback on a small form after a course, e.g. what they liked, disliked, and what they need to improve, without showing their names. This is a small thing I do by myself. Also, I talked to students, and I base on their their interests in continuing to study with me. In our university, students do not know the name of the lecturer when they enrol in a course. Therefore, when students send emails asking me if I will teach the following course or not, this may partly show my success. That means I can assess my teaching through talking to them and asking for their feedback.

\section{Researcher}

How did sharing professional knowledge with colleagues affect your professional development?

\section{Interviewee}

We rarely shared experience with each other. Normally, we share it with people we are close to, but not much. For informal sharing, yes, we normally talked and learned from each other. For formal forms, sometimes there were some small workshops, or seminars, in our department from which we could learn a lot. For example, there was a seminar about Endnote, which was very helpful, or a seminar about How to write the discussion part in a research report, which was also very good. However, there were only a few events like these, just a few every year. There were more informal sharing, but not enough for me to improve. The more important thing is self-regulated learning (tự học), or attending events in other places. Learning from sharing experience was very limited because I found few people who would be willing to share, and share honestly (thật tình). (...). It was hard to share my teaching and learning with more experienced staff. First, It was difficult to find a chance to meet and talk to them. The lecturers rarely come to this staff room as it is in a far place. Second, we have never asked them how to teach a subject because we did not dare to ask 
(...), and we wondered if asking such a thing may make them feel uncomfortable, e.g., being considered not generous if they do not share, or feeling uncomfortable to share.

What we normal did was sharing experience when we participated in the English speaking club (ESC). We discussed and shared experience with each other. For example, I can say "Ah, in my class, I used this warm-up activity". Also, the ESC mainly focused on speaking and listening skills, so it was very comfortable for us to share ideas. We usually brought to the ESC what we found interesting in our classrooms. Mainly, there are three people to run the ESC. That's why we normally share all things we know when we sit together to plan the programme for ESC

\section{Researcher}

So, you meant that running ESC enabled you and your colleagues to share professional experience?

\section{Interviewee}

Yes. Because it was hard to find new things for each week session, we had to exploit all experience we have in teaching and shared with each other. Also, after trying new things successfully in ESC, we would apply them in our own teaching.

\section{Researcher}

How has your participation in the ESC affected your teaching?

\section{Interviewee}

Regular attendance of ESC had a great effect on my teaching. First, I liked sharing experience with the other members while discussing the club activities, and I could apply this experience in my teaching a lot. Second, I learned the skills to run the club, e.g. how to instruct others, how to speak in public. My classes were effective when I applied these skills.

\section{Researcher}

As you mentioned before, you also participated in the reform of foreign language teaching. How did this affect your learning and teaching?

\section{Interviewee}

I found this project very good. Of course, I will have more opportunities to attend training courses because I belong to this project from now to 2020. At the moment some lecturers in my department have been attending training courses overseas. Sooner or later I will try to have a course overseas to learn about teaching methods. (...). Second, I have a chance to do more research because I must design teaching materials, both for the classes for primary school teachers and the classes for teaching B1, B2 level of the CEFR. We have to do a lot of searching from the Internet and select 
information, which is good for our research skills. An important thing is that we realise a direction for developing teachers. However, although the project is good, implementing it is similar to giving teachers "a good-health medicine" just for a short time. This will not have a long-lasting effect when they return to their local schools and provinces where they find insufficient conditions to apply what they have learned.

We are thinking about a research project to recommend the ways to maintain long-term effects. If they cannot apply what they have learned, we feel very concerned about this. Together with teaching, we have some small research which we might not think about if we haven't participated in the project. For example, for the coming CamTESOL, we will present how to teach English to children. While teaching this, we found it interesting and would like to present about this. Without teaching previous courses, we would not discover this topic for our presentation.

\section{Researcher}

How have you carried out this small research or prepared for the presentation?

\section{Interviewee}

Generally, I do not need to collect many data for our presentation. We will mainly present about the methods we have applied successfully. It is like sharing experience. We will present how we conduct one lesson. Then we will present the teaching techniques, and have the participants practice and apply these techniques in a given lesson.

\section{Researcher}

In the present teaching context, what factors influence your professional learning and development?

\section{Interviewee}

Generally, because I'm young, I will have many opportunities to learn. In the future, when I have more experience, I will have more opportunities, and will be chosen to attend training courses or workshops. Also, I will have support to do some research or to be appointed to attend these events; or it will be easier if I ask for permission to attend these. Besides, now I have many opportunities to improve my research ability. For example, our university has bought many programmes or software, so it is convenient and free for me to search for materials.

I find the university and the department are very supportive. The department has completed a form showing each lecturer's priorities for a certain professional field. (...). Now the department has a clear direction. The lecturers state their expectations and the department will decide their priorities when there are related training courses, both inside and outside the country, given by the MOET. It is very convenient with this clear direction. 


\section{Researcher}

Did you mean that the department investigated lecturers' expectations and needs?

\section{Interviewee}

Yes, because previously there were questions regarding why the department assigned this lecturer rather than that one to attend a certain PLD session. Therefore, later it was good to have a survey about lecturers' expectations. The department will consider the lecturers' stated expectations, and this is also based on the specialisation groups they belong to. For example, those in the Teaching Methodology group will be given priorities related to develop methodology rather than language skills. Next, lecturers' expectations will be listed according to time order. If they have the same interests, priorities will be given to more experienced ones.

\section{Researcher}

What do you think about the ways to assess the effects of activities for lecturers' professional learning and development?

\section{Interviewee}

Now the university has an assessment form used at the end of each course in each term. The form covers all aspects, e.g. classroom management, teaching methods. Students are asked to complete the form with their assessment, without giving their names. The university will synthesise the feedback and send back the results to lecturers so that lecturers can know the evaluations of their courses and find ways for improvement.

\section{Researcher}

What are your plans for your PLD?

\section{Interviewee}

As I mentioned, I like attending workshops and training courses very much. After stating my expectations, I have been prepared, firstly for IELTS so that I can attend these events when they are available.

\section{Researcher}

How do you prepared for IELTS?

\section{Interviewee}

I practise by myself. In order to be assigned to attend these workshops, lecturers must show the IELTS certificate, gaining 6.5 or 7.0 band score. This is the prerequisite for being eligible to apply 
for these training courses, before other aspects are considered. Therefore, if lecturers want to apply for these training courses, they must meet the criteria.

\section{Researcher}

What kinds of workshops or training courses are these?

\section{Interviewee}

These are long training courses or workshops, may be overseas, given to the lecturers who participate in the language reform projects. Over the past year, there have been courses in Brunei, America for two months, and New Zealand. In Vietnam, there were courses in Hanoi and HCM city. However, to attend these events, lecturers must have IELTS, often from 7.0.

\section{Researcher}

Among many activities for professional learning you have mentioned, e.g. workshops, courses, selfregulated learning, teamwork, which do you think has influenced your professional development most?

\section{Interviewee}

I found participating in a training course the most influential. As I said, factors of an effective activity are time and presenters. Attending the course at University X, I learned a lot because it was long. I could practise more, so gradually I could remember things longer, and found it practical. For short events, they usually end before we can learn new things, so it is not good. Therefore, I give priority to training courses.

\section{Researcher}

What aspects of the language reform project do you expect to learn more about so that you can implement the reform more effectively?

\section{Interviewee}

I expect to be trained more on the aspect of enhancing learners' language competence. This is now the main part. Providing teaching methodology classes is just a minor part. The main part is language enhancement according to CEFR standards, but no one in the training team has been formally trained about this. We mainly teach based on the available textbooks. To be more effective, we need more training on teaching methods used for textbooks designed according to CEFR. Now we are not professional in teaching these.

\section{Researcher}

What recommendations do you have for more effective PLD for yourself and other lecturers? 


\section{Interviewee}

First, we would like to have more experience sharing in the ESC. We do not have a lot of support from the department and the university. (...) We wish that in some ESC sessions, we could invite senior lecturers who are strong at certain fields such as American Culture, to come and share their experience. We wish to have more support both spiritually and financially. Financial support is important because we intend to organise many activities for students but we cannot due to limited budget. Second, regarding attending workshops or courses, young lecturers don't have much priority. (...). There should be more support for young lecturers to attend training courses (...).

\section{Researcher}

Is there a regulation that lecturers will share what they have learned from the training courses they attended with the others in the department?

\section{Interviewee}

No. There have not been many lecturers to do that, partly because of complicated paper work related to asking for financial support for presenters. Besides, it is hard to find the time to gather lecturers for experience sharing. We usually have to postpone this so many times that lecturers lose interests in organising seminars to share experience. For example, the department has just had some seminars recently although we have planned many seminars for the whole year. Because we have been intensively involved in B1, B2 classes for primary school teachers from Monday to Sunday, no free time at all, it is hard to gather many lecturers for sharing experience.

\section{Researcher}

Are there other important things related to your PLD that you want to share with me?

\section{Interviewee}

When there is a certain PLD programme, I will be willing to participate in it. Sometimes, because of time constraint and heavy workload, I do not have much motivation for self-regulated learning. I think there should be many projects or activities to motivate lecturers and give lecturers opportunities to attend them. And then they are more motivated for self-regulated learning.

\section{Researcher}

Thank you very much for sharing your views and experiences with me during the talk. I wish you will achieve your professional aspirations and have many more meaningful PLD opportunities. 
Appendix P. Summary of PLD ObServations

\begin{tabular}{|c|c|c|c|c|c|c|c|}
\hline PLD & Forms & $\begin{array}{l}\text { Content/ } \\
\text { Topic }^{26}\end{array}$ & $\begin{array}{l}\text { Facilitator } \\
\text { Presenter }\end{array}$ & Attendees & Activities & Duration & Resources \\
\hline $\begin{array}{l}\text { A.O } \\
1^{27}\end{array}$ & seminar & $\begin{array}{l}\text { Pedagogical } \\
\text { practice }\end{array}$ & $\begin{array}{l}\text { EFL } \\
\text { lecturer }\end{array}$ & $\begin{array}{l}5-6 \\
\text { EFL lecturers }\end{array}$ & $\begin{array}{l}\text { Presentation, } \\
\text { Discussions }\end{array}$ & 1 hour & $\mathrm{n} / \mathrm{a}$ \\
\hline $\begin{array}{l}\text { A.O } \\
2\end{array}$ & seminar & $\begin{array}{l}\text { Research } \\
\text { engagement }\end{array}$ & $\begin{array}{l}\text { EFL } \\
\text { lecturer }\end{array}$ & $\begin{array}{l}5-6 \\
\text { EFL lecturers }\end{array}$ & $\begin{array}{l}\text { Presentation, } \\
\text { Discussions }\end{array}$ & 1 hour & $\begin{array}{l}\text { Materials, } \\
\text { CDs }\end{array}$ \\
\hline $\begin{array}{l}\text { A.O } \\
3\end{array}$ & seminar & $\begin{array}{l}\text { Research } \\
\text { engagement }\end{array}$ & $\begin{array}{l}\text { EFL } \\
\text { lecturer }\end{array}$ & $\begin{array}{l}25 \\
\text { EFL } \\
\text { lecturers, } \\
\text { post graduate } \\
\text { students }\end{array}$ & $\begin{array}{l}\text { Presentation, } \\
\text { Demonstration }\end{array}$ & 1 hour & $\mathrm{n} / \mathrm{a}$ \\
\hline $\begin{array}{l}\text { A.O } \\
4\end{array}$ & conference & $\begin{array}{l}\text { Pedagogical } \\
\text { practice }\end{array}$ & $\begin{array}{l}\text { EFL } \\
\text { lecturers }\end{array}$ & $\begin{array}{l}25 \\
\text { lecturers and } \\
\text { teachers of } \\
\text { different } \\
\text { disciplines, } \\
\text { Department } \\
\text { of Education } \\
\text { staff; from } \\
\text { different } \\
\text { provinces }\end{array}$ & $\begin{array}{l}\text { Presentation, } \\
\text { Attendees' } \\
\text { reflections on } \\
\text { the } \\
\text { implementation } \\
\text { of the initiative } \\
\text { in their local } \\
\text { contexts }\end{array}$ & 2 days & $\begin{array}{l}\text { Online } \\
\text { resources }\end{array}$ \\
\hline $\begin{array}{l}\text { A.O } \\
5\end{array}$ & workshop & $\begin{array}{l}\text { Teacher } \\
\text { education } \\
\text { (bilingual) }\end{array}$ & $\begin{array}{l}\text { EFL } \\
\text { lecturers } \\
\text { and } \\
\text { academic } \\
\text { leaders }\end{array}$ & $\begin{array}{l}25 \\
\text { Academic } \\
\text { leaders, } \\
\text { teacher } \\
\text { educators in } \\
\text { different } \\
\text { disciplines } \\
\text { from } \\
\text { different } \\
\text { provinces }\end{array}$ & $\begin{array}{l}\text { Presentation } \\
\text { from the expert, } \\
\text { Group } \\
\text { discussions and } \\
\text { presentation, } \\
\text { Reflections and } \\
\text { experience } \\
\text { sharing among } \\
\text { educators }\end{array}$ & 1 day & $\mathrm{n} / \mathrm{a}$ \\
\hline
\end{tabular}

${ }^{26}$ To protect the identities of the presenters and the institutions, the titles of the observed PLD events were not be presented. Instead, general topics were used: (1) pedagogical practices (e.g., EFL teaching techniques, using IT in EFL teaching), (2) general education (e.g., HE in international contexts / in Vietnam), (3) teacher education (e.g., teacher education in international contexts / in Vietnam), and (4) research engagement

${ }^{27}$ A.O1: Observation 1 conducted at University A; C.O1: Observation 1 conducted at University C 


\begin{tabular}{|c|c|c|c|c|c|c|c|}
\hline PLD & Forms & $\begin{array}{l}\text { Content/ } \\
\text { Topic }^{26}\end{array}$ & $\begin{array}{l}\text { Facilitator } \\
\text { Presenter }\end{array}$ & Attendees & Activities & Duration & Resources \\
\hline $\begin{array}{l}\text { A.O } \\
6\end{array}$ & $\begin{array}{l}\text { training } \\
\text { course }\end{array}$ & $\begin{array}{l}\text { Pedagogical } \\
\text { practice }\end{array}$ & $\begin{array}{l}\text { foreign } \\
\text { expert }\end{array}$ & $\begin{array}{l}34 \\
\text { EFL lecturers } \\
\text { and teachers } \\
\text { (from local } \\
\text { area and a } \\
\text { neighbouring } \\
\text { province) }\end{array}$ & $\begin{array}{l}\text { Presentations, } \\
\text { demonstrations, } \\
\text { practices, } \\
\text { reflections and } \\
\text { feedback }\end{array}$ & $\begin{array}{l}6 \\
\text { sessions } \\
\text { (6 days), } \\
\text { once a } \\
\text { week }\end{array}$ & $\begin{array}{l}\text { Handouts } \\
\text { and } \\
\text { teaching } \\
\text { materials }\end{array}$ \\
\hline $\begin{array}{l}\text { C.O } \\
1\end{array}$ & workshop & $\begin{array}{l}\text { Teacher } \\
\text { education } \\
\text { (bilingual) }\end{array}$ & $\begin{array}{l}\text { foreign } \\
\text { expert/ } \\
\text { volunteer }\end{array}$ & $\begin{array}{l}\text { Over 50, } \\
\text { lecturers } \\
\text { within the } \\
\text { Education } \\
\text { Faculty }\end{array}$ & $\begin{array}{l}\text { Presentations, } \\
\text { discussions }\end{array}$ & $\begin{array}{l}1 \\
\text { morning }\end{array}$ & Handouts \\
\hline $\begin{array}{l}\text { C.O } \\
2\end{array}$ & workshop & $\begin{array}{l}\text { General } \\
\text { education } \\
\text { (bilingual) }\end{array}$ & $\begin{array}{l}\text { foreign } \\
\text { volunteer }\end{array}$ & $\begin{array}{l}28 \\
\text { Mixed types: } \\
\text { lecturers and } \\
\text { students } \\
\text { within the } \\
\text { university }\end{array}$ & $\begin{array}{l}\text { Presentations, } \\
\text { discussions }\end{array}$ & 1 hour & $\mathrm{n} / \mathrm{a}$ \\
\hline $\begin{array}{l}\text { C.O } \\
3\end{array}$ & workshop & $\begin{array}{l}\text { Research } \\
\text { engagement } \\
\text { (bilingual) }\end{array}$ & $\begin{array}{l}\text { foreign } \\
\text { expert and } \\
\text { internal } \\
\text { Vietname } \\
\text { se lecturer }\end{array}$ & $\begin{array}{l}30 \\
\text { lecturers } \\
\text { within the } \\
\text { university }\end{array}$ & $\begin{array}{l}\text { Presentations, } \\
\text { discussions }\end{array}$ & 1 hour & Handouts \\
\hline $\begin{array}{l}\text { C.O } \\
4\end{array}$ & workshop & $\begin{array}{l}\text { Pedagogical } \\
\text { practice }\end{array}$ & $\begin{array}{l}\text { external } \\
\text { foreign } \\
\text { expert }\end{array}$ & $\begin{array}{l}57 \\
\text { Mixed types: } \\
\text { EFL } \\
\text { lecturers and } \\
\text { local EFL } \\
\text { teachers }\end{array}$ & $\begin{array}{l}\text { Presentations, } \\
\text { practices }\end{array}$ & $\begin{array}{l}1 \\
\text { morning }\end{array}$ & Handouts \\
\hline $\begin{array}{l}\text { C.O } \\
5\end{array}$ & workshop & $\begin{array}{l}\text { Research } \\
\text { engagement }\end{array}$ & $\begin{array}{l}\text { foreign } \\
\text { expert/ } \\
\text { volunteer } \\
\text { and } \\
\text { internal } \\
\text { lecturer }\end{array}$ & $\begin{array}{l}50 \\
\text { Mixed types: } \\
\text { university } \\
\text { lecturers, } \\
\text { government } \\
\text { officers } \\
\text { within the } \\
\text { province }\end{array}$ & $\begin{array}{l}\text { Presentations, } \\
\text { discussions }\end{array}$ & $\begin{array}{l}1 \\
\text { morning }\end{array}$ & Handouts \\
\hline
\end{tabular}




\begin{tabular}{|c|c|c|c|c|c|c|c|}
\hline PLD & Forms & $\begin{array}{l}\text { Content/ } \\
\text { Topic }^{26}\end{array}$ & $\begin{array}{l}\text { Facilitator } \\
\text { Presenter }\end{array}$ & Attendees & Activities & Duration & Resources \\
\hline $\begin{array}{l}\text { C.O } \\
6\end{array}$ & $\begin{array}{l}\text { Training } \\
\text { course }\end{array}$ & $\begin{array}{l}\text { Pedagogical } \\
\text { practice } \\
\text { (in } \\
\text { Vietnamese) }\end{array}$ & $\begin{array}{l}\text { software } \\
\text { providers/ } \\
\text { technician }\end{array}$ & $\begin{array}{l}30 \\
\text { EFL } \\
\text { lecturers and } \\
\text { lecturers in } \\
\text { other } \\
\text { disciplines in } \\
\text { Teacher } \\
\text { Education } \\
\text { Faculty }\end{array}$ & $\begin{array}{l}\text { Presentations, } \\
\text { demonstrations, } \\
\text { (little) practices }\end{array}$ & $\begin{array}{l}6 \\
\text { sessions, } \\
\text { every } \\
\text { evening }\end{array}$ & $\begin{array}{l}\text { Handouts } \\
\text { and } \\
\text { guide- } \\
\text { book }\end{array}$ \\
\hline $\begin{array}{l}\text { C.O } \\
7\end{array}$ & $\begin{array}{l}\text { training } \\
\text { course }\end{array}$ & $\begin{array}{l}\text { Pedagogical } \\
\text { practice }\end{array}$ & $\begin{array}{l}\text { external } \\
\text { foreign } \\
\text { expert }\end{array}$ & $\begin{array}{l}36 \\
\text { EFL } \\
\text { lecturers and } \\
\text { EFL primary } \\
\text { school } \\
\text { teachers }\end{array}$ & $\begin{array}{l}\text { Presentations, } \\
\text { demonstrations, } \\
\text { practices, } \\
\text { reflections and } \\
\text { feedback }\end{array}$ & $\begin{array}{l}3 \\
\text { sessions, } \\
2 \text { days }\end{array}$ & $\begin{array}{l}\text { Handouts } \\
\text { and } \\
\text { teaching } \\
\text { materials }\end{array}$ \\
\hline
\end{tabular}

